\author{
UNIVERSIDADE DE SÃO PAULO \\ FACULDADE DE FILOSOFIA, LETRAS E CIÊNCIAS HUMANAS \\ DEPARTAMENTO DE GEOGRAFIA \\ PROGRAMA DE PÓS-GRADUAÇÃO EM GEOGRAFIA HUMANA
}

LÚCIA FERREIRA LIRBÓRIO

\title{
O Circuito Espacial de Produção do Algodão Naturalmente Colorido na Paraíba-Brasil
}

Versão corrigida

São Paulo

2017 


\title{
O Circuito Espacial de Produção do Algodão Naturalmente Colorido na Paraíba-Brasil
}

\author{
Versão Corrigida
}

Tese apresentada ao

Departamento de Geografia da Faculdade de Filosofia, Letras e Ciências Humanas da Universidade de São Paulo para a obtenção do título de Doutor em Geografia.

Área de Concentração: Geografia Humana

De acordo,

Profa. Dra. Rosa Ester Rossini

Orientadora

São Paulo 
Autorizo a reprodução e divulgação total ou parcial deste trabalho, por qualquer meio convencional ou eletrônico, para fins de estudo e pesquisa, desde que citada a fonte.

Catalogação na Publicação

Serviço de Biblioteca e Documentação

Faculdade de Filosofia, Letras e Ciências Humanas da Universidade de São Paulo

L768

LIRBORIO, LUCIA FERREIRA

/ LUCIA FERREIRA LIRBORIO ; orientadora ROSA

ESTER ROSSINI. - São Paulo, 2017.

$293 \mathrm{f}$.

Tese (Doutorado)- Faculdade de Filosofia, Letras

e Ciências Humanas da Universidade de São Paulo.

Departamento de Geografia. Área de concentração:

Geografia Humana.

1. Algodão naturalmente colorido. 2. Agricultura familiar. 3. Embrapa Algodão. 4. Semiárido. 5.

Inovação. I. Rossini, Rosa Ester, orient. II. Título. 
Ficha de aprovação

Nome: Lúcia Ferreira Lirbório

E-mail: lucialirborio@usp.br; lucialirborio@hotmail.com

Título: O Circuito Espacial de Produção do Algodão Naturalmente Colorido na Paraíba-Brasil

Orientadora: Profa. Dra. Rosa Ester Rossini

LIRBÓRIO, Lúcia Ferreira Lirbório. O Circuito Espacial de Produção do Algodão Naturalmente Colorido na Paraíba-Brasil. Tese de Doutorado do Programa de PósGraduação em Geografia Humana do Departamento de Geografia da Faculdade de Filosofia, Letras e Ciências Humanas da Universidade de São Paulo, 2016.

\section{Banca Examinadora:}

Prof.(a) Dr.(a):

Julgamento:

Prof.(a) Dr.(a):

Julgamento:

Prof.(a) Dr.(a):

Julgamento:

Prof.(a) Dr.(a):

Julgamento:

São Paulo, de de 2016 . 
Dedico esta Tese aos meus pais Lia e Paraná por todo apoio e amor.

Aos meus irmãos: Flávia, Letícia, Solange, José, Dayane e a minha sobrinha Laura por todo incentivo e carinho. 


\section{AGRADECIMENTOS}

Início meus agradecimentos com a frase de uma sábia mulher, a Profa. Dra. Rosa Ester Rossini, que diz: "A vida é feita de acasos felizes". Pois bem, a minha vida até aqui foi feita de muitos acasos felizes. A jornada na Universidade abriu muitas oportunidades em minha vida e, nesse ambiente, fiz grandes amigos. Agora concluo o voo mais alto de minha vida: o Doutorado. Não teria chegado até aqui sem o apoio dos familiares e amigos, por isso dedico as linhas que seguem para agradecer a algumas dessas pessoas.

Agradeço à Profa. Dra. Rosa Ester Rossini por ter aceitado me orientar no Doutorado e ter dado todas as condições necessárias para a realização dessa pesquisa. Agradeço ainda pela oportunidade de compartilhar sua sempre agradável companhia. Obrigada pelas muitas vezes que me convidou para participar dos memoráveis almoços aos sábados e compartilhar desse momento de "deleite" gastronômico e cultural, onde com grande alegria, aprendia também ali naqueles momentos de descontração com a senhora e seus amigos (Dr. Renato e as senhoras: Ruth, Amelinha e Mariana). Obrigada ainda pela paciência e incentivo durante toda essa jornada de trabalho.

Agradeço a toda minha família, em especial aos meus pais (Lia e Paraná) e aos meus irmãos: Flávia, Letícia, Solange, José e Dayane (e a minha sobrinha Laura) por compreenderem os momentos em que não pude estar presente e por toda ajuda indispensável para que eu concluísse essa etapa da minha vida acadêmica. Quando estive desanimada, minha irmã Dayane teve a sensibilidade de encontrar um lugar no sítio, onde tivesse sinal de telefone para me desejar um bom dia de trabalho. A minha irmã Flávia sempre numa torcida incondicional, desde quando iniciei à graduação e tantas vezes demonstrou orgulho das minhas conquistas. Letícia, Solange e José me acolheram quando vim morar em São Paulo. Agradeço ainda aos meus cunhados, Didi e Maranhão, por todo carinho e ajuda nesse percurso.

À minha madrinha, Jacy Souto Maior da Mota Silveira, por todo amor e incentivo. Foi em sua casa que descobri novos horizontes, pois no contato com seu filho Emanuel Souto da Mota Silveira, a quem também dirijo meus agradecimentos, almejei entrar na universidade. Agradeço a Elisabeth da Mota Silveira e aos seus filhos, Tamires e Tomás, pela amizade e incentivo.

A Maria Baltar e Eduardo Sotero que, sem sobra de dúvidas, ajudaram nesse longo caminho. Foram eles que me levaram do sítio Parijós (Bom Jardim - PE) e me deram a oportunidade de sonhar, de mudar minha trajetória de vida.

À Profa. Thais Correia de Andrade, minha professora na Universidade Federal de Pernambuco (UFPE), por todo ensinamento, incentivo e amizade. Por ter me indicado para trabalhar junto com seu pai, o Prof. Manuel Correia de Andrade, na Cátedra Gilberto Freyre. 
Agradeço (em memória) ao Prof. Manuel Correia de Andrade e aos colegas da Cátedra Gilberto Freyre: Pricila Miranda, Cecilia Cysneiros, Maria Rita Machado, Danilo Magliano, Luciane Barbosa, Douglas Viana e Luiz Antônio.

Aos professores do curso de Licenciatura em Geografia que muito contribuíram para minha formação: Aldemir Dantas (em memória), Lucivânio Jatobá, Ana Cristina de Almeida Fernandes, Vanice Selva, Hernani Löebler, Paola Santana, Edna Medeiros, Caio Maciel e Graça Kater (em memória).

Aos meus amigos da UFPE: Sunamita Rodrigues, Edilson Carneiro, Carlos André e, claro, as amigas do "quarteto fantástico" Edjane Maria dos Santos, Maria Helena Serafim e Tyene Eufrásio. A vocês, minhas amigas, agradeço por todos os momentos compartilhados, alegrias, expectativas e torcida incondicional.

À Profa. Dra. Ana Cristina de Almeida Fernandes pela orientação no mestrado e pelos ricos momentos de aprendizado no Grupo de Pesquisa em Inovação, Tecnologia e Território (GRITT) - UFPE. Aproveito e agradeço aos amigos do GRITT: Sunamita Iris Rodrigues, à Priscila Batista, Allison Oliveira, Claudemice Rafael, Jurema Monteiro, Fátima Cabral e Douglas Viana, um grande amigo.

À Simone Cruz, amiga e incentivadora dessa jornada, obrigada pelos trabalhos que você conseguiu para mim e que me permitiram, no período em que não tinha bolsa de estudo, manter-me em São Paulo e regressar à Recife.

Ao Prof. Dr. Mario Vale que supervisionou meu estágio de Doutorado no Instituto de Geografia e Ordenamento do Território da Universidade de Lisboa (IGOTUL), Portugal.

À Coordenação de Aperfeiçoamento de Pessoal de Nível Superior (CAPES) pela concessão de uma bolsa de estudos do Programa institucional de Doutorado Sanduíche no Exterior (PDSE).

Aos amigos brasileiros, que ajudaram a diminuir as saudades do Brasil e que, como eu, tiveram a oportunidade de desfrutar de um momento áureo na qualificação do Ensino Superior brasileiro com a mobilidade internacional nos diversos níveis de formação acadêmica: Bruno Maia Halley, o "Rei Sol", Elis Amanda Atanásio, Marina Furtado, Renata Pimentel, Rafael Nicolau Carvalho, Carlos Monteiro e Welington.

Aos amigos, Prof. Dr. Antônio Cordeiro Feitosa e Profa. Dra. Marcia Manir M. Feitosa, companheiros de estudos na Biblioteca Nacional de Lisboa.

Aos colegas do IGOT-UL: Tiago Estevam, Debora Ferreira da Cunha, Numo Rodrigues, e Alexsandra Rocha.

Esse doutorado não teria sido o mesmo, se não tivesse conhecido meu grande amigo Paul Clívilan Santos Firmino. Ao seu lado compartilhei muitos momentos de alegrias e dificuldades. Companheiro de todas as horas e de todos os lugares: CRUSP, LABOPLAN, Lisboa, das viagens, do frio, da fome (risos) e do sono (risos).

Aos colegas de orientação que, juntos, criaram um ambiente profícuo de estudos e aprendizado: Aline Lima Santos, André Luís Gomes, Elisa Pinheiro de 
Freitas, Danton Bini, Dirce Soken, José Fonseca da Rocha Filho, Mateus de Almeida Prado Sampaio, Maria Leidiana Mendes, Markelly Fonseca e Valtemir Evangelista.

A Pedro Mezgraves pela solidariedade acadêmica e por toda ajuda com o meu computador que insistia em quebrar nos momentos mais impróprios.

A Mateus Sampaio pelo zelo na elaboração dos mapas e sua sempre disponibilidade em ajudar os colegas.

O Laboratório de Geografia Política e Planejamento Territorial e Ambiental (LABOPLAN), cuja infraestrutura foi indispensável na realização da pesquisa e onde a convivência com diversos colegas se configurou em momentos de trocas de experiências e aprendizado. Assim, agradeço de modo especial a Ana Eliza Pereira (Aninha) por toda ajuda dispensada e carinho. Aos colegas: Aline Oliveira, Fábio Brito, Igor Venceslau, Olivia Wakeman, Claudia Blanco, Victor Zuliani lamonti e Flávia Grimm.

Aos estimados amigos do CRUSP: Ivan Rocha, Ignácio Sanchez, Fran Alavina, Juliana Luquez, Eudes Leopoldo e Michel Rocha. Foi uma experiência maravilhosa conviver com vocês, tomar aqueles inúmeros cafés, momentos de descontração e apoio mútuo.

À Denise Martins de Souza pela amizade e leitura atenta da tese.

À Jane Roberta de Assis Barbosa pela companhia sempre agradável e palavras de incentivo.

A Ricardo Leão pessoa de alma leve e coração transparente pelas boas energias.

Aos amigos Ivan Rochas, Leonardo Holanda e Richard Remédios pela tradução dos resumo.

A Thiago Guerim pela amizade, boa convivência e por toda ajuda acadêmica. Nossas conversas madrugadas a fora foram sem sombra de dúvidas fundamentais na realização desse trabalho.

À Auta Narjara Brito pela paciência na fase final da tese e pelos momentos de descontração.

À Mirian por toda ajuda prestada na transcrição das entrevistas. afetuoso

À Adriana Renata e Nice por sempre terem me recebido com um abraço

Ao amigo de longa data José Leonardo do Nascimento.

Ao Programa de Pós-Graduação em Geografia Humana (PPGH) por ter oferecido as condições necessárias para realização do Doutorado.

À Rosangela Garcéz, secretária da Pós-Graduação em Geografia Humana, que sempre de forma muito atenciosa atendeu minhas solicitações. 
Aos professores Hervé Téry e Ana Cristina Almeida Fernandes pelas valiosas contribuições durante a banca de qualificação.

Ao CNPq pela concessão da bolsa de doutorado, sem a qual essa pesquisa teria sido realizada com maiores dificuldades.

À Profa. Dra. Mónica Arroyo pelos ensinamentos e afeto.

Aos pesquisadores da Embrapa Algodão: Luiz Paulo de Carvalho, Vicente Paula Queiroga, Odilon Reny Ferreira da Silva e Gilvan Alves Ramos, a este último agradeço de forma especial, pelas diversas bibliografias e informações concedidas, pelo incentivo e seriedade com o qual defende o Projeto Algodão Naturalmente Colorido Orgânico. Agradeço ainda a Geraldo Oliveira, que me acompanhou de forma muito atenciosa em um trabalho de campo.

Ao Dr. Joacy Santos, pesquisador apaixonado pelo algodão, por todas as informações e materiais concedidos.

Aos agricultores do assentamento Margarida Maria Alves, por terem cedido um pouco de seu tempo nas vezes que os visitei e compartilharam informações sobre suas experiências de vida e com a produção de algodão colorido orgânico, especialmente aos senhores Aluísio e Betinho, homens com olhares expressivos que carregam consigo a força do trabalho e de esperança por um futuro melhor.

Ao Prof. Dr. Paulo Sérgio Cunha Farias pelas ricas conversas em Campina Grande - PB.

À presidente da COOPNATURAL: Maysa Gadelha.

À presidente da Natural Cotton Color: Francisca Vieira

Às artesãs da Vila do Artesão por terem parado suas atividades para, gentilmente, contar-me sobre seu trabalho com o algodão naturalmente colorido.

Ao Prof. Dr. Alfredo Teles de Carvalho pelo carinho e atenção.

A Bruno Freitas pelos momentos de alegria e descontração na fase final dessa jornada.

É inevitável que alguns amigos não tenham sido citados, assim peço desculpas e sintam-se abraçados pelo meu carinho e amizade. 
Bate a enxada no chão

Limpa o pé de algodão

Pois pra vencer a batalha, É preciso ser forte, robusto, valente ou nascer no sertão Tem que suar muito pra ganhar o pão E a coisa lá "né" brinquedo não Mas quando chega o tempo rico da colheita Trabalhador vendo a fortuna se deleita Chama a família e sai, pelo roçado vai Cantando alegre ai, ai, ai, ai, ai, ai, ai, Sertanejo do norte

Vamos plantar algodão Ouro branco que faz nosso povo feliz Que tanto enriquece o país Um produto do nosso sertão Algodão (Luiz Gonzaga) 


\section{RESUMO}

A pesquisa desvelou o circuito espacial de produção do algodão naturalmente colorido na Paraíba. Procuramos destacar o papel da pesquisa pública, através do sistema de ações da Embrapa Algodão, localizada em Campina Grande-PB na transformação das condições tecnológicas desse tipo de algodão e sua viabilização para exploração comercial; a organização espacial da produção; os atores envolvidos e as novas relações que se estabelecem com o sistema de produção do algodão naturalmente colorido orgânico. Nossa tese é de que a Embrapa Algodão foi central no processo de recuperação da cotonicultura brasileira, que enfrentou grave crise na década de 1980 e levou ao declínio dessa cultura até o início década de 1990. De modo geral o presente trabalho, inserido nos recentes debates da geografia, procurou destacar o papel da ciência, da pesquisa, da inovação na constituição de um circuito espacial de produção, tendo como estudo de caso a Embrapa e o Algodão Naturalmente Colorido. No contexto da crise nacional do algodão essa empresa foi responsável pela pesquisa, melhoramento e desenvolvimento de cultivares de algodão branco adaptado para as condições ambientais do bioma Cerrado e o algodão naturalmente colorido, uma planta silvestre nativa para as condições do Semiárido e viável para o processamento industrial. Na pesquisa constatou-se que a reorganização da produção algodoeira na Paraíba (colorido), a partir dos anos 2000, foi resultado da combinação de diferentes variáveis, dentre as quais destacam-se a pesquisa (Embrapa) e o marketing e propaganda (empresários), além de variáveis regionais/locais representadas pela agricultura familiar e produção orgânica. Tal reorganização apresenta atualmente duas regiões de produção distintas: região do Cerrado e a região Semiárido, regiões que se caracterizam por diferentes modos de produção concretos, no sentido proposto por Santos ([1996] 2008). Além do algodão naturalmente colorido atualmente ser desenvolvido em sistema de produção orgânica, nas outras fases de produção, os pequenos empresários que fazem uso do algodão colorido em suas produções tem buscado se adequar as exigências das normas estabelecidas pelos mercados consumidores, formado principalmente por turistas, pessoas preocupadas com a sustentabilidade ambiental e social, com destaque para os consumidores dos países europeus. A pesquisa demostrou ainda que a confiança que há em torno dos trabalhos de pesquisa da Embrapa Algodão extrapolam os limites das pesquisas agronômicas, a ponto da instituição ser utilizada no marketing comercial de empresas.

Palavras Chave: Embrapa Algodão; algodão naturalmente colorido, agricultura familiar, inovação. 


\begin{abstract}
The research unveiled the space circuit of naturally coloured cotton production in Paraíba. We try to highlight the role of public research, through the actions of Embrapa Algodão system, located in Campina Grande (Paraíba) in the transformation of technological conditions aforementioned sort of cotton and their development for commercial exploitation; the spatial organization of production; the actors involved and the new relations established with the naturally coloured organic cotton production system. Our thesis is that the Embrapa Algodão was very important in the process of recovery of the Brazilian cotton industry, which suffer crisis in the 1980s and led to the decline of this farming until the early 1990s. Overall this paper, inserted in recent debates geography, sought to highlight the role of science, research, innovation in the creation of a spatial circuit production, taking as a case study the Embrapa Algodão and Naturally Coloured Cotton. In the context of national cotton crisis such company was responsible for research, improvement and development of white cotton cultivars tailored to the environmental conditions of the Cerrado biome and naturally coloured cotton, which is a native wild plant to the conditions of semi-arid and feasible for processing industrial. This research found out that the reorganization of cotton production in Paraíba (coloured), from the 2000s, was a result from the combination of different variables, among which stand out the research (Embrapa) and the marketing and advertising (business) as well as regional/local variables represented by family farming and organic production. Such reorganization currently has two distinct production areas: the Cerrado region and the semi-arid region, which are regions characterized by different specific modes of production, in the sense proposed by Santos ([1996] 2008). Besides naturally coloured cotton currently being developed in organic production system, at other stages of production, small business owners who uses coloured cotton in their productions have been trying to adapt yourselves to the requirements of the standards set by consumer markets, mainly consisting of tourists, people concerned about the environmental and social sustainability, especially for consumers in European countries. The survey also demonstrated that confidence that there is about research works of Embrapa Algodão transcend the limits of agronomic research, to the point of the institution to be used in commercial marketing companies.
\end{abstract}

Keywords: Embrapa Algodão; naturally coloured cotton, family farming, innovation. 


\section{RESUMEN}

La investigación dio a conocer el circuito espacial de producción del algodón naturalmente colorido en Paraíba. Intentamos destacar el papel de la pesquisa pública a través del sistema de acciones de la Embrapa Algodão, localizada en Campina Grande-PB en la transformación de las condiciones tecnológicas de este tipo de algodón y la viabilidad para su explotación comercial; la organización espacial de la producción; los actores involucrados y las nuevas relaciones que se establecen con el sistema de producción del algodón naturalmente colorido orgánico. Nuestra tesis es que Embrapa Algodão fue determinante en el proceso de recuperación de la industria del algodón brasileña, que enfrentó una grave crisis en la década de los 80 y llevó al declive de esa cultura hasta los inicios de la década de los 90. De modo general, el presente trabajo, insertado en los recientes debates de geografía, buscó destacar el papel de la ciencia, de la investigación, de la innovación en la constitución de un circuito espacial de producción, teniendo como caso de estudio a Embrapa y el algodón naturalmente colorido. En el contexto de la crisis nacional del algodón, esa empresa fue la responsable por la investigación, mejoramiento y desarrollo de variedades de algodón blanco adaptado a las condiciones ambientales del bioma Cerrado y el algodón naturalmente colorido, una planta silvestre nativa para las condiciones semiáridas y viable para el procesamiento industrial. En la investigación se encontró que la reorganización de la producción algodonera en Paraíba (colorido), a partir del año 2000, fue el resultado de la combinación de diferentes variables, entre las cuales se destacan la investigación (Embrapa) y el marketing y propaganda (empresarios), además de variables regionales/locales representadas por la agricultura familiar y la producción orgánica. Tal reorganización presenta actualmente dos regiones de producción distintas: región Cerrado y la región Semiárido, regiones que se caracterizan por diferentes modos de producción concretos, en el sentido propuesto por Santos ([1996] 2008). Además de que el algodón naturalmente colorido está siendo desarrollado en un sistema de producción orgánico, en las otras fases de producción, los pequeños empresarios que hacen uso del algodón colorido en sus producciones, están buscando adaptarse a las exigencias de las normas establecidas por los mercados consumidores, formando principalmente por turistas, personas preocupadas con la sustentabilidad ambiental y social, destacando los consumidores de los países europeos. La investigación demostró que la confianza que existe en torno de los trabajos de investigación de Embrapa Algodão extrapolan los límites de las investigaciones agronómicas, al punto de la institución ser utilizada en el marketing comercial de empresas.

Palabras claves: Embrapa Algodão; algodón naturalmente colorido, agricultura familiar, innovación. 


\section{LISTA DE FIGURAS}

Figura 1 - Taxonomia de Inovação. 41

Figura 2 - "ondas" de criação de instituição de ensino e pesquisa no Brasil. 45

Figura 3 "ondas" de criação de instituição de ensino e pesquisa no Nordeste. .46

Figura: 4 - Laboratórios Virtuais e Projetos da Embrapa no Exterior. 69

Figura 5 - Algodão Mocó (Gossypium hirsutum L.marie galante). .93

Figura 6- Regiões de preservação de espécies de algodão G. barbadense, G. mustelinum e G. hirsirum marie galante no Brasil.. 99

Figura 7 - Máquina para prensar o algodão - século XVIII. 112

Figura 8 - Bolandeira fundada em 1865 no distrito de Queimadas (Campina Grande)PB... 113

Figura 9 - Carregador de Algodão - Século XVIII. 116

Figura 10 - Média do maior e menor preço do algodão no período de (18291921). 118

Figura 11 - Colheita manual de algodão naturalmente colorido - Peru. 161

Figura 12 - Descaroçamento manual de algodão colorido - Peru. 161

Figura 13 - acomodação de mistura de algodão para formação do rolo- Peru. 162

Figura 14 - Rolos de algodão colorido nativo -Peru. 162

Figura 15- Fiação manual do algodão colorido nativo - Peru. 162

Figura 16- Tecelagem manual de algodão colorido nativo - Peru. 162

Figura 17 -Tecelagem peruana feita, por nativos pré-colombianos. 163

Figura 18 - Têxtil com algodão colorido. 163

Figura 19 - Capulhos de algodão silvrestre naturalmente colorido.. 167

Figura 20: Cultivar BRS 200. 176

Figura 21: Cultivar BRS Verde. 177

Figura 22- Cultivar BRS Safira 178

Figura 23 - Cultivar BRS Rubi. 179

Figura 24 - Cultivar BRS Topázio 179

Figura 25 - Vestido de algodão naturalmente colorido com detalhe em renda renascença. 198

Figura 26 - Cultivares de algodão colorido desenvolvidas pelo IAC 206

Figura 27 - Calendário Agrícola do Agreste. 210

Figuras 28 e 29 - Dia de Campo de Algodão Colorido na Fazenda Campos, no município de Salgado de São Felix - PB. 
Figura 30 - Pivô Central utilizado no cultivo de Algodão Colorido BRS Safira no Sítio União - São Bento - PB

Figura 31 - Agricultor retirando 0 algodão branco do meio do algodão colorido. 220

Figura 32 - Algodão com fibra branca entre o algodão colorido.

Figura 33 - Cultivo de algodão colorido consorciado com milho e feijão no Assentamento Margaria Maria Alves - Juarez Távora-PB....................................222

Figura 34 - Missão Técnica do Paraguai conhecendo as instalações da CAMPAL, Patos-PB. 230

Figura 35 - Missão Técnica do Paraguai conhecendo o Campo Experimental da Embrapa Algodão Patos - PB. 230

Figura 36 - Missão Técnica do Peru - Visita ao campo de multiplicação de sementes do Assentamento Margarida Maria Alves - Juarez TávoraPB. 230

Figura 37 - Missão Técnica do Peru - Visita Miniusina de beneficiamento de algodão do Assentamento Margarida Maria Alves - Juarez Távora-PB. 230

Figura 38 -Selos de produção orgânica Fox Fibre. 233

Figura 39 - Parede Interna da CAMPAL com frase alusiva ao novo " ciclo" de produção de algodão da Paraíba. 234

Figuras 40 e 41 - Algodão colorido no interior da CAMPAL a espera de beneficiamento 236

Figura 42 - Local onde antes era armazenado algodão colorido orgânico na CAMPAL, hoje inativo. 236

Figura 43 - Descaroçador de algodão de 50 serras. 239

Figura 44 - Prensa hidráulica para enfardar o algodão sendo manuseada por um agricultor. 239

Figura 45 - Miniusina de beneficiamento de algodão do assentamento Margarida Maria Alves 242

Fifura 46 - Miniusina de beneficiamento de algodão móvel de 20 serras. 244

Figura 47 - Espaçamento entre as fileiras de algodão colorido - Assentamento Margarida Maria Alves - Juarez Távora-PB.

Figura 48 - Mutirão para colheita do algodão colorido no assentamento Margarida Maria Alves - Juarez Távora-PB. 247

Figura 49 - Fardos de Algodão colorido. 248

Figura 50 - Primeiro vestido de algodão colorido natural feito no Brasil na Bienal Brasileira de Design 254

Figura 51 e 52 - Exposição de tecidos e artigos feitos com algodão colorido na BIOFACH -2015 259

Figuras 53 e 54 - Peças de algodão fracionadas para as artesãs Vila do Artesão Campina Grande-PB. 259 
Figuras 55 - Artesanato feito com algodão colorido Vila do Artesão - Campina Grande-PB.

Figuras 56 e 57 - Algumas técnicas de artesanato manual utilizadas nas confecções de algodão colorido. .262

Figura 58- Artesanato com algodão colorido - COOPNATURAL 263

Figura 59 - Referência dos artesões a identidade geográfica do algodão colorido 264

Figura 60 - Selo de Indicação Geográfica do Algodão naturalmente colorido da Paraíba. 264

Figura 61 - COOPNATURAL 266

Figura 62 - Países onde eram comercializados os produtos derivados do Algodão Colorido da Paraíba (2010). 268

Figura 63 - Cliente experimenta um vestido de algodão colorido na BIOFACH - Japão (2013) 272

Figura 64 - Lugar de produção da Natural Cotton Color 273

Figura 65 - Roupas feitas com algodão naturalmente colorido na São Paulo Fashion Week (2016). .274

Figura 66 - Denuncia de falsificação de algodão colorido na Paraíba 276 


\section{LISTA DE GRÁFICOS E QUADROS}

Gráfico 1 - Investimentos em Pesquisa e Desenvolvimento na Agropecuária nos países na América Latina e do Caribe (2016) .71

Gráfico 2 - Perfil Institucional da Pesquisa Agropecuária no Brasil (2016). .72

Quadro 01: Pontos fortes e pontos fracos na abordagem de sistema de inovação.....34 Quadro 02 - Periodização da criação de instituições de Ensino e Pesquisa no Brasil e no Nordeste.

Quadro 03 - Instituições de ensino e pesquisa criadas no Nordeste de acordo com as "ondas"...

Quadro 04 - Pontos Positivos e Negativos que caracterizavam a pesquisa agrícola na década de $1970 .$.

Quadro - 05 - Distribuição institucional da Pesquisa Agropecuária no Brasil 1972

Quadro 06 - Unidades Descentralizadas da Embrapa: distribuição no território brasileiro.

Quadro 07 - Diferenças entre o Sistema Embrapa de Pesquisas e o Sistema de

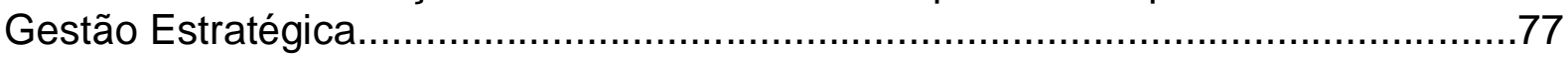

Quadro 08 - Organizações Estaduais de Pesquisa por região geográfica. 80

Quadro 09 - Participação das OEPAs nos projetos dos Macroprogramas da Embrapa.

Quadro 10 - Espécies de algodão silvestre e seus centros de origem geográfica.

Quadro 11 - Estações Experimentais de Algodão no Brasil na década de 1920 .....127

Quadro 12 - Nível de Formação dos Pesquisadores da Embrapa (2016).. 154

Quadro 13- Espécies silvestres de algodão colorido e sua distribuição geográfica. 168

Quadro 14 - Características das Cultivares de Algodão Colorido: BRS 200 Marrom, BRS Verde, BRS Rubi, BRS Safira, BRS Topázio em comparação a cultivar branca BRS $1878 \mathrm{H}$

Quadro 15- Evolução da área plantada de algodão colorido na Paraíba (20002006)..... 203

Quadro 16 - Evolução da área plantada com algodão colorido na Paraíba (20022014)..... 203

Quadro 17 - Dados sobre produção de algodão orgânico no mundo (2016) 225

Quadro 18 - Bancos Públicos e Privados em Campina Grande - PB. 264

Fluxograma 1 192 


\section{LISTA DE TABELAS}

Tabela 1 - Importação de algodão na Inglaterra (1860-1866).

Tabela 2 - Área Plantada, Produção Algodão em Caroço e Produtividade do Algodão em Caroço, por Região Geográfica, e Estados do Brasil na safra 1975/1976

Tabela 3 - Os dez principais países em área colhida de algodão (ha) (1975-1976, 1980-1981, 1985-1986, 1995-1996, 2005-2006, 2010-2011, 20152016) 140

Tabela 4 - Os dez principais países em produção de algodão (T) (1975-1976, 19801981, 1985-1986, 1995-1996, 2005-2006, 2010-2011, 20152016). 140

Tabela 5 - Brasil - Área Plantada, Produtividade e Produção de Algodão na Safra 2012/2013 e 2013/2014, segundo estados maiores produtores. 143

Tabela 6 - Produção Mensal de Peças COOPNATURAL 2004/2005 267

\section{LISTA DE MAPAS}

Mapa 1 - Localização das Unidades de Pesquisa Descentralizada da Embrapa. .66

Mapa 2 - Variação na quantidade de algodão arbóreo e herbáceo no Nordeste entre 1990 e 2014. 144

Mapa 3 - Variação na quantidade produzida de algodão herbáceo no Brasil (1990 e 2014). 146

Mapa 4 - Evolução da área plantada com algodão no Brasil em período selecionado (1920, 1950, 1980, 2010)..... 148

Mapa 5 - Evolução da produção do algodão na região do Semiárido e do Cerrado do Nordeste Brasileiro (1990 - 2015). 149

Mapa 6 - Sede da Embrapa Algodão e Campos Experimentais na região Nordeste e Centro-Oeste. 184

Mapa 7 - Municípios que cultivavam algodão naturalmente colorido em

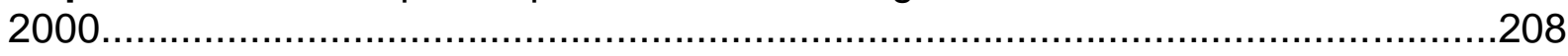

Mapa 8 - Municípios que cultivavam algodão naturalmente colorido em 2008.........208

Mapa 9 - Municípios que cultivavam algodão naturalmente colorido (2016).............208

Mapa 10 - Mundo: destino da exportação de produtos derivados de algodão naturalmente colorido da paraíba (2016). 


\section{LISTA DE SIGLAS}

AMDE - Agência Municipal de Desenvolvimento Econômico

APEX - Brasil - Agência Brasileira de Promoção de Exportações e Investimentos

APL - Arranjos Produtivos Locais

APTA - Agência Paulista de Tecnologia dos Agronegócios

ASSAM - Associação para Suprimento do Algodão de Manchester

C T \&l - Ciência, Tecnologia e Inovação

CAI - Complexo Agroindustrial

CGAPLCAACP - Comitê Gestor do Arranjo Produtivo Local de Confecções e Artefatos de Algodão Colorido da Paraíba

CGEE - Centro de Gestão e Estudos Estratégicos

CNEPA - Centro Nacional de Pesquisa de Ensino e Pesquisa Agrícola

CNPA - Centro Nacional de Pesquisa de Algodão (Embrapa Algodão)

COOPNATURAL - Cooperativa de Produção Têxtil e Afins do Algodão do Algodão do

Estado da Paraíba

CR - Complexo Rural

DGP - Diretoria Geral de Pesquisas

DNPEA - Departamento Nacional de Pesquisa e Experimentação Agropecuária

DPE - Departamento de Pesquisa e Experimentação

EBDA - Empresa Baiana de Desenvolvimento Agrícola S.A.

EMATER-PB - Embrapa Algodão e da Empresa de Extensão Rural da Paraíba

Embrapa - Empresa Brasileira de Pesquisa Agropecuária

EMDAGRO - Empresa de Desenvolvimento Agropecuário do Estado de Sergipe

EMEPA - Empresa Estadual de Pesquisa Agropecuária da Paraíba S/A

EMPAER-MT - Empresa Matogrossense de Pesquisa e Assistência Técnica e Extensão Rural S.A.

EMPARN - Empresa de Pesquisa Agropecuária do Rio Grande do Norte

EPAGRI - Empresa de Pesquisa Agropecuária e Extensão Rural de Santa Catarina S.A

EPAMIG - Empresa de Pesquisa Agropecuária de Minas Gerais

EPE - Escritório de Pesquisa e Experimentação

FEPAGRO - Fundação Estadual de Pesquisa Agropecuária 
GNTD - Grupo de Estudos para o Desenvolvimento do Nordeste

IAC - Instituto Agronômico de Campinas

IAPAR - Instituto Agronômico do Paraná

IBGE - O Instituto Brasileiro de Geografia e Estatística

IDATERRA-MS - Instituto de Desenvolvimento Agrário, Assistência Técnica e Extensão Rural de Mato Grosso do Sul

IG - Indicação Geográfica

INCAPER - Instituto Capixaba de Pesquisa

INPI - Instituto Nacional de Propriedade Industrial

IPA - Empresa Pernambucana de Pesquisa Agropecuária

OEPAs - Organizações Estaduais de Pesquisa Agropecuária

P\&D - Pesquisa \& Desenvolvimento

PESAGRO - Empresa de Pesquisa Agropecuária do Rio de Janeiro

PIB - Produto Interno Bruto

PNPB - Programa Nacional de Produção e Uso de Biodiesel

RPA - Região Produtiva Agrícola

RPA - Regiões Produtivas Agrícola

SAIN - Sociedade Auxiliadora da Industria Nacional

SEG - Sistema de Gestão Estratégica

SENAI - Serviço Nacional de Aprendizagem Industrial

SINDIVEST - Sindicato do Vestuário da Paraíba

SNI - Sistema Nacional de Inovação

SNPA - Serviço Nacional de Pesquisa Agronômica

SNPA - Sistema Nacional de Pesquisa Agropecuária

SUDENE - Superintendência de Desenvolvimento do Nordeste

UFCG - Universidade Federal de Campina Grande

UNITINS - Universidade do Estado do Tocantins 
Capítulo 1. GEOGRAFIA E INOVAÇÃO: A FORMAÇÃO SOCIOESPACIAL $\begin{array}{llll}\text { BRASILEIRA } & E & O & \text { SISTEMA }\end{array}$ INOVAÇÃO

1.1. Sistema Nacional de Inovação: uma breve

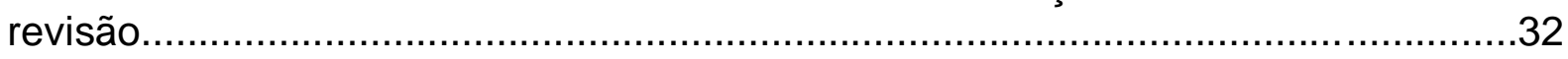

1.2. O Papel da pesquisa pública no sistema nacional de inovação............................37

1.3. Interação entre o Sistema de Ciência e Tecnologia e o Setor

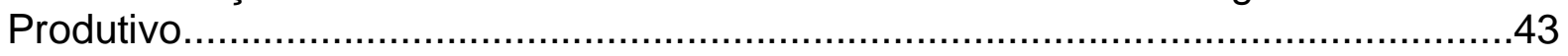

Capítulo 2. A EMBRAPA E A CONSTITUIÇÃO DO SISTEMA TERRITORIAL DE

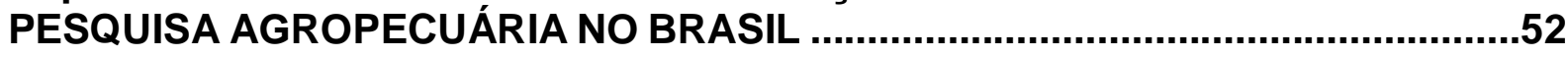

2.1. O Contexto histórico da criação da Embrapa................................................55

2.2. As Unidades de Pesquisa descentralizadas da Embrapa e Consolidação do Sistema Nacional da Pesquisa Agropecuária............................................................64

2.3. O modelo de Gestão da Pesquisa da Embrapa e a articulação com as Organizações Estaduais de Pesquisa Agropecuária ..............................................74

Capítulo 3. O ALGODÃo NO BRASIL: DO PERÍOdO PRÉ - TÉCNICO AO PERÍODO TÉCNICO - CIENTÍFICO - INFORMACIONAL ........................................

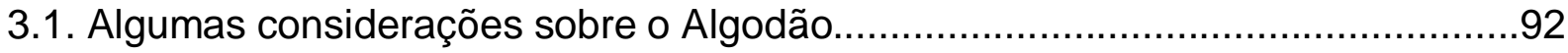

3.2. O algodão brasileiro no período pré-técnico: do período pré-colonial aos primeiros

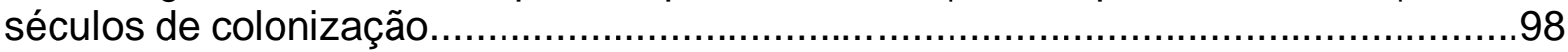

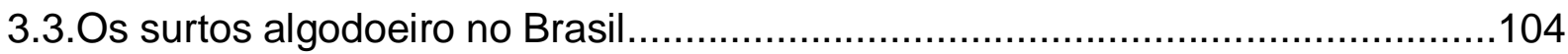

3.3.1. As inovações na indústria têxtil e o primeiro surto de produção do algodão no Brasil. 105

3.3.2. A Guerra de Secessão: primeiros esforços de mudanças técnicas na produção

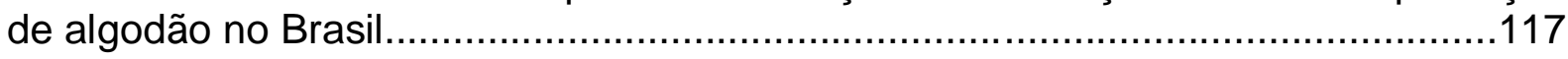

3.3.3. Mudança em curso: as bases da pesquisa algodoeira no Brasil....................124

3.3.4. A nova racionalidade na produção algodoeira e a hegemonia de São

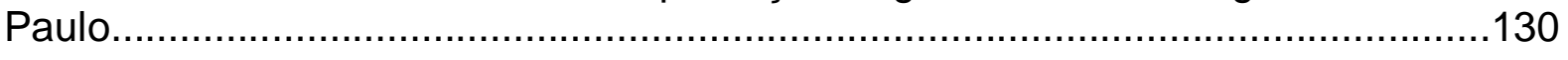

3.3.5. A pesquisa para 0 melhoramento genético do algodão no

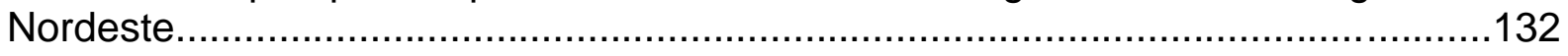


3.3.6. Crise na cotonicultura brasileira (1980-1995)

3.3.7.A retomada na produção algodoeira do Brasil e as novas dinâmicas (19952016)

Capítulo 4. A REINVENÇÃo DA CULTURA ALGODOEIRA NO NORDESTE: 0 ALGODÃO NATURALMENTE COLORIDO NA PARAÍBA.

4.1. Do algodão colorido natural como "contaminação" ao algodão colorido natural como inovação. 160

4.2. Panorama da Pesquisa e Melhoramento Genético do Algodão Colorido Natural. 168

4.3 . A trajetória tecnológica do Algodão Colorido no Brasil 172

4.4. O processo de territorialização do algodão colorido na Paraíba 184

Capítulo 5. O CIRCUITO ESPACIAL DE PRODUÇÃO DO ALGODÃO NATURALMENTE COLORIDO DA PARAÍBA 194

5.1. Dinâmicas espaciais das áreas de cultivo de algodão colorido da Paraíba (20002016) 199

5.1.1. As Inovações no cultivo do algodão colorido 209

5.2 . O beneficiamento do algodão e as novas possibilidades para a agricultura familiar. .234

5.2.1. O Assentamento Margarida Maria Alves: polo de produção e beneficiamento do algodão colorido da Paraíba. 238

5.3 - O fio e as tramas do algodão naturalmente colorido. 251

5.4 - Os lugares de produção de confecções e afins do algodão colorido da Paraíba e sua circulação no mercado 260 


\section{INTRODUÇÃO}

A presente pesquisa buscou analisar a produção do algodão naturalmente colorido no estado da Paraíba e seu circuito espacial de produção. Considerando, que na atualidade, as atividades econômicas e sociais se desenvolvem com crescente utilização de conhecimento científico que imprimem novos conteúdos tecnológicos aos sistemas de objetos e sistemas de ações, que definem o espaço geográfico (Santos, 2008[1996]); buscamos também analisar a mobilização da principal empresa pública de pesquisa agropecuária do país, a Empresa Brasileira de Pesquisa Agropecuária (Embrapa), por meio de sua unidade descentralizada de pesquisa de produto, a Embrapa Algodão, localizada no município de Campina Grande-PB, no desenvolvimento de conhecimento científico e tecnológico para a cotonicultura brasileira em especial para o algodão naturalmente colorido.

O lançamento da primeira cultivar de algodão naturalmente colorido no Brasil no ano 2000 provocou especulações sobre a retomada da produção algodoeira na região Semiárida do Nordeste brasileiro onde, secularmente, essa cultura teve importância econômica e social. Considerado uma inovação em matéria prima têxtil, o algodão naturalmente colorido brasileiro ganhou repercussão internacional, devido à qualidade tecnológica da fibra desenvolvida, dos processos sociais e ambientais que o envolvem e que serão analisados no decorrer dessa pesquisa.

Nossa hipótese é de que a Embrapa Algodão foi central na renovação da produção algodoeira nacional, depois da crise que atingiu essa cultura provocada pela praga do bicudo na década de 1980 e outros fatores, a exemplo da abertura da economia brasileira na década de 1990; reorganização da agropecuária nacional coma expansão da exploração agropecuária no domínio do bioma Cerrado, no qual a região Centro-Oeste se destaca. E como hipótese secundária, acreditamos que a introdução do cultivo comercial do algodão naturalmente colorido marca um novo período na história da produção algodoeira nacional, em particular da região Semiárida.

No Brasil o programa de melhoramento de algodão naturalmente colorido teve início em 1989, no contexto da crise da produção algodoeira nacional e coube ao Estado através da infraestrutura pública de pesquisa agrícola, a pesquisa, melhoramento e criação das primeiras cultivares de algodão colorido no país. Essa 
situação denota a importância do Estado na promoção da pesquisa pública e como agente econômico.

A importância dos centros de pesquisa pública, das universidades é tema sobre o qual já havíamos tecido algumas reflexões durante o mestrado, realizado na Universidade Federal de Pernambuco, quando estudamos a contribuição da Embrapa Semiárido, no desenvolvimento da fruticultura irrigada no Vale do Submédio São Francisco (LIRBÓRIO, 2012).

A região mencionada faz parte dos enclaves de modernização agrícola no Brasil, criados a partir da década de 1970. Mesmo situada em uma região onde as condições climáticas são severas, o Semiárido brasileiro, no qual parte expressiva da população enfrenta problemas com os longos períodos de estiagem, há intensa produção de frutas para exportação e uso de sistema técnico agrícolas que se alinham às produções mais modernas do setor. No estudo supracitado já havíamos constatado a importância da produção de conhecimento local, para resolução de problemas tecnológicos na agricultara.

Assim, para além da pesquisa agronômica que culminou no desenvolvimento de cultivares de algodão naturalmente colorido, analisamos as outras etapas que perfazem o circuito espacial de produção dos derivados do algodão colorido, beneficiamento, industrialização, confecção de roupas e artesanato, circulação e consumo final.

Nesse contexto quando iniciamos a nossa pesquisa algumas questões se sobressaíam, como o fato de mesmo sendo considerado produto inovador e sendo possível cultivá-lo em outros estados do Nordeste, o cultivo e a produção de confecção se restringiam ao território paraibano. Teria isso relação com o fato da Embrapa Algodão estar localizada em Campina Grande? A questão da territorialização da produção do algodão naturalmente colorido foi um dos objetivos que buscamos analisar na pesquisa

As questões que tangenciam a produção do algodão colorido produzido na Paraíba são complexas. A diversidade de atores sociais envolvidos: o sistema de ações públicas, via Embrapa Algodão, EMATER-PB, os empresários locais, os agricultores familiares, as intencionalidades relacionadas a produção do algodão colorido, os agentes econômicos externos ao lugar. A análise desse todo complexo, só poderia ser compreendido tomando como referência, o espaço geográfico, 
enquanto instância social, conforme proposto por Santos (2008 [1985]). Como uma instância da sociedade há imbricação entre diferentes instâncias.

Consideramos o espaço como uma instância da sociedade, ao mesmo título que a instância econômica e a instância cultural-ideológica. Isso significa que, como instância, ele contém e é contido pelas demais instâncias, assim como cada uma delas o contém e é por ele contido. (Santos, 2008 [1985], p. 12).

Para compreender a complexidade que envolve essa atividade estabelecemos alguns objetivos específicos que guiou a resolução da nossa problemática de pesquisa. Os objetivos específicos foram:

1. Identificar e analisar os principais avanços técnicos e científicos na cotonicultura brasileira, com destaque para as pesquisas desenvolvidas pela Embrapa Algodão;

2. Compreender o processo de pesquisa e desenvolvimento do algodão naturalmente colorido pela Embrapa Algodão;

3. Identificar e analisar o processo de territorialização do algodão naturalmente colorido do território paraibano;

4. Identificar e analisar as possibilidades e limites da produção de algodão colorido no Brasil.

\section{Algumas notas sobre a metodologia}

No desenvolvimento da pesquisa procuramos relacionar a teoria e os dados empíricos obtidos durante a realização da pesquisa de campo. Assim, pudemos afirmar que a pesquisa se constituiu em duas etapas principais: a de gabinete e a pesquisa de campo, por sua vez não aconteceram de forma isolada.

\section{Pesquisa de Gabinete}

$\mathrm{Na}$ fase de gabinete procuramos identificar, analisar e compreender os conceitos que pudessem nos ajudar nos alicerces da pesquisa geográfica. Fizemos levantamentos de dados estatísticos, elaboração de gráficos, mapas, tabelas dentre outros. As pesquisas foram feitas em livros, artigos científicos, sites e não privilegiou apenas os estudos relacionados à geografia, fizemos amplo uso de bibliografia da 
história, da economia, agronomia e outras áreas do conhecimento. No decorrer da pesquisa buscamos relacionar a teoria com dados empíricos e dessa forma não elaboramos um capítulo essencialmente teórico, mas a teoria está diluída ao longo da pesquisa, na medida em que compreendemos que teoria e empiria se complementam.

Contudo, para que o leitor pudesse compreender um pouco como foi construída a arquitetura dessa tese, teceremos alguns comentários sobre os conceitos que se sobressaíram, e porque o mobilizamos nessa pesquisa. Conforme já mencionado o conceito de espaço geográfico adotado na pesquisa foi o desenvolvido pelo geógrafo Milton Santos que, em seus estudos, propôs que a compreensão do espaço geográfico perpassa pela compressão da técnica e dos sistemas técnicos de acordo com os diferentes meios geográficos, sempre levando em consideração o tempo.

Assim buscamos sempre valorizar as dimensões temporal e espacial em nossas analises. A compreensão do arranjo espacial por sua vez se faz mediante a consideração de algumas categorias de análise do espaço proposta pelo autor citado: a forma, função, estrutura e processo.

Ainda considerando a dimensão temporal, procuramos desenvolver uma periodização dos principais eventos relacionados a lavoura algodoeira no país, de acordo com os períodos de uso do território brasileiro propostos por Santos e Silveira (2011): período pré-técnico, período técnico e o período técnico-científico informacional.

O conceito de formação socioespacial foi de suma importância na compreensão de como, ao longo do tempo, a produção algodoeira nacional se inseriu na divisão territorial do trabalho internacional e nacional, e como as heranças técnicas e sociais permanecem no desenvolvimento dessa atividade, no que tange a produção de algodão naturalmente colorido, constituindo as rugosidades do espaço geográfico, ou heranças de períodos anteriores.

O conceito de formação socioespacial também foi importante na análise da formação do sistema de pesquisa agrícola no país. Isso porque, como utilizamos o conceito de sistema nacional de inovação, que tem origem em debates da economia a partir da década de 1970, quando alguns estudiosos procuraram entender os fatores da mudança tecnológica e perceberam, que o desenvolvimento de inovação, na perspectiva tradicional, na qual o desenvolvimento de uma inovação ocorria de forma 
linear: pesquisa básica, pesquisa aplicada e produto final. Os estudiosos do Sistema de Inovação compreendem a inovação como um processo sistêmico e interativo. Ainda segundo esse conceito as fontes de conhecimento capazes de gerar inovação não se restringem ao ambiente das empresas, e que outras organizações podem contribuir no desenvolvimento de inovações a depender do setor de atividade, a exemplo do conhecimento que é produzido nos Centros de Pesquisa Pública ou em Universidades.

A dimensão da inovação como fenômeno relacional tem sido estudado pela Geografia Econômica e outras áreas de conhecimento, e um aspecto do desenvolvimento de inovação que até pouco tempo não era considerada, principalmente pela economia passou a despertar interesse de pesquisadores, como o espaço geográfico e seu constructo histórico e social contribuem no processo de atividades inovadoras.

De antemão esclarecemos que os debates da Geografia Econômica contemporânea, em especial a denominada Geografia do Conhecimento e Inovação tem sido trabalhada por muitos pesquisadores, principalmente buscando compreender quais os fatores que contribuem para o desenvolvimento de determinadas atividades, em um espaço geográfico, em especial aquelas que são mais intensivas em conhecimento científico. É um debate que tem o espaço urbano e a indústria o centro de suas análises.

Nosso objetivo aqui, não foi o de estudar as questões relacionadas diretamente a aglomeração de atividades industriais, mas um elemento que tem se destacado nesses estudos, a produção de conhecimento enquanto importante fator de produção. Nosso ponto de partida foi a agricultura e a produção de conhecimento tecnológico para a mesma, a partir do caso da Embrapa Algodão e do algodão naturalmente colorido.

Nos estudos sobre sistema nacional de inovação, se destaca o papel que as instituições de pesquisa, públicas (universidades e institutos de pesquisa) e privadas podem exercer no desenvolvimento tecnológico das nações, em especial, nos países em desenvolvimento, conforme destacado por alguns autores (ALBUQUERQUE, 1996; ALBUQUERQUE e CASSIOLATO, 2000; SUZIGAN e ALBUQUERQUE, 2008; SUZIGAN; ALBUQUERQUE; CARIO, 2011; IBAÑEZ, 2012; RAPINI et al., 2009). 
Em estudo desenvolvido pelo economista Eduardo da Mota Albuquerque em 1996, o autor chegou à conclusão que o Brasil se insere em um grupo de países que embora tenham uma infraestrutura de Ciência e Tecnologia (C\&T) constituída não conseguem mobilizar na mesma proporção número de pesquisadores em relação os países desenvolvidos. E a interação entre a base de C\&T do país com o setor produtivo, se limita a poucas atividades, caracterizando dessa forma um sistema nacional de inovação imaturo.

\section{Pesquisa de Campo}

No que se refere à pesquisa de campo, a mesma se constituiu como instrumento indispensável para realização dessa pesquisa. Devido à produção de algodão naturalmente colorido ser uma atividade recente no, país há escassez de dados. Os órgãos responsáveis pela elaboração das estatística e produção da agricultura, como - IBGE, não disponibilizam informações sobre esse tipo de algodão, apenas fornecendo dados sobre o algodão branco por tipo de ciclo de cultura, perene ou anual.

Foram realizados três trabalhos de campo, o primeiro em junho de 2014, 0 segundo em junho de 2015 e julho de 2016. As pesquisas de campo foram realizadas nos municípios paraibanos de: João Pessoa, Campina Grande, Juarez Távora, Patos e São Mamede. Nos trabalhos de campo realizamos entrevistas abertas e semiestruturadas. Nesse período foram entrevistados 5 (cinco) pesquisadores da Embrapa Algodão e 2 (dois) técnicos agrícolas dessa instituição, que fazem o acompanhamento técnico na transferência de tecnologia do algodão colorido. Além das entrevistas, a produção bibliográfica dessa instituição foi importante na aquisição de conhecimento sobre a atuação e desenvolvimento das ações da mesma em relação as suas atividades de pesquisa e transferência de tecnologia.

No primeiro trabalho de campo realizado em 2014 nos deparamos com a drástica redução das áreas de cultivo de algodão colorido na Paraíba, esse fato nos levou a concentramos nossa pesquisa em relação à área plantada com algodão naturalmente colorido no Assentamento de reforma agrária Margarida Maria Alves, localizado no município de Juarez Távora-PB, onde se encontra a maior produção de algodão colorido do estado da Paraíba atualmente (2016). No assentamento citado além de 
buscar elementos relacionados a produção propriamente dita procuramos entender as novas relações sociais e técnicas que o cultivo do algodão colorido orgânico trouxe para os agricultores nesse assentamento ou se apenas reproduziam as relações do antigo sistema pecuária-algodão branco-agricultura de subsistência. No referido Assentamento foram realizadas 10 (dez) entrevistas, 2 (duas) delas com mulheres, as demais com homens. Em 2015 foi feita uma entrevista com o presidente em exercício da Cooperativa Mista dos Agricultores de Algodão de Patos (CAMPAL). Também entrevistamos 1 (um) agrônomo da Empresa de Extensão Rural da Paraíba EMATER - PB. Como o circuito de produção do algodão colorido não se restringe a produção no campo e a maior visibilidade desse produto se dá a partir de sua inserção no mercado, quando já é transformado em produto final, fase em que as estratégias de marketing valoriza ainda mais esse algodão como inovação sustentável foi realizada entrevista em $2016 \mathrm{com}$ as presidentes das principais empresarias atualmente envolvidas com a produção de derivados do algodão naturalmente colorido, a presidente da COOPNATURAL, em Campina Grande e a presidente da Natural Cotton Color em João Pessoa. Mesmo considerando que há um número muito maior de pequenos empresários que trabalham com produtos derivados do algodão colorido, as duas organizações mencionadas são expressivas no entendimento do circuito espacial de produção desse produto. Ainda em Campina Grande foram entrevistadas 8 (oito) artesãs que trabalham com o algodão naturalmente colorido na Vila do Artesão.

Além dessa introdução a tese é composta de 5 (cinco) capítulos e das considerações finais. No Capítulo 1. A GEOGRAFIA E O SISTEMA NACIONAL DE INOVAÇÃO - nossa intenção foi compreender e analisar a inovação em seu processo de desenvolvimento atual, e como os fatores territoriais são considerados.

O Capitulo 2. A EMBRAPA E A CONSTITUIÇÃO DO SISTEMA TERRITORIAL DE PESQUISA AGROPECUÁRIA NO BRASIL - buscamos inserir a Embrapa no atual debate que considera a infraestrutura de pesquisa pública para o desenvolvimento de alguns setores da economia nacional, com atenção para a formação da base de pesquisa brasileira, considerando os fatores históricos e geográficos de sua formação. O Capitulo 3 - O ALGODÃO NO BRASIL: DO PERÍODO PRÉ - TÉCNICO AO PERÍODO TÉCNICO - CIENTÍFICO - INFORMACIONAL - teve o objetivo de analisar histórica e geograficamente a produção do algodão no Brasil, tratando das principais 
transformações que atingiram esse setor, chegando a novidade do período atual que é a produção de algodão naturalmente colorido.

No Capítulo 4 - O ALGODÃO NATURALMENTE COLORIDO NA PARAíBA: A REINVENÇÃO DA CULTURA ALGODOEIRA NO NORDESTE - são analisados os processos que levaram ao desenvolvimento das cultivares de algodão naturalmente colorido pela Embrapa Algodão, o contexto em que essa matéria prima é lançada como novo produto, os atores que participaram desse processo e a apropriação dos atores locais desse produto.

O Capitulo 5 - O CIRCUITO ESPACIAL DE PRODUÇÃO DO ALGOdÃO NATURALMENTE COLORIDO DA PARAÍBA - analisa o circuito espacial de produção do algodão naturalmente colorido ao longo dos últimos 16 anos e os elementos que apontam para uma tendência de produção de algodão orgânico na região semiárida do Nordeste brasileiro, as possibilidades e limites dessa produção. 


\section{Capítulo 1. GEOGRAFIA E INOVAÇÃO: A FORMAÇÃO SOCIOESPACIAL BRASILEIRA E O SISTEMA DE INOVAÇÃO}

Nos anos recentes tem crescido no âmbito da Geografia Econômica os estudos sobre o espaço geográfico e a inovação. A dimensão espacial é analisada principalmente para compreender como os fatores territoriais: organização espacial, infraestrutura de Ciência, Tecnologia e Inovação (CT\&l) (universidades, empresas de pesquisa pública e privada, agências de fomento à pesquisa, atividades econômicas intensivas em conhecimento) normas, valores e cultura podem ser fatores de desenvolvimento econômico e social de um país, lugar ou região.

Desde o início do século XXI o tema da inovação vem ganhando espaço na política de desenvolvimento brasileiro, principalmente relacionadas ao aproveitamento da infraestrutura de ciência e tecnologia na ampliação das possibilidades de desenvolvimento nacional. A principal inspiração dos estudos realizados por pesquisadores brasileiros é o conceito de Sistema Nacional de Inovação (SNI).

\subsection{Sistema Nacional de Inovação: uma breve revisão}

Segundo Edquist (2005) quem utilizou o termo "National System of Innovation", pela primeira vez foi o economista Christopher Freeman em 1987, porém Freeman (1995) atribui a Lundvall o uso pela primeira vez do termo. Freeman (1995) destaca ainda que Friedrich List - 1841 teria antecipado o conceito de sistema nacional de inovação em sua concepção de "The National System of Political Economy", mesmo que com outra terminologia. Freeman reconhece também que List não poderia prever algumas transformações hoje em curso e que são fundamentais para compreensão do SNI.

\footnotetext{
"Not only did List anticipate these essential features of current work on national systems of innovation, he also recognised the interdependence of the import of foreign technology and domestic technical development. [...] Although List anticipated many features of the contemporary debate about national systems of innovation (even though his terminology was different), it would of course be absurd to imagine that he could have foreseen all the changes in the world economy and national economies over the next century and a half. In particular, he did not foresee the rise of in-house professionalised Research and Development (R\&D) in industry, still less the rise of multi-national (or transnational) corporations (TNCs), operating production establishments in many different countries and increasingly also setting up R\&D outside their original base. These are major new
} 
developments which deeply affect the whole concept of national systems. (FREEMAN, 1995, p. 6-8.).

Segundo Freeman (1995), Friedrich List pretendeu em seu trabalho compreender o porquê do atraso econômico da Alemanha em relação à Inglaterra, e reconheceu que uma das formas de superar esse atraso, seria o investimento da Alemanha, não apenas na proteção da indústria nascente, e importação de tecnologias, seria necessário também 0 investimento em Pesquisa \& Desenvolvimento no país e que o sistema educacional teria importante contribuições a dar.

Freeman (1995) define o SNI "como uma rede, formada por instituições públicas e privadas, cuja iniciativa de atividades de pesquisa e interação é muito importante, inclusive para difusão de novas tecnologias". A partir da análise da literatura, observa-se certo consenso a respeito da definição, do que vem a ser denominado como SNI, bem como a importância deste para o desenvolvimento tecnológico e econômico dos países. Uma definição mais geral de sistemas de inovação (nacional) inclui todos os fatores institucionais, organizacionais, políticos, sociais, econômicos e outros fatores que influenciam o desenvolvimento, difusão e uso de inovações Lundvall, 1992; Freeman 1987 (apud Edquist, 2005). Essa definição ampla do que é SNI, é apontado por Edquist (2005) como sendo uma fragilidade na conceituação do mesmo, pois não limita o que faz parte do SNI, bem como não define os elementos que devem ficar de fora.

A literatura sobre sistemas de inovação aponta três níveis de sistemas de inovação, os sistemas nacionais de inovação, os sistemas regionais de inovação e os sistemas setoriais de inovação, porém um não exclui o outro e muitas vezes se complementam. É importante destacar que a base territorial é fundamental na concepção de SNI, bem como a valorização da escala de análise, destacando-se a escala nacional. Com base na literatura existente sobre SNI Edquist (2005) identificou seis pontos fortes e três pontos fracos na abordagem sobre SNI conforme podemos verificar no Quadro 01. 
Quadro 01: Pontos fortes e pontos fracos na abordagem de sistema de inovação

\begin{tabular}{|c|c|c|}
\hline \multicolumn{2}{|r|}{ PONTOS FORTES } & PONTOS FRACOS \\
\hline 1 & $\begin{array}{l}\text { O processo de aprendizado é considerado como essencial no } \\
\text { sistema de inovação }\end{array}$ & $\begin{array}{l}\text { Falta de coerência entre os } \\
\text { autores sobre o que é } \\
\text { instituição; }\end{array}$ \\
\hline 2 & $\begin{array}{l}\text { Holística e interdisciplinar, uma vez que envolve procura envolver } \\
\text { os vários aspectos relevantes para acontecimento da inovação e } \\
\text { reconhece a importância da contribuição das várias áreas do } \\
\text { conhecimento para o desenvolvimento de inovações; }\end{array}$ & $\begin{array}{l}\text { Não definição do que deve } \\
\text { ser incluído no SNI e o que } \\
\text { pode ficar de fora; }\end{array}$ \\
\hline 3 & $\begin{array}{l}\text { Interdependência e não linearidade, aspectos fundamentais, } \\
\text { dado a complexidade da inovação e a importância de aquisição } \\
\text { de conhecimento de várias fontes, inclusive sendo destaque o } \\
\text { feedback dos consumidores; }\end{array}$ & $\begin{array}{l}\text { Não ser uma teoria, devido } \\
\text { ao caráter empírico, o que } \\
\text { suscita entre alguns } \\
\text { pesquisadores o anseio por } \\
\text { formulações mais teóricas. }\end{array}$ \\
\hline 4 & $\begin{array}{l}\text { A abordagem do SI pode abranger tanto inovações de produtos } \\
\text { como de processos, bem como subcategorias desse processo } \\
\text { (inovações organizacionais); }\end{array}$ & 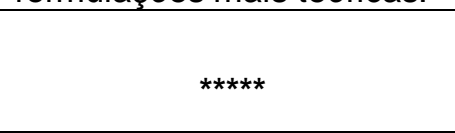 \\
\hline 5 & Enfatiza o papel das instituições; & 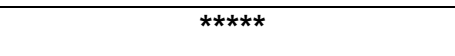 \\
\hline 6 & $\begin{array}{l}\text { Leva em consideração os aspectos históricos e evolucionários, } \\
\text { reconhecendo, as particularidades de cada nação. }\end{array}$ & 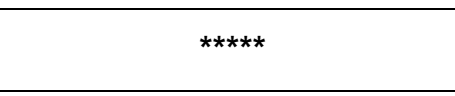 \\
\hline
\end{tabular}

Fonte: Elaboração própria a partir de EDQUIST (2005).

Albuquerque (1996, p.57) define Sistema Nacional de Inovação, como "construção institucional, produto de uma ação planejada e consciente ou de um somatório de decisões não planejadas e desarticuladas, que impulsionam o progresso técnico em economias capitalistas complexas" o autor considera o SNI como um arranjo institucional envolvendo múltiplos participantes como: firmas e suas redes de cooperação e interação; universidades e institutos de pesquisa; instituições de ensino; sistema financeiro; sistemas legais; mecanismos mercantis e não-mercantis de seleção; governos e mecanismos e instituições de coordenação.

Um dado importante é que só a existência desses atores não é suficiente, para existência de um SNI consolidado, pois é preciso sobretudo, a existência de fortes interações entre os mesmos. Tal constatação, fez com que Albuquerque (1996) a partir da análise da produção científica e tecnológica do Brasil e outras informações, propusesse uma tipologia sobre SNI, na qual situou a posição de alguns países em desenvolvimento. Na mesma o autor constatou que o Brasil, faz parte de um grupo de países com sistemas de inovação imaturos. Conforme a tipologia proposta por 
Albuquerque (1996) existe três categorias de SNI, a saber: maduros, catching up ${ }^{1}$ e imaturos:

1. Maduros - Os países cujo SNI, é considerado maduro, são aqueles que possuem a capacidade de manter seus países na liderança da fronteira tecnológica internacional. Fazem parte deste grupo os principais países capitalistas desenvolvidos. A identificação dos países que fazem parte desse grupo pode ser feita através de sua capacidade de geração e participação na liderança da produção científica mundial. Os países que encontra se nessa posição são: os Estados Unidos, o Japão, a Alemanha, a Inglaterra e a Itália.

2. Catching up - fazem parte dessa categoria os países cujo objetivo central de seus sistemas de inovação é a difusão de inovações. São países que possuem elevado dinamismo tecnológico, dinamismo que não é derivado de sua capacidade de geração tecnológica, mas de uma elevada capacidade de difusão, relacionada a uma forte atividade tecnológica interna que os capacita para absorver avanços gerados nos grandes centos mais avançados. Envolve dois subconjuntos: os países 'pequenos de alta renda', Suécia, Dinamarca, Holanda e Suíça e os países asiáticos de desenvolvimento recente e a celerado, como Coréia do Sul e Taiwan. Os países dessa categoria desenvolvem especializações nacionais bastante claras em alguns nichos de mercado internacional.

3. Imaturos - os países que se encontram nesse grupo, são países cujos sistemas de inovação não se completaram: são países que construíram sistema de ciência e tecnologia que não se transformaram e sistemas de inovação. Fazem parte dessa categoria: o Brasil, a Argentina, o México, a Índia e a África do Sul. (ALBUQUERQUE, 1996, p.58-59).

Os países que possuem sistema de inovação imaturo ou incompleto, embora apresente infraestrutura de ciência e tecnologia, não possui número de pesquisadores proporcionalmente ao dos países desenvolvidos e há pouca articulação entre a base de ciência e tecnologia e o setor produtivo, pois, normalmente se tratam de países com atividades econômicas tradicionais ${ }^{2}$ e que até recentemente demandaram pouco conhecimento especializado (ALBUQUERQUE, 1996; 2000).

Albuquerque (2000) fez uma divisão em três subcategorias de sistema de inovação considerando os diferentes níveis de desenvolvimento dos países subdesenvolvidos, quanto aos seus sistemas de inovação imaturo, a primeira subcategoria denominada "países com estrutura de ciência e tecnologia pouco eficaz" faz parte desse subgrupo: o Brasil, o México, a Índia e a África do Sul; o segundo subgrupo é formado por países do Leste Europeu, que tem em comum o fato de serem ex-economias socialistas e estarem em fase de transição para uma economia de mercado, pertencem a esse grupo: a Rússia, a Polônia, a Hungria, a Bulgária, etc.;

\footnotetext{
${ }^{1}$ Entende-se por catch up o processo perseguido pelos países para superar o subdesenvolvimento.

${ }^{2}$ Atividades primárias como produtos agrícolas para exportação.
} 
alguns países do Sudeste Asiático, são países que possuem em comum crescimento econômico recente, são eles: a Tailândia, a Malásia, a Indonésia e as Filipinas.

Por fim Albuquerque (2000) inclui mais um subconjunto de países que não possuem se quer as condições mínimas necessárias, para existência de um sistema de inovação. Essa categoria de acordo com o autor serve para delimitar o caráter intermediário do conjunto dos sistemas de inovação "imaturos". Fazem parte dessa categoria países como: a Turquia, países da região sub Saara, o Afeganistão entre outros.

Considerando a capacidade de manipulação de grande número de informações e conseguir que as mesmas sejam portadoras de inovação tecnológica é um paradigma que permeia a sociedade contemporânea. O debate sobre o processo de geração de inovação é elemento central da economia contemporânea, principalmente da vertente denominada de "Economia do Aprendizado", proposta por Lundvall (1996).

No cenário atual para realização de inovações, alguns atores são considerados essenciais, para que as mesmas sejam possíveis. Além das inovações desenvolvidas pelas indústrias, que são as grandes responsáveis pelas mudanças tecnológicas, merece destaque o papel que pode ser desempenhado por universidades, institutos de pesquisa pública ou privada, o feed back dos consumidores, os concorrentes, entre outros (COHEN; NELSON; WALSH, 2002).

A compreensão de que o sistema educacional e de conhecimento científico podem ser importantes catalisadores de inovações despertou o interesse de vários pesquisadores que se debruçaram sobre o tema com a finalidade de avaliar quanto do conhecimento desenvolvido nos espaços de pesquisa pública, incluindo nessa categoria as universidades e os centros de pesquisa pública têm influenciado no progresso tecnológico.

Nesse sentido a constituição dos sistemas nacionais de inovação é visto como importante elo onde os processos inovativos podem acontecer, sendo inclusive capaz de permitir que alguns países, que devidos aos diversos contextos históricos e políticos, consigam superar o atraso tecnológico, em relação aos países onde, o SNI é considerado maduro ${ }^{3}$.

\footnotetext{
${ }^{3} \mathrm{Na}$ tentativa de propor uma tipologia de sistemas de inovação que enquadrasse a situação de países em desenvolvimento, como o Brasil, Albuquerque (1996) divide os sistemas de inovação em "maduros e "imaturos. No grupo dos considerados maduros, encontra se os Estados Unidos, o Japão, a Alemanha, a Suécia e a Holanda.
} 


\subsection{O Papel da pesquisa pública no sistema nacional de inovação}

Quando se houve falar em inovação a primeira coisa que se imagina é que se trate de mudanças tecnológicas, de produtos ou serviços e que estes produtos estão sendo comercializados, gerando lucros para os empresários. Essa é a visão mais difundida na literatura econômica, contudo recentemente tem tido grande apreço na literatura sobre inovação, as inovações organizacionais e de marketing (OECD, 1997).

De acordo com a OECD ${ }^{4}$ (1997), em sua revisão a respeito da compreensão do que é a inovação, é salutar o entendimento da concepção de inovação para Schumpeter, uma vez que muitas das pesquisas desenvolvidas sobre SNI e que tem na inovação aspecto essencial, são realizadas por neoschumpterianos:

\footnotetext{
O argumento de Schumpeter é de que o desenvolvimento econômico é desenvolvido pela inovação, por meio de um processo dinâmico em que as novas tecnologias substituem as antigas, processo por ele denominado 'destruição criadora'. Segundo Schumpeter, inovações radicais engendram rupturas mais intensas, enquanto 'inovações incrementais' dão continuidade ao processo de mudança.

Shumpeter (1934), propôs uma lista de cinco tipos de inovação:

1 - introdução de novos produtos;

2 - introdução de novos métodos de produção;

3 - abertura de novos mercados;

4 - desenvolvimento de novas fontes provedoras de matérias primas e outros insumos;

5 - criação de novas estruturas de mercado em uma indústria. (OECD, 1997, p. 36)
}

De acordo com a OECD (1997, p.55) inovação é "a implementação de um produto (bem ou serviço) novo ou significativamente melhorado, ou um processo, ou um novo método de marketing, ou um novo método organizacional nas práticas de negócios, na organização do local de trabalho ou nas relações externas". A inovação pode ser de quatro tipos: inovação de produtos, inovação de processo, inovação organizacional e inovação de marketing ${ }^{5}$.

Os conceitos de inovação organizacional e de marketing ainda estão em fase de construção, pois embora sejam práticas já existentes, não eram tão amplamente

\footnotetext{
${ }^{4}$ A OECD é um fórum único no qual os governos de 30 democracias trabalham juntos para endereçar os desafios econômicos, sociais e ambientais da globalização. OECD, (1997:4).

${ }^{5} \mathrm{O}$ algodão naturalmente colorido, desenvolvido com tecnologia da Embrapa Algodão é uma inovação de produto, na medida em que o mesmo já existia na natureza e teve suas características tecnológicas transformadas por esse instituto de pesquisa. Ao mesmo tempo em que há crescente uso do marketing social a fim de promover o uso de produtos derivados do algodão naturalmente colorido no mercado, especialmente o mercado europeu.
} 
exploradas como fator de inovação. No caso da inovação de marketing essa abordagem é ainda mais recente e foi mais difundida com o avanço de novas tecnologias da informação, OECD (1997). Para melhor compreendermos quais são as principais nuances de cada um desses tipos de inovações, apresenta-se abaixo uma breve exposição sobre o que as caracteriza:

As inovações de produto - envolvem mudanças significativas nas potencialidades de produtos e serviços. Incluem-se bens e serviços totalmente novos e aperfeiçoamentos importantes para produtos existentes;

As inovações de processo - representam mudanças significativas nos métodos de produção e de distribuição;

As inovações organizacionais - referem-se à implementação de novos métodos organizacionais, tais como mudanças em práticas de negócios, na organização do local de trabalho ou nas relações externas da empresa;

As inovações de marketing - envolvem a implementação de novos métodos de marketing, incluindo mudanças no design do produto e na embalagem, na promoção do produto e sua colocação, e em métodos de estabelecimento de preços de bens e de serviços (OECD, 1997, p.57-61).

É relevante para literatura sobre inovação na atualidade, o reconhecimento, de que a inovação não é restrita a modificações na mercadoria e com finalidade necessariamente de chegar ao mercado. Perez 2004 (apud DOSSA, 2010, p. 25) caracteriza dois tipos de inovação, a inovação incremental e a inovação radical:

\begin{abstract}
Inovações incrementais são aquelas melhorias sucessivas em produtos ou processos existentes, e essas melhorias originam aumentos gerais de produtividade. As inovações incrementais caracterizam se por frequentes incrementos em eficiência técnica, produtividade e precisão dos processos e por trocas regulares nos produtos para conseguir melhor qualidade, reduzir custos e ampliar a gama de usos.

Já as inovações radicais são as que introduzem novos produtos ou processos, sendo essencialmente um ponto de partida de forma que impulsionam o crescimento e a troca estrutural da economia.
\end{abstract}

De certa forma quando Shumpeter (1982) analisou as formas pelas quais o empresário poderia obter lucro ele já havia chegado a essa constatação sobre esses dois tipos de inovações: a radical e a incremental. Para o autor a inovação incremental tratava-se de uma reorganização dos fatores de produção, ou de um conhecimento já existente e que com novo uso poderia gerar algum lucro para o empresário, porém esse lucro ao longo do tempo deixaria de existir, porque não se tratava de inovação 
radical, ou seja, de mudança estrutural, como a criação de um produto ou processo completamente novo.

As inovações incrementais ganham evidência no conceito de SNI, uma vez que para os estudiosos desse conceito um dos aspectos considerado como relevante na constituição do mesmo é a capacidade dos países que não se encontram na fronteira tecnológica em absorver e difundir o conhecimento e inovação gerada nos países desenvolvidos. A difusão da inovação é de certa forma a concretização dos processos inovadores, à medida que é por meio desse processo que outras pessoas vão tomar conhecimento das novidades tecnológicas.

Entre as formas para se obter tecnologia e conhecimentos desenvolvidos pelos países da fronteira tecnológica e que inclusive foi estratégia adotada por países como o Japão 6 e o Brasil, é o envio de estudantes para complementarem seus estudos em universidades no exterior e assim ter contato com conhecimentos e tecnologias mais atualizadas; outro meio é a contratação de pesquisadores desses países, que vem ajudar no desenvolvimento das competências internas nos países menos desenvolvidos; e outra possibilidade é a fixação de trabalhadores nas firmas estrangeiras, para que eles possam ter acesso a alguns conhecimentos, que só são adquiridos com a prática e assim, os habilite posteriormente a empregar esses conhecimentos nos seus países de origem (MAZZOLENI e NELSON, 2005).

Por outro lado Mazzoleni e Nelson (2005) apontam que só a cópia das novas tecnologias desenvolvidas nos países da fronteira tecnológica, não é suficiente, para que os países que se encontram em uma posição inferior, no que se refere ao desenvolvimento de tecnologias, especialmente em setores como saúde e agricultura. No caso da agricultura a importação de novas cultivares por exemplo exige a adaptação para as condições geográficas de cada país ${ }^{7}$. No caso da medicina, há alguns tipos de enfermidades que são mais comuns em umas áreas geográficas e

\footnotetext{
${ }^{6}$ O Japão foi extremamente bem sucedido em seu processo de catch up e atualmente é um país que em termos econômicos e tecnológicos situa-se entre as principais potencias mundiais.

7 A agricultura é um campo especialmente rico no que se refere à necessidade dos países desenvolverem um sistema de pesquisa agrícola que possa viabilizar tanto o desenvolvimento de suas capacidades internas para aproveitamento de seu potencial produtivo, quanto à realização de adaptações tecnológicas de cultivares desenvolvidas em outros territórios, com condições ambientais diferentes. Muito dessa prática está presente na Embrapa e outras organizações de pesquisa nacional que ao longo do tempo desenvolveram conhecimento sobre diversos aspectos da produção agropecuária do Brasil.
} 
outras não. Dada as particularidades desses dois setores: saúde e agricultura o desenvolvimento das potencialidades internas de cada país é essencial.

$\mathrm{Na}$ literatura SNI a interações entre universidades/instituto de pesquisaempresa é considerada elemento chave para o desenvolvimento de inovações, que funcionam como meio para a realização de fluxos de trocas de conhecimentos entre as firmas e outras organizações para o desenvolvimento e a difusão de inovações.

Edquist (2001) chama atenção para o fato dessas interações ocorrem de forma diferenciada nos diferentes países, o autor cita, por exemplo, que nos Estados Unidos a interação entre universidades e empresas é mais comum; no Japão as interações ocorrem mais entre as empresas e os institutos de pesquisa, há ainda países em desenvolvimento como o Brasil, onde a experiência de interação entre universidade/instituto de pesquisa-empresa acontece pontualmente em algumas áreas do conhecimento, como será discutido mais adiante.

Lundvall (1996) reconhece que as inovações desenvolvidas internamente nas firmas, devido à complexidade que envolve o processo inovativo precisa por vezes interagir com diversas áreas do conhecimento, não se limitando apenas aos conhecimentos desenvolvidos no interior das empresas, sendo de fundamental importância as trocas externas. Por isso, é tão importante a interação com instituições de pesquisa e mesmo com redes de contatos não necessariamente formais, mas que possam facilitar o acesso a determinados tipos de conhecimento.

Segundo Fernandes e Lima (2006) a inovação é um processo coletivo, interativo, cumulativo, não linear e sistêmico. É coletivo à medida que vários são os agentes envolvidos no desenvolvimento de inovações, uma vez que dada a complexidade da inovação, há necessidade de vários tipos de conhecimentos, devido ao fato de um único individuo não possui todos os conhecimentos necessários no desenvolvimento da inovação; é interativo por que a troca de conhecimento entre os agentes é indispensável para que a inovação aconteça; é cumulativo, na medida em que o conhecimento acumulado favorece o desenvolvimento de conhecimento novo ao longo do tempo; é não linear ${ }^{8}$ porque se processa em várias etapas e que as fontes

\footnotetext{
${ }^{8}$ O modelo Linear postula que a inovação começa com a pesquisa básica, seguido por pesquisa aplicada e desenvolvimento e termina com a produção e difusão. Embora a inovação não seja linear, para o surgimento de inovação em áreas onde o conhecimento científico é mais latente, é preciso que os agentes responsáveis pela inovação tenham conhecimento sobre as pesquisas básicas, para que possam melhor aproveitar os outros tipos de conhecimentos (COHEN; NELSON; WALSH, 2002).
} 
de conhecimento são diversas; e é sistêmico na medida em que a inovação é resultado da ação de vários agentes e das relações entre eles.

Para Edquist (2001, p.7) inovações "are new creations of economic significance normally carried out by firms (or sometimes individuals). They may be brand new, but are more often new combinations of existing elements". Assim como os demais autores citados Edquist (2001) reconhece a complexidade que envolve o conceito de inovação, e sumariamente apresenta uma taxonomia sobre inovação (ver Figura 1):

Figura 1 - Taxonomia de Inovação

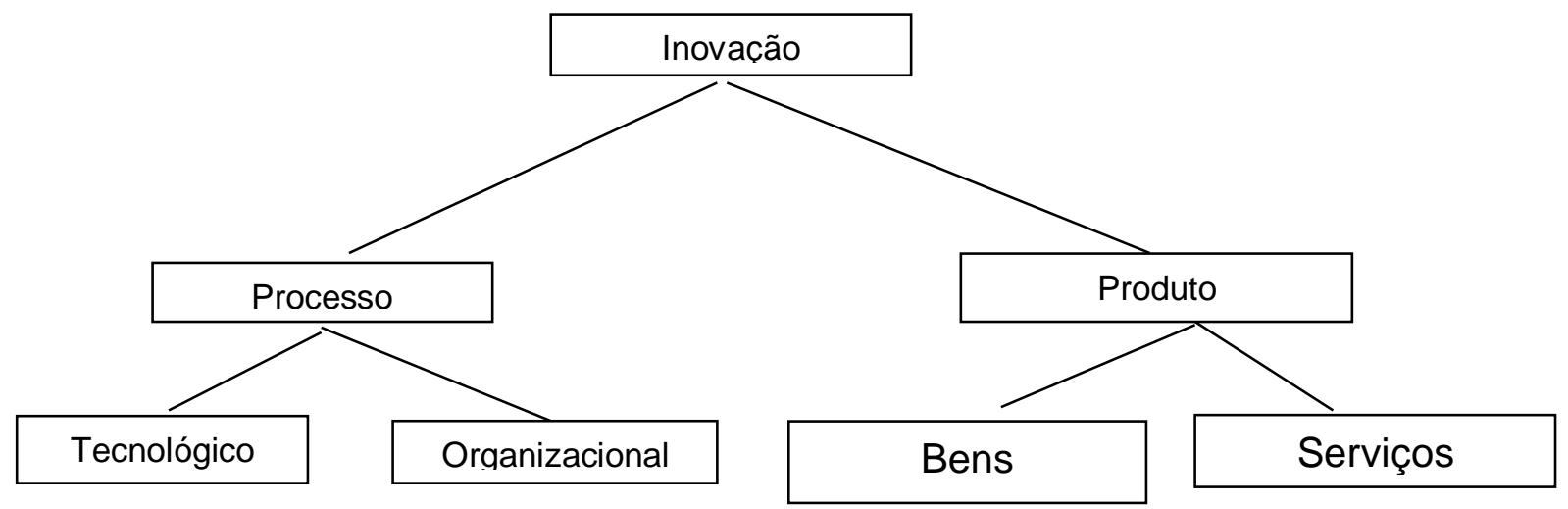

Fonte: EDQUIST, 2001.

O autor mencionado destaca ainda o fato, de em geral, nos estudos sobre inovação, ser dada maior ênfase aos aspectos relacionados às inovações tecnológicas de processo e de produto, considerando seus aspectos mais tecnológicos, enquanto os aspectos intangíveis do processo, só recentemente começou a receber atenção, em especial dos economista evolucionista, ou os ligados a economia do aprendizado como Lundvall (1996).

Nesse sentido merece atenção a valorização do conhecimento tácito desenvolvido internamente nas organizações, e que implicam em grandes oportunidades para diferenciação dos processos que ocorrem nas empresas e que até recentemente não tinha grande reconhecimento como aspecto relevante dos processos inovativos. 
Gerther (2005), ao considerar que numa época em que o sucesso competitivo depende cada vez mais da capacidade de produção de produtos e processos novos ou melhorados, o conhecimento tácito constitui a base mais importante de criação de valor com base na inovação, por isso, as inovações organizacionais merecem atenção, dado o fato de carregar consigo algumas práticas que não são passíveis de codificação. A seguir será feita uma breve distinção entre conhecimento codificado, tácito.

Segundo Morgan (2004), o conhecimento codificado é explicito e padronizado e pode ser transferido a longas distancias e através das fronteiras organizacionais, por meio de livros, documentos e mais recentemente de forma digital. As tecnologias da informação tem permitido uma rápida codificação do conhecimento e permitido que esse conhecimento chegue aos mais recônditos lugares de forma muito rápida, porém o autor diz que a informação se difunde rapidamente, mas o seu entendimento não.

Assim o autor diz que geralmente o conhecimento codificado é comparado a um espiral em que o conhecimento tácito se transforma em conhecimento codificado, seguindo por um movimento de volta para a prática onde novas formas tácitas de conhecimento são desenvolvidas e esse movimento espiral é o cerne da aprendizagem individual na aprendizagem organizacional. O conhecimento tácito é pessoal e depende do contexto social, sendo difícil ser comunicado a longas distancias. Por isso é dada tanta importância as interações pessoais em um contexto de experiências partilhadas (MORGAN, 2004; GERTLER; 2005; LUNDVALL, 2006).

Maskel e Malmberg 2000 (apud Gertler 2005) defendem explicitamente a importância da dimensão espacial para a transmissão do conhecimento tácito, considerado por esses autores como sendo determinante para a atividade inovativa. Os autores citados se fundamentam em três argumentos, a saber: 1- o conhecimento tácito desafia a articulação fácil e é melhor adquirido pela experiência, é difícil de ser trocado por longas distancias; 2 - sua natureza de contexto especifico torna-o especialmente espesso, uma vez que ambas as partes podem trocar esses conhecimentos de forma eficiente somente compartilhada em contexto social comum, e os elementos mais importantes deste contexto social são definidos localmente e 3 a natureza do processo de inovação em si e, em particular a importância crescente dos processos de aprendizagem socialmente organizado dos grupos. 
Na literatura sobre SNI se destaca a importância da interação entre o sistema de conhecimento de um país, lugar ou região com o setor produtivo. Isso decorre entre outros fatores, da atual dinâmica econômica que se fundamenta entre outros aspectos no conhecimento. Na economia baseada no conhecimento e na inovação, merece destaque o conhecimento e a capacidade de inovação das empresas e de outros setores da sociedade, conforme proposto por Lundvall (1996).

A economia do aprendizado é proposta por Lundvall (1996) como sendo uma nova fase da economia atual, na qual o aprendizado, a capacidade de aprender é cada vez mais determinada pela posição relativa de indivíduos, empresas e sistemas nacionais. Ainda segundo Lundvall (1996) o conceito de economia do aprendizado pode ser utilizado em duplo sentido. Primeiro evocando uma perspectiva teórica na economia, na qual a ênfase está em explicar e entender o processo de mudança em tecnologia, habilidades, preferências e instituições; segundo pode se referir aos traços históricos específicos, o que faz o conhecimento e a aprendizagem importantes em todos os níveis da economia.

Outro aspecto relevante da economia do conhecimento é que o sucesso de indivíduos, empresas e regiões econômicas e nacionais refletem sua capacidade de aprender. Essa capacidade de aprendizado é considerada, importante aspecto para o desenvolvimento dos SNI, Lundvall (1996).

Para melhor compreender os tipos de conhecimento Lundvall (1996) sugere uma tipologia com 4 (quatro) tipos de conhecimento, a saber: know-what; know-why; knowhow e know-who.

1 Know-what - refere se ao conhecimento dos fatos, aqui conhecimento é próximo ao que normalmente é chamado de informação;

2 Know-why - faz referência sobre os conhecimentos de princípios e leis de conhecimento na mente humana e na sociedade;

3 Know-how - refere-se às habilidades, a capacidade de fazer algo. Deve esta relacionado às capacidades de produção do trabalhador. Mas é importante perceber também que isso representa um papel chave em muitas outras atividades e na esfera econômica.

4 Know-who - é basicamente a experiência tácita, que não pode ser facilmente transmitida. Esse conhecimento irá desenvolver tipicamente em suas formas mais altas somente depois de anos de experiência de prática diária, através do aprender fazendo e da interação com outros experts ativos na mesma área (LUNDVALL, 1996, p. 7-8). 
Os dois primeiros tipos de conhecimento o know-what e know-why podem são adquiridos através do conhecimento codificado. Nos dois últimos o know-howe knowwho, a troca de conhecimento ocorre de forma tácita, ou seja, com o acompanhamento das experiências, por isso o acesso a determinadas networks são fundamentais, para se ter acesso a informações que não são facilmente repassadas para pessoas que não fazem parte de determinada rede social.

Com essa nova compreensão da importância do conhecimento e da inovação para a dinâmica econômica, a necessidade de interação entre instituições de pesquisa são fundamentais, pois as mesmas por meio de seus recursos humanos e infraestrutura de pesquisa podem ajudar a resolver questões ou desenvolver novas tecnologias, principalmente em países com economias como a do Brasil, onde existe uma limitada cultura por parte do setor produtivo em investir em P\&D interno, recaindo sobre o Estado os maiores investimentos em P\&D.

De acordo com Suzigan e Albuquerque (2008) a baixa interação entre universidade/ instituto de pesquisa - empresa no Brasil decorre de três aspectos principais: o caráter tardio do surgimento das universidades públicas e institutos de pesquisa; a industrialização recente e a tardia criação de sistemas de financiamento de pesquisas. Os mesmos autores afirmam ainda, que nos casos de sucesso em que são identificados "pontos de interação", a mesma é resultado de uma construção de longo prazo, com esforços que persistem ao longo do tempo. Albuquerque e Suzigan (2008) destacaram as áreas de conhecimento e as instituições nas quais há interação.

\footnotetext{
1 - nas ciências da saúde, produção de soros e vacinas (Instituto Oswaldo Cruz);

2 - nas ciências agrárias: algodão, florestas para celulose, grãos, carnes (IAC - Instituto Agronômico de Campinas, Embrapa);

3 - em mineração, engenharia de materiais e metalurgia, a produção de minérios, aços e ligas metálicas especiais (Universidade Federal de Minas Gerais);

4 - em engenharia aeronáutica, a produção de aviões pela Embraer (CTA e ITA);

5 - em geociências, extração de petróleo e gás pela Petrobrás (COOPER -UFRJ, Unicamp) (ALBUQUERQUE e SUZIGAN, 2008, p.6-7).
}

Suzigan e Albuquerque (2008) sugerem uma periodização da criação das instituições no país, na qual são incluídas as instituições de ensino superior, institutos de pesquisa, instituições coordenadoras ou gestoras de políticas públicas de ciência 
e tecnologia, que os autores denominarão como "ondas", conforme podemos visualizar na Figura 2.

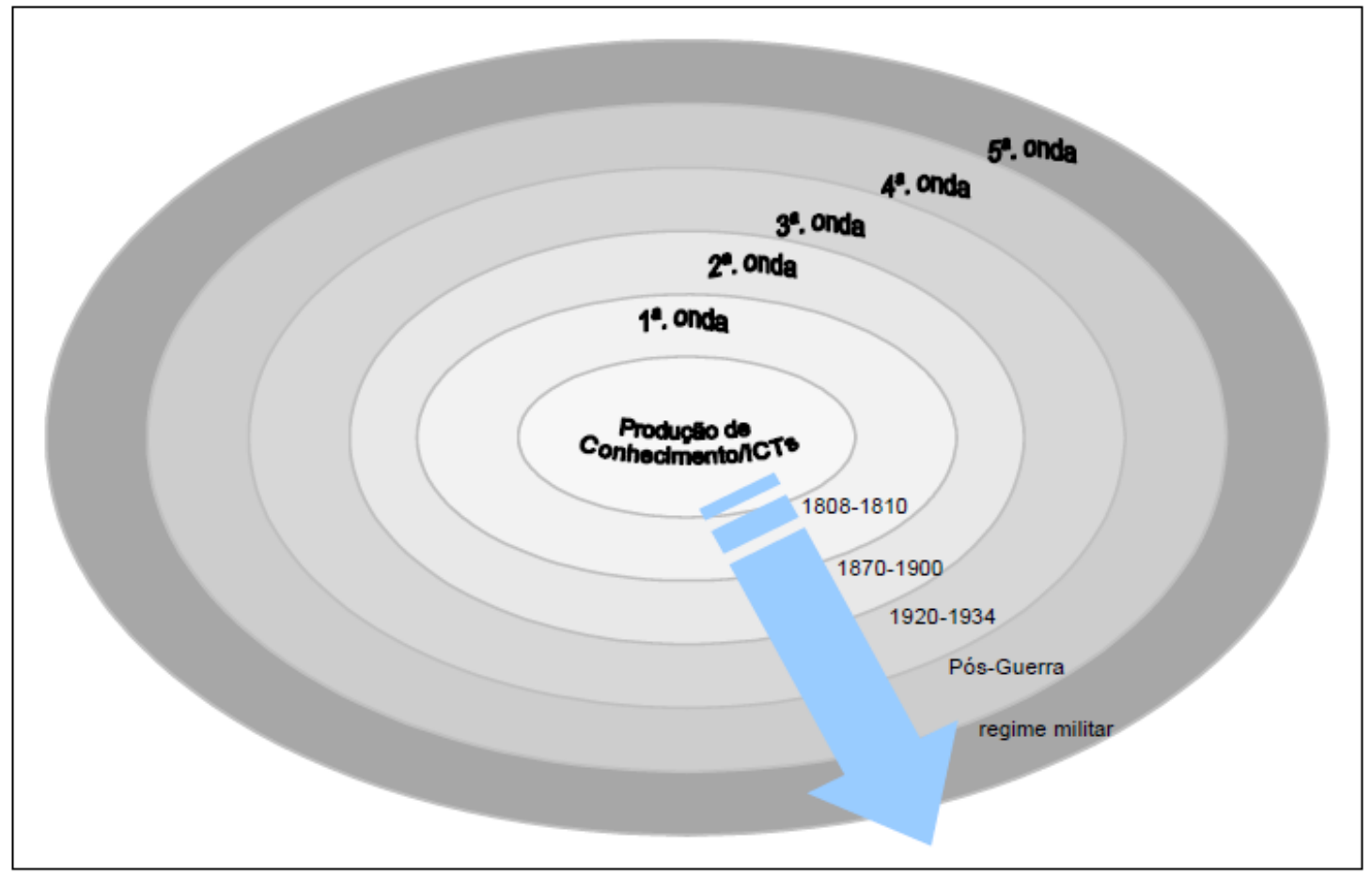

Figura 2 - "ondas" de criação de instituição de ensino e pesquisa no Brasil Fonte: FERNANDES; SOUZA; SILVA (2009).

Na primeira "onda" que corresponde ao período de 1808 - 1810, os autores chamam atenção para o longo período existente para o surgimento das primeiras instituições no país. Esse longo período se deve ao sistema colonial, que impediu entre outras coisas a formação de recursos humanos. Só a pós a chegada da família real no Brasil em 1808, é que percebendo as limitações da colônia em relação às necessidades culturais da corte, é que vai ser estimulada a criação de instrumentos que viabilizem o conhecimento no país. Fazem parte da primeira "onda":

a criação do Curso de Anatomia e Cirurgia do Rio de Janeiro, o Curso de Anatomia e Cirurgia de Salvador, o Jardim Botânico (também em 1808), a Biblioteca Nacional e a Academia Militar (1810) que pode ser compreendido, este último, como um estabelecimento de ensino de engenharia implícito (Cunha, 1980; Schwartzman, 1979). Podem ser incluídos nesta "onda" pioneira, o Laboratório Químico Prático do Rio de Janeiro (1812), cuja finalidade, segundo Schwartzman (1979), seria o "fabrico de sabão sólido", o Museu Real (1818), depois transformado em Museu Imperial, que abrigaria o 
primeiro Laboratório de Física e Química (1824),assim como as primeiras tentativas para implantação de uma indústria siderúrgica no país, entre as quais a Real Fábrica de Ferro do Morro de Gaspar Soares, em Minas Gerais, "criada em 1808 por iniciativa oficial", como registra Schwartzman (1979) (ALBUQUERQUE e SUZIGAN,2008,p.14-15).

Para esse mesmo período, considerando a diferença na distribuição das instituições no território, Fernandes; Souza e Silva (2009) identificam que se na região onde estava concentrada a força econômica e política do período há debilidade na criação das instituições; no Nordeste a situação é ainda mais grave.

Como as instituições no Nordeste só começaram a surgir, na quarta "onda" proposta por Suzigan e Albuquerque (2008) Fernandes; Souza e Silva (2009) fizeram algumas modificações no período de duração das "ondas" de criação das instituições de ensino e pesquisa no Nordeste, conforme a Figura 3, onde pode se observar o período de duração das "ondas".

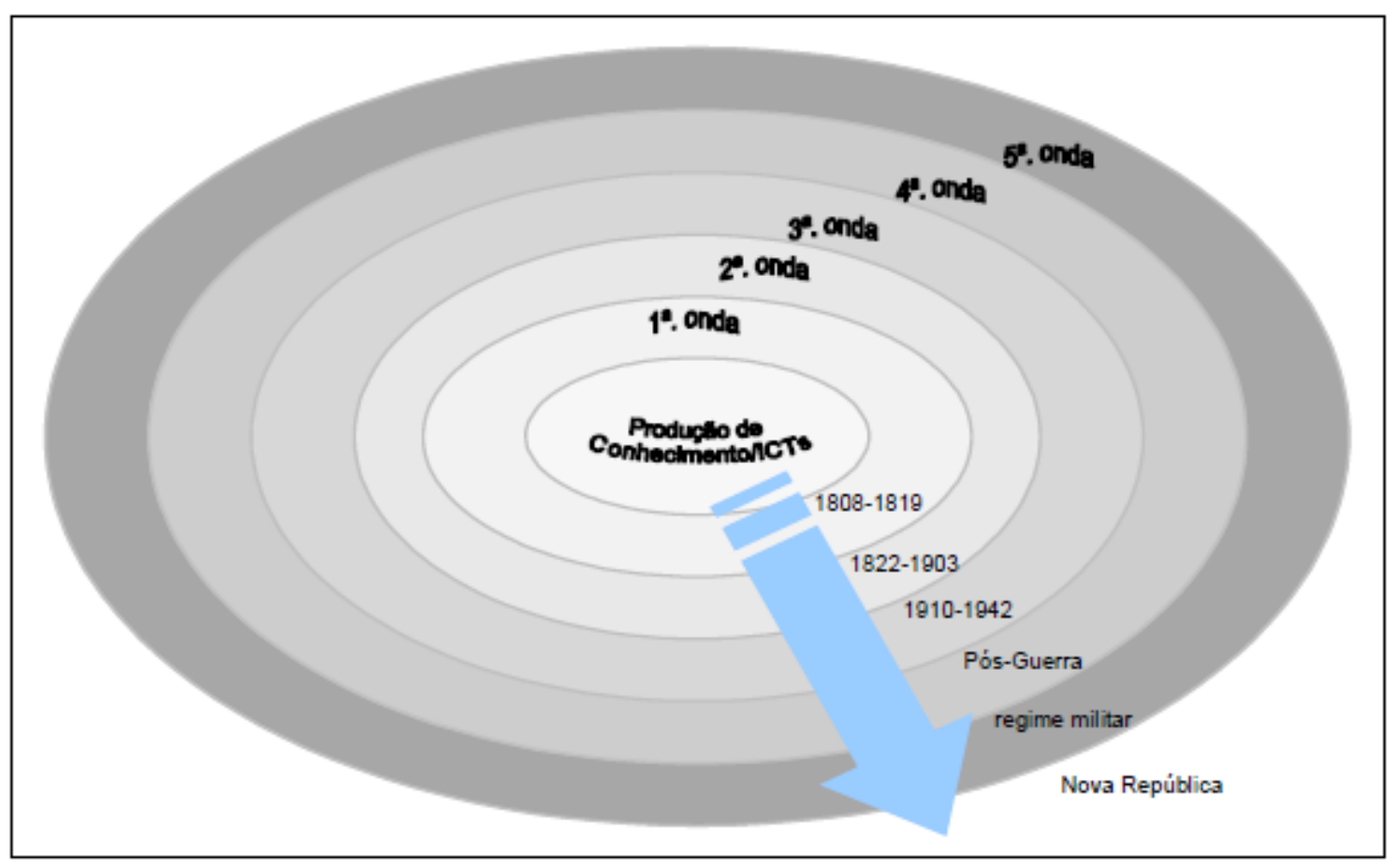

Figura 3 - "ondas" de criação de instituição de ensino e pesquisa no Nordeste. Fonte: FERNANDES; SOUZA E SILVA (2009).

O tempo de duração das três primeiras "ondas" foi ampliado e adicionou-se uma sexta "onda", cujo início é marcado pela Nova República, quando finalmente começam a surgir instituições de fomento à pesquisa na região, com implicações 
sobre a interação dos grupos de pesquisa com a sociedade, sob a influência da criação do Ministério de Ciência e Tecnologia. Essas alterações na duração entre uma "onda" e outra podem ser melhor observadas a partir das observações do Quadro 2:

Quadro 2 - Periodização da criação de instituições de Ensino e Pesquisa no Brasil e no Nordeste

\begin{tabular}{|c|c|c|c|}
\hline \multicolumn{2}{|c|}{$\begin{array}{l}\text { "ONDAS" DE CRIACCÃO DAS } \\
\text { INSTITUICCÕES DE ENSINO E PESQUISA - } \\
\text { SUZIGAN E ALBUQUERQUE (2008) }\end{array}$} & \multicolumn{2}{|c|}{$\begin{array}{l}\text { “ONDAS” DE CRIAÇÃO DAS INSTITUIÇÕES } \\
\text { DE ENSINO E PESQUISA NO NORDESTE - } \\
\text { FERNANDES; SOUZA E SILVA - } 2011 \\
\end{array}$} \\
\hline $1^{\text {a } ~ " o n d a " ~}$ & $1808-1810$ & $1^{\text {a }}$ "onda" & $1808-1819$ \\
\hline $2^{\mathrm{a}}$ "onda" & $1870-1900$ & $2^{a}$ "onda" & $1822-1903$ \\
\hline $3^{\text {a "onda" }}$ & $1920-1934$ & $3^{\text {a "onda" }}$ & $1910-1942$ \\
\hline $4^{a}$ "onda" & Pós Guerra (1945 - 1964) & $4^{a}$ "onda" & Pós Guerra \\
\hline \multirow[t]{2}{*}{$5^{\text {a } \text { "onda" }}$} & Regime Militar (1964-1985) & $5^{\text {a "onda" }}$ & Regime Militar \\
\hline & & 6a "onda" & Nova República \\
\hline
\end{tabular}

Fonte: FERNANDES; SOUZA; SILVA (2009).

Embora Suzigan e Albuquerque (2008) não tenham se referido a essa sexta "onda", a mesma pode ser desdobrada para leitura da criação de outras instituições de ensino e pesquisa no território brasileiro. Isso devido às mudanças na política de ciência e tecnologia adotada no país, que apesar de ainda não dar conta dos desafios da nação, reconhece a heterogeneidade e demandas, especificas de cada região.

Retomando a periodização elaborada por Fernandes; Souza e Silva (2009) sobre a criação das instituições de ensino e pesquisa no Nordeste elaborou - se o Quadro 3, no qual podem ser verificados de acordo com as "ondas", quais foram as instituições criadas, o período e a localização geográfica, dentro da região Nordeste. 
Quadro 3 - Instituições de ensino e pesquisa criadas no Nordeste de acordo com as "ondas".

\begin{tabular}{|c|c|}
\hline $\begin{array}{l}1 \text { a "onda” } \\
1808-1819\end{array}$ & $\begin{array}{l}\text { Escola de Cirurgia da Bahia - 1808; Escola de Cirurgia do Recife - 1819; Academia Médico - Cirúrgica da Bahia - } 1915 \\
\text { (posteriormente passou a ser a Faculdade de Medicina da Bahia - 1832). }\end{array}$ \\
\hline $\begin{array}{l}\mathbf{2}^{\mathrm{a}} \text { “"onda” } \\
1822-1903\end{array}$ & $\begin{array}{l}\text { Escola de Farmácia e Odontologia de Salvador - } 1824 \text { (fechada no ano seguinte); Escola de Direito do Recife - 1827; Imperial Escola } \\
\text { Agrícola da Bahia - 1875; Faculdade de Livre Direito da Bahia - 1891; Escola de Engenharia do Recife - 1896; Escola Politécnica } \\
\text { da Bahia -1897; Escola de Farmácia e Odontologia do Recife - 1902; Escola de Direito do Ceará - 1903; Imperiais Institutos de } \\
\text { Agricultura da Bahia e de Pernambuco, ambos em 1859; Instituto Sergipano de Agricultura - 1860. }\end{array}$ \\
\hline $\begin{array}{l}3^{a} \text { “"c } \\
1910\end{array}$ & $\begin{array}{l}\text { 'Conferencias Açucareira', na Bahia e em Pernambuco - } 1902 \text { (organização que deram impulsos aos esforços da pesquisa nos } \\
\text { Institutos Imperiais); Estações Experimentais: a de Campos, no estado do Rio de Janeiro e a de Escada, na zona da mata } \\
\text { pernambucana - 1910; Escola Superior de São Bento - } 1914 \text { (que deu origem a Escola Superior de Agricultura em Pernambuco em } \\
\text { 1936, posteriormente absorvida pela Universidade Federal Rural de Pernambuco - UFRPE - 1936); Escola de Agronomia do Ceará } \\
\text { - 1918; Escola de Farmácia de Fortaleza - 1916; Faculdade de Direito do Maranhão - 1918; Faculdade de Medicina do Recife - } \\
\text { 1920; Faculdade de Direito de Maceió - Escola de Agronomia do Nordeste, em Areias na Paraíba - 1934; Instituto de Pesquisa } \\
\text { Agronômica de Pernambuco - } 1935 \text { (atual Empresa Pernambucana de Pesquisa Agropecuária); Instituto Tecnológico de } \\
\text { Pernambuco - 1942; Instituto do Câncer do Ceará 1944. }\end{array}$ \\
\hline $\begin{array}{l}4^{a} \text { "onda" } \\
\text { Pós Guerra }\end{array}$ & $\begin{array}{l}\text { Instituto de Química Agrícola e Tecnologia da Bahia - } 1945 \text { (três anos mais tarde deu origem ao Instituto Tecnológico da Bahia); } \\
\text { Faculdade de Farmácia de São Luiz - MA - 1945; Faculdade de Economia de Campina Grande - PB - 1947; As Faculdades de } \\
\text { Medicina de Fortaleza - 1948; Maceió - 1951, João Pessoa - 1951, Campina Grande - 1951, Natal -1955, São Luiz - 1958 e Aracajú } \\
\text { - 1961; As Escolas de Engenharia de Campina Grande - 1951, Maceió - 1955; Fortaleza - 1955 e Natal - 1957; Instituto Agronômico } \\
\text { do Nordeste, em Recife - 1951; Universidade Federal da Bahia - 1946; Universidade do Recife (federalizada dois anos depois); } \\
\text { Universidade Federal Rural de Pernambuco - } 1947 \text { (criada como órgão do Ministério da Agricultura); Universidade Federal do Ceará } \\
\text { - 1954; Universidade de Paraíba (Federalizada em 1960); Universidade do Rio Grande do Norte e Universidade Federal do } \\
\text { Maranhão - ambas em 1958; Universidade Federal de Alagoas - 1961; Universidade Federal de Sergipe 1963; Instituto Joaquim } \\
\text { Nabuco - 1947; Universidade Católica de Pernambuco - UNICAP- 1951. }\end{array}$ \\
\hline $\begin{array}{l}\text { 5a "onda" } \\
\text { Regime Militar }\end{array}$ & $\begin{array}{l}\text { Universidade Federal Piauí - 1968; Universidade Regional do Nordeste, em Campina Grande - PB - 1967; Curso de Direito -1967 } \\
\text { - PB. Em } 1987 \text { a UERN, é estadualizada para se tornar Universidade Estadual de Paraíba; Escola Politécnica da Paraíba - } 1952 \\
\text { (que vai originar o campus de Campina Grande da UFPB, em 1986). }\end{array}$ \\
\hline $\begin{array}{l}\text { 6" "onda" } \\
\text { Nova República }\end{array}$ & $\begin{array}{l}\text { Secretária de Ciência e Tecnologia de Pernambuco, atual SECTEC, e a FACEPE, Fundação de Amparo à Ciência e Tecnologia - } \\
\text { 1989; Agência Nacional do CNPq, no Recife. A partir da são criadas Instituições fomento em C\&T nos demais estados da região. }\end{array}$ \\
\hline
\end{tabular}

Fonte: FERNANDES; SOUZA; SILVA (2009). 
A partir do Quadro 3, pode-se observar um reduzido número de instituições de ensino e pesquisa na região, principalmente nas duas primeiras "ondas" e grande concentração das mesmas nos estados da Bahia e de Pernambuco. Na terceira "onda", constata-se uma maior distribuição das instituições na região, porém é na quarta "onda" que se verifica maior número de instituições criadas, cobrindo todos os estados da região, com a criação de várias faculdades e inclusive, a criação de dez universidades na região.

Merece ainda destaque o fato de Pernambuco na quarta "onda" possuir três universidades: a Universidade Federal de Pernambuco (UFPE), a Universidade Federal Rural de Pernambuco (UFRPE) e a Universidade Católica de Pernambuco (UNICAP). Na quinta "onda" são criadas mais duas universidades, a Universidade Federal do Piauí e a Universidade Federal da Campina Grande, que segundo Fernandes; Souza e Silva (2009) a criação dessa última universidade é resultado de esforços da sociedade local.

Compreendendo a importância que a pesquisa exerce no desenvolvimento de novas potencialidades tanto econômicas quanto sociais, e que a interação entre instituições de pesquisa e empresas são relevantes para o desenvolvimento de alguns setores econômicos, e da pouca tradição de interação entre os centros de pesquisa e empresa no Brasil, merecem destaque as interação apontada na literatura sobre o caso da Embrapa por Suzigan e Albuquerque (2008) e Fernandes, Souza e Silva (2009).

O caso da Embrapa, como exemplo de sucesso em termos de esforço para criação e consolidação de um Sistema Nacional de Pesquisa Agropecuária, é de extrema relevância para o país, uma vez que a Embrapa, é resultado de esforços institucionais com a finalidade de atender as demandas do setor agropecuário diante dos novos desafios e oportunidades para economia brasileira ${ }^{9}$.

Essa Embrapa revolucionou o planejamento da pesquisa agropecuária brasileira, tornou possível a incorporação de áreas que devido às condições naturais não se prestavam ao aproveitamento agrícola, como Cerrado brasileiro hoje, a maior área produtora de grãos e fibras no país, feito esse possível através da fixação biológica de nitrogênio no solo e outras intervenções agroquímicas. A partir da

\footnotetext{
${ }^{9}$ Considerando que a agropecuária responde por parte importante do PIB brasileiro, a criação de instituições que desse suporte ao desenvolvimento do setor não acontece de forma aleatória, mas como estratégia de manutenção em um mercado que se torna cada vez mais competitivo.
} 
introdução de novos conhecimentos, técnicas modernas, aumentou a produtividade em áreas que tradicionalmente só tinham aumento de sua produção, mediante expansão da área cultivada e intensificação do trabalho humano (CABRAL, 2005).

É uma instituição pioneira na área de interação no país, pois desde o memento de sua criação, foi levado em consideração a necessidade de integrar os vários centros onde se desenvolvia algum tipo de pesquisa agropecuária no país e com o setor produtivo. Os centros universitários constituíram-se importantes aliados na formação de recursos humanos, levando ao surgimento de alguns cursos de PósGraduação. Era preciso superar a falta de especialização dos pesquisadores engajados no desenvolvimento da pesquisa agrícola no país.

Como resultado, vários pesquisadores brasileiros foram incentivados a ir complementar seus estudos em universidades no exterior, principalmente nos Estados Unidos e na Europa. Essa busca pela qualificação em países onde o conhecimento encontrava-se mais avançado é identificado por Mazzoleni e Nelson (2002) como uma das formas utilizadas, para absorção de conhecimento nos centros, mais desenvolvidos e adotado nos países de origem desses estudantes, promovendo assim, a difusão do conhecimento. No caso dos pesquisadores da Embrapa, eles não apenas conseguiram difundir os novos conhecimentos obtidos, como gerar inovações para o setor. Esse fato a coloca hoje como uma das instituições de pesquisa agropecuária mais importantes do mundo (BEINTEMA; AVILA; PARDEY, 2001; BUAINAIN et.al,2014).

Investir na formação da equipe de pesquisadores e técnicos foi uma das prioridades, pois se percebia que sem tal investimento o Brasil não conseguiria acompanhar e aproveitar as novas oportunidades econômicas que lhe apareciam. Além do perfil da urbanização brasileira que naquele momento passava por uma inversão demográfica, com a maior parte de sua população ocupando os centros urbanos, o que demandava a necessidade de abastecimento desses centros, inclusive de produtos com preços acessíveis. O mercado mundial também necessitava dos produtos agrícolas brasileiro.

O setor de pesquisa agrícola antes da criação da Embrapa em 1973 era frágil em três aspectos: recursos humanos qualificados, recursos financeiros contínuos e desigualdade na distribuição geográfica dos centros de pesquisa. Retomaremos as considerações sobre essas fragilidades mais adiante, por agora é oportuno chamar 
atenção para a desigual distribuição das unidades de pesquisa. O Sudeste brasileiro, principalmente o estado de São Paulo, concentrava o maio número de instituições que desenvolviam alguma pesquisa agrícola.

As regiões onde a situação da pesquisa agrícola era mais grave eram as regiões Norte, Nordeste e Centro - Oeste, que como vimos na periodização da criação das instituições de ensino e pesquisa elaborada por Fernandes, Souza e Silva (2009) para à primeira região, foi ainda mais retardatária em relação ao Sudeste do país e só recentemente, tem recebido estímulos favoráveis ao incentivo de pesquisas, mediante políticas públicas.

Diante das evidencias acima citadas, é oportuno considerar que ao contrário do que Suzigan e Albuquerque (2008) supunham para descentralização das unidades das Embrapa, de que estas tinham sido distribuídas pelo território, talvez sem a intenção de descentralizar a pesquisa, essa descentralização teve realmente como objetivo redistribuir competências de pesquisa pelo país, de forma a atender as demandas de cada região aproveitando as potencialidades agrícolas já existentes, melhorando-as e inserindo novas culturas. 


\title{
Capítulo 2. A EMBRAPA E A CONSTITUIÇÃO DO SISTEMA TERRITORIAL DE PESQUISA AGROPECUÁRIA NO BRASIL
}

A agricultura contemporânea não se fundamenta apenas nos fatores naturais de produção, esta tem demandado cada vez mais conhecimentos especializados, que vão desde o desenvolvimento de instrumentos técnicos, ao conhecimento em química fina e biotecnologia. Esta última tem a capacidade de alterar as propriedades genéticas dos vegetais e animais, sendo responsável por uma verdadeira revolução na história da agricultura e da humanidade. Uma definição da complexidade que envolve o conceito de biotecnologia, principalmente em sua fase mais moderna pode ser constatado a seguir:

\begin{abstract}
A biotecnologia pode ser definida como um conjunto de técnicas de manipulação de seres vivos ou parte destes para fins econômicos. Esse conceito amplo inclui técnicas que são utilizadas em grande escala na agricultura desde o início do século XX, como a cultura de tecidos, a fixação biológica de nitrogênio e o controle biológico de pragas. Mas o conceito inclui também técnicas modernas de modificação direta do DNA de uma planta ou de um organismo vivo qualquer, de forma a alterar precisamente as características desse organismo ou introduzir novas. [...] o surgimento da biotecnologia moderna marca o início de um novo estágio para a agricultura e reserva um papel de destaque à genética molecular (SILVEIRA; BORGES; BAUINAIN, 2005, p. 2).
\end{abstract}

Segundo Silva (1996), a modernização da agricultura se dá quando através do conhecimento científico a humanidade passa a reproduzir artificialmente as condições necessárias a produção agrícola, caracterizando a subordinação da natureza ao capital, criando as condições necessárias para maior produtividade da produção e do trabalho. Essas intervenções técnicas na agricultura podem ser constatadas mediante as seguintes ações:

Se faltar chuva, irriga-se; se não houver solos suficientemente férteis, adubase; se ocorrerem pragas e doenças, responde-se com defensivos químicos ou biológicos; e se houver ameaças de inundações, estarão previstas formas de drenagem (SILVA, 1996.p.3).

A fase anterior a industrialização da agricultura no Brasil, é quando essa atividade era desenvolvida com maior dependência das condições naturais de produção ${ }^{10}$. Silva (1996) denominou essa fase como Complexo Rural (CR). No CR os

\footnotetext{
${ }^{10}$ A integração da indústria com a produção agrícola terá maior expressão a partir dos anos 1930 sendo intensificada a partir da década de 1970.
} 
fatores de produção se limitavam as condições naturais, os insumos da produção eram desenvolvidos no interior da propriedade, normalmente havia predominância de um produto para exportação e não possuía maior divisão do trabalho. Um exemplo CR foi a cultura cana-de-açúcar até aproximadamente o fim do século XVIII.

Silva (1996) designa o período de industrialização da agricultura, ou seja, quando o campo se industrializa, como sendo a passagem do CR para o Complexo Agroindustrial (CAI). A mudança do CR para o CAI no Brasil, de acordo com Silva (1996) aconteceu no início do século XIX, com o desenvolvimento da cultura cafeeira, que ao contrário da cultura da cana-de-açúcar demandou uma maior divisão de trabalho, criação de sistemas técnicos, como as linhas férreas, para facilitar o deslocamento da produção entre outros.

Desde o início de sua formação territorial e econômica, a agricultura assumiu papel relevante na composição do Produto Interno Bruto (PIB) brasileiro, porém por longos anos a produção agrícola acontecia sem o investimento em pesquisas científicas para o setor e sem grandes investimentos em infraestrutura técnica.

A esse estágio na evolução das técnicas adotadas na agricultura Santos e Silveira (2011) situam em sua periodização da história do uso do território brasileiro como fazendo parte do período natural ou pré-técnico, em que as atividades agrícolas se assentavam levando em consideração os aspectos geográficos naturais da região onde a atividade era desenvolvida, a exemplo da cultura da cana-de-açúcar. O mercado era, sobretudo o de exportação, as produções dos produtos da alimentação básica estavam restritas a uma circulação local e regional, devido à ausência de redes de circulação no território.

Essa afirmativa pode ser constatada, por exemplo, quando nos estudos referentes à exploração econômica da cana-de-açúcar, são destacados os fatores que influenciaram no sucesso dessa atividade na zona da mata nordestina, na qual as características do solo de massapé, do clima quente e úmido que devidos as suas características de uma estação chuvosa e outra seca, potencializa o desenvolvimento da sacarose, garantindo a qualidade do açúcar, tão bem ressaltados nas obras de Freyre (2004); Andrade (2011[1963]).

Como já mencionado, a agricultura com destaque aquela que se destinava a exportação para a metrópole Portugal era desenvolvida sem grandes sofisticações técnicas. Entre os fatores que justificam os baixos investimentos em melhores fatores 
técnicos de produção, destacam-se o modelo de produção, baseado na exploração em grandes latifúndios, o que favorecia o aumento da produção com incorporação de novas áreas a ser produzida em detrimento do aumento da produtividade do produto a partir de melhoramentos técnicos; outro fator que retardou o desenvolvimento técnico científico da agricultura brasileira foi a exploração da mão-de-obra africana, uma vez que numerosa e submetida à exaustão de sua força de trabalho, fazia com que os proprietários, não buscassem alternativas para reduzir o número de trabalhadores (FURTADO, 2005; ANDRADE, 2011[1963]).

Na primeira metade da década de 1960 , no livro "A Terra e o Homem no Nordeste", o geógrafo Manuel Correia de Andrade trouxe um panorama da situação do Nordeste brasileiro, no que se referia aos aspectos da apropriação e exploração agrícola na região, as relações de trabalho e em alguns trechos fez, menção aos baixos investimentos da região em pesquisa para o setor agropecuário em comparação as iniciativas da região Sudeste, principalmente as do estado de São Paulo.

Porém, é importante destacar conforme mencionado na por Fernandes; Silva e Souza (2009), que embora poucas tenham sido as iniciativas de formação de uma base de C\&T, através da criação de instituições de ensino e pesquisa, existia no Nordeste algumas iniciativas de pesquisas agrícola como as realizadas pelos Imperiais Institutos de Agricultura ${ }^{11}$, considerado por estes autores, como uma primeira iniciativa de institucionalização da pesquisa na região, contudo não se pode deixar de considerar o longo espaçamento de tempo entre o início das atividades agrícolas no Nordeste e a criação de instituição de pesquisa para a área.

Considerando que os esforços de pesquisa agropecuária ao longo do tempo foram se constituindo, porém de forma desigual no território, o planejamento da pesquisa agropecuária no país ganhou outro rumo a partir da década de 1970, com a criação da Empresa Brasileira de Pesquisa Agropecuária - Embrapa.

Dada a importância que a Embrapa exerce na pesquisa agropecuária do país, no próximo tópico, serão explorados os antecedentes que levaram à criação dessa empresa de pesquisa pública; a sua consolidação e reconhecimento da qualidade das pesquisas desenvolvidas, inclusive o reconhecimento da importância da instituição à

11 O instituto Imperial Instituto Baiano foi criado em 1859, no mês de novembro e o Imperial instituto Imperial Pernambucana, no mês de dezembro do mesmo ano, este último de vida efêmera". ALBUQUERQUE e SILVA (2008). 
nível internacional, a estratégia de sucesso da mesma e sua função no Sistema Nacional de Pesquisa Agropecuária - SNPA e as dificuldades enfrentadas pelas Organizações Estaduais de Pesquisa Agropecuária e como essa situação evidencia a fragilidade do atual SNPA.

\subsection{O Contexto histórico da criação da Embrapa}

O Brasil das décadas de 1960 e 1970 encontrava-se em franco crescimento urbano e industrial, o aumento significativo da população urbana demandava cada vez mais o abastecimento do mercado de produtos agrícolas. A produção de alimentos no país tinha como base de produção a expansão da área produzida em detrimento do aumento de produtividade, com a adoção de conhecimentos técnicos científicos que aperfeiçoassem as áreas agrícolas. Era urgente que medidas fossem tomadas, com o objetivo de reverter essa situação ${ }^{12}$.

Diante de tal contexto no ano de 1972 o Ministério da Agricultura, instituiu um Grupo de Trabalho - GT, com a missão de fazer o levantamento a respeito da situação da pesquisa agropecuária no país, no prazo de 1 (um) mês (EMBRAPA, 2006). Antes de enveredarmos pela trajetória de criação da Embrapa é preciso considerar os esforços anteriores de pesquisa federal na área.

Em 1933, foi criado dentro do MA, a Diretoria Geral de Pesquisas (DGP), a mesma foi renomeada um ano depois passando a se chamar Diretoria Geral de Pesquisas, com três subdivisões para as quais desenvolvia pesquisas sobre: lavouras, animais e vegetais; em 1937 é criado o Centro Nacional de Pesquisa de Ensino e Pesquisa Agrícola (CNEPA); o CNEPA possuía além das atividades de pesquisa, o ensino, as atividades ligadas ao ensino passaram a não fazer mais parte de suas atividade e o mesmo foi renomeado como, Serviço Nacional de Pesquisa Agronômica (SNPA); em 1962 o SNPA foi fundido com o Departamento Nacional de Pesquisa Animal dando origem ao Departamento de Pesquisa e Experimentação

\footnotetext{
${ }^{12}$ Além dos fatores internos estava em curso em toda à América do Sul a criação de instituições de pesquisa agrícola estimulada pelo governo norte-americano. É preciso lembrar que para expansão do modelo da revolução agrícola da década de 1950 se realizar plenamente era indispensável que os países em desenvolvimento comprassem os pacotes tecnológicos para agricultura formulado pelas grandes empresas do setor agrícola dos EUA. Não é à toa que somado a criação das instituições de pesquisa nos países em desenvolvimento foi incentivado a ampliação do crédito rural e a extensão rural.
} 
(DPE). Em 1967 o DPE passa a ser o Escritório de Pesquisa e Experimentação (EPE); este transformou-se em 1971 em Departamento Nacional de Pesquisa e Experimentação Agropecuária (DNPEA), sendo o antecessor da atual Embrapa criada em 1973 (BEINTEMA; AVILA; PARDEY,2001).

Os responsáveis pela elaboração e diagnóstico da situação da pesquisa agropecuária no país foram o engenheiro Agrônomo Otto Lyra Schrader, diretor da Divisão de Pesquisa Fitotécnica, do Departamento Nacional de Pesquisa Agropecuária, do Ministério da Agricultura e o Dr. José Irineu Cabral, do Instituto Interamericano de Cooperação para Agricultura - IICA, o último após a decisão de criação da Empresa Brasileira de Pesquisa Agropecuária, foi o seu primeiro Diretor Presidente (EMBRAPA, 2006).

O resultado do diagnóstico elaborado pelo GT deu origem ao "Livro Preto", que consiste no relatório final das constatações sobre a situação da pesquisa agrícola no país e que continha as sugestões para a criação da nova empresa de pesquisa agropecuária. Esse relatório serviu de base para a criação da Embrapa.

Segundo Cabral (2005) o Livro Preto possui algumas curiosidades que merecem ser mencionadas:

1 - Ficou conhecido como 'Livro Preto' por que tem a capa de cartolina preta, que foi a única cor de cartolina que a secretária Yonice Venâncio encontrou para encaderná-lo;

2 - A Portaria no 143 criou um Grupo de Trabalho constituído por apenas duas pessoas, exigências do então ministro da Agricultura, que não confiava em grupos formados por muitos integrantes;

3 - A terceira curiosidade, sem dúvida, é a constatação da atualidade da maioria das propostas contidas no Livro Preto, que corresponde às diretrizes, aos fundamentos e aos princípios atualmente vigentes na Embrapa (EMBRAPA, 2006).

Após a investigação realizada pelo GT foram levantados alguns pontos que eram favoráveis ao desenvolvimento da pesquisa agropecuária brasileira, bem como as barreiras que precisavam urgentemente ser superadas. Entre os aspectos positivos da situação da pesquisa agropecuária naquele momento o GT identificou:

1 - A existência de uma apreciável rede de instituições de pesquisa e experimentação sob uma orientação unificada do Departamento Nacional de Pesquisa Agropecuária - DNPEA, cobrindo todo território nacional, distribuída pelas diversas regiões do país, com vistas ao estudo de problemas agronômicos específicos. 
2 - A disponibilidade de equipamentos e de instalações de campo e de laboratórios, cuja utilização poderia ser intensificada sem comprometer os trabalhos em andamento.

3 - Disponibilidades de meios de divulgação científica, pois possuía na época cerca de 20 principais periódicos, com destaque para a revista 'Pesquisa Agropecuária Brasileira' - PAB, que foi criada pelo DNPEA.

4 - A existência de materiais e resultados de pesquisa de reconhecido valor, que uma vez aplicados pelo produtor, redundariam em substancial melhoria no rendimento da produção e da produtividade se, de imediato, fosse generalizada a adoção desses conhecimentos pelos consumidores da pesquisa.

5 - A existência de um pequeno grupo de dirigentes e profissionais altamente qualificados, que liberado da sobrecarga de atribuições e responsabilidades, poderá aumentar a sua eficiência.

6 - O sistema de reunir especialistas de diferentes procedências e dedicados aos problemas da produção, em 'comissões nacionais', por produto, como subsídio para o planejamento, coordenação e avaliação de projetos nacionais específicos e prioritários.

7 - A consciência existente, hoje em dia, para uma programação nacional integrada de pesquisa agropecuária no país, com base nas necessidades e prioridades estabelecidas para o desenvolvimento. Pode-se aqui, incluir os resultados já alcançados no aprimoramento do sistema de planejamento, no sentido de estimular a participação de outras entidades interessadas nos programas de pesquisa (EMBRAPA, p.6-8, 2006).

Os pontos de estrangulamento, que mostrava a emergência de uma reforma no então DNPEA, foram muitas, dessa forma procurar-se-á ressaltar as mais importantes:

1 - deficiência quanto às políticas e estratégias da pesquisa agropecuária e falhas nas distribuições institucionais e operacionais das unidades de trabalho, que indicavam alta concentração no Sul e no Sudeste do país;

2 - Além da distribuição desigual dos institutos de pesquisa, uma preocupação que era crucial para superação da situação da pesquisa agropecuária era referente aos recursos humanos (orientados basicamente para pesquisa), pois foi identificada uma escassez acentuada de pessoal com perfil de liderança e de pesquisador;

3 - Limitada e descontinuada interação do governo com o setor produtivo;

4 - Servidores carentes em treinamento especializado, principalmente de cursos de pós-graduação;

5- Ausência de uma política salarial atrativa e por fim falta de ações competentes para a captação de recursos financeiros destinado a investimentos destinados a investigar uma política científica e tecnológica sustentada (EMBRAPA, p.8 - 21, 2006).

Segundo Crestana e Souza (2008, p.48) os relatores do GT, se beneficiaram do estudo, realizado por uma Comissão de Alto Nível, estabelecida pelo Ministério da Agricultura e do Planejamento através da Portaria Interministerial $n^{0} 280$, de 24 de junho de 1970, dois anos antes da formação do GT, e que tinha por objetivo a formulação de um programa de expansão das atividades de pesquisa agropecuária brasileira. 
Esse novo programa deveria capacitar o país a receber empréstimos e assistência técnica importantes do governo norte-americano, objetivando alavancar o segmento de pesquisa agropecuária do setor público. A assistência técnica seria ofertada pela Agência Norte Americana para o Desenvolvimento Internacional (USAID - United States Agency for International Development). (CRESTANA e SOUZA, 2008, p. 49).

As semelhanças entre as constatações dos pontos que eram favoráveis e os pontos desfavoráveis para a pesquisa agropecuária no país identificados pela Comissão e Altos Estudos e posteriormente pelo GT, podem ser constatados no Quadro 4. 
Quadro 4 - Pontos Positivos e Negativos que caracterizavam a pesquisa agrícola na década de 1970.

\begin{tabular}{|c|c|c|c|}
\hline Comissão de Alto Nível & Grupo de Trabalho & Comissão de Alto Nível & Grupo de Trabalho \\
\hline \multicolumn{2}{|c|}{ Aspectos Positivos } & \multicolumn{2}{|c|}{ Aspectos Negativos } \\
\hline $\begin{array}{l}\text { Presença de pesquisa agropecuária em todas as } \\
\text { regiões do país. }\end{array}$ & $\begin{array}{l}\text { A existência de uma apreciável rede de instituições } \\
\text { de pesquisa e experimentação sob uma orientação } \\
\text { unificada do Departamento Nacional de Pesquisa } \\
\text { Agropecuária - DNPEA, cobrindo todo território } \\
\text { nacional, distribuída pelas diversas regiões do país. }\end{array}$ & $\begin{array}{l}\text { Falta de pessoal devidamente } \\
\text { qualificado para o exercício da } \\
\text { atividade de pesquisa. }\end{array}$ & $\begin{array}{l}\text { Falta generalizada de } \\
\text { conhecimentos dos diversos } \\
\text { problemas e causas que } \\
\text { determinam a baixa } \\
\text { capacidade das atividades de } \\
\text { pesquisa e de transferência } \\
\text { de tecnologia. }\end{array}$ \\
\hline $\begin{array}{l}\text { Existência de razoável infraestrutura de instalações, } \\
\text { laboratórios e equipamentos de campo }\end{array}$ & $\begin{array}{l}\text { A disponibilidade de equipamentos e de instalações } \\
\text { de campo e de laboratórios. }\end{array}$ & Baixo salário dos pesquisadores & $\begin{array}{l}\text { Limitada e descontinuada } \\
\text { ação do Governo com o setor } \\
\text { privado. }\end{array}$ \\
\hline $\begin{array}{l}\text { Boas possibilidades de financiamento sobretudo de } \\
\text { fonte externa }\end{array}$ & & Falta generalizada de incentivos & $\begin{array}{l}\text { O Modelo institucional, que } \\
\text { impedia a agilidade e } \\
\text { flexibilidade necessárias } \\
\text { para o dinamismo necessário } \\
\text { de um sistema nacional de } \\
\text { pesquisa agropecuária }\end{array}$ \\
\hline \multirow[t]{3}{*}{$\begin{array}{l}\text { Existência de longa tradição de pesquisa, atestada } \\
\text { pela série de resultados importantes nas mais } \\
\text { diferentes áreas do conhecimento }\end{array}$} & $\begin{array}{l}\text { A existência de materiais e resultados de pesquisa } \\
\text { de reconhecido valor, que uma vez aplicados pelo } \\
\text { produtor }\end{array}$ & $\begin{array}{l}\text { Inexistência de mecanismos de } \\
\text { promoção de reconhecimento ao } \\
\text { mérito }\end{array}$ & $\begin{array}{l}\text { As atuais atividades de } \\
\text { coordenação e e de } \\
\text { comunicação a nível nacional } \\
\text { regional e local, em geral se } \\
\text { revestiam de caráter precário } \\
\text { e funcionavam quase sempre } \\
\text { 'ad hoc'. }\end{array}$ \\
\hline & $\begin{array}{l}\text { Disponibilidade de meios de divulgação científica, } \\
\text { pois possuía na época cerca de } 20 \text { principais } \\
\text { periódicos, com destaque para a revista 'Pesquisa } \\
\text { Agropecuária Brasileira' - PAB }\end{array}$ & Escassez de recursos & $\begin{array}{l}\text { Uma acentuada deficiência } \\
\text { nas relações de coordenação } \\
\text { no processo de planejamento } \\
\text { e na execução das atividades } \\
\text { de pesquisa entre os órgãos } \\
\text { de pesquisa e os serviços de } \\
\text { apoio à agricultura, } \\
\text { especialmente os de } \\
\text { assistência técnica, de } \\
\text { financiamento e de } \\
\text { comercialização }\end{array}$ \\
\hline & $\begin{array}{l}\text { A existência de um pequeno grupo de dirigentes e } \\
\text { profissionais altamente qualificados }\end{array}$ & $\begin{array}{l}\text { Irregularidade na distribuição dos } \\
\text { poucos recursos disponíveis }\end{array}$ & $\begin{array}{l}\text { A inexistência de um plano } \\
\text { integrado de pesquisa } \\
\text { agropecuária com os fatores } \\
\text { mais importantes que }\end{array}$ \\
\hline
\end{tabular}




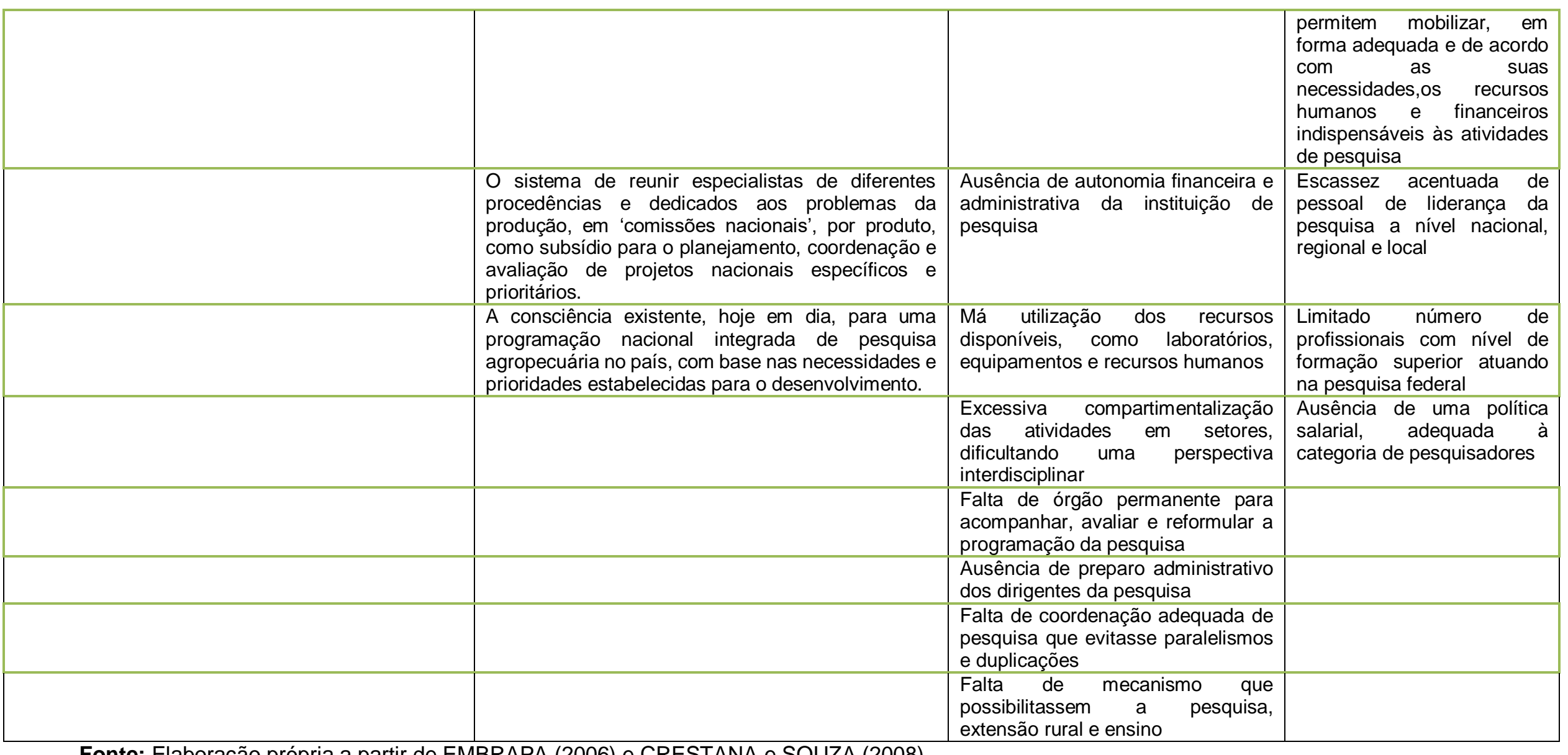

Fonte: Elaboração própria a partir de EMBRAPA (2006) e CRESTANA e SOUZA (2008). 
Apresentada as vantagens e limitações para o desenvolvimento de um modelo de pesquisa agropecuária integrada, capaz de dar conta da diversidade territorial do país, é preciso destacar que embora o ambiente político da época, não fosse de democracia, em virtude do Golpe Militar, a política desenvolvimentista perseguida pelos militares, permitiu que muitas das medidas necessárias, para o desenvolvimento de um setor estratégico como a agricultura fosse possível.

A distribuição desigual no território, das instituições de pesquisa agropecuária no país e os órgãos responsáveis pelas mesmas era, conforme destacado pelo GT, motivo de grande preocupação, uma vez que o Sudeste, principalmente o estado de São Paulo concentrava o maior número de instituições de pesquisa, conforme Quadro 5.

Quadro - 5 - Distribuição institucional da Pesquisa Agropecuária no Brasil (1972)

\begin{tabular}{|c|c|c|c|c|c|c|}
\hline \multicolumn{7}{|c|}{ Alta Centralidade Federal } \\
\hline Estados & $\begin{array}{l}\text { Ministério } \\
\text { da } \\
\text { Agricultura }\end{array}$ & MEC & $\begin{array}{l}\text { Outros } \\
\text { Federal }\end{array}$ & $\begin{array}{l}\text { Governo } \\
\text { do Estado }\end{array}$ & Outros & Total \\
\hline $\begin{array}{l}\text { Minas } \\
\text { Gerais }\end{array}$ & 11 & 6 & - & - & - & 17 \\
\hline Paraná & 8 & 4 & - & 6 & - & 18 \\
\hline $\begin{array}{l}\text { Santa } \\
\text { Catarina }\end{array}$ & 6 & 0 & - & 1 & 3 & 10 \\
\hline Amazonas & 3 & 0 & - & - & 1 & 4 \\
\hline \multicolumn{7}{|c|}{ Alta Centralidade Estadual } \\
\hline São Paulo & 3 & - & - & $38^{*}$ & - & 41 \\
\hline${ }^{*}$ Inclui quatro & escolas esta & ais de a & mia & & & \\
\hline \multicolumn{7}{|c|}{ Relativa Descentralização } \\
\hline Bahia & 8 & 1 & 9 & 7 & - & 25 \\
\hline Pernambuco & 4 & 10 & - & 20 & - & 34 \\
\hline $\begin{array}{l}\text { Rio Grande } \\
\text { do Sul }\end{array}$ & 5 & 7 & - & 4 & 4 & 28 \\
\hline
\end{tabular}

Fonte: EMBRAPA, 2006.

Uma das proposições essenciais que constava nas reflexões do GT era a necessidade de uma articulação mais direta e continua dos esforços de pesquisa que seria doravante coordenado pela nova Empresa. Mas essa empreitada só seria possível com a articulação entre; outras esferas do governo, estados, setor produtivo, e com as universidades. No caso das universidades os relatores apontavam o fato de que essas, além de contribuírem com o desenvolvimento da pesquisa básica seriam, responsáveis pela formação de recursos humanos qualificados. 
Como no Brasil, na época poucas eram as instituições que ofereciam cursos de Pós-Graduação, e dado a urgência da formação de quadro profissional com formação adequada, as universidades brasileiras foram estimuladas a ofertarem cursos de Pós-Graduação ligada, sobretudo a Agronomia. Além da criação de cursos de Pós-Graduação, uma medida considerada por Cabral (2005); Crestana e Souza, (2008) da maior relevância, foi o envio de mais de 2000 funcionários do antigo DNPEA, para realizarem cursos de Pós-Graduação no exterior, principalmente em universidades da Europa e dos Estados Unidos.

Essa visão integradora de ações que tinham como finalidade dar suporte para o desenvolvimento de uma agricultura moderna e colocar o país na fronteira da produção e exportação de alimentos, é certamente um esforço merecedor de atenção. Tomando por base a concepção do conceito de SNI, proposto por Albuquerque (1996) que consiste em ação planejada ou não de atores que tem por objetivo o desenvolvimento tecnológico no país, podemos afirmar, que nesse sentido a Embrapa constitui- se em um exemplo de sistema de inovação na agropecuária brasileira.

Outro aspecto que merece ser evidenciado como atitude inovadora e que certamente foi, uma das grandes responsáveis pelo sucesso da Embrapa, foi o modelo institucional e organizacional, pois a mesma trata-se de uma Empresa Pública com personalidade Jurídica Privada. O caráter privado da empresa foi proposto com a finalidade de que a mesma não ficasse presa as amaras da burocracia da gestão pública, que poderia retardar o desenvolvimento dos objetivos da nova Empresa. $\mathrm{O}$ novo modelo organizacional da pesquisa passou a ser desenvolvida de forma concentrada, baseada em planos nacionais de pesquisa por projetos regionais e de produtos, com diretrizes nacionais, subsidiados pelas demandas das unidades descentralizadas (CABRAL, 2005).

A flexibilidade administrativa da Embrapa é destacada entre outros por EMBRAPA, 2006; CABRAL, 2005; ALBUQUERQUE e SILVA, 2008; BEINTEMA; AVILA; PARDEY, 2001, que reforçam o modelo institucional da Embrapa como sendo um dos elementos responsáveis, pelo sucesso da instituição. Mas é preciso dizer que os mesmos autores relatam que a flexibilidade do período de criação da instituição já não é mais a mesma e que está instituição tem a cada dia se burocratizado, conforme pode-se constatar a seguir: 
Pelo efeito sucessivo da legislação, a Embrapa entrou no século 21 desprovida de suas características de flexibilidade e agilidade institucionais. No lugar das características de dinâmica institucional dos anos 1970, a Empresa vai se caracterizando por uma estrutura rígida, que limita a agilidade gerencial. $E$ isso acontece quando novos e importantes desafios se manifestam (ALBUQUERQUE e SILVA, 2008, p.53).

Após a aprovação da criação da Embrapa os institutos federais regionais, os campos de pesquisa experimentais, e o patrimônio material, passaram a pertencer a Embrapa. Os pesquisadores que faziam parte do DNPEA passaram por um processo seletivo passando a compor o quadro de pessoal da nova empresa, os demais foram redistribuídos por repartições estaduais de pesquisa. Vale destacar que a Empresa embora possua uma administração indireta, devido ao fato de ser uma empresa pública de direito privado encontra-se vinculada ao MAPA, mas tem plenos poderes administrativos (CABRAL, 2005).

No que diz respeito aos recursos financeiros, essenciais ao desenvolvimento das pesquisas que doravante seriam desenvolvidas, a Embrapa passou a ter um orçamento próprio, que anualmente é repassado pelo Governo Federal, assegurando a continuidade de suas pesquisas sem sofrer, por exemplo, com o maior ou menor interesse de quem esteja à frente do poder político ${ }^{13}$. Outras fontes de recursos poderiam chegar através da venda de pacotes tecnológicos desenvolvidos pela empresa e vendidos a iniciativa privada, essa última além de comprar os produtos produzidos pela Embrapa, poderiam apontar demandas potenciais, o que manteria a pesquisa agropecuária atualizada (EMBRAPA, 2006).

Entre as estratégias de atuação da Embrapa, com a finalidade de desenvolver o setor agropecuário do país foram criadas além, da Unidade Central com sede em Brasília, unidades descentralizadas, com a finalidade de superação do atraso agrícola nas diversas regiões do país, principalmente aquelas mais carentes de pesquisa, como o Norte, Nordeste e Centro-Oeste. Essa atitude é considerada pioneira para o desenvolvimento estratégico e territorial da pesquisa agropecuária e será apreciado no tópico a seguir.

${ }^{13} \mathrm{O}$ orçamento da Embrapa em 2015 foi $\mathrm{R} \$ 3$ bilhões e o capital social da Embrapa em 2016 era $\mathrm{R} \$$ 62milhões. 
2.2 - As Unidades de Pesquisa descentralizadas da Embrapa e Consolidação do Sistema Nacional da Pesquisa Agropecuária

Mencionado os motivos que levaram a criação da Embrapa, é importante destacar a visão territorial da nova empresa, para o sucesso de suas ações. 0 reconhecimento da grande concentração dos recursos de pesquisa agropecuária na região Sudeste e Sul fez com que entre as medidas tomadas com o objetivo de tornar eficiente em seus propósitos de desenvolver a agropecuária a nível nacional, foi criada unidades de pesquisa em todas as regiões do país, considerando as diferenças e potencialidades regionais.

Dessa forma os antigos institutos regionais de pesquisa agropecuária e alguns Campos Experimentais desses institutos pertencentes ao antigo DNPEA, foram absorvidos e transformados em unidades da Embrapa. Hoje a Embrapa possui unidades de pesquisa em quase todos os estados brasileiros, exceto nos estados de Alagoas, Rio Grande do Norte e Espirito Santo. A ausência de unidades descentralizadas nesses estados, não significa que as ações de pesquisa comandadas pela Embrapa não se façam presentes nesses territórios.

Atualmente a Embrapa é formada por um sistema constituído por 17 Unidades Centrais, 46 unidades de pesquisa e serviço descentralizadas no território brasileiro, Laboratório Virtuais no Exterior (Labex) e Escritórios Internacionais na América Latina e na África. As Unidades Centrais estão localizadas no edifício sede da Empresa em Brasília; as unidades descentralizadas possuem a seguinte tipologia: unidades de serviço, unidades de pesquisa pásica, unidades de temas básicos, unidades ecorregionais.

As Unidades Centrais são responsáveis por planejar, supervisionar, coordenar e controlar as atividades relacionadas à execução de pesquisa agropecuária e a elaboração das políticas agrícolas. Assim as Unidades Centrais ocupam lugar de destaque na hierarquia da empresa, embora os demais tipos de unidades possuam relativa autonomia em sua atuação.

As respectivas unidades por modalidade podem ser observadas no Quadro 6, e a distribuição das unidades descentralizadas da Embrapa no território brasileiro, bem como os tipos de unidades podem ser visualizadas no Mapa 1. 
Quadro 6 - Unidades Descentralizadas da Embrapa: distribuição no território brasileiro

\begin{tabular}{|c|c|c|c|c|c|c|c|c|}
\hline \multirow{2}{*}{$\begin{array}{l}\text { Unidades Administrativas } \\
\text { Unidades Central - Brasília/ } \\
\text { DF }\end{array}$} & \multicolumn{2}{|c|}{ Unidades de serviço } & \multicolumn{2}{|c|}{ Unidades de produtos } & \multicolumn{2}{|c|}{ Unidades pesquisa de temas básicos } & \multicolumn{2}{|c|}{$\begin{array}{l}\text { Unidades ecorregionais } \\
\text { (inclui unidades de pesquisa agroflorestal ou } \\
\text { agropecuária das ecorregiōes brasileira) }\end{array}$} \\
\hline & Unidade & Munic./UF & Unidade & Munic./UF & Unidade & Munic./UF & Unidade & Munic./UF \\
\hline $\begin{array}{l}\text { Gabinete do Diretor } \\
\text { Presidente }\end{array}$ & Embrapa Café & Brasília -DF & Embrapa Algodão & $\begin{array}{c}\text { Campina } \\
\text { Grande-PB }\end{array}$ & Embrapa Agrobiologia & Itaguaí/RJ & Embrapa Acre & Rio Branco/AC \\
\hline $\begin{array}{l}\text { Acessória de Auditória } \\
\text { Interna }\end{array}$ & $\begin{array}{c}\text { Embrapa Gestão } \\
\text { Territorial }\end{array}$ & $\begin{array}{c}\text { Campinas - } \\
\text { SP }\end{array}$ & $\begin{array}{l}\text { Embrapa Arroz e } \\
\text { Feijão }\end{array}$ & $\begin{array}{l}\text { Santo Antônio } \\
\text { de Goiás/GO }\end{array}$ & Embrapa Agroenergia & Brasília/DF & $\begin{array}{l}\text { Embrapa Agropecuária } \\
\text { Oeste }\end{array}$ & Dourados/MS \\
\hline $\begin{array}{l}\text { Acessória de Inovação } \\
\text { Tecnológica }\end{array}$ & $\begin{array}{l}\text { Embrapa Informação } \\
\text { Tecnológica }\end{array}$ & Brasília -DF & $\begin{array}{l}\text { Embrapa Caprino e } \\
\text { Ovinos }\end{array}$ & Sobral/CE & $\begin{array}{l}\text { Embrapa Agroindústria } \\
\text { de Alimentos }\end{array}$ & Guaratiba/RJ & Embrapa Agrossilvipastoril & Sinop/MT \\
\hline Acessória Jurídica & $\begin{array}{c}\text { Embrapa transferência } \\
\text { de Tecnologia }\end{array}$ & Brasília -DF & Embrapa Florestas & Colombo/PR & $\begin{array}{c}\text { Embrapa Agroindústria } \\
\text { Tropical }\end{array}$ & Fortaleza/CE & Embrapa Amapá & Macapá/AP \\
\hline Acessória Parlamentar & & & $\begin{array}{c}\text { Embrapa Gado de } \\
\text { Corte }\end{array}$ & $\begin{array}{c}\text { Campo } \\
\text { Grande/MS }\end{array}$ & $\begin{array}{c}\text { Embrapa Estudos e } \\
\text { Capacitação }\end{array}$ & Brasília/DF & $\begin{array}{c}\text { Embrapa Amazônia } \\
\text { Ocidental }\end{array}$ & Manaus/AM \\
\hline Secretaria de Comunicação & & & $\begin{array}{l}\text { Embrapa Gado de } \\
\text { Leite }\end{array}$ & $\begin{array}{c}\text { Juiz de } \\
\text { Fora/MG }\end{array}$ & $\begin{array}{l}\text { Embrapa Informática } \\
\text { Agropecuária }\end{array}$ & Campinas/SP & Embrapa Amazônia & Belém/PA \\
\hline $\begin{array}{c}\text { Secretaria de Gestão } \\
\text { Estratégica }\end{array}$ & & & Embrapa Hortaliças & Brasília -DF & $\begin{array}{c}\text { Embrapa } \\
\text { Instrumentação }\end{array}$ & São Carlos/SP & Embrapa Cerrados & Brasília/DF \\
\hline $\begin{array}{l}\text { Secretaria de Relações } \\
\text { Internacionais }\end{array}$ & & & $\begin{array}{c}\text { Embrapa Mandioca } \\
\text { e Fruticultura }\end{array}$ & $\begin{array}{c}\text { Cruz das } \\
\text { Almas - BS }\end{array}$ & $\begin{array}{c}\text { Embrapa Meio } \\
\text { Ambiente }\end{array}$ & Jaguariúna/SP & Embrapa Clima Temperado & Pelotas /RS \\
\hline $\begin{array}{l}\text { Secretária Executiva do } \\
\text { PAC Embrapa }\end{array}$ & & & $\begin{array}{l}\text { Embrapa Milho e } \\
\text { Sorgo }\end{array}$ & $\begin{array}{l}\text { Sete Lagoas } \\
-M G\end{array}$ & $\begin{array}{c}\text { Embrapa } \\
\text { Monitoramento por } \\
\text { Satélite } \\
\end{array}$ & Campinas/SP & Embrapa Cocais & São Luis/MA \\
\hline $\begin{array}{l}\text { Departamento de Pesquisa } \\
\text { \& Desenvolvimento }\end{array}$ & & & $\begin{array}{c}\text { Embrapa Pecuária } \\
\text { Sudeste }\end{array}$ & $\begin{array}{c}\text { São } \\
\text { Carlos/SP }\end{array}$ & $\begin{array}{c}\text { Embrapa Recursos } \\
\text { Genéticos e Biológicos }\end{array}$ & Brasília/DF & Embrapa Meio Norte & Teresina/PI \\
\hline $\begin{array}{c}\text { Departamento de } \\
\text { Tecnologias da Informação }\end{array}$ & & & $\begin{array}{c}\text { Embrapa Pecuária } \\
\text { Sul }\end{array}$ & Bagé/RS & Embrapa Solos & $\begin{array}{c}\text { Rio de } \\
\text { Janeiro/RJ }\end{array}$ & Embrapa Pantanal & Corumbá/MS \\
\hline $\begin{array}{l}\text { Departamento de } \\
\text { Transferência de } \\
\text { Tecnologias }\end{array}$ & & & $\begin{array}{l}\text { Embrapa Pesca e } \\
\text { Aquicultura }\end{array}$ & Palmas/TO & & & Embrapa Rondônia & Porto Velho/RO \\
\hline $\begin{array}{c}\text { Departamento de Gestão } \\
\text { de Pessoas }\end{array}$ & & & Embrapa Soja & Londrina/PR & & & Embrapa Semiárido & Petrolina/PE \\
\hline $\begin{array}{c}\text { Departamento de } \\
\text { Administração Financeira }\end{array}$ & & & $\begin{array}{c}\text { Embrapa Suínos e } \\
\text { Aves }\end{array}$ & Concórdia/SC & & & $\begin{array}{c}\text { Embrapa Tabuleiros } \\
\text { Costeiros }\end{array}$ & Aracaju/SE \\
\hline $\begin{array}{c}\text { Departamento de } \\
\text { Administração do Parque } \\
\text { Estação Biológica Embrapa }\end{array}$ & & & Embrapa trigo & $\begin{array}{c}\text { Passo } \\
\text { Fundo/RS }\end{array}$ & & & & \\
\hline $\begin{array}{c}\text { Departamento de } \\
\text { Patrimônio e Suprimentos }\end{array}$ & & & $\begin{array}{c}\text { Embrapa Uva e } \\
\text { Vinho }\end{array}$ & $\begin{array}{c}\text { Bento } \\
\text { Gonçalves/RS }\end{array}$ & & & & \\
\hline
\end{tabular}

Fonte: Embrapa (2015).

Elaboração: LIRBÓRIO, 2015. 


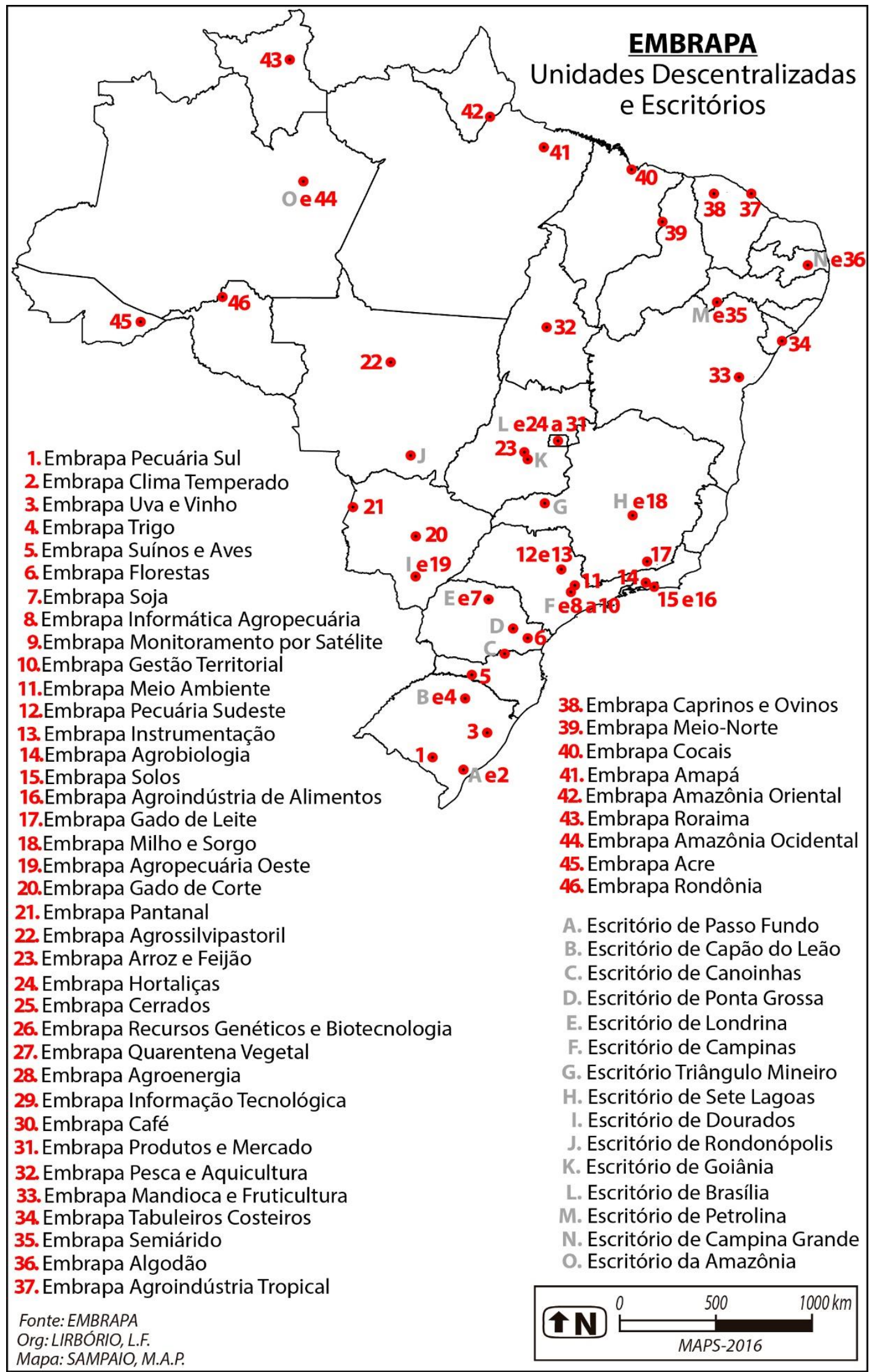


A partir da análise da distribuição das unidades de pesquisa da Embrapa, é possível verificar que a mesma se apresenta territorialmente dispersa, conforme já mencionado, porém ainda se observa grande concentração nos estados do Sudeste/Sul, como no caso de São Paulo, que conta com cinco unidades e o Rio Grande do Sul com quatro unidades, enquanto a maioria dos estados contam com apenas uma unidade.

Além do considerável número de unidades no Sudeste observa-se a concentração de alguns centros de pesquisa estratégicos e que envolvem conhecimentos fundamentais para atual dinâmica do setor agrícola, como por exemplo, a Embrapa Instrumentação (São Carlos/SP); Embrapa Informática Agropecuária (Campinas/SP), Embrapa Gestão Territorial (Campinas /SP), Embrapa Monitoramento por Satélite (Campinas SP).

As Unidades acima citadas se encontram na porção do território brasileiro no qual a agricultura apresenta maior conteúdo técnico-científico-informacional. Além do mais, a presença de fatores de infraestrutura técnica e científica, como as principais universidades do país (Universidade de São Paulo/USP; Universidade Estadual de Campinas/UNICAMP; Universidade Federal de São Carlos/UFSCAR) oferecem as condições necessárias para que as mesmas estejam sempre prontas a responder aos principais paradigmas da agricultura contemporânea.

Entre esses paradigmas merece atenção a crescente informatização da produção no campo, na medida em que os equipamentos agrícolas possuem inúmeros softwares acoplados aos maquinários agrícolas que geram informações importantes para a produção. Através dos dados que esses equipamentos coletam, é possível aumentar a produtividade agrícola, assim como utilizar os recursos de forma mais eficiente.

Ainda em relação a concentração de maior número de unidades de pesquisa da Embrapa destacamos Brasília/DF, pois nesse território existe oito unidades de pesquisa e as unidades administrativas. Entre as unidades de pesquisa no Distrito Federal merece atenção a Embrapa Recursos Genéticos e Biotecnologia (CENARGEN) ${ }^{14}$, é nesta unidade que se encontra o principal

\footnotetext{
${ }^{14}$ No CENARGEM há mais de 100 mil acessos de germoplasma vegetal.
} 
banco de Germoplasma do país. A definição de Germoplasma compreendida por essa unidade de pesquisa é:

\begin{abstract}
material que constitui a base física da herança sendo transmitida de uma geração para outra. Significa a matéria onde se encontra um princípio que pode crescer e se desenvolver, sendo definido ainda, como a soma total dos materiais hereditários de uma espécie. Existem cinco categorias de Germoplasma: parentes silvestres; populações locais (landraces) ou cultivares primitivas; cultivares que foram substituídas; linhagens experimentais, mutações e outros produtos dos programas de melhoramento; cultivares modernas (EMPRAPA, 2012)
\end{abstract}

É oportuno destacar que algumas unidades de pesquisa de produtos, nem sempre estão no município onde aquele produto tem maior produção, como é o caso da Embrapa Soja, que se encontra no município de Londrina / PA, pois no momento de criação dessa unidade esse estado apresentava maior taxa de produção desse produto, hoje a maior produção encontra-se no Mato Grosso. Situação semelhante ocorre com a Embrapa Algodão instalada no município de Campina Grande-PB na época em que o Nordeste respondia pela maior área plantada com a lavoura algodoeira do país e atualmente é na região CentroOeste onde se localizam as maiores áreas plantadas desse produto. Por sua vez conforme será demonstrado no Capítulo 3 a existência de Campos Experimentais de pesquisa nos lugares em que as culturas são desenvolvidas são estratégicas para o bom desempenho das mesmas.

Além das unidades descentralizadas, a Embrapa possui Laboratórios Virtuais - Labex e Projetos no exterior, o que facilita o intercâmbio de conhecimento científico entre os pesquisadores dessa instituição com os dos países onde os laboratórios e projetos estão instalados, facilitando dessa forma a troca de conhecimento, parcerias na realização de pesquisas e transferência de tecnologias. Há unidades do Labex nos Estados Unidos, na França, no Reino Unido, na Coréia do Sul e na China. A Embrapa Projetos em outros países são: Projeto Embrapa África (Mali, Gana, Senegal e Moçambique); Projeto Embrapa Américas: Panamá, Equador, Colômbia e Venezuela. Na Figura 4 podemos visualizar a presença da Embrapa em outros países e continentes. 
Figura 4 - Laboratórios Virtuais e Projetos da Embrapa no Exterior

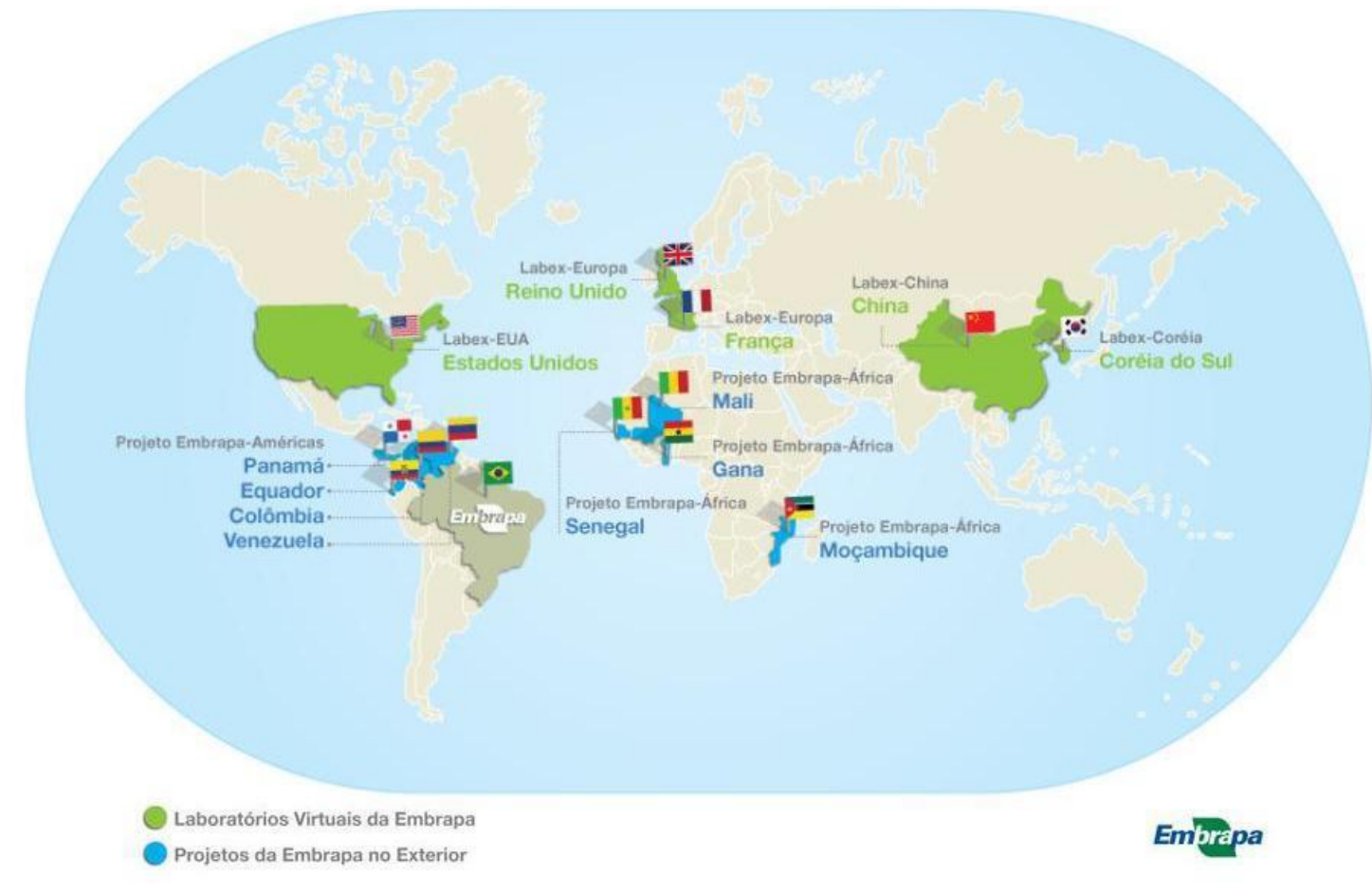

Fonte: Disponível em:

< https://www.embrapa.br/busca-de-noticias/-/noticia/1482010/japao-hospeda-novo-laboratoriovirtual-da-embrapa-na-asia>

Acessado em: 10 de junho de 2016.

A presença da Embrapa em outros países foi favorecida pela emenda constitucional - MP/502/2010, que propôs a permissão para que a Embrapa possa "exercer qualquer das atividades integrantes de seu objeto social fora do território nacional, em conformidade com o que dispuser seu estatuto social." Essa MP, foi aprovada sem alteração de seu texto em 2 de março de 2011.

Crestana e Souza (2008), divide a evolução da agricultura brasileira em duas fases, a primeira a "agricultura nos trópicos" e a segunda a "agricultura dos trópicos". As referências as características conferidas a essa divisão podem ser verificadas a baixo:

"Por agricultura nos trópicos entende-se aquela se desenvolve na região a partir da experiência do senso comum e da adaptação de conhecimentos técnico - científicos elaborados em outras áreas do globo. A força da investigação interna é ainda fraca, tanto em termos 
de formação e treinamento de alto nível dos seus cientistas e tecnólogos, quanto de solidas instituições de ensino e pesquisa, além serem parcos os investimentos em ciência e tecnologia para a área da agricultura,

A agricultura dos trópicos está baseada na construção de solida massa crítica de pesquisadores com alto nível de formação acadêmica, de treinamento e experiência em pesquisa, de gestão competente, e de agricultores e políticas públicas eficientes, além de instituições científicas fortes e dinâmicas, financiamentos abundantes e extensão rural de qualidade. Os investimentos em ciência e tecnologia para a agropecuária atingem nível elevado, possibilitando o funcionamento de laboratórios e a capacitação continua de pessoal especializado.

Se a agricultura nos trópicos fundamentava-se, entre outros fatores, na vastidão da fronteira agrícola, no baixo uso de insumos agrícolas na produção de produtos tradicionais, no relativo descaso com a qualidade em favor da quantidade na pouca utilização da máquina e equipamentos, na reduzida produção tecnológica interna na baixa e instável utilização do crédito rural e no baixo prestigio do setor rural, a agricultura dos trópicos firmava-se na produção endógena de tecnologias, no desenvolvimento forçado ou induzido de contingentes africanos, europeus e asiáticos , e, nas últimas décadas, na vasta cooperação internacional, de investimento em talentos humanos especializados, no largo uso da tecnologia, no acesso ao crédito, no crescente sombreamento da distinção rural-urbana, na modernização institucional e na atenção à qualidade dos produtos e do meio ambiente (CRESTANA; SOUZA, 2008, 45-46).

O investimento brasileiro em pesquisa agropecuária é o maior da América Latina e Caribe segundo dados da ASTI ${ }^{15} /$ FRIP $^{16}$ (2016). A liderança do Brasil em relação a outros países da América Latina não se limita apenas a quantidade de recursos destinado a pesquisas no setor, mas também em relação a formação dos recursos humanos e infraestrutura de pesquisa. Os dados referentes a despesas ligadas a pesquisa agropecuária no Brasil e em outros países América Latina e Caribe podem ser analisados a partir do Gráfico 1.

${ }^{15}$ Agricultural Science Technology Indicators (ASST)

${ }^{16}$ International Food Policy Research Institute (IFPRI) 
Gráfico 1 - Investimentos em Pesquisa e Desenvolvimento (P\&D) nos países da América Latina e Caribe

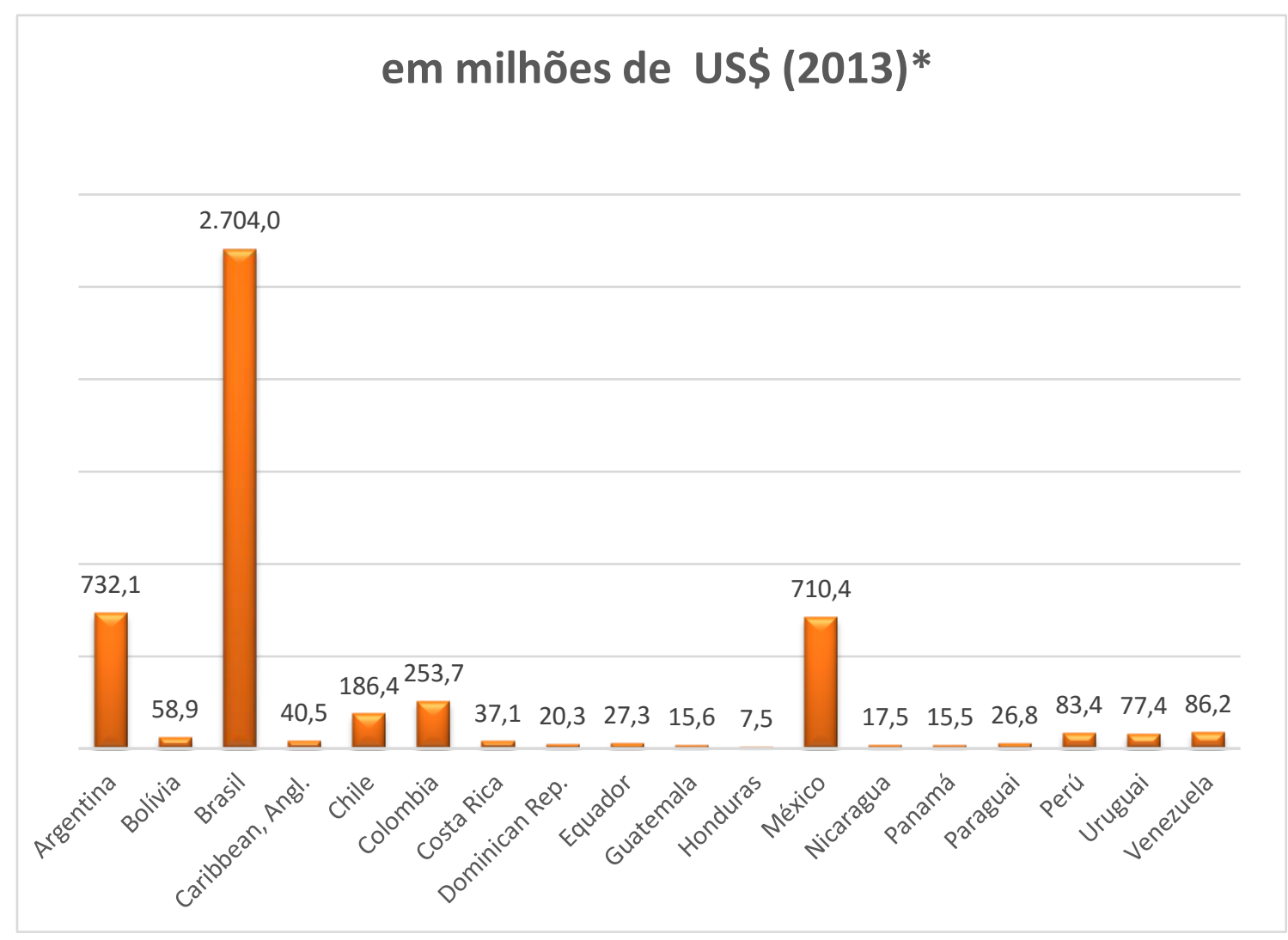

Elaboração: LIRBÓRIO, L.F. 2016

Fonte: ASTI/IFRI, $2017^{*}$ a preços constantes de 2011.

Conforme podemos analisar no Gráfico 1 o Brasil responde por mais da metade de toda a despesa com pesquisa agropecuária da América Latina e Caribe. A Argentina é o segundo país que mais investe em pesquisa agropecuária ( US\$732,1 milhões), em terceiro lugar o México (US\$710,4 milhões), seguido pela Colômbia (253,7 milhões).

O maior número de pesquisadores dedicados à pesquisa agropecuária em tempo integral no Brasil estão vinculados à Embrapa, seguido dos pesquisadores que desenvolvem pesquisa nas universidades, ou nas Organizações Estaduais de Pesquisa (OEPAS) e outros. Conforme pode ser analisado no Gráfico 2. 
Gráfico 2 - Perfil institucional dos pesquisadores ligados à agropecuária no Brasil

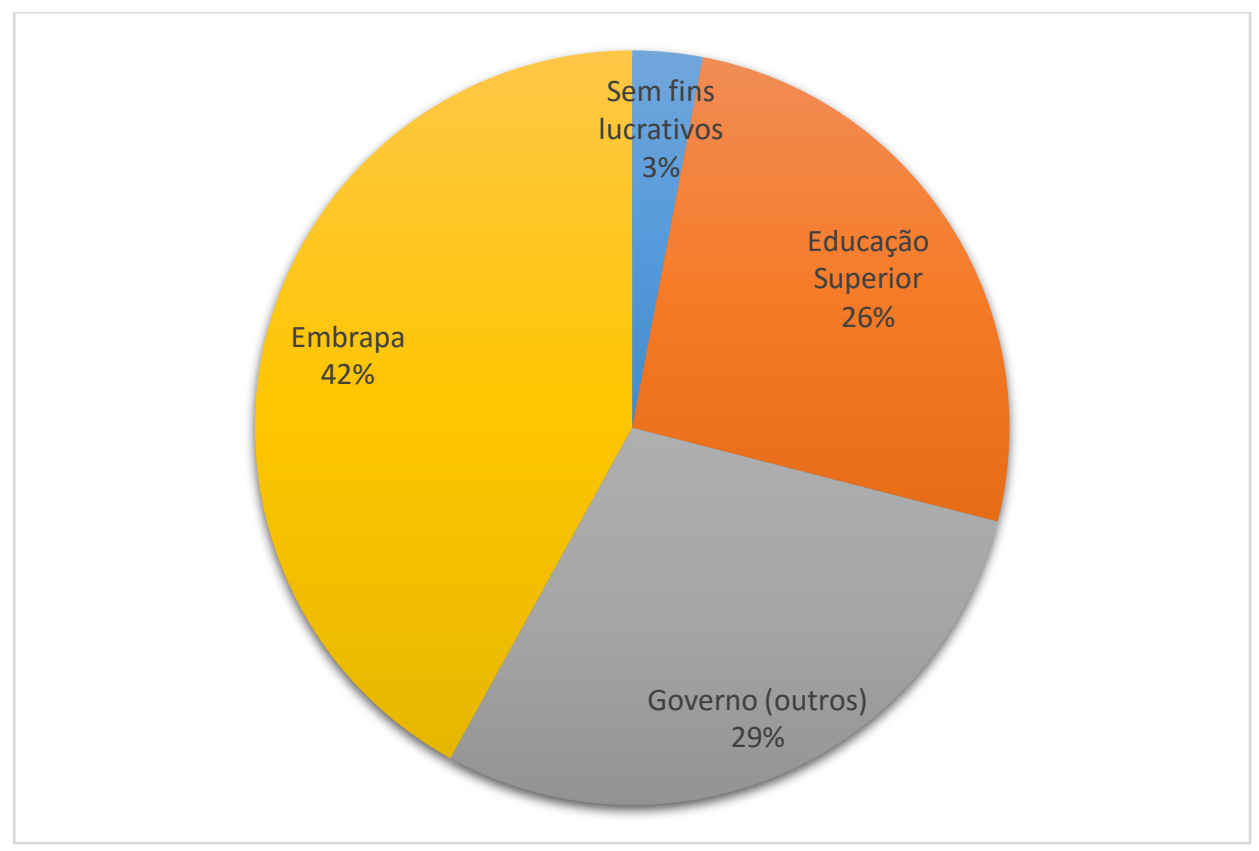

Elaboração: LIRBÓRIO, L.F. 2017

Fonte: ASTI/IFRI, 2017 * a preços constantes de 2011.

A situação apresentada no Gráfico 2 demonstra a importância da pesquisa pública para esse importante setor da economia brasileira. Os dados referentes a investimento por parte do setor privado não foram contabilizados. É preciso considerar que algumas das principais empresas privadas com capacidade de investimento em pesquisa agropecuária são algumas das principais multinacionais, a exemplo da BUNGE, CARGIL, MONSANTO, etc, que possuem seus departamentos de P\&D nos países sedes dessas empresas. Por sua vez um aspecto da maior relevância são as parcerias realizadas entre essas empresas multinacionais com os centros de pesquisa brasileiro, especialmente com a Embrapa.

Além da Embrapa existem duas outras instituições ligadas ao governo federal, que desenvolvem pesquisa agropecuária no país: o Instituto Chico Mendes, ligado ao Ministério do Meio Ambiente e a Comissão Executiva do Plano da Lavoura Cacaueira (CEPLAC), que tem por finalidade fiscalizar as 
atividades desenvolvidas pelo Centro de Pesquisa do Cacau (CEPEC) (BEINTEMA; AVILA; PARDEY, 2001).

De acordo com Beintema; Avila e Pardey (2001) a participação do setor privado no desenvolvimento da pesquisa agropecuária no Brasil é recente, datado a partir da década de 1970. Entre as instituições privadas que desenvolve pesquisa agropecuária destaca-se a multinacional Monsanto que domina o setor de grãos no país, essa empresa comprou algumas empresas brasileiras que realizavam pesquisas, principalmente no setor de sementes de milho e soja, como foi o caso da Agroceres Sementes, que foi comprada pela Monsanto em 1996. Além da Agroceres Sementes a Monsanto, comprou a FT Sementes. Essa prática acaba por fazer com que essas multinacionais detenham o monopólio sobre a produção de sementes no país. Em 1998, a Monsanto comprou mais duas empresas que realizavam pesquisas ligadas aos cultivos de soja, milho e sorgo no Brasil a Brasbabell, que pertencia a multinacional De Kabell e as operações de sementes da também multinacional Cargill.

Além dos institutos de pesquisa agropecuária pública e das empresas privadas identificadas na amostra realizada por Beintema; Avila e Pardey (2001) foram identificadas a partir do fim da década de 1990, algumas organizações sem fins lucrativos que também desenvolvem pesquisa agropecuária, são elas: a Cooperativa de Usinas de Açúcar de São Paulo - COPERSUCAR ${ }^{17}$, o Fundo de Defesa da Citricultura (FUNDECITROS), também em São Paulo; o Instituto Rio Grandensse do Arroz (IRGA); a Fundação de Experimentação de Pesquisa em Trigo (FUNDACET) e a Cooperativa Central Agropecuária de Desenvolvimento Tecnológico de Economia (COODETEC).

Além da missão de viabilizar pesquisa, inovação e desenvolvimento sustentável para agropecuária brasileira, a Embrapa apresenta grande desempenho na realização de pesquisas sobre os biomas de cada região do país, através de suas unidades ecorregionais, com o objetivo de reduzir as diferenças regionais.

É relevante compreender que solucionar os problemas referente as desigualdades regionais é uma tarefa que exige esforços de todos os setores da

17 "A COPERSUCAR é uma das agências líderes na pesquisa de cana-de-açúcar no mundo, incluindo pesquisas sobre variedades de cana geneticamente modificadas". (BEINTEMA; AVILA e PARDEY, 2001. p.32) 
sociedade e que só o esforço dessa instituição não é suficiente. Por isso é tão importante, por exemplo, a atuação articulada entre a Embrapa e as Organizações Estaduais de Pesquisa, pois essas últimas se bem estruturadas poderia ter uma maior eficiência no processo de transferência de tecnologia em uma escala maior, ou seja, chegando, por exemplo, a escala municipal, tornando o desenvolvimento do setor possível ${ }^{18}$.

Contudo, há uma crença por parte de alguns governos estaduais de que cabe ao governo federal os investimentos em pesquisa não só para a agricultura, mas para outros setores também. Essa posição afeta diretamente os resultados que poderiam ser alcançados se houvesse uma maior cooperação entre as esferas de governo, com o propósito de levar o desenvolvimento para a sociedade.

No que diz respeito a pesquisa agropecuária no Brasil a responsável pela coordenação das entidades que desenvolvem pesquisa agropecuária é a Embrapa. Cabe a Embrapa a coordenação do Sistema Nacional de Pesquisa Agropecuária - SNPA. No próximo tópico, faremos uma análise do atual sistema de gestão da pesquisa desenvolvida pela Embrapa, e como esse modelo pode de alguma forma reverter o quadro de dificuldades enfrentadas pelas OEPAs.

2.3. O modelo de Gestão da Pesquisa da Embrapa e a articulação com as Organizações Estaduais de Pesquisa Agropecuária

Administrativamente a Embrapa é constituída por um Conselho de Administrativo composto por seis integrantes: dois representantes do setor público, dois do setor privado o Presidente da Embrapa e o secretário-executivo são indicados pelo MAPA. Os representantes do setor privado são escolhidos pelo Ministro da Agricultura, com base numa lista de candidatos selecionados a partir de seleção pública. Para a implementação das decisões do Conselho Administrativo, a Embrapa possui uma Diretoria Executiva, formada por um Diretor Presidente e três diretores Executivos, todos nomeados com base na indicação do MAPA (BEINTEMA; AVILA; PARDEY, 2001).

$18 \mathrm{Em}$ nossas pesquisas de campo contatamos forte interação entre os pesquisadores da Embrapa Algodão com pesquisadores da EMATER-PB. 
Nas unidades descentralizadas a escolha dos seus dirigentes é feita através de seleção pública na qual qualquer pesquisador da unidade de pesquisa pode concorrer. Mesmo as unidades descentralizadas, possuindo autonomia para a gestão das atividades desenvolvidas, em algumas questões como decisões sobre investimento em infraestrutura, despesas de manutenção, essas decisões são tomadas a nível nacional, pela Diretoria Executiva.

Além da responsabilidade pelo desenvolvimento da pesquisa agropecuária brasileira, a Embrapa é responsável pela coordenação das ações do Sistema Nacional de Pesquisa Agropecuária - SNPA. O SNPA, em sua forma vigente, foi instituído em 1992 pela Portaria no 193 (7/8/1992) do Ministério da Agricultura, autorizado pela Lei Agrícola (Lei oㅡ 8.171, de 17/1/1991). O SNPA é constituído pela Embrapa e suas Unidades de Pesquisa e de Serviços, pelas Organizações Estaduais de Pesquisa Agropecuária (OEPAs), por universidades e institutos de pesquisa de âmbito federal ou estadual, bem como por outras organizações, públicas e privadas, direta ou indiretamente vinculadas à atividade de pesquisa agropecuária. Os objetivos do SNPA são:

1. Compatibilizar as diretrizes e estratégias de pesquisa agropecuária com as políticas de desenvolvimento, definidas para o País, como um todo, e para cada região, em particular.

2. Assegurar constante organização e coordenação das matrizes de instituições que atuam no setor, em torno de programação sistematizada, visando eliminar a dispersão de esforços, sobreposições e lacunas não desejáveis.

3. Favorecer o desenvolvimento de um sistema nacional de planejamento para pesquisa, acompanhamento e avaliação.

4. Estabelecer um sistema brasileiro de informação agrícola, com formação de banco de dados para a pesquisa e desenvolvimento agropecuário, facilitando o acesso aos usuários e clientes da pesquisa agropecuária.

5. Promover o apoio à organização e racionalização de meios, métodos e sistemas com desenvolvimento em informatização das instituições.

6. Proporcionar a execução conjunta de projetos de pesquisa de interesse comum, fomentando uma ação de parceria entre instituições, no desenvolvimento de ciência e tecnologia para a agropecuária.

7. Coordenar o esforço de pesquisa para atendimento às demandas de regiões, estados e municípios, a fim de proporcionar melhor suporte ao desenvolvimento da agropecuária.

8. Promover o intercâmbio de informações e documentação técnicocientífica, nas áreas de interesse comum.

9. Favorecer o intercâmbio de pessoal, para capacitação e assessoramento interinstitucional.

10. Possibilitar apoio técnico, administrativo, material e financeiro entre instituições integrantes, na medida das necessidades e interesses da programação e missões a desempenhar (EMBRAPA, 2012). 
As OEPAs são fundamentais para eficiência do SNPA, porém nos relatórios elaborados pelo Centro de Gestão e Estudos Estratégicos (CGEE, 2006; 2009) foi constatado que as OEPAs estão passando por serias dificuldades financeiras, de recursos humanos e direcionamento de suas pesquisas. Foi verificado também que as OEPAs, participam de poucos projetos em parceria com a Embrapa.

Com o objetivo de reverter essa situação, a partir das principais dificuldades observadas na atuação das OEPAs, foi elaborado sob a coordenação do CGEE em 2009 um projeto que viabilizava alternativas para que as OEPAs, pudessem participar mais ativamente de pesquisas em parceria com a Embrapa, e mesmo a formação de redes de pesquisa entre as OEPAs.

A avaliação da equipe do CGEE, que conduziram a pesquisa sobre a situação das OEPAs, no que diz respeito à participação destas nos Macroprogramas de pesquisas da Embrapa, constatou que a participação das OEPAs, eram mínimas mesmo nos Macroprogramas em que o papel das OEPAs são estratégicos, como os Macroprogramas 4 e 6 , que se destinam respectivamente a pesquisas relacionadas a: Transferência de Tecnologia e Comunicação Empresarial e Apoio ao desenvolvimento da Agricultura Familiar e a Sustentabilidade do Meio Rural (CGEE, 2009).

Antes de seguirmos para em quais Macroprogramas há a participação de OEPAs, é preciso caracterizar cada um dos Macroprograma, em torno dos quais atualmente são desenvolvidas as pesquisas desenvolvidas da Embrapa, por meio do seu Sistema de Gestão Estratégica da pesquisa (SEG).

O SEG foi criado em 2003, em substituição a antiga forma de gestão e planejamento da pesquisa desenvolvida pela Empresa, o Sistema Embrapa de Planejamento (SEP), no qual as pesquisas eram desenvolvidas a partir de projetos com as demanda da sociedade, resultado da tentativa de maior aproximação da Empresa com a sociedade. As principais diferenças entre o SEP e o SEG, foram destacadas por Dossa (2010), conforme podemos constatar no Quadro 7 . 
Quadro 7 - Diferenças entre o Sistema Embrapa de Pesquisas e o Sistema de Gestão Estratégica

\begin{tabular}{|c|c|c|}
\hline \multirow{5}{*}{$\begin{array}{l}\text { Instrumentos de } \\
\text { operacionalização da } \\
\text { programação de } \\
\text { pesquisas. }\end{array}$} & SEP & SEG \\
\hline & $\begin{array}{l}19 \text { Programas Nacionais (16 } \\
\text { de P\&D e } 3 \text { de } \\
\text { desenvolvimento } \\
\text { institucional) }\end{array}$ & $\begin{array}{c}6 \text { Macroprogramas (3 de } \\
\text { P\&D, } 1 \text { de Transferência de } \\
\text { Tecnologia e Comunicação } \\
\text { Empresarial, } 1 \text { de } \\
\text { Desenvolvimento } \\
\text { Institucional e } 1 \text { de Apoio ao } \\
\text { Desenvolvimento da } \\
\text { Agricultura Familiar e à } \\
\text { Sustentabilidade do Meio } \\
\text { Rural) e } 1 \text { Programa } \\
\text { Nacional } \\
\text { de Pesquisa e } \\
\text { Desenvolvimento do Café }\end{array}$ \\
\hline & $\begin{array}{l}\text { Demanda espontânea de } \\
\text { Projetos }\end{array}$ & $\begin{array}{l}\text { Indução de projetos via } \\
\text { Editais }\end{array}$ \\
\hline & $\begin{array}{c}\text { Programas de P\&D } \\
\text { representando temas e } \\
\text { linhas } \\
\text { de pesquisa }\end{array}$ & $\begin{array}{l}\text { Macroprogramas de P\&D } \\
\text { representando caráter } \\
\text { científico e tecnológico e } \\
\text { forma de arranjo da pesquisa }\end{array}$ \\
\hline & $\begin{array}{l}\text { Demandas Prioritárias } \\
\text { estabelecidas anualmente }\end{array}$ & $\begin{array}{l}\text { Demandas Prioritárias } \\
\text { estabelecidas continuamente }\end{array}$ \\
\hline
\end{tabular}

Fonte: DOSSA, 2010.

O SEG é formado por seis Macroprogramas, são eles: Macroprograma 1 (MP1) - Grandes Desafios Nacionais; Macroprograma 2 (MP2) - Competitividade e Sustentabilidade Setorial; Macroprograma 3 (MP3) - Desenvolvimento Tecnológico e Incremental do Agronegócio -; Macroprograma 4 (MP4) Transferência de Tecnologia e Comunicação Empresarial; Macroprograma 5 (MP5) - Desenvolvimento Institucional e Macroprograma 6 (MP6) - Apoio aos Desenvolvimento da Agricultura Familiar e à Sustentabilidade do Meio Rural. Além dos Macroprogramas citados, há um programa exclusivo para a cadeia produtiva do café, denominado Consórcio Brasileiro de Pesquisa e Desenvolvimento do Café (CBP\&D Café). As características de cada um dos Macroprogramas podem ser verificadas a seguir:

O Macroprograma 1 objetiva a gestão de projetos de P\&D de base científica elevada, de caráter transdisciplinar e multi-institucional, que abordam pesquisas estratégicas e exigem para sua execução arranjos institucionais complexos ou grandes redes, bem como a aplicação intensiva de recursos; 
O Macroprograma 2 - objetiva a gestão de projetos de P\&D de base científica aplicada, que abordam pesquisas estratégicas ou eventualmente básicas, de natureza temática ou interdisciplinar, que exigem a formação de clusters, equipes interativas e redes.

O Macroprograma 3 - objetiva a gestão de projetos de P\&D em transferência de tecnologia, organização de informação e viabilização de contratos de prestação de serviços não rotineiros. Prioriza apoio aos projetos finalísticos que possibilitam a concretização dos impactos da pesquisa desenvolvida, em redes pelas equipes do SNPA.

O Macroprograma 4 - tem por objetivo a gestão de projetos e a transferência de tecnologia e de comunicação empresarial, para desenvolver a integração entre atividades de P\&D e o mercado e aprimorar o relacionamento da Embrapa com seus públicos de interesse.

O Macroprograma 5 - tem como objetivo gerir projetos e processos que visem à consolidação e atualização dos instrumentos de gestão estratégica da Embrapa (Planos Diretores, Agenda Institucional e Modelo de Gestão Estratégica Corporativo); a melhoria dos resultados e o aumento da efetividade organizacional, por meio do desenvolvimento de novos processos ou da melhoria incremental ou inovadora dos processos técnicos/administrativos da Unidade/Empresa; o desenvolvimento e a utilização plena do potencial dos talentos humanos da Empresa; a implantação da gestão por processo na Empresa e a realização de ações que visem a adoção dessa forma de organização e divisão do trabalho.

O Macroprograma 6 - tem por objetivo a gestão de projetos para fornecer suporte a iniciativas de desenvolvimento sustentável da agricultura familiar e de comunidades tradicionais, na perspectiva de agregação de valor e, prioritariamente, com abordagem territorial.

O CBP\&D Café - coordenado pela Embrapa, tem a finalidade de conceber e executar a pesquisa e o desenvolvimento do café, referido no protocolo firmado entre o Ministério da Agricultura, Pecuária e Abastecimento (MAPA) e o Ministério do Desenvolvimento, Indústria e Comércio Exterior (MDIC), assinado em Belo Horizonte, em 14 de agosto de 1996. Basicamente, constitui-se na conjugação de recursos humanos, físicos, financeiros e materiais das instituições signatárias, e a captação de recursos adicionais para o desenvolvimento do café no âmbito de competência das instituições, segundo as normas e procedimentos estabelecidos nos termos de constituição e no termo de referência (CGEE, 2009, p. 93-97).

Dos vinte e seis estados brasileiros, apenas 16 possuem OEPAs, fato que dificulta maior dinâmica no SNPA, a não existência de empresas ou instituições de pesquisas a nível estadual, e a falta de direcionamento das pesquisas desenvolvidas pelas empresas que existem, são apontadas nos relatórios do CGEE (2006, 2009) como fatores relevantes para o baixo desempenho dessas instituições, é preciso considera por sua vez que há diferenças organizacionais, culturais significativas entre as OEPAs. 
O próprio fato de só recentemente alguns estados terem criado suas empresas estaduais de pesquisa agropecuária e em bases frágeis, faz com que as diversas OEPAs, possuam desempenho diferenciados no campo da pesquisa agropecuária. Pode-se citar como exemplo a longa experiência do IAC, em comparação com a Universidade Federal do Tocantins, que é a responsável pela execução das pesquisas agropecuárias do Estado do Tocantins. O fato das pesquisas de P\&D Agropecuário, estar sendo desenvolvidos por uma universidade, reforça o papel dessa instituição de Ensino e Pesquisa em países com o sistema nacional de inovação imaturo.

Os estados brasileiros nos quais existe OEPAs, os mesmos possuem apenas uma unidade, com exceção do estado de São Paulo, que possui seis organizações estaduais, evidenciando a hegemonia da pesquisa agropecuária no estado. As dezesseis OEPAs são: a Agência Goiana de Desenvolvimento Rural e Fundiário - Agência Rural; a Empresa Matogrossense de Pesquisa e Assistência Técnica e Extensão Rural S.A. (EMPAER-MT); o Instituto de Desenvolvimento Agrário, Assistência Técnica e Extensão Rural de Mato Grosso do Sul (IDATERRA-MS); a Universidade do Estado do Tocantins (UNITINS); a Empresa Baiana de Desenvolvimento Agrícola S.A. (EBDA); a Empresa de Desenvolvimento Agropecuário do Estado de Sergipe (EMDAGRO); Empresa Estadual de Pesquisa Agropecuária da Paraíba S/A (EMEPA); a Empresa de Pesquisa Agropecuária do Rio Grande do Norte (EMPARN); a Empresa Pernambucana de Pesquisa Agropecuária (IPA); a Agência Paulista de Tecnologia dos Agronegócios (APTA) (Compreende os seis institutos a seguir: Instituto Agronômico de Campinas (IAC), Instituto Biológico (IB), Instituto de Economia Agrícola (IEA), Instituto de Pesca (IP), Instituto de Tecnologia de Alimentos (ITAL) e Instituto de Zootecnia (IZ); a Empresa de Pesquisa Agropecuária de Minas Gerais (EPAMIG); o Instituto Capixaba de Pesquisa (INCAPER); a Empresa de Pesquisa Agropecuária do Rio de Janeiro (PESAGRO); a Empresa de Pesquisa Agropecuária e Extensão Rural de Santa Catarina S.A (EPAGRI); a Fundação Estadual de Pesquisa Agropecuária (FEPAGRO); Instituto Agronômico do Paraná (IAPAR) (EMBRAPA, 2012). No Quadro 8, podemos verificar a distribuição das OEPAs por região geográfica. 
Quadro 8 - Organizações Estaduais de Pesquisa por região geográfica

\begin{tabular}{|l|l|l|l|}
\hline Norte e Centro Oeste & Nordeste & Sudeste & Sul \\
\hline AGENCIA RURAL & EBDA & APTA & EPAGRI \\
\hline EMPAER - MT & EMDRAGO & EPAMING & FEPADRO \\
\hline IDATERRA -MS & EMEPA & INCAPER & IAPAR \\
\hline & EMPARN & PASSAGRO - RIO & \\
\hline & IPA & & \\
\hline
\end{tabular}

Fonte: Embrapa (2012).

Além da inexistência de organizações estaduais de pesquisa em todos os estados do país, nos que existem há pouca interação entre estas e os projetos desenvolvidos pela Embrapa. A constatação da pouca participação das OEPAs nos Macroprogramas foram destacadas pelo CGEE (2009) no qual pode ser constatado que além da baixa integração das OEPAs, mesmo nos Macroprogramas em que há maior necessidade de relações multiinstitucionais as OEPAs em que ocorreram maior número de participação, encontravam-se na região Sudeste. O Consórcio Brasileiro de Pesquisa e Desenvolvimento do Café (CBP\&D Café) foi dos projetos de pesquisa da Embrapa o que contou com maior participação de OEPAs.

De acordo com os dados obtidos pelo CGEE (2009) apenas 13 OEPAs participavam no desenvolvimento de projetos dos Macroprogramas e suas participações davam-se da seguinte forma: no MP1, que engloba mais de uma centena de projetos, em apenas seis projetos foram constatados a presença de quatro OEPAs - o IAPAR, o IAC, a EMPERN, a EMEPA e a EPAGRI; no MP2, em que o tema suscita a formação de redes de pesquisa abrindo possibilidades para as OEPAs, foram constatados a participação das OEPAs em 13 projetos; no MP3, que conta com mais de 500 projetos foi constatado a presença de OEPAs em apenas dois projetos; não há participação devido ao fato deste MP tratar de problemas institucionais da Embrapa. No caso CBP\&D Café, observase uma maior participação de OEPAs em 65 projetos porém concentrados em poucas OEPAs. A participação geral das OEPAs nos projetos dos Macroprogramas e do CBP\&D Café em que há participação de alguma OEPAs podem ser constatados no Quadro 9 a seguir: 
Quadro 9 - Participação das OEPAs nos projetos dos Macroprogramas da Embrapa.

\begin{tabular}{|l|l|l|l|l|}
\hline OEPA & MP1 & MP2 & MP3 & CBP\&D Café \\
\hline EMPARN & 1 & 3 & 0 & 0 \\
\hline EMEPA & 1 & 1 & 0 & 0 \\
\hline IPA & 0 & 3 & 0 & 0 \\
\hline EBDA & 0 & 2 & 0 & 7 \\
\hline EPAMIG & 0 & 5 & 0 & 40 \\
\hline PESAGRO & 0 & 0 & 0 & 4 \\
\hline IAC - SP & 2 & 0 & 0 & 35 \\
\hline INCAPER & 1 & 0 & 0 & 23 \\
\hline IZ-SP & 1 & 0 & 0 & 0 \\
\hline IAPAR & 4 & 1 & 2 & 29 \\
\hline EPAGRI & 1 & 2 & 0 & 0 \\
\hline FEPAGRO & 0 & 2 & 0 & 0 \\
\hline EMPAER & 1 & 0 & 0 & 0 \\
\hline UNITINS & 1 & 0 & 0 & 0 \\
\hline Total & 13 & 19 & 2 & 138 \\
\hline
\end{tabular}

Fonte: Elaboração própria a partir de CGEE, 2009.

A partir da análise dos dados do Quadro 09, é possível verificar o número de projetos nos quais as OEPAs mencionadas participam dos Macroprogramas. No MP1, o destaque é para o IAPAR, com participação em quatro projetos, o IAC, fica em segundo lugar e as demais OEPAs possuem uma ou nenhuma participação no MP1.

No MP2 a EPAMING é a OEPA, que possui maior participação nos projetos desse macroprograma, com participação em cinco projetos, em segundo lugar com participação em três projetos são identificados o IPA e a EPARN, em terceiro lugar com participação em dois projetos foram identificadas a EBDA, a EPAGRI e a FEPAGRO. No MP3, apenas o IAPAR, participa de dois projetos.

A maior participação das OEPAs em Projetos da Embrapa foi constatada no CBP\&D Café, com participação em sessenta e cinco projetos. A EPAMING liderou a participação entre as OEPAs, com participação em quarenta projetos, o IAC participava de trinta e cinco projetos, o IAPAR, ficou em terceiro lugar com 
a participação em vinte e nove projetos e o INCAPER teve a participação em vinte e três projetos.

Como a participação nos Macroprogramas, dar-se através de uma seleção via edital, e a liderança dos projetos necessariamente devem ser de um pesquisador da Embrapa, é fundamental a interação entre os pesquisadores das OEPAs com os da Embrapa. No relatório de 2006 do CGEE, as OEPAs identificavam a Embrapa como uma concorrente e não como uma aliada no desenvolvimento de pesquisas e transferência de tecnologia essa situação de certa forma impede que maiores interações ocorressem entre as OEPAs e a Embrapa.

Um aspecto destacado para a baixa interação entre as OEPAs e a Embrapa refere-se a baixa qualidade das pesquisas desenvolvidas pelas OEPAs, bem como os baixos investimentos em qualificação profissional das organizações estaduais de pesquisa, que em sua maioria encontram-se com o seu quadro de pesquisadores defasados e em alguns casos desatualizados, dificultando maior interação entre a Embrapa e as OEPAs. Por outro lado, considerando que essa articulação é fundamental para eficiência do SNPA é preciso que haja um trabalho intensivo no sentido de aproximar essas instituições.

Em 2008, por meio da criação do Programa de Fortalecimento e Crescimento da Embrapa - PAC - Embrapa, que tem por objetivo a revigorar as ações de pesquisa da Embrapa, uma oportunidade de fortalecimento das OEPAs surgiu, pois entre os dez projetos que fazem parte do PAC - Embrapa um tem por finalidade dar suporte financeiro para o fortalecimento das OEPAs, de uma soma de $R \$ 914$ milhões destinados ao programa, $R$ \$ 264 milhões serão destinados as OEPAs e o restante será investido na própria Embrapa.

É importante, destacar, que só os investimentos por parte da Embrapa, não é suficiente para que as OEPAs exerçam o seu papel dentro do SNPA, pois é preciso que os governantes dos respectivos estados onde se encontram as OEPAs, invistam em uma política mais ofensiva no que se refere a pesquisa agropecuária. 


\section{CAPITILO 3 - O ALGODÃO NO BRASIL: DO PERÍODO PRÉ - TÉCNICO AO PERÍODO TÉCNICO - CIENTÍFICO - INFORMACIONAL}

A história do algodão no território brasileiro, é anterior à colonização do país realizada por Portugal no século $\mathrm{XVI}^{19}$. Assim como o açúcar, que até $\mathrm{o}$ século XVI era considerado artigo de luxo devido à sua raridade, uma vez que a quantidade produzida era pequena, sendo inclusive utilizado como parte de dotes de casamentos e presentes para reis e rainhas, peças feitas de algodão também foram objetos de desejo.

Crônicas cuneiformes fazem alusão a uma rainha asiática que acumulava a renda de dois anos e três meses com o fim de comprar em Babilônia um único vestido de algodão entretecido de ouro e ornado de pedras preciosas (ZISCHKA, 1936, p. 16-17)

A fibra foi considerada "ouro branco", por sua valorização comercial, sobretudo, na segunda metade do século XVIII, devido ao desenvolvimento da indústria têxtil inglesa e consequente aumento na demanda por essa matéria prima $^{20}$. Além de contribuir economicamente, o cultivo do algodão, associado com a pecuária, atividade subsidiária a cana-de-açúcar, foi responsável pela ocupação e fixação de população em vasto território no interior do país, especialmente, no Semiárido brasileiro (SILVA e LIMA 1982; FURTADO, 2005; ANDRADE, 2011).

A produção de algodão no Brasil, como buscaremos demonstrar ao longo desse capítulo, passou por muitas transformações. Nossa intenção é analisar a dinâmica desse produto no território brasileiro. Inspirados nas leituras de Milton

\footnotetext{
${ }^{19}$ Segundo Amaral (1950), o algodão brasileiro já havia sido enviado para a Europa antes da colonização oficial pelos portugueses. Os franceses que desenvolviam escambo com o povo nativo desde antes de 1500 já haviam levado algodão para seu país. Ainda segundo o autor tal fato é uma confirmação de que o território brasileiro já era conhecido pelos europeus antes da chegada da esquadra de Cabral ao litoral baiano.

20 O domínio da técnica de tecer algodão é milenar. A Índia antes da revolução industrial, já possuía indústria têxtil relativamente bem desenvolvida. O desenvolvimento de inovações que tornaram possível a fiação e tecelagem do algodão em larga escala, como a roda de fiar hidráulica, o tear mecânico e o descaroçador foram a base para a indústria têxtil moderna, a qual a Inglaterra foi a nação pioneira. Como forma de proteger e garantir o monopólio da indústria têxtil inglesa, esse país, impôs elevados impostos sob a importação de tecidos indianos. Tal situação gerou grandes problemas para a população indiana que encontrava, no circuito de produção, fonte de emprego e renda. É preciso dizer ainda que o processo de produção dos tecidos indianos era artesanal, enquanto na Inglaterra a partir do século XVIII esse processo vai ser feito por maquinas, e a energia a vapor foi a força motriz empregada (BRAUDEL, 2005).
} 
Santos, que propõe que a Geografia é a filosofia das técnicas, nosso fio condutor é a evolução do sistema técnico de produção dessa cultura, com ênfase para os principais eventos que contribuíram para o aumento da demanda de cultivo desse produto no país, sejam eles internacionais, ou nacionais. Na análise do sistema técnico detivemos nossa atenção para a constituição do sistema de conhecimento científico que possibilitou as metamorfoses dessa cultura.

Partimos do pressuposto de que, assim como o conjunto das atividades relacionadas a agricultura e pecuária brasileira, a cotonicultura se desenvolveu por séculos com pouco conteúdo técnico, seja relacionado aos instrumentos utilizados no cultivo ${ }^{21}$, técnicas de beneficiamento e mesmo da adoção de plantas que apresentassem melhores rendimentos.

A produção do algodão no Brasil, ao longo do tempo sofreu muitas transformações, desde os espaços de produção, a finalidade da matéria prima e sistemas técnicos. O período analisado compreendeu desde o período précolonial, até o presente. Foi dado destaque para o desenvolvimento de pesquisas, melhoramento, e criação de cultivares de algodão naturalmente colorido pelos pesquisadores da Embrapa Algodão ao longo dos últimos vinte e sete anos (1989-2016).

O cultivo de algodão naturalmente colorido marca novo período na história da produção de algodão no país, pois na contramão da hegemonia da produção do algodão branco surge a possibilidade de inserção do algodão colorido. Além da diferenciação na cor esse novo período é marcado pela entrada do país na produção de algodão orgânico, nova tendência mundial, ainda que a escala de produção seja muito reduzida ${ }^{22}$.

\footnotetext{
${ }^{21}$ Os instrumentos técnicos utilizados consistiam no uso da enxada, para abrir as covas onde são depositadas as sementes, a foice empregada no processo de poda das plantas, quando se tratava de variedade de algodão perene e arado movido à tração animal para gradear a terra.

${ }^{22} \mathrm{Em} 1989$ tem início na Embrapa Algodão, o Programa de Melhoramento Genético do Algodão Colorido. As primeiras cultivares foram disponibilizadas para cultivo comercial em 2000 , contudo o conhecimento da existência de algodão nativo naturalmente colorido no país, remonta ao século XVIII. Em 1779 o botânico Manuel Arruda da Camara em sua "Memória sobre a Cultura dos algodoeiros e sobre methodo de escolher e ensacar, etc." ao falar das variedades de algodão existentes na Colônia já citava a existência de algodões silvestres de fibra colorida, a variedade "macaco" cor de ganga e uma variedade que também apresentava fibra colorida. Camara (1779),fala ainda das limitações de uso desse tipo de algodão, pois a coloração natural da fibra dificultava o processo de branqueamento e tingimento "há outra variedade de algodoeiro bravo, com o fruto maior, com a lã da mesma cor de gânga: tanto esta, como a variedade chamada de macaco, não pode servir para chitas, nem outras obras, que levem tinta; porque está côr parda he tão aderente, que resiste à operação do embranquecimento, e nem aceita outra côr artificial, sem se lhe tirar aquela natural." (CAMARA, 1779, p. 115).
} 
Assim, buscamos identificar e analisar eventos ${ }^{23}$ que de alguma forma contribuíram para o surgimento de iniciativas no sentido de aperfeiçoar essa cultura e que, ao longo do tempo proporcionaram a formação de um sistema de pesquisa para o setor. Por sua vez compreende-se que tal situação faz parte de um todo mais complexo, que é a formação sócio espacial brasileira.

As atividades produtivas do Brasil se desenvolvem a sombra das necessidades dos países desenvolvidos, configurando o que Santos (1978), baseado em Max Sorre, chama de paisagem derivada, ou seja, havia um centro emissor de ordens e um centro receptor, de tal forma que na divisão territorial do trabalho cabia ao Brasil a oferta de produtos agrícolas e o algodão foi um desses produtos.

A dimensão temporal indispensável à análise do espaço geográfico conforme Santos (2008 [1985], p. 36), foi considerada em nossa análise, pois como propõe o autor os acontecimentos internos a uma formação socioespacial, muitas vezes são definidas na escala global, especialmente no caso dos países subdesenvolvidos.

A introdução da dimensão temporal no estudo da organização do espaço envolve considerações numa escala muito ampla, isto é a escala mundial. O comportamento dos subespaços do mundo subdesenvolvido está geralmente determinado pelas necessidades das nações que estão no centro do sistema mundial (SANTOS, 2008 [1985], p. 36).

Assim adotamos a proposta de periodização dos usos do território brasileiro desenvolvida por Santos e Silveira (2011). Os autores citados compreendem o território usado como sinônimo de espaço geográfico. O Espaço geográfico de acordo com Santos (2008 [1996]) é um conjunto indissociável de sistemas de objetos e de sistemas de ações. Os objetos podem ser tanto de ordem natural, quanto artificiais. Os objetos naturais são aqueles disponíveis na

\footnotetext{
23 A compreensão de evento adotada para fins dessa pesquisa tem como referência as proposições do Geógrafo Milton Santos, para quem os eventos são acontecimentos que se destacam em um determinado contexto histórico e geográfico, espaço - temporal, capazes de provocar mudanças em uma dada realidade. Esses eventos podem ser de ordem natural ou acontecimentos sociais, são singulares e não se repetem. Segundo Santos (2008, p. 145 [1996]) "Quando falamos num evento passado, é de sua presença anterior num dado ponto da flecha do tempo, de um 'presente passado' que estamos falando. Quando falamos dum evento futuro, é de uma suposição que estamos falando, a suposição de que se realizará num presente futuro.
} 
natureza e sua existência não é resultado da ação humana, a exemplo dos rios, das plantas, etc., ainda que estes, nos dias atuais, cada vez mais sofram intervenções técnicas.

Exemplos claros de intervenções técnicas e constituição de objetos cada vez mais artificiais, é o próprio melhoramento genético realizado em plantas e animais, capazes de gerar novas espécies, verdadeiros híbridos. Tal prática foi ainda mais ampliada a partir da segunda metade do século $X X$ com 0 desenvolvimento das ciências, como a Engenharia Genética e da Biotecnologia, que tem transformado substancialmente as condições de produção e mesmo da vida.

Os sistemas de ações são as intencionalidades, as ideias. São realizadas pelas pessoas em determinada situação, com objetivos. O sistema de ações envolve as relações sociais, do qual fazem parte as normas, regras, instituições, cultura, etc.

Santos e Silveira (2011) analisam o meio geográfico brasileiro a partir de três grandes períodos, de acordo com a presença e uso das técnicas, já que a ação do ser humano no espaço se dá mediada pela mesma. Os referidos períodos são: pré-técnico ou natural, período técnico e período técnico científico - informacional.

Período natural, ou pré - técnico - nesse período as relações entre os seres humanos e a natureza se dão de forma mais "harmoniosa". As intervenções do trabalho humano, são mais limitadas, pois as técnicas de que dispõe são reduzidas, e as ações das pessoas no espaço sofrem maior influência do meio natural. A própria circulação no território nesse período era muito restrita, e o corpo humano se constituía ele mesmo em fator técnico, transpondo as dificuldades de deslocamento e descobrindo novos meios de intervir na natureza de forma a atender suas necessidades.

O período técnico - nesse período já se constata maior presença técnica, mas a mesma estava circunscrita a alguns pontos do território, sobretudo nos lugares e cujas atividades econômicas estavam voltadas para atender demandas externas. Essa situação se deve às bases da formação histórica e econômica brasileira, enquanto fornecedora de bens primários de 
elevado valor, como: o açúcar, o ouro, o algodão, o cacau entre outros, se desenvolvendo a sombra dos interesses de Portugal e de outros países desenvolvidos.

Assim os principais centros fornecedores de produtos foram sendo equipados, mas como os espaços de produção não são homogêneos os objetos artificiais (estradas, portos, indústrias, etc.) foram se concentrando em pontos do território, resultando na formação de vários meios técnicos, um "arquipélago de mecanização incompleta" (SANTOS; SILVEIRA, 2011).

O período técnico - científico -informacional - tem como marco inicial o período pós Segunda Guerra Mundial (1945), o mesmo é caracterizado por grandes inovações técnicas, entre as quais merecem destaque 0 desenvolvimento dos sistemas de transporte, de comunicação e de informação. O desenvolvimento dos sistemas técnicos tornou possível o acesso a informação dos mais diversos lugares em tempo real, fato que em tempos anteriores eram inimagináveis. Essa situação muda substancialmente as formas de produção e as dinâmicas econômicas, cada vez mais globais.

Ainda segundo Santos (2008[1996]), na atualidade, há uma universalização das técnicas, uma verdadeira globalização, mas no processo de globalização os lugares se diferenciam, pois, cada território possui condições únicas, tais como formação cultural, normas, valores e instituições. Benko (2001, p. 40) é da mesma opinião, de que a globalização não promove a homogeneização dos lugares.

Com base na compreensão do que caracteriza o meio geográfico de acordo com os períodos estabelecidos acima; buscamos fazer correlação com a produção algodoeira no Brasil. O marco temporal envolveu (1) do período précolonial aos primeiros séculos de colonização; (2) segunda metade do século XIX (1861-1875); (3) primeira metade do século XX (1930 -1983); (4) 19831992); (5) 1992-2000; e (6) (2000 - 2016).

Orientados pela compreensão, do que caracteriza os macros períodos compreendidos por Santos e Silveira (2011), meio pré-técnico, técnico científico e técnico-científico - informacional, procuramos definir subperíodos, arbitrados 
pelo propósito da pesquisa que é analisar os principais momentos da lavoura algodoeira no país.

O primeiro período é marcado por um longo intervalo de tempo, em que as práticas de produção estavam mais ligadas à coleta, roças itinerantes, ou roçados. Com a chegada dos portugueses e consequente colonização, há uma demanda maior pelo algodão para produção de tecidos, mas ainda as técnicas empregadas, eram as dominadas pelos nativos, e a produção era de subsistência.

O segundo período teve como referência principal o período da Guerra da Secessão (1861-1865) embora a Guerra tenha durado até 1865, não é de forma imediata que se reorganizam os mercados norte-americanos e europeu, assim alongamos nossas análises até o ano de 1875, quando a exportação do algodão brasileiro perde importância e a produção algodoeira se volta para as necessidades internas do país.

A referida Guerra provocou o segundo surto de produção de algodão no país. Esse evento também marca a introdução de novas técnicas de produção, especialmente em São Paulo, por conta da entrada de imigrantes vindos do Sul dos Estados Unidos. Além dos imigrantes norte-americanos, merece atenção a intervenção inglesa, através da Associação para o Suprimento do Algodão de Manchester (Manchester Cotton Supply Association) que com o propósito de assegurar matéria prima para as indústrias inglesas, foi responsável pela introdução de novas variedades de algodão no Brasil.

A Sociedade Auxiliadora da Indústria Nacional, também foi relevante na articulação dos interesses dos produtores nacionais. Nos chamou atenção ainda a criação de uma fazenda experimental, a Fazenda São Carlos no município de Itu na província de São Paulo, a mesma serviu como espaço de divulgação de melhores práticas agronômicas, da cultura algodoeira e de outras culturas agrícolas.

O terceiro período tem como referência inicial a década de 1930. período marca um novo surto na produção nacional de algodão, com destaque para o estado de São Paulo, devido à crise econômica mundial que culminou internamente na crise do café abrindo espaço para outras culturas. Esse período 
é referência no processo de modernização da cultura no estado paulista, a partir das ações do Instituto Agronômico de Campinas (IAC) e da Bolsa de Mercadorias e Valores de São Paulo. Para o mesmo período, constatou-se que no Nordeste a produção de algodão, se manteve com poucas mudanças, ainda que respondesse pela maior área cultivada, com destaque para o algodão de fibra longa, chamado mocó. Tomamos como marco para o fim desse período os primeiros anos da década de 1980, especificamente 1983 com a introdução da praga do bicudo (Anthomonus grandis Boheman), no país.

Consideramos a criação do Centro Nacional de Pesquisa de Algodão (CNPA) - Embrapa Algodão em 1975, o evento na direção de grandes transformações na lavoura algodoeira nacional, contudo preferimos delimitar o quarto período a partir de 1983, porque entendemos que a crise provocada pela introdução da praga do bicudo, foi a base para a transformação da renovação da cultura algodoeira no país ${ }^{24}$.

$O$ quinto período teve como referência $o$ ano em que foi desenvolvida a cultivar CNPA ITA 1992, desenvolvida pela Embrapa Algodão. Essa cultivar foi desenvolvida para as condições edafoclimáticas do Cerrado e marca a renovação da cultura algodoeira no país que se dará em novas bases de produção, predominará a racionalidade na produção e o país retoma o posto de grande exportador mundial dessa fibra.

O sexto período teve como referência, a disponibilização para cultivo comercial de cultivares de algodão naturalmente colorido, resultado de pesquisas também desenvolvida por pesquisadores da Embrapa Algodão. Assim delineamos que a partir do ano 2000 há no país dois principais sistemas de produção de algodão: a produção do algodão branco, produzido em grande escala, concentrado no Bioma do Cerrado brasileiro; a produção de algodão branco em sistema convencional, com o uso de insumos químicos também é realizado por pequenos e médios produtores e a produção desenvolvida em

\footnotetext{
${ }^{24}$ A praga do bicudo no território brasileiro, inicialmente atingiu as produções de algodão do município de Campinas -SP. Esse município na época era um dos principais centros de produção desse produto. Há pesquisadores que acreditam que essa praga foi introduzida no país de forma proposital, para prejudicar a produção algodoeira do país.
} 
pequenas propriedades por agricultores familiares, de algodão orgânico, seja o colorido ou o branco.

O último período a ser analisado trata da recuperação da cotonicultura brasileira nos anos 1990, período em que sua produção passou a ter grande aporte dos recursos técnicos-científicos-informacionais, e grande inversão de capitais, na frente de expansão da agricultura no bioma Cerrado. Principalmente nos estados de Mato Grosso, Goiás e Bahia, e outros locais que se mostraram mais susceptíveis a adoção das novas materialidades da agricultura científica globalizada.

Segundo Santos (2001) as atividades agrícolas cada vez mais se fazem a partir do uso da ciência, da tecnologia e da informação de forma a aumentar a produtividade de um produto, em uma área menor, e essa atividade está cada vez mais integrada com outros setores, sofrendo influências das mesmas leis que regem outros aspectos da produção econômica. E em algumas partes do território nordestino ${ }^{25}$ que constituem de acordo com Elias (2011) novas Regiões Produtivas Agrícolas (RPAs). Segundo a autora as RPAs são:

\begin{abstract}
Os novos arranjos territoriais produtivos agrícolas, os territórios das redes agroindustriais, escolhidos para receber os mais expressivos investimentos produtivos inerentes ao agronegócio globalizado, representando suas áreas mais competitivas. Nelas encontram-se partes dos circuitos espaciais da produção e círculos de cooperação de importantes commodities agrícolas, evidenciando a dinâmica territorial do agronegócio (ELIAS, 2011. p. 157).
\end{abstract}

O processo de retomada da produção do algodão no Brasil e no Nordeste em particular, não ocorre de forma homogênea, pois a força dos atores sociais não são simétricas, de tal forma que é preciso pensar como na atual fase se inserem os agricultores familiares, sejam os proprietários de terras, ou aqueles que se encontram em assentamentos de reforma agrária e dispõe de poucos recursos financeiros e técnicos, mas que historicamente tiveram na cultura algodoeira um importante componente de sua renda ${ }^{26}$.

\footnotetext{
${ }^{25}$ São exemplos desses lugares do agronegócio globalizado o Oeste Baiano, com destaque para as cidades de Luiz Eduardo Magalhães e Barreiras, grandes produtores de soja e algodão. Recentemente, constata-se a inserção de territórios pertencentes aos estados do Piauí, Maranhão e Tocantins, formando a região de produção denominada MAPITOBA .

${ }^{26}$ Segundo Freire e Beltrão (2008) no Brasil até a década de 1980 se distinguiam dois perfis de produtores de algodão: um de base familiar, concentrado principalmente na região Nordeste e outro com perfil empresarial, concentrado no Centro-Sul do país. Na região Nordeste os autores
} 
Nesse sentido investigar a inserção da produção de algodão naturalmente colorido no estado da Paraíba, resultado de ação planejada pelo Estado, através da Embrapa Algodão em parceria com agentes econômicos e sociais, é uma possibilidade de compreender como uma tecnologia e uma política pública podem modificar a realidade desses agricultores. Avaliar como os mesmos se inserem nesse novo circuito espacial de produção diferenciado, já que o produto por eles cultivado carrega componentes de conhecimento especializado, agregando valor ao produto, com forte apelo ecológico e social.

Procuramos dar ênfase às inovações alcançadas pela produção algodoeira em seu processo de modernização, e o papel que o Estado brasileiro desempenhou ao longo do tempo. Nesse sentido compartilhamos das ideias propostas por Suzigan e Albuquerque (2008; 2011), para os quais a produção de conhecimento científico no Brasil ocorreu de forma lenta e concentrada em alguns setores.

Os autores (op. cit., p. 18-19) procuraram compreender a insignificante interação o do setor produtivo e a infraestrutura de ciência e tecnologia brasileira a partir de uma perspectiva histórica na qual identificam três fatores principais para tal situação: (1) criação tardia de instituições de ensino superior e pesquisa no país, (2) industrialização retardatária e (3) tardio início das instituições monetárias e financeiras no Brasil. Essa tríade contribuiu para existência de interações entre o sistema de Ciência \&Tecnologia apenas em alguns casos isolados. O algodão é um desses casos no qual o Brasil, possui expertise, e duas das principais referências na pesquisa desse produto, são empresas públicas de pesquisa: o Instituto Agronômico de Campinas (IAC) e a Embrapa, através de sua unidade de pesquisa descentralizada, Embrapa Algodão, com sede na cidade de Campina Grande - Paraíba.

destacam ainda, o fato de muitos dos agricultores familiares não disporem da propriedade da terra e cultivarem em regime de parceria com grandes proprietários de terras da região. 


\section{1 - Algumas considerações sobre o Algodão}

Algodão é o nome dado ao tecido, a fibra e a planta que o produz. É uma fibra natural, e principal matéria prima da indústria têxtil moderna. É considerado uma planta trina, pois além do uso da pluma seu principal produto comercial, possui em suas sementes elevada quantidade de óleo, constituindo-se importante oleaginosa, com potencialidades para geração de biodiesel, as suas sementes com a ausência do gossipol (substancia tóxica) podem ser utilizadas na alimentação humana (BELTRÃO et al., 2008[1999]).

Segundo Santana et al. (1997) o algodão é considerado uma das plantas de aproveitamento mais completo:

Em razão da enorme gama de aplicação de seus produtos e subprodutos, especialmente a fibra que, em virtude, das características intrínsecas, comprimento, uniformidade de comprimento, finura, maturidade, resistência, alongamento, com e sedosidade, se transfere para os fios, tecidos e confecções, dando-lhes diversidade de aplicação, beleza e sensação de bem-estar a quem as usa (SANTANA, et al. 1997,p. 1).

O algodão pertence ao gênero Gossypium e existe na natureza 52 (cinquenta e duas) espécies, dessas apenas 4 (quatro) foram domesticadas e são utilizadas pela humanidade, as demais são espécies silvestres. São chamadas silvestres as espécies que não possuem valor econômico, pois não possuem línter, ou seja, fibras nas sementes ou quando existe são tão curtas que não são viáveis para fiação.

As espécies cultivadas são: Gossypium herbaceum L. , Gossypium arboreum L., Gossypium barbadense L, Gossypium hirsutum L.. As duas primeiras são nativas dos continentes Asiático e Africano, e as duas últimas são nativas do Novo Mundo, o continente Americano. O Gossypium herbaceum, possui fibras curtas e já teve grande importância comercial, atualmente é plantada apenas em algumas regiões secas da África e da Ásia. O Gossypium arboreum $L$. tem valor comercial e é plantado na Índia, também possui fibras curtas. O Gossypium barbadense $L$. é muito apreciado comercialmente, pois possui fibras longas e extralongas, possui ciclo de produção perene e seu centro de origem geográfica seria o litoral Norte do Peru. O Gossypium hirsutum L. possui fibras médias, e atualmente é a principal espécie cultivada (CARVALHO, 2008). 
Essas quatro espécies são responsáveis por toda a produção mundial de algodão. As espécies $G$. herbaceum L. e a $G$. arboreum L. respondem por $6 \%$ da produção, o $G$. barbadense $L$. por $12 \%$ e o $G$. hirsutum a mais consumida, responde por $82 \%$ dessa matéria prima (CARVALHO, 2008; SOUZA; PEIXOTO; TOLEDO, 1995).

As espécies cultivadas comercialmente no Brasil são do gênero Gossypium hirsutum $L$. das raças marie galante e Gossypium hirsitum L. r. latifolim de ciclo anual. A raça marie galante é produzida nos estados do Nordeste, e é conhecida popularmente como algodão "mocó", ou Seridó, possui como características: plantas de porte alto $(3-4 \mathrm{~m})$, arbustivas, semiperenes (3-6 anos), frutos pequenos, em pequena quantidade, e sementes com pouco ou nenhum línter, fibras longas e extralongas (maiores que $36 \mathrm{~mm}$ ) (ver, Figura 5). A raça latifolium é encontrada, principalmente no Sul do Brasil, são plantas de porte baixo $(1,2 \mathrm{e}$ 1,5 m), arbustivas, de ciclo anual, capulhos grandes e em grande quantidade, fibras médias e totalmente cobertas por línter (SOUZA; PEIXOTO; TOLEDO, 1995).

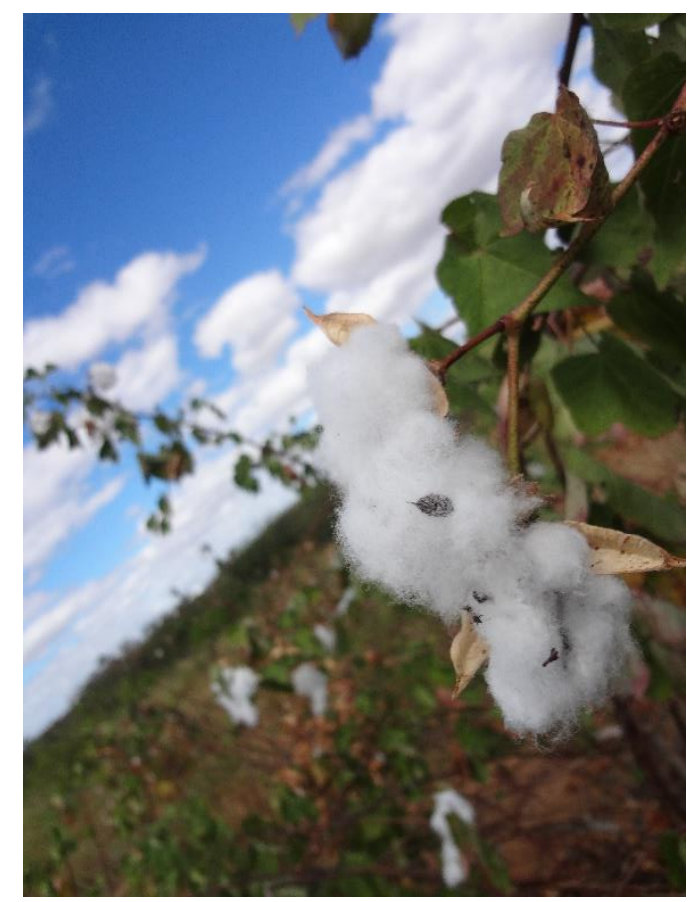

Figura 5 - Algodão Mocó (Gossypium hirsutum L.marie galante)

Foto: LIRBÓRIO, 2015.

Local: Campo Experimental da Embrapa Algodão - Patos-PB. 
As características da fibra do algodão são extremamente importantes para a indústria têxtil moderna. A resistência da fibra é condição indispensável no processamento industrial, pois as máquinas modernas devido à velocidade de rotação precisam de fibras resistentes, e esse é um dos argumentos utilizados para explicar o reduzido uso de variedades de algodão colorido, pois estes possuem fibras curtas, ásperas e pouco resistentes.

Ainda em relação ao tamanho das fibras é preciso considerar que o algodão utilizado inicialmente na indústria têxtil inglesa era proveniente dos Estados Unidos, da variedade G. hirsitum de fibras médias, então às máquina de fiar e tecer tinham como referências as características desse tipo de algodão. Assim, conforme será analisado adiante, quando houve a crise no fornecimento do algodão dos Estados Unidos para a Europa, período em que foi estimulada a produção de algodão em outros lugares do mundo, entre os quais a Índia (que já possuía uma indústria têxtil desenvolvida) foi necessário fazer a adaptação das máquinas utilizadas na fiação pois, o algodão indiano possuía fibras curtas (CANABRAVA,2011 [ 1951]; BELTRÃO et al., 2008[1999]; BRAUDEL, 2005).

O algodão mocó foi sem sombra de dúvidas a variedade de maior relevância na cultura algodoeira do Semiárido brasileiro, até os anos 1980, sobretudo na região do Seridó que envolve parte do Sertão da Paraíba e do Sertão do Rio Grande do Norte. As condições ambientais do Semiárido favorecem o bom desenvolvimento das características dessa planta que é muito resistente a altas temperaturas e a seca.

(...) O Polígono das secas, que compreende mais de $58 \%$ do total do Nordeste brasileiro, ou seja $950.000 \mathrm{Km}^{2}$ e onde, via de regra, ocorrem problemas com a distribuição irregular das chuvas e déficit hídrico, os vegetais e animais, devido à escassez de água nessa região, evoluíram e se adaptaram a essas irregularidades climáticas, caracterizadas por temperatura elevada, pequena variação média anual de 23 e $27^{\circ} \mathrm{C}$, a insolação alcança valores de 2.800 horas/ano, com densidade de fluxo radiante acima de $\mathrm{cal} / \mathrm{cm} \%$ dia e luminosidade acima de 100.000 lux nos dias claros e chuvas concentradas em um único período do ano, com precipitações medias anuais entre 400 e 800 mm (Duque, 1973,1980; Pontes, 1975; Santana, 1994, Beltrão, 1995).

Essas variáveis climatológicas proporcionam a formação e obtenção de fibra de excelente qualidade, com características físicas, como comprimento, finura, maturidade, resistência, alongamento, reflectância, e grau de amarelecimento com valores excepcionais, com valores iguais aos valores dos melhores algodões do mundo, como o do Peru, Egito e Sudão, com fibra longa e extra-longa (SANTANA, et al., 1997, p. 1-2). 
No mercado mundial do algodão há uma classificação da pluma do algodão de acordo com as características de cor, tamanho da fibra, resistência e finura. Os mais apreciados são os que possuem coloração mais branca ${ }^{27}$, fibras longas, resistentes e finas.

Além de possuir fibras longas e resistentes, o algodão mocó é altamente tolerante à seca, fator que permitiu o seu cultivo em amplas áreas do Semiárido nordestino. A resistência dessa variedade aos grandes períodos de seca é destacada por Freire e Barreiro Neto (1983, p. 4) " A seca de 1877 provocou a morte da maioria das plantações de algodão do Nordeste, restando apenas algumas raízes de um algodão posteriormente conhecido como 'mocó' na região do Seridó do Rio Grande do Norte".

$\mathrm{Na}$ literatura científica há divergências quanto à possível origem do nome mocó. Para Martins (1946 apud Moreira et. al, 1989) essa denominação tem origem no nome dado a sementes de algodão provenientes da Suíça, introduzidas no Rio Grande do Norte entre 1886 e 1896, chamada de Mako (pronuncia figurada de Makô). Faria Melo, também citado por Moreira et. al.,(1989) afirma que a palavra mocó é uma corruptela do nome Makô, e que esse algodão seria uma variedade de algodão egípcio introduzido no Rio Grande do Norte, no século XIX. Há ainda quem acredite que a origem no nome mocó, tem a ver com a semelhança entre as sementes do algodoeiro com o excremento de um roedor existente na região e que possui o mesmo nome (MOREIRA, et. al., 1989).

Essa variedade não suscita dúvidas apenas em relação a origem do seu nome mais inclusive de sua origem geográfica. Há quem afirme que sementes dessa planta tenham sido introduzidas no Nordeste em diversas épocas, outros afirmam que a mesma seria nativa da região do Seridó. Para Moreira et. al, 1989 a segunda opção parece mais verdadeira:

A hipótese mais provável parece ser mesmo a que defende ser este
algodoeiro nativo do Seridó, onde foi registrado pela primeira vez mais
ou menos em 1860 . Sua presença foi aí notificada pelo capitão
Francisco Raimundo, que afirma tê-lo visto nas trincheiras de serrote
do lugar denominado "Olho D' Água da Siriema", em Acari, Rio Grande
do Norte Moreira et. al, 1989, p. 6).

Devido as características apresentadas nessas raças, especialmente no que se refere ao seu ciclo de produção, qualidade e tamanho das fibras

\footnotetext{
${ }^{27}$ Mesmo os algodões de fibra branca passam por processos de alvejamento.
} 
convencionou-se no Brasil a chamar o algodão de ciclo perene, de algodão arbóreo, e o algodão de ciclo anual de herbáceo. Essa situação de acordo com Souza, et al. , (1995), gera confusão quanto a espécie, já que o arbóreo não diz respeito a $G$. arboreum $L$. e o herbáceo não tem a ver com a espécie $G$. hebaceum $L^{28}$.

No Brasil há duas representantes da espécie $G$. barbadense L., o rim-deboi e o macaco. A primeira variedade citada foi amplamente cultivada no Nordeste brasileiro nos primeiros anos de exploração da cultura algodoeira. $O$ algodão macaco, que possui fibra de cor marrom, era utilizado para artesanato e devido ao interesse comercial pelo algodão branco, sua produção foi muito restrita, levando até recentemente ao desconhecimento de sua existência no país pela maior parte da população.

Essa situação como melhor analisaremos será modificada a partir do aproveitamento econômico de cultivares de algodão de fibra naturalmente colorida, resultado das pesquisas de melhoramento genético realizado no Centro Nacional de Pesquisa do Algodão (CNPA) - Embrapa Algodão.

A primeira variedade tem esse nome, porque suas sementes são soldadas e sem línter, lembrando o rim bovino, possui fibras curtas e ásperas, sendo facilmente descaroçado manualmente. São encontrados nos sertões brasileiros e possuem porte alto. $O$ algodão macaco ocorre principalmente nos estados do Mato Grosso e do Mato Grosso do Sul, apresentando fibras curtas e de coloração ferruginosa, sementes isoladas e recobertas por línter, também colorido (SOUZA, et al., 1995).

No Quadro 10 podemos verificar algumas espécies silvestres de algodão e seus respectivos centros de origem. Na Figura 6 são indicadas as áreas de preservação de espécies nativas brasileiras de algodão silvestre. É encontrado algodão mocó, nos estados do Rio Grande do Norte e Bahia, assim como também a espécie $\mathrm{G}$. mustelinum. ${ }^{29} \mathrm{O}$ algodão $\mathrm{G}$. barbadense é encontrado em ampla extensão do território nacional, como o litoral e porções mais interioranas.

\footnotetext{
${ }^{28}$ Mesmo considerando que as denominações de algodão arbóreo e herbáceo, não são corretos do ponto de vista da taxonomia das plantas, as mesmas serão adotadas para fins dessa pesquisa, devido ao seu amplo uso no país e na literatura científica brasileira sobre o assunto.

${ }^{29}$ A variedade G. mustelinum é endêmica do Nordeste do Brasil.
} 
O grande número de lugares em que há ocorrência e preservação de algodão da variedade $G$. barbadense se deve ao fato de nos processos migratórios agricultores levarem consigo sementes desse algodão. 
Quadro 10 - Espécies de algodão silvestre e seus centros de origem geográfica

\begin{tabular}{|c|c|}
\hline Espécie de Gossypium & Centro de Origem \\
\hline G. arboreum & África \\
\hline G. herbaceum & Arábia \\
\hline G. anomalum & África \\
\hline G. truphillum & África \\
\hline G. trifurcatum & África \\
\hline G. bricchet tii & África \\
\hline G. benadirense & África \\
\hline G. papits - viridis & Ilha de Cabo Verde \\
\hline G. sturtianum & Austrália \\
\hline G. nandewarense & Austrália \\
\hline G. robinsonii & Austrália \\
\hline G. australe & Austrália \\
\hline G. costulatum & Austrália \\
\hline G. cunninghmii & Austrália \\
\hline G. nelsonni & Austrália \\
\hline G. pilosum & Austrália \\
\hline G. populifolium & Austrália \\
\hline G. puchelum & Austrália \\
\hline G. entryle & Austrália \\
\hline G. exiguum & Austrália \\
\hline G. londorriense & Austrália \\
\hline G. marchantii & Austrália \\
\hline G. nobile & Austrália \\
\hline G. rotundifolium & Austrália \\
\hline G. klotzschianum & Ilhas Galápagos \\
\hline G. riamondii & Peru \\
\hline G. aridum & México \\
\hline G. armourianum & México \\
\hline G. davidsonii & México \\
\hline G. gossypioides & México \\
\hline G. harknessii & México \\
\hline G. laxum & México \\
\hline G. lobatum & México \\
\hline G. schuendimanii & México \\
\hline G. thurberi & México \\
\hline G. trilobum & México \\
\hline G. turneri & México \\
\hline G. stocksii & Arábia \\
\hline G. somalense & Arábia \\
\hline G. areysianum & Arábia \\
\hline G. longicalyx & África \\
\hline G. tomcntosum & Havaí \\
\hline G. mustelinum & Brasil \\
\hline G. darwinii & Ilhas Galápagos \\
\hline G. lancelolatum & México \\
\hline
\end{tabular}

Fonte: GIL (apud FREIRE, 2000, p. 13-14).

Adaptação: LIRBÓRIO, Lucia Ferreira.2016. 
Figura 6 - Regiões de preservação de espécies de algodão G. barbadense, G. mustelinum e G. hirsirum marie galante no Brasil.

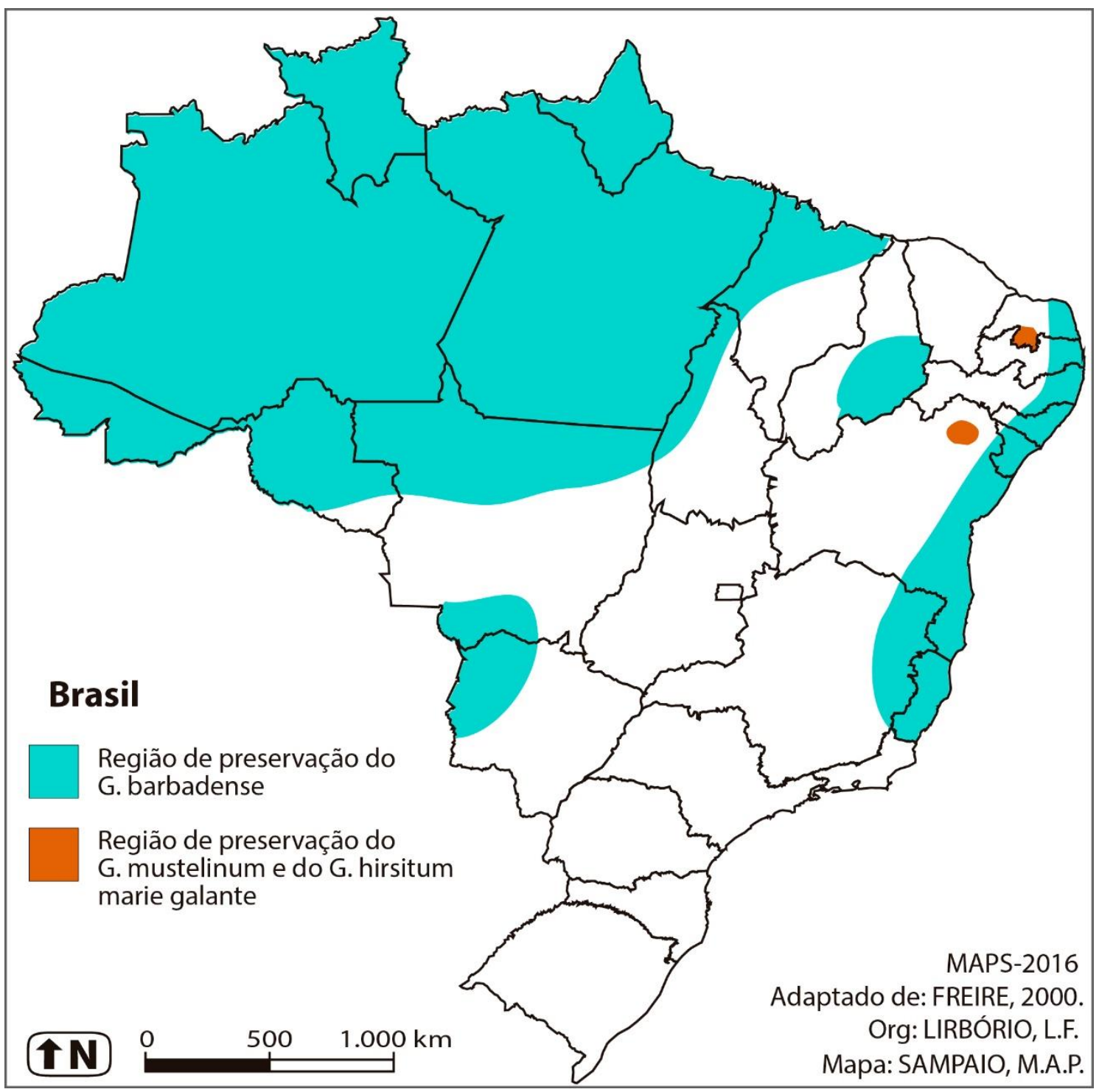

3.2 - O algodão brasileiro no período pré-técnico: do período pré-colonial aos primeiros séculos de colonização

A escala temporal de produção do algodão no período pré-técnico compreende desde a fase em que o algodão nativo era coletado pelos índios, e cultivado em roçados pelos que já praticavam a agricultura, pois sabe-se que a maioria das comunidades indígenas era formada por coletores e caçadores, nos 
primeiros séculos da colonização. Como marco final desse período estabelecemos o início do surto de produção de algodão no país em $1861{ }^{30}$.

Compreende-se que a produção do algodão nesse longo período se dá sem grandes intervenções técnicas, ainda que a própria agricultura seja um fenômeno técnico complexo. Nesse período as práticas agrícolas são desenvolvidas, sobretudo, amparadas nos fatores naturais de produção, como solo, clima, temperatura, relevo, disponibilidade de terras para ampliação da produção, já que a introdução nem mesmo de adubos naturais eram comuns nesse período.

\begin{abstract}
O despontar da agricultura foi também sinônimo de desmatamento, todavia esse processo não significou a implantação de próteses nos lugares, mas à imposição a natureza de um primeiro esboço da presença técnica. Todavia a natureza comandava direta ou indiretamente, as ações humanas. A precariedade ou pobreza das técnicas disponíveis constituía o corpo do homem como principal agente de transformação tanto na produção como no enfrentamento das distancias, e aqui ainda a natureza triunfa e o homem se adapta (SANTOS; SILVEIRA, 2011, p. 29).
\end{abstract}

Os primeiros anos da colonização brasileira são marcados pelos desafios que a natureza impunha aos invasores. Não foi fácil para os portugueses dominarem a densa floresta atlântica, o que posteriormente foi feito com tamanha violência, restando atualmente muito pouco da vegetação nativa.

Além da vegetação densa do litoral, o relevo também se constituiu em obstáculo para ocupação do território brasileiro, a exemplo do planalto paulista, conforme destacado por Prado Junior (1981[1945]) e Holanda (1994). O primeiro autor ressalta ainda as potencialidades dos solos e do clima nessa porção do território para o desenvolvimento da agricultura e ocupação humana, já que as condições ambientais se assemelhavam com as de onde vinham os colonizadores, mais favoráveis que as encontradas no interior do Nordeste, frequentemente atingido por longos períodos de seca.

\footnotetext{
$30 \mathrm{O}$ algodão não foi nos primeiros anos de exploração colonial produto de grande importância econômica, contudo já se registrava sua exportação no primeiro século de dominação do território brasileiro, não só por portugueses. Segundo Dean (1995, p, 64) os franceses que constantemente se mostravam um risco aos negócios portugueses também levavam em seus carregamentos algodão "Às vezes, os feitores franceses também completavam seus carregamentos com algodão. O navio Pélérine levou 5,5 toneladas em sua viagem de 1532, outro indicador da escala e produtividade da agricultura tupi".
} 
No processo de desmatamento das densas florestas tropicais, a extração de madeiras nobres, como o pau-brasil, cuja exploração é considerada o primeiro ciclo econômico do país, contribuíram sensivelmente para a destruição desse ambiente natural. Os sucessivos ciclos econômicos, sobretudo os agrícolas causaram devastações e perda de biodiversidade incalculável (PRADO JUNIOR, 2004 [1942]; DEAN, 1994).

Mesmo com intervenções técnicas, as relações do ser humano com a natureza, nos primeiros séculos de colonização, são marcadas por um tempo lento (SANTOS e SILVEIRA, 2011). Antes da colonização o território brasileiro já era ocupado por diversos povos nativos, mas a relação dos mesmos com o espaço natural era menos predadora do que o fora com os desbravadores, que ávidos em extrair as riquezas da terra, foram continuamente invadindo o interior do continente e expropriando seus recursos.

Antes de ser explorado economicamente pelos colonizadores o algodão já era conhecido e usado pelos indígenas, contudo o mesmo se configurava como produto de subsistência, uma vez que o seu uso se restringia ao consumo pela comunidade, sem valor de troca.

O primeiro registro de identificação desse produto pelos portugueses no Brasil é encontrado na famosa carta de Pero Vaz de Caminha para o rei de Portugal, D. Manuel, datada de 1 de maio de 1500, na qual ele descreve ter visto entre as índias brasileiras uma " mulher moça com menino ou menina no colo, atado com um pano não sei de que aos peitos, que não the aparecia se não as perninhas" (HOLANDA, 1994).

A referência a esse pano "de não sei o que" é encontrado em vários estudos, entre os quais podemos citar: Bastos (1938), Prado Junior (2004 [1942]), Vincenzi (1944) e Holanda (1994). Amaral (1949, p. 460) afirma enfaticamente que o tal "pano de não sei o que" era tecido com algodão. Ainda sobre o uso do algodão o referido autor diz que " os indígenas usavam-no em tecidos para certas peças do reduzido indumento, para cinta de castidade obrigatória às donzelas de algumas tribos, e para as tochas incendiárias, expedidas em pontas de flechas aos acampamentos inimigos". 
Holanda (1994), faz referência a uma carta enviada pelo padre jesuíta Manuel da Nóbrega ao mestre Sião, quarenta anos depois da carta enviada por Caminha, na qual fala da abundância de algodão na colônia, mas que não havia entre os indígenas quem soubesse tecer e por isso pedia que fosse enviado para o Brasil alguns tecelões. Esse pedido se dava devido à necessidade de fazer roupas para os novos convertidos ao cristianismo, os índios.

Começava aí mais um ato de violação dos direitos e cultura dos povos nativos, com a imposição de costumes europeus, da religião cristã, e do trabalho forçado. Ainda segundo Holanda (1994, p. 211) "Nove anos mais tarde, conforme outras cartas jesuíticas, já existia pelo menos um índio com seu tear, numa das aldeias baianas, tendo aprendido por iniciativa dos padres (...) aplicavam-no agora a plantar algodão, fiarem-no e vestirem-se".

Embora, o padre jesuíta acima mencionado, afirme que não havia entre os nativos quem soubesse fiar e tecer o algodão, Moreira e Santos (1994), afirmam não haver dúvidas de que alguns grupos indígenas já conheciam a planta, antes do "descobrimento" do Brasil. De acordo com os autores citados, algumas das tribos praticavam ainda que rudimentarmente a tecelagem e para execução dessa prática pressupõe um conhecimento de longo tempo dessa planta conforme destacam:

$\mathrm{Na}$ verdade, parece fora de dúvida que certas tribos indígenas, do Brasil, como os Carirís, possuíam uma adiantada agricultura e que o algodoeiro chegou mesmo a ser por eles cultivado, juntamente com outras plantas que faziam parte de sua subsistência [...] a planta era cultivada e a fibra rudimentarmente fiada e tecida para a fabricação de rede de dormir e de panos usados nas vestimentas. Portanto o algodoeiro devia ser uma planta já bem antiga e com elas certas tribos indígenas deviam estar bem familiarizadas para que estivessem fiando e tecendo a sua fibra na época do descobrimento. Há de convir que a atividade de fiação não é um trabalho simples, mesmo baseado em teares primitivos, e com e como tal para que ela pudesse ser exercida por aqueles grupos indígenas deve ter exigido um tempo relativamente longo de contato com a planta e a sua fibra (MOREIRA e SANTOS, 1994, p. 8).

A descrição da forma como os indígenas brasileiros, especificamente os tupinambás da Bahia "criavam o algodão" e a versatilidade de seu uso pelos mesmos é contada pelo cronista Gabriel Soares de Sousa, em sua obra " Tratado Descritivo do Brasil", escrita em 1587, na qual além de descrever o ciclo vegetativo da planta, o uso, fala também do manejo conforme podemos analisar a seguir: 
Manim chamam os índios ao algodão, cujas árvores parecem marmeleiros arruados e em pomares, mas, a madeira dêle é como sabugueiro, mole e oca por dentro; a folha parece de uma pereira, com o pé comprido, vermelho, com o sumo da qual curam feridas esprimidos nelas. A flor do algodão é uma campaínha amarela muito formosa, donde nasce um capulho, que ao longe parece uma noz verde, o qual se fecham com três folhas grossas e duras, da feição das com que se fecham os botões das rosas; e como o algodão está de vez, que é de agosto em diante, abrem-se estas folhas, com que se fecham estes capulhos, e vã-se secando e mostrando o algodão que tem dentro muito alvo, e se não apanham logo cai no chão; e em cada capulho dêstes estão quatro de algodão, cada um do tamanho de um capulho de sêda; e cada capulho dêstes tem dentro um caroço preto, com quatro ordens de carocinho é do tamanho do feitio dos ratos, que é a semente donde o algodão nasce, o qual no mesmo ano em que semeia da novidade. Éstes caroços de algodão come o gentio pizados e depois cozidos, o que se faz em papas que chamam mingaú. As árvores destes algodoeiro duram sete a oito anos e mais, quebrandoIhe cada ano as pontas grandes a mão, porque se secam, para que lancem outros filhos novos, em que tomam mais novidade, os quais algodões se alimpam a enxada, duas e três vezes cada ano, para que as ervas os não acanhe (SOUSA, 1987, p. 207, grifo da autora).

A produção de algodão nos primeiros séculos de colonização, era voltada para atender à demanda interna de seus centros produtores. Era utilizado para produzir tecidos rústicos e de baixa qualidade, já que os tecidos de melhor qualidade eram importados, e também não era permitido o desenvolvimento de maquinofatura na colônia.

Entre os séculos XVI e XVII, o cultivo do algodão no Brasil, era feito em pequenas lavouras, muitas delas ao redor das moradias, esses cultivos estavam circunscritos aos núcleos de povoamento mais importantes da colônia. Com destaque para Pernambuco, Bahia e São Paulo. Segundo Moreira e Santos (1994, p. 12) a partir do século XVII houve uma expansão da lavoura algodoeira pelo país "expandiu-se a tal ponto que só raramente se podia encontrar nesta época um local que não estivesse entregue a este cultivo, fiando e tecendo a fibra do algodão". Ainda de acordo com Moreira e Santos (op. cit., p. 13) essa expansão da lavoura pelo Brasil, está relacionada a múltiplos fatores, entre os quais destacam:

Desde o emprego no preparo para dos pavios de lamparina até a sua utilização na confecção de linhas de coser e bordar, bem como no fabrico de panos grossos para roupa dos escravos. Não só isto, mas a semente da planta passou a ser utilizada também na alimentação animal e até o próprio vegetal empregado como forragem (SANTOS e MOREIRA, 1994, P. 13). 
O uso dos restos do algodão para alimentação animal, se constituiu importante elemento, para expansão dessa cultura pelos Sertões nordestino, para onde paulatinamente foi empurrada a atividade pecuária. É importante frisar que ainda nesse período a produção era feita em pequenas quantidades. Mediante a necessidade por esse produto no país que também foi ocasionado pelo aumento da população, como destacado por Andrade (2011[1963]).

O algodão assim como outros produtos agrícolas de exportação passaria a atender à função determinada às colônias tropicais, que segundo o historiador Caio Prado Junior, tinham como finalidade o fornecimento de gêneros tropicais de elevado interesse para o comércio nos países desenvolvidos, e é nessa condição que o Brasil se insere como fornecedor de bens primários de alto valor comercial, além do açúcar, um dos poucos produtos que passava por processo de industrialização na colônia.

Para entender o sistema de produção de algodão no Brasil se faz necessário compreender sua estrutura fundiária. A estrutura fundiária brasileira foi formada baseada na tríade: grande propriedade, monocultura, e trabalho escravo (PRADO JUNIOR, 1981[1945]; 2004[1942]; FURTADO, 2005[1958]; ANDRADE, 2011[1963]). Como o objetivo era obter cada vez mais lucro a partir do produto que fosse comercializado, a cana-de-açúcar, matéria prima para o açúcar que devido à sua raridade no mercado até o século $\mathrm{XV}$, gerou muita riqueza para Portugal, monopolizou também a terra e o trabalho para sua produção e dessa forma outras culturas, como o milho, o feijão, a mandioca e outros, ocuparam espaços secundários.

Em relação ao cultivo do algodão que nos primeiros anos de exploração no Nordeste do país era considerado como produto da agricultura de subsistência, seu espaço de produção não será diferente dos que ocupavam os produtos alimentares, sendo uma cultura marginal, ao império verde da cana.

\section{3 - Os surtos algodoeiros no Brasil}

A produção algodoeira no Brasil, é marcada por momentos de elevada produção e reduções drásticas, isso esteve relacionado até a década de 1930 ao fato do mesmo ser destinado, sobretudo à exportação. $O$ primeiro grande 
momento na produção do algodão para exportação ocorreu na segunda metade do século XVIII (1750), devido ao desenvolvimento das inovações na indústria têxtil, e da Guerra de Independência dos Estados Unidos, iniciada em 1775 e findada em 1783 conforme será detalhado no item 3.3.1.

Outro grande momento da história desse produto ocorreu, quase um século depois, entre 1861 e 1875, que teve como evento máximo para a grande demanda pelo produto brasileiro a Guerra da Secessão, nos Estados Unidos, entre o Norte industrial e o Sul agrário, onde predominava o sistema de monocultura, entre elas a do algodão. Consideramos que o surto de produção do século XIX é, particularmente, importante pois haverá introdução, de novas técnicas relacionadas à cultura do algodão no país.

3.3.1. As inovações na indústria têxtil e o primeiro surto de produção do algodão no Brasil

De lavoura de subsistência nos primeiros séculos, o algodão se tornou uma das principais atividades agrícolas do século XVIII. O crescimento da produção de algodão no país nesse período foi impulsionado pelo desenvolvimento industrial da Inglaterra que teve como indústria pioneira, a têxtil. Esse produto passou a ter grande valorização como produto de exportação, sendo convertido em grande lavoura.

Nesse período o Brasil contou com condições de mercado excepcionais, pois os Estados Unidos, que até então era o principal fornecedor de algodão à Inglaterra, estava fora do mercado. A ausência dos Estados Unidos se deu por conta da Guerra de Independência desse país com sua metrópole, a Inglaterra. Assim sem poder acessar o mercado norte americano, fornecedor de algodão, a Inglaterra se viu obrigada a buscar novos fornecedores, como o Brasil e a Índia. O tipo de algodão produzido nesses dois países, por sua vez, possuíam fibras curtas e os cultivados nos Estado Unidos, possuíam fibras médias. Tal situação proporcionou o desenvolvimento de inovações incrementais ${ }^{31}$ nos teares ingleses, para poder processar as fibras curtas.

31 Segundo Perez 2004, (apud DOSSA, 2010, p.25) inovações incrementais são: "aquelas melhorias sucessivas em produtos ou processos existentes, e essas melhorias originam aumentos gerais de produtividade. As inovações incrementais caracterizam-se por frequentes 
Entre as consequências do aumento da produção do algodão no Brasil, merece atenção a redução da área destinada ao cultivo de produtos alimentares. Pois mesmo sendo possível plantar produtos alimentares intercalados com a lavoura de algodão, como o milho e o feijão, que possuem um ciclo de produção menor que o do algodão, por vezes essa situação não ocorria. Isso porque onde o algodão passou a ser cultivado, em grande escala, os fazendeiros sequiosos pelo lucro acabavam por dificultar o plantio de alimentos consorciados (BASTOS, 1938). Nos roçados dos trabalhadores livres e donos de pequenas propriedades havia a prática da policultura, principalmente no Agreste, que é uma faixa de transição entre a Zona da Mata e o Sertão nordestino (ANDRADE, 2011 [1963]).

As fazendas nas quais as lavouras algodoeiras vicejavam, embora esse produto ganhasse cada vez mais espaço como produto rendoso, disputavam espaço com a pecuária, que era uma atividade subsidiária da cana-de-açúcar, já que os bovinos eram utilizados como força motriz nos engenhos. O gado também se constituiu uma das principais fontes de proteína de que dispunham as populações dos núcleos urbanos litorâneos.

Com receio dos danos que os animais pudessem provocar a preciosa cultura canavieira, essa atividade foi sendo dirigida para o interior do território, formando as fazendas. Não era incomum que algumas dessas fazendas também fossem de propriedade dos senhores de engenho. Esses muitas vezes deixavam seu gado sob os cuidados do vaqueiro e residiam nas capitais (ANDRADE, 2011 [1963]).

Conforme já mencionado a produção do algodão no Brasil será de grande destaque a partir do século XVIII. Andrade (2011 [1963], p. 157) afirma que "essa cultura teve importância relativa no primeiro século de colonização, mas fora eclipsada nos dois séculos seguintes, para ressurgir estonteante no século XVIII". Prado Junior (1981[1945]; 2004[1942]) tem a mesma opinião, para o geógrafo e historiador o algodão foi o responsável pelo "renascimento da agricultura brasileira" no século XVIII.

incrementos em eficiência técnica, produtividade e precisão dos processos e por trocas regulares nos produtos para conseguir melhor qualidade, reduzir custos e ampliar a gama de usos". 
Sobre o incentivo para o cultivo do algodão na Colônia nessa época, Camara (1797) nos revela como fora o acontecido, que teria tido início em 1777:

(...) a noticia do grande lucro, que podia dar o algodão, a quem o cultivasse foi penetrando pouco a pouco nos matos, e despertando os agricultores. Nos anos de 1777 até 1781 animaram-se os povos de huma nova força, então é que se virão os Certões mais habitados, e cultivados e tem-se de tal modo fomentado a cultura e o negócio do algodão (CAMARA, 1797, p. 29).

O cultivo do algodão assim como a monocultura canavieira se deu com baixo investimento em técnicas de produção, já que em sua maioria os atores de sua produção eram os mesmos. A força de trabalho escrava e a ampla disponibilidade de terras, foram fatores relevantes no atraso técnico da agricultura brasileira, pois os grandes produtores se valiam da disponibilidade de terras e intensificação do trabalho escravo para aumentarem suas produções (SZMRECSÁNYI, 1990).

Prado Junior (2004[1942]) fez duras críticas ao baixo espírito empreendedor do colonizador em relação aos tradicionais meios de produção empregados, pois enquanto não tinham concorrentes seus negócios iam bem, mas quando outras áreas também começavam a produzir, como dispunham de tecnologias mais avançadas, o Brasil ficava em desvantagem. Essa situação aconteceu com produtos como a cana-de-açúcar, que levou muitos anos para introduzir variedades mais produtivas, com o algodão e outros.

O desenvolvimento da agricultura no período que temos em vista, embora bastante considerável, é muito mais quantitativo que qualitativo. Daí sua precariedade, e salvo em casos excepcionais sua curta duração. No terreno do aperfeiçoamento técnico, o progresso da agricultura brasileira é naquele período práticamente nulo. Continuava em princípio do séc. XIX, e mais ou menos nas mesmas condições continuará por muito tempo, com os mesmos processos que datavam do início da colonização. Processos bárbaros, destrutivos, explicáveis na primeira fase da ocupação; mas que começavam já, pela insistência neles, em fazer sentir seus efeitos devastadores. Para instalação de novas culturas, nada de novo se realizava que o processo brutal, copiado dos indígenas, da 'queimada' para o problema do esgotamento do solo, outra solução não se descobria ainda que o abandono puro e simples do local por anos e anos consecutivos (...) Em matéria de lavra do solo nada verdadeiramente se práticava de eficiente ,e além da queima e roçada para limpeza indispensável - e isto mesmo apenas sumariamente e sem mais que o conhecido processo indígena da coivara - não se fazia mais que abrir em regos ou covas, conforme o caso para lançar nela a semente. Aliás de instrumentos agrícolas não se conhecia mais que a enxada. Nada mais primário. O problema da escolha ou seleção de variedades a serem cultivadas pode-se considerar desconhecido. Até o início do século só se conhecia uma 
única variedade de cana-de-açúcar, a mesma que se cultivava desde o início da colonização (PRADO JUNIOR, 2004[1942], p. 135-137, grifos da autora)

No caso do algodão identificou-se que a primeira iniciativa no sentido de produzir um documento escrito no qual há sistematização de informações sobre a cultura algodoeira no país em língua portuguesa, para orientação aos produtores só veio a ocorrer na segunda metade do século XVIII, quando a produção dessa malvácea passou a ter relevância na pauta de exportação do país.

Deve-se a Manuel Arruda da Camara em 1797, a publicação do primeiro manual de orientação sobre essa cultura no país: "Memória sobre a cultura dos algodoeiros, e sobre o methodo de escolher e ensacar, etc." A referida "Memória" foi escrita a pedido do Príncipe Regente, D.João VI. Manuel Arruda da Camara era filho de portugueses, nascido em Goiana, vila pertencente a capitania de Pernambuco. Conforme o mesmo descreve em sua "Memória sobre a cultura dos algodoeiros", por não possuir recursos suficientes para a montagem de um engenho açucareiro se dedicava a outras culturas, como o algodão (CAMARA, 1797).

A dedicação a outras atividades, como a pecuária e depois o algodão foi o caminho encontrado por aqueles colonos que não possuíam capital o suficiente para custear um engenho. Furtado (2005) afirma que os custos de manutenção dos engenhos, perante os lucros que proporcionava era vantajoso, mas as despesas para montagem de um engenho eram elevadas. Arruda Camara é considerado uma pessoa muito culta, formado em Filosofia, pela Universidade de Coimbra; estudou Ciências Naturais em Montpellier - França; fazia parte de várias associações científicas, tinha conhecimentos sobre botânica e foi considerado o pai da agronomia brasileira por Caio Prado Junior (KOSTER, 1942 [1817]; VINCENZI, 1944; PRADO JUNIOR, 2004 [1942]).

Além do domínio científico, Manuel Arruda, como já falamos, possuía plantações de algodão e dessa forma, sua lavoura era também seu campo experimental. Ele desenvolvia suas plantações nas margens do rio Paraíba do 
Norte ${ }^{32}$. A soma do conhecimento científico e do conhecimento prático o permitiu através de suas "Memórias sobre a cultura dos algodoeiros" difundir algumas técnicas de produção no campo (plantio, poda, controle das principais pragas), como deveria ser feito a catação, o descaroçamento, e o ensacamento do algodão. $O$ botânico ainda chama atenção para 0 uso da bolandeira, em Pernambuco, movida à tração animal, considerada técnica mais avançada que as churkas indiana.

O objetivo do manual escrito por Arruda Camara era disseminar na colônia informação para que outros produtores pudessem reproduzir, pois segundo o mesmo em outras áreas o cultivo do algodão se dava de forma muito precária, a exemplo do Maranhão, província que se destacou nas exportações de algodão, como demonstraremos no próximo tópico.

Prado Junior (2004[1944]), chama atenção para o fato de Manuel Arruda da Camara mesmo tendo contribuído para a difusão de conhecimento e técnicas empregadas na cultura algodoeira, da época, não fazer referência à uma das principais inovações relacionada a essa cultura, o "cotton-gin" descaroçador desenvolvido por Eli Whitney em 1793, nos Estados Unidos e que revolucionou a produção algodoeira daquele país. Acreditamos que o não conhecimento por parte do botânico se deve ao fato de naquele tempo o acesso à informação e à difusão das técnicas levar mais tempo para acontecer. A introdução do descaroçador a que se refere Prado Junior, vai ocorrer a partir da década de 1861, principalmente em São Paulo (CANABRAVA, 2011[1951]; MOREIRA e SANTOS, 1994).

Ignorou-se por completo uma descoberta que revolucionou completamente a cultura algodoeira, dando-lhe um impulso que a transformaria. Sete anos depois do invento de Whitney, um dos espíritos mais cultos e informado da colônia Manuel Arruda da Camara, botânico e lavrador - pode-se considera-lo pai da agronomia brasileira - escrevia sua Memória sobre a cultura dos algodoeiros, em que mostra desconhecer totalmente o evento máximo de sua época no domínio de que se ocupa (PRADO JUNIOR, 2004[1944], p.138-139).

O descaroçador inventado por Whitney, era um equipamento relativamente simples. De acordo Zischka (1936, p.44) o princípio do

\footnotetext{
${ }^{32}$ Território atualmente correspondente ao estado da Paraíba
} 
descaroçador consistia "em dois cilindros de madeira, seguros com pregos, apanhavam o algodão, puxavam-no com uma espécie de serra de dentes embotados que retinha os caroços".

Segundo Zischka (1936) sem o desenvolvimento do descaroçador de Whitney, a produção algodoeira dos Estados Unidos corria sérios riscos, pois com os inventos anteriores dos ingleses Richard Arkwrighit, que desenvolveu a máquina de fiar algodão, movida a água e por isso chamada "máquina d'água" a qual obteve a patente em 1769; do tear mecânico inventado por Edmund Cartwrighit em 1784, movido a vapor houve aumento exponencial do consumo de algodão.

Como o descaroçamento era feito manualmente, o processo era muito lento e árduo sendo estritamente necessário o desenvolvimento do descaroçador. Como dito por Santos (2008[1996]) o desenvolvimento da técnica geralmente não se dá só, mas em conjunto. Nesse caso específico observa-se que o surgimento de uma técnica veio acompanhada de outras. No caso da indústria têxtil as principais técnicas inventadas foram: máquina à vapor, por James Watt (1769), roda de fiar mecânica, por Richard Arkwright (1769), tear mecânico, por Edmund Cartwright (1766) e o descaroçador de Eli Whitney (1794).

Quanto à ampla difusão desse descaroçador entre os cotonicultores do Sul dos Estados Unidos, indicada por Prado Junior (2004[1942]), é considerado normal, já que conforme Zischka (1936) a riqueza gerada pelo "ouro branco", as dificuldades de descaroçamento manual foram as condições necessária para o invento de Whitney e os cotonicultores mal podiam esperar para fazer uso desse equipamento.

É importante conhecer qual contexto histórico Whitney estava inserido, que o motivou pelo desenvolvimento do descaroçador. Assim como os demais inventores das importantes máquinas que transformaram a indústria têxtil de sua época, ele não estava ligado diretamente a produção de algodão, mas circunstancias o levaram a participar dessa conjuntura.

Eli, nasceu em 1765, em Westboro, Massachusettes, aos onze anos de idade trabalhava em uma fábrica de pregos, dez anos depois trabalhou em uma 
fábrica de sua propriedade no fornecimento de armas para o governo americano. Conhecia todos os processos de fabricação das armas e como não dispunha de funcionários habilidosos, resolveu aos invés de ensina-los todo o processo de fabricação da arma, ensinar parte do processo. Assim seus funcionários se especializavam no desenvolvimento de uma determinada peça, agilizando a produção. Esse fato segundo Zischka (1936), o fez "o Ford de sua época".

Com o dinheiro que já tinha acumulado, deixou sua fábrica de armas sob os cuidados da família e decidiu fazer o curso de direito na Universidade de Yale, considerada a Oxford da América. Como os custos para se manter na Universidade eram muito altos, os seus recursos não tardaram em acabar, teve que abandonar o curso de direito e aceitar ser preceptor de uma família de plantadores de algodão em Savannah (ZISCHKA, 1936).

Embebido pelo ambiente que dominava seu cotidiano, o aumento da demanda de algodão pela Inglaterra, a ampliação da produção cotonícula e as perdas acarretadas pela incapacidade de descaroçamento das grandes quantidades de algodão pelos escravos, ele teve ali o input para a sua invenção, que fora a princípio financiada pela família da qual era preceptor.

Tão importante foi o invento de Whitney que a patente do mesmo foi assinada pelo próprio presidente dos Estados Unidos, George Washington. De acordo com Zischka (1936, p. 46) "Mal começaram as primeiras máquinas de Whitney a trabalhar, manifestou-se uma verdadeira febre de algodão e um 'boom' muito maior do que aquele que seguira à revelação dos inventos de Arkwright e Cartwright".

No Brasil a importância das contribuições de Manuel Arruda da Camara, a partir do referido manual são reconhecidas por vários estudiosos, tais como: Bastos (1938); Prado Junior (2004 [1942]; 1981[1945]); Amaral (1949); Koster (1942 [1817]), Vincenzi (1944); Andrade (2011[1963]); Moreira e Santos, 1994.

Além dos métodos de cultivo e descaroçamento, outra contribuição de Arruda Camara foi a criação de uma máquina de ensacamento e enfardamento do algodão, já que antes da mesma tal processo se dava de forma muito árdua, pois os escravos colocavam o algodão no saco e com o peso do próprio corpo iam compactando o algodão (ver, Figura 7). No escrito, o autor também faz 
referência às variedades de algodão cultivadas na colônia, segundo o qual a variedade mais produtiva era a "Maranhão". Também fala da extração do óleo, da semente do algodão, que poderia ser utilizado para iluminação.

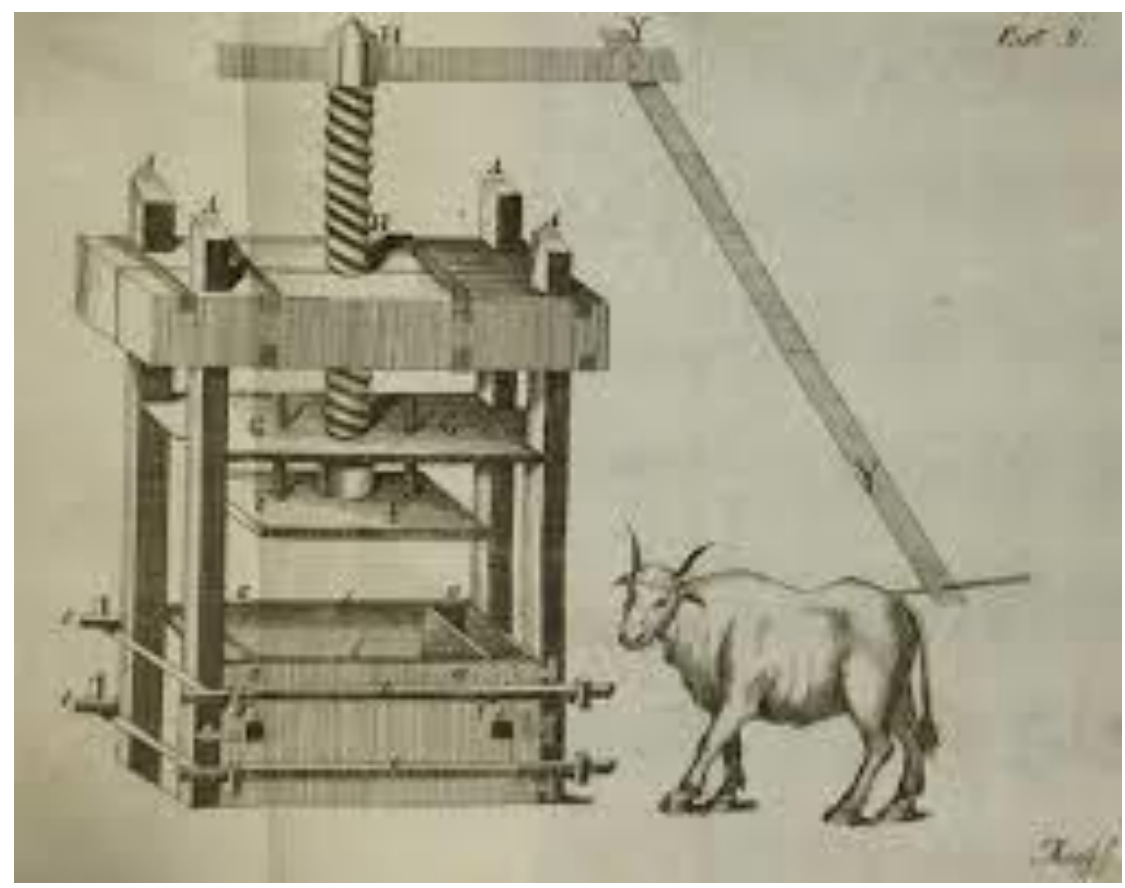

Figura 7 - Máquina para prensar o algodão - século XVIII Fonte: CAMARA, 1797, p. 113.

Os altos preços alcançados por esse produto despertaram o interesse dos grandes proprietários de terra, e também de pequenos proprietários. Segundo Andrade (2011[1963]) o algodão foi responsável por uma verdadeira revolução agrária no Agreste Nordestino. A revolução a que se refere o autor tem a ver com o fato de participarem da produção pequenos e grandes proprietários, isso foi proporcionado devido aos custos de produção do algodão serem menores do que para manter um engenho de açúcar, por exemplo. Assim muitas pessoas foram atraídas para essa atividade. Colaborou para isso a crise que atingia a produção de açúcar e que liberou mão de obra ociosa da indústria açucareira.

A produção do algodão era considerada pelo autor citado, uma cultura mais democrática que a cana-de-açúcar:

O algodão era por natureza mais democrático que a cana-de-açúcar. Não só grandes proprietários, utilizando mão de obra escrava e assalariada, cultivavam-no, como também pequenos proprietários, foreiros e moradores. A industrialização mais barata e menos urgente 
que a cana colocou o beneficiamento do algodão na mão de pequenos comerciantes que, com suas bolandeiras, a princípio e seus descaroçadores, depois estabeleciam-se em cidades, vilas e povoações, passando a comprar a matéria prima ao agricultor para vendê-la, após o beneficiamento, aos exportadores. Daí ter contribuído desde os primeiros tempos para o desenvolvimento da vida urbana, ao contrário do que ocorria com a cana-de-açúcar, ainda hoje as cidades localizadas no Agreste são maiores e tem mais vida comercial que as da região da Mata (ANDRADE, 2011[1963], p.158-159).

Por possuir industrialização mais barata, que a açucareira com a expansão da cultura para o Agreste, os comerciantes começaram a instalar em algumas cidades, suas bolandeiras ${ }^{33}$ e depois seus descaroçadores. Isso criava, maior divisão do trabalho e favorecia o crescimento das cidades agrestinas que passaram a ter maior dinamismo do que as cidades localizadas na Zona da Mata (ver, Figura 8) (ANDRADE, 2011[1963]).

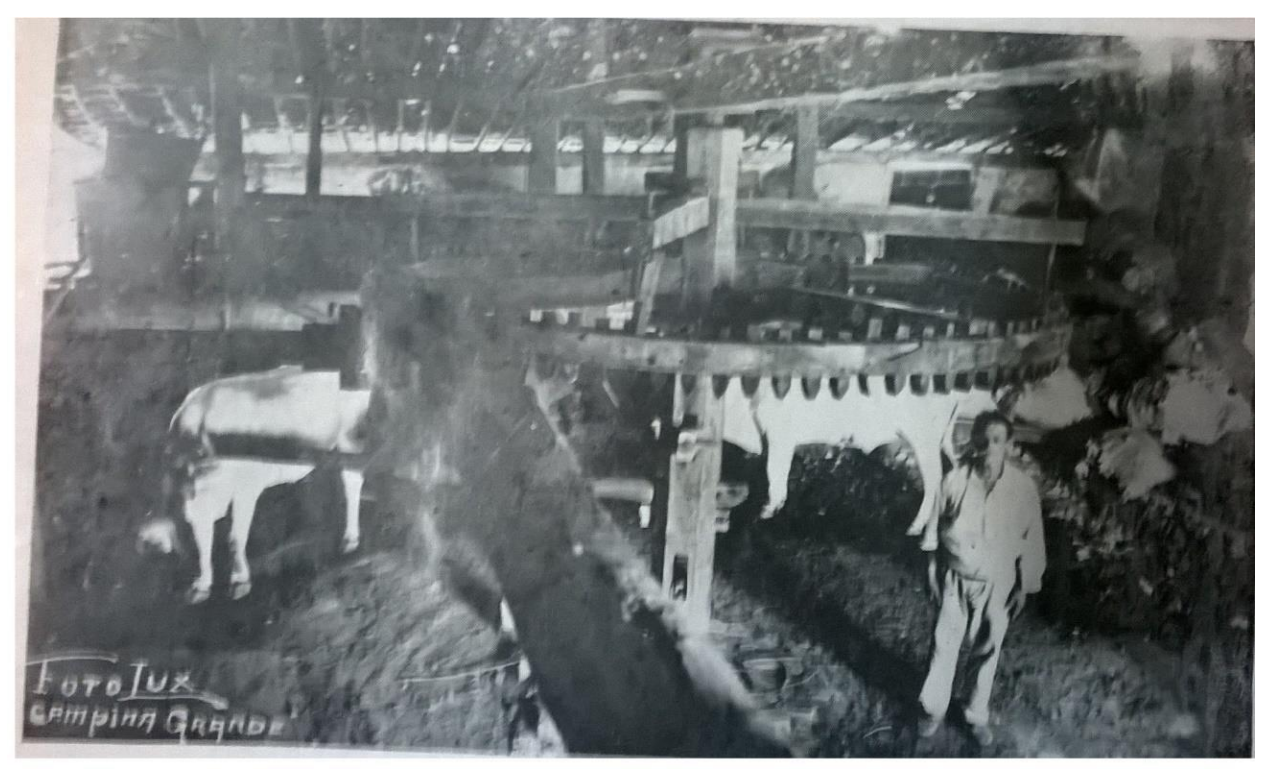

Figura 8 - Bolandeira fundada em 1865 no distrito de Queimadas (Campina Grande)-PB Fonte: MARIZ, 1939, p. 58.

Segundo Andrade (2011, [1963], devido ao crescimento da exportação do algodão no Brasil, a partir de 1750 foi criada em Pernambuco, uma inspeção do algodão, depois transformada em Alfândega do Algodão, destinada a fazer o

${ }^{33}$ Citando Pereira da Costa, Moreira e Santos (1994, p. 76), dizem que " o nome desse aparelho deriva-se de uma das peças dos antigos engenhos de açúcar ou maquinismo ou do maquinismo empregado no serviço de ralar mandioca para o fabrico da farinha". Para os autores há mais semelhança com esse último. 
exame e classificação do artigo destinado à exportação e recolher os impostos desse produto.

A capitania do Maranhão é sem sombra de dúvidas o caso mais emblemático dos impactos econômicos desse produto, pois a partir da comercialização do algodão essa capitania se inseriu na história econômica do país. Na época o Maranhão era uma capitania muito pobre. Devido à falta de moedas o fio e o tecido de algodão eram utilizados como tal ${ }^{34}$ (Prado Junior, 2004 [1942]); KOSTER, 1942[1817]; ANDRADE, 2011[1963], CAMARA, 1797):

\begin{abstract}
Maranhão antigamente não deitava algodão algum para a Europa, e só o cultivava para gasto no paiz, que era tão pobre, que o fio que os seus habitantes fiavão do algodão, era a moeda Provincial, servindo-se dela para comprar o que precisavão, de sorte que até nos açougues a carne era comprada a troco de novelos de fios; até que o llustrissimo Senhor General Tales animou os Agricultores, obrigando a Companhia a fiar de muitos escravatura, ferramentas, etc. e desde então principiou Maranhão enriquecer , e aumentar (CAMARA, 1797,pág. 7).
\end{abstract}

Segundo Prado Junior (2004 [1942]); contribuiu para o sucesso da produção algodoeira no Maranhão, a atuação da Companhia Geral do Comércio do Grão-Pará e do Maranhão, criada durante a administração do Marques de Pombal (1750-1777). A atuação da referida Companhia, foi além do monopólio de exportação do algodão, coube à mesma fornecer aos lavradores: créditos, escravos e ferramentas.

De acordo com o referido autor (op. cit., 150) a produção do algodão causou transformações ainda mais profundas no Maranhão. Produzido em sistema de monocultura, o algodão modificou o perfil étnico da capitania maranhense, com a introdução crescente de escravos para trabalharem nessa cultura:

Com o algodão vieram os escravos africanos - ou vice-versa preferivelmente -; modifica-se a feição étnica da região, até então composta na sua quase totalidade, salvo a minoria de colonos brancos, de índios e seus derivados mestiços. O algodão, apesar de branco, tornará preto o Maranhão (PRADO JUNIOR, 2004 [1942], p. 150).

\footnotetext{
${ }^{34}$ As instituições financeiras no Brasil e o uso do papel moeda no Brasil aconteceram tardiamente, o Banco do Brasil, só foi fundado em 1808, com a vinda da corte portuguesa para o Brasil, que havia fugido da Europa, por causa da Guerra Napoleônica.
} 
O interesse pelo cultivo do algodão se difundiu rapidamente na colônia e outras capitanias começaram a se destacar, a exemplo de Pernambuco, Bahia, Rio Grande do Norte, que possuíam mais recursos que o Maranhão e rapidamente desbancaram a capitania maranhense da exportação do algodão.

Com maior divisão do trabalho essa cultura contribuiu para o desenvolvimento de cidades como Campina Grande, no Agreste paraibano, onde atualmente se encontra a sede da Embrapa Algodão. Essa cidade no segundo surto de produção de algodão na segunda metade do século XIX, tornase o mais importante centro de comercialização do algodão do país, e o segundo do mundo, posição que ocupará até a primeira metade do século XX. E não fosse a ausência de um porto de maior calado no estado talvez não tivesse perdido esse posto, haja vista que a exportação do algodão era feita pelo porto do Recife que devido a maior profundidade podia receber embarcações de maior porte. ${ }^{35}$.

Dada as dificuldades de transporte próprias da época, o qual era feito no lombo de burros ou mulas, mesmo com tantas vantagens este fator encarecia $o$ produto final. Um dos registros dessa prática foi feito pelo inglês Henry Koster (vide Figura 9) em uma de suas passagens pelo Agreste pernambucano, mais precisamente no povoado de Bom Jardim - PE ${ }^{36}$ no início do século XVIII.

\footnotetext{
${ }^{35}$ Não temos condições de esgotar a dinâmica das principais cidades do Nordeste e do Brasil que tiveram importância na atividade algodoeira, contudo devido à relevância que esse produto teve para formação socioeconômica de Campina Grande, cidade que abriga a sede da Embrapa Algodão teceremos alguns comentários sobre a mesma.

${ }^{36}$ Esse povoado, pertencia a cidade de Limoeiro e foi elevado à categoria de cidade em 1879. No mesmo foram instaladas bolandeiras e devido ao desenvolvimento proporcionado pelo beneficiamento do algodão, recebeu no início do século XX um ramal da linha férrea da Companhia Great Western.
} 


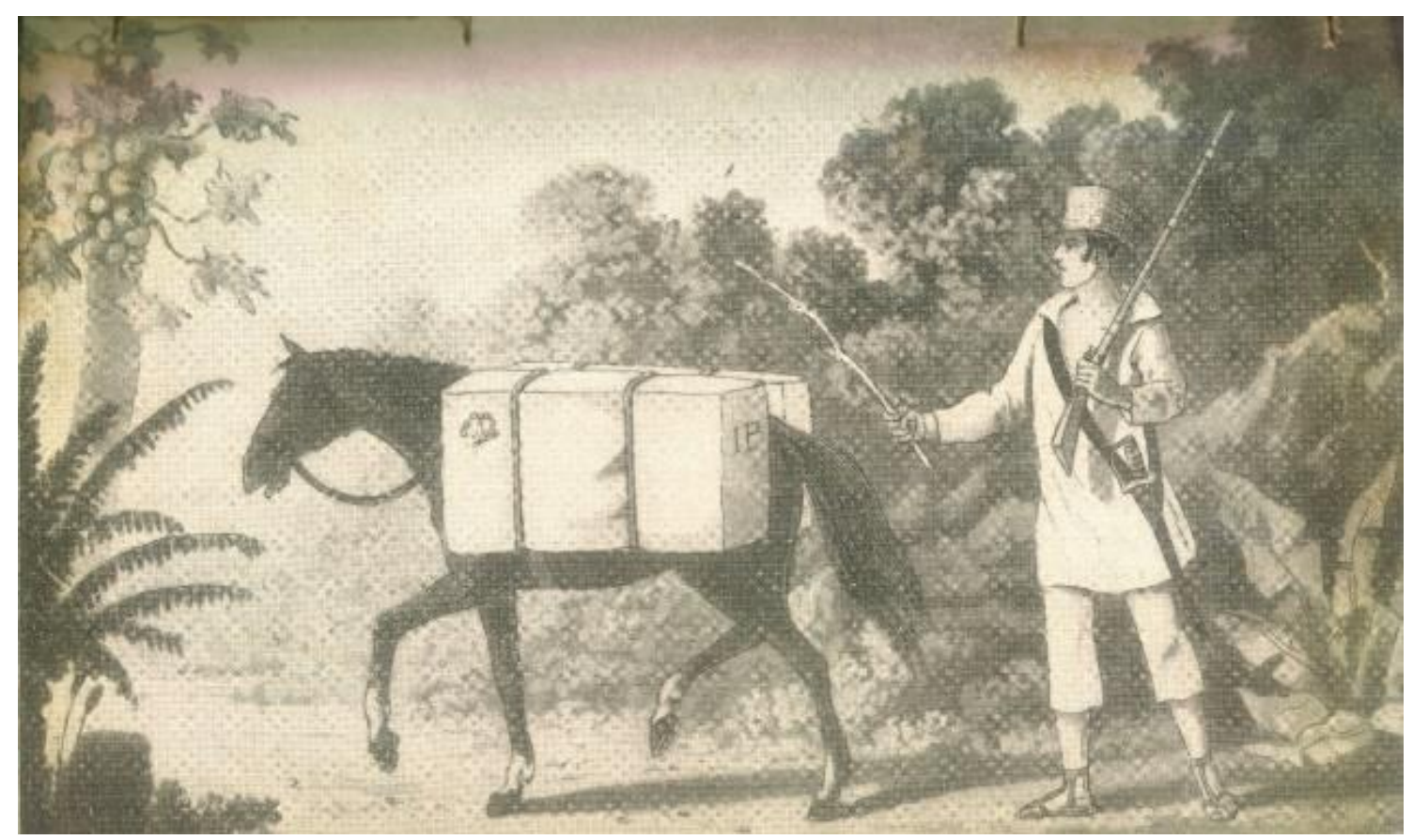

Figura 9 - Carregador de Algodão - Século XVIII.

Fonte: KOSTER, 1942[1817].

Andrade (2011[1963]), pág. 159), destaca o fato dessa cultura poder ser desenvolvida em associação com culturas alimentares, e que tudo na planta era aproveitado: a pluma, a semente e a rama, que depois da colheita servia como ração para o gado. "Essa vantagem viria a animar os grandes proprietários da região, sempre criadores de gado, uma vez que aumentariam seus lucros sem abandonar, ao contrário melhorando ainda mais a sua atividade econômica tradicional"

Mesmo tendo sido o algodão um dos principais produtos agrícolas da exportação brasileira, assim como o conjunto do setor agropecuário no país, poucas foram as iniciativas no sentido de melhorar a qualidade da produção, como foi destacado até agora.

Naquele período havia dois sistemas de produção do algodão bem distintos: a lavoura de subsistência e a grande lavoura. Não se pode perder de vista que mesmo sendo produzido para consumo interno, quando esse produto passou a ser valorizado pelo comércio internacional, o mesmo ocupou vastas extensões de terra, assim como ocorre em relação à monocultura canavieira. 
3.3.2. A Guerra de Secessão: primeiros esforços de mudanças técnicas na produção de algodão no Brasil

Após a euforia na produção de algodão, causada na segunda metade do século XVIII, devido ao desenvolvimento dos meios de produção da indústria têxtil e da Guerra de Independência dos Estados Unidos, a produção de algodão no Brasil se volta para o mercado interno. E por quase um século se mantém nessa situação. Contudo, não podemos afirmar que não tenha ocorrido exportação de algodão nesse período.

Um evento que reacendeu a produção algodoeira no país veio a ocorrer em 1861, e mais uma vez está relacionado com a ausência dos Estados Unidos na oferta dessa matéria prima, conforme pode ser analisado na Tabela 1. 0 evento máximo a que nos referimos foi a Guerra de Secessão dos Estados Unidos (1861-1865), entre o Norte industrial e Sul agrário.

Tabela 1 - Importação de algodão pela Inglaterra (1860-1866)

\begin{tabular}{|r|r|r|r|r|}
\hline Ano & E.U. & \multicolumn{1}{|l|}{ Brasil } & \multicolumn{1}{l|}{ Egito } & Outros países \\
\hline 1860 & 2.512 .582 & 100.157 & 106.880 & 557.247 \\
& & & & \\
\hline 1861 & 1.760 .002 & 94.825 & 93.425 & 946.850 \\
\hline 1862 & 61.604 & 113.903 & 125.276 & 983.464 \\
\hline 1863 & 108.193 & 112.383 & 168.636 & 694.134 \\
\hline 1864 & 155.741 & 167.141 & 202.466 & 1.512 .385 \\
\hline 1865 & 374.661 & 274.170 & 268.811 & 1.305 .120 \\
\hline 1866 & 955.473 & 334.989 & 137.601 & 1.652 .628 \\
\hline
\end{tabular}

Fonte: CANABRAVA apud. O Auxiliador, 1869, p.90

A dependência que a Inglaterra e outros países europeus como a França e a Alemanha, tinham do fornecimento de algodão dos EUA fez com que o primeiro país, buscasse alternativas efetivas para reduzir essa dependência. Alguns anos antes de eclodir a guerra civil nos Estados Unidos, a Inglaterra em sua "fome" pelo algodão criou a Associação para Suprimento do Algodão de Manchester (ASSAM), que almejava estimular a produção de algodão em outras partes do mundo. Essa Associação teve papel central no estímulo e incremento na produção algodoeira na Província de São Paulo, conforme analisado por Canabrava (op. cit.): 
O crescimento dos suprimentos de algodão da Índia, do Egito, da Turquia, como do Brasil, estavam ligados aos esforços realizados pelos ingleses, em várias partes do mundo, para incrementar a produção algodoeira de modo a enfrentar o problema criado pela queda das exportações norte-americanas. Aliás a Inglaterra foi o único país da Europa que se interessou vivamente em desenvolver a produção algodoeira no Brasil. (CANABRAVA, op. cit. p.78).

[...] Desde 1861, por meio de uma atividade incansável junto aos agricultores paulistas $e$ as autoridades governamentais, os representantes dos interesses das indústrias têxteis inglesas se empenharam em criar na Província de São Paulo, um mercado de suprimento de algodão para as fabricas da Inglaterra (CANABRAVA, op. cit. p.79).

De tão valorizado no mercado, o algodão passou a ser chamado "ouro branco". Na Figura 10 é possível observar a média dos preços altos e baixos, que algodão atingiu no período compreendido entre 1829 e 1921 na Bolsa de Valores de New York. Os momentos que se destacam são os correspondentes a guerra civil dos EUA e durante a Primeira Guerra Mundial. Nessas ocasiões a produção brasileira de algodão teve picos de produção (BROWN, 1927; MOREIRA e SANTOS, 1994).

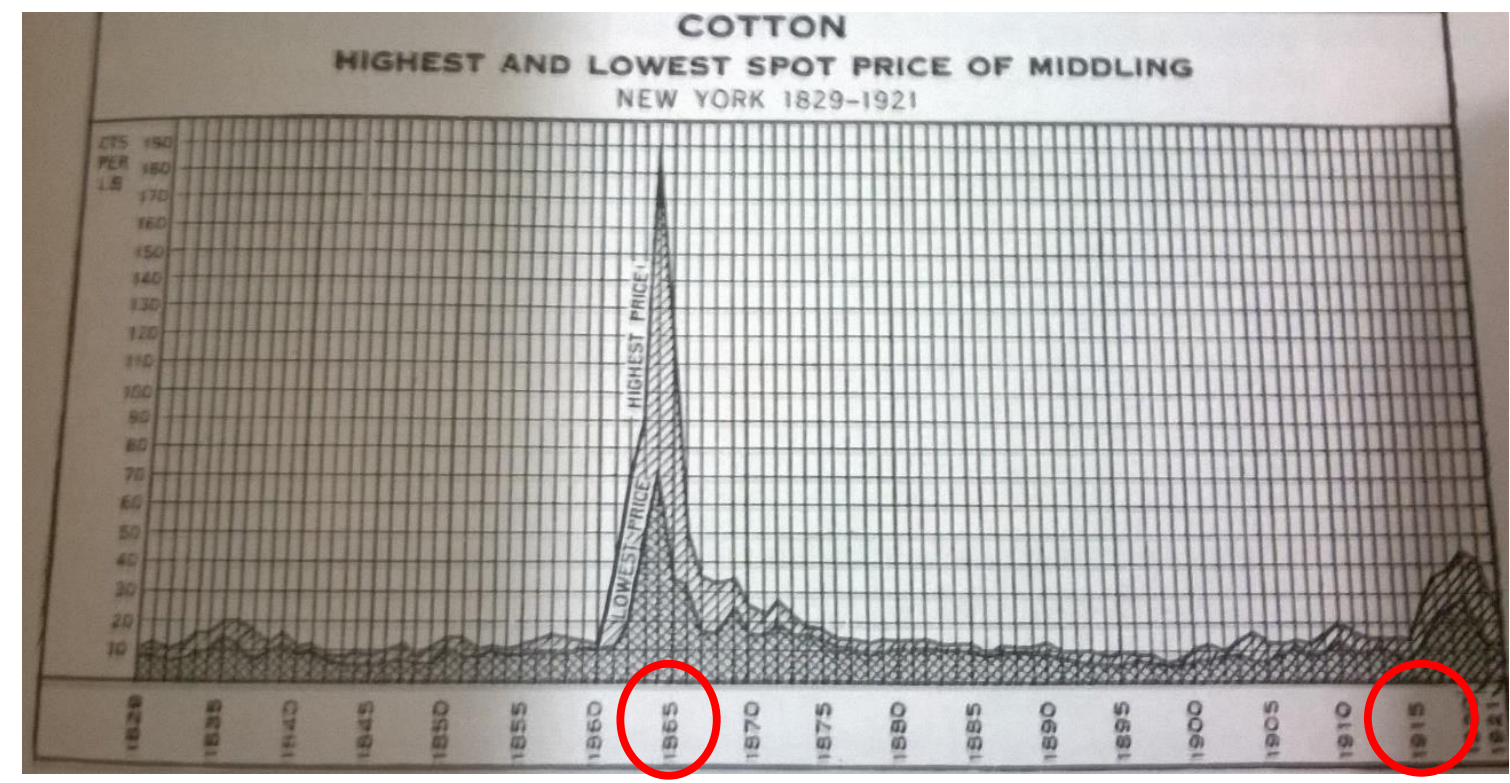

Figura 10 - Média do maior e menor preço do algodão no período de 1829-1921 Fonte: BROWN, 1927, p. 389.

As ações lideradas pela Inglaterra, com o objetivo de garantir 0 fornecimento do algodão, foram responsáveis pelos indícios de uma primeira mudança no sistema técnico de produção de algodão no Brasil. Entre essas 
mudanças, destacamos a introdução de novas variedades ${ }^{37}$, preocupação em aperfeiçoar a cultura, criando maior racionalização no processo produtivo (CANABRAVA, 2011[1951]).

Além da referida Associação, a participação dos atores locais foi essencial para o crescimento da produção de algodão na Província de São Paulo. Podese destacar a atuação da Sociedade Auxiliadora da Industria Nacional (SAIN); a nível da província paulista foi de significativa importância a atuação do inglês Jean Jacques Albertin, superintendente da estrada de ferro Santos - Jundiaí, em construção na época (CANABRAVA, op. cit.); do fazendeiro Carlos llidrío; na esfera do Estado o Ministério da Agricultura, vinculada ao Ministério da Agricultura, Comercio e Obras Públicas e o Imperial Instituto Fluminense de Agricultura (CANABRAVA, op. cit).

Canabrava, op. cit., atribui a Jean Jaques Albertin, a responsabilidade pelo segundo ciclo de produção de algodão na Província de São Paulo. Foi Albertin, um dos principais entusiastas da produção algodoeira, nessa região. $O$ mesmo teria encontrado plantas de algodão abandonado às margens do rio Tietê, em 1861 e diante do contexto histórico no qual havia uma demanda pelo produto, ele enviou para a ASSAM, alguma pluma do algodão nativo que ele colheu.

A ASSAM enviou para a província, mediada pelo contato de J.J. Albertim, sementes, manual de orientações agronômicas sobre a cultura, e um descaroçador. Em relação à introdução de novas variedades, essas eram as cultivadas nos Estados Unidos, a Gossipium hirsitum Upland.

De acordo com Canabrava (op. cit.) essa não teria sido a primeira vez que o algodão herbáceo foi introduzido na região. Só que devido ao abandono da cultura algodoeira na Província por muitos anos, existindo apenas alguns pontos isolados de produção, os agricultores já não sabiam mais os princípios básicos da cultura, tais como: quantidade de sementes por cova, período mais indicado para plantio, etc., conforme destacado a seguir:

\footnotetext{
${ }^{37}$ Embora não tenha sido a primeira vez que cultivares de ciclo anual tenham sido introduzidas no país, o que chama atenção nesse caso é a orientação para a produção, pois não se tratava mais de uma produção ao acaso.
} 
[...] As autoridades municipais se referem às variedades importadas dos Estados Unidos durante a guerra civil como desconhecidas ainda, das quais se ignorava completamente o modo de cultivo. Somos levados a admitir que se trata em 1861, de uma segunda introdução na província de São Paulo, de variedades de ciclo anual, as quais foram recebidas como uma cultura nova - e de fato o era para a grande maioria dos municípios - tão insignificante havia sido a sua primeira incursão em território paulista (CANABRAVA, op. cit.p.91).

A SAIN, representante dos interesses privados, foi de grande importância na divulgação entre os fazendeiros e agricultores de informações sobre essa lavoura. Através dessa Associação, a ASSAM enviou mais sementes e manuais traduzidos para o português com orientações sobre a lavoura algodoeira e as características das fibras desejadas pelas indústrias.

Conforme Canabrava (op. cit. p. 96), a SAIN foi responsável pela divulgação de conhecimentos técnicos sobre a lavoura algodoeira na Província de São Paulo. Essa associação publicou os três principais manuais escritos no país sobre essa cultura nesse período. Os manuais foram: o Manual do Cultivador do Algodão de autoria de Candido Nascente d' Azambuja; a Memória do Padre Antônio Caetano da Fonseca e Monographia do Algodoeiro de Frederico Leopoldo Cesar Burlamaqui.

$\mathrm{Na}$ época não havia um órgão autônomo responsável pela agricultura, embora a agricultura no país fosse a principal fonte de riqueza. $O$ que existia era o Ministério de Agricultura, como já mencionado vinculada a um Ministério com outras atribuições. Esse Ministério cuidava mais dos assuntos burocráticos. Não possuía equipes técnicas que pudessem dar orientações sobre a cultura aos agricultores.

Contudo esse Ministério foi importante na disseminação da cultura algodoeira nas províncias do império. Através dele foram adquiridas sementes, de outros países além dos EUA, como do Peru e da Índia. As sementes adquiridas, foram distribuídas nas províncias produtoras de algodão. O Ministério também emitiu algumas circulares relativos ao cultivo de algodão.

Com respeito ao algodão, a circular 1871 tinha relação especial, pois com o fim de facilitar aos lavradores a 'acquisição de sementes e mudas de que carecerão para melhorar as culturas existentes ou ensaiar nova', comunicava às Câmaras, que o governo imperial 
fornecia gratuitamente as sementes ou as mudas requisitadas pelos munícipes (CANABRAVA, op. cit.p.91).

Em contrapartida os agricultores que adquirissem as sementes doadas pelo Ministério deveriam dar informações sobre como estavam sendo desenvolvida as lavouras. O objetivo era que o conhecimento prático desses agricultores servisse na orientação para outros agricultores e assim melhorassem os resultados obtidos com a cultura.

$\mathrm{Na}$ ausência de instituições de pesquisa própria e diante das dificuldades encontradas pelos agricultores na adaptação das novas variedades de algodão introduzidas na Província de São Paulo, o Ministério como forma de dar resposta as demandas apresentadas pelos plantadores de algodão, buscou dos próprios lavradores respostas a partir de suas experiências.

Destacou-se na referida província as contribuições do fazendeiro Carlos llidro da Silva ${ }^{38}$. Ele era do município de Itu, e já desenvolvia em sua fazenda, melhoramentos agrícolas. A fazenda São Carlos, de sua propriedade serviu como modelo de produção agrícola. Isso aconteceu sobretudo a partir de 1859, quando o fazendeiro contraiu, empréstimo às instituições financeiras da província para modernizar sua propriedade (CANABRAVA, op. cit.).

Para concessão do empréstimo o fazendeiro se comprometeu a empregar o que houvesse de mais moderno em termos de instrumentos agrícolas e técnicas de produção. O proprietário ainda se comprometia a divulgar informações para que outros agricultores pudessem ter acesso a informações sobre como melhor produzir (CANABRAVA, op. cit.).

Além de receber em sua propriedade e orientar agricultores ou pessoas designadas e que tivessem interesse sobre as práticas agrícolas, postas em prática em sua propriedade, ele deveria publicar nos jornais de maior circulação da Província informações sobre as culturas praticadas em sua propriedade. Em 1861, diante da necessidade apresentada em relação a cultura algodoeira, o governo provinciano aproveitou a existência dessa iniciativa já consolidada e

\footnotetext{
${ }^{38}$ Carlos llidro, era formado em Direito, mas devido ao seu contato com o campo e de leituras especializadas possuía amplo conhecimento sobre técnicas agrícolas.
} 
orientou que fosse desenvolvido na Fazenda São Carlos, experimentos para orientar a cultura do algodão em ascensão. Carlos llidro, teve papel relevante na difusão de melhores práticas para cultura algodoeira:

O governo provincial aproveitou de uma iniciativa já existente, de colaboração entre um governo e um particular, em prol da renovação dos métodos e do equipamento da lavoura da Província, para colocala à serviço de uma cultura em especial do algodão. Como resultado das ordens do Presidente da Província, a fazenda São Carlos, antes dedicada sobretudo ao cultivo do café, passou a ser um campo experimental da lavoura do algodão, com o projeto de se tornar o "ramo principal” daquele estabelecimento (CANABRAVA, op. cit., 108).

O Imperial Instituto Fluminense de Agricultura também foi importante, pois plantou lavouras de algodão, e teve acesso a alguns tipos de descaroçadores, afim de observar o melhor desempenho entre eles e recomendar aos agricultores o que demonstrasse melhor desempenho. Esse esforço mostra o início de uma densidade técnica antes inexistente, por sua vez restrita a poucos pontos do território. Mesmo em São Paulo, pois os preços para adquirir os equipamentos agrícolas eram elevados, então só os fazendeiros, tinham as condições de obter esses meios de produção.

Diante do exposto, observa-se que houve toda uma mobilização e articulação de atores para desenvolver na Província paulista, o cultivo do algodoeiro. Algumas dessas ações devem ter transbordado para outros lugares do território, principalmente as coordenadas pela Sociedade Auxiliadora da Indústria e pelo Ministério da Agricultura.

Embora o algodão tenha se tornado produto de interesse e valorizado no mercado, foi necessário trabalho sistemático, para convencer os agricultores a investirem nessa cultura, pois aí outras culturas agrícolas já estavam consolidadas, o café e a cana de açúcar que, na época, figuravam como principais produtos da exportação brasileira.

A produção do algodão na Província de São Paulo, inicialmente foi desenvolvida nas grandes fazendas, mas como os fazendeiros achavam essa cultura mais trabalhosa que a produção cafeeira, embora os recursos financeiros investidos no desenvolvimento da cultura fossem menores, logo essa cultura foi 
relegada a pequenos proprietários, que possuíam propriedades de até quatro alqueires $(9,7$ hectares).

Em relação à mão-de-obra empregada, predominava a familiar e trabalhadores livres. Os imigrantes italianos também plantavam algodão entremeado com as culturas principais, assim chegou-se a plantar juntos o algodão e o café, o primeiro servindo para o sombreamento dos cafezais mais jovens.

Segundo Arruda (in: CANABRAVA, 2011[1951] a produção do algodão nas pequenas propriedades, acabou provocando problemas relacionados à falta de alimentos de subsistência, pois esses eram produzidos nas pequenas propriedades e, em consequência, houve aumento nos preços dos produtos da alimentação básica.

Rejeitado nas grandes fazendas de terras férteis adequadas ao café, o algodão foi acolhido nas pequenas propriedades por agricultores de posses reduzidas, cujo espaço de cultivo predominante não ultrapassava quatro alqueires, sendo raras as áreas entre quarenta a cinquenta alqueires (...) ainda assim, as pequenas propriedades não eram especializadas. Produziam café, cana e gêneros alimentícios ao lado do algodão. Investiam minguados recursos de capital, operando com mão de obra familiar, agregando camaradas, trabalhadores livres colhidos no seio da pobreza, o que Ihes conferia um caráter pseudodemocrático, com reduzida ou nenhuma intervenção de escravos. (...) um desdobramento nocivo da introdução dessa atividade foi a redução do número de braços destinados à produção de subsistência, pois eram exatamente as pequenas propriedades que a elas se dedicavam, resultando em carestia alimentar -agravada ainda, pela atração da mão de obra livre para as fileiras do exército e a construção ferroviária (ARRUDA, 2011, p. 11. In: CANABRAVA, 2011[1951]).

Após o fim do conflito interno nos EUA, é reestabelecido o mercado entre esse país e a Inglaterra, a demanda pela produção algodoeira do Brasil foi reduzida. Como vimos o domínio técnico da produção do algodão no Brasil se mostrava incipiente, e nos EUA o sistema técnico e de conhecimento sobre essa cultura já possuía longa trajetória.

A incapacidade do Brasil em manter-se no mercado competitivamente com outros países, de acordo com Prado Junior (2004 [1942]) e Celso Furtado (2005 [1959]), ocorreu em função dos baixos investimentos em fatores técnicos de produção. O país só conseguia alcançar picos de inserção de seus produtos 
em momentos excepcionais, principalmente quando os países que possuíam condições técnicas de produção superiores estavam fora do mercado.

A produção de algodão na Província de São Paulo, contou ainda com a introdução de instrumentos técnicos um pouco superiores em relação ao que se conhecia até então no Brasil, devido à vinda de alguns colonos do Sul dos Estados Unidos, que haviam fugido da Guerra. Esses migrantes já possuíam conhecimento sobre a cultura desenvolvida em seu país.

3.3.3. Mudança em curso: as bases da pesquisa algodoeira no Brasil

O atraso técnico na produção algodoeira no Brasil acompanhava os outros setores da agricultura. Essa situação está relacionada com a tardia criação das instituições de ensino e pesquisa no país. Em relação a cotonicultura ${ }^{39}$ brasileira queremos chamar atenção para algumas iniciativas no sentido de desenvolver um conhecimento científico com vista ao incremento comercial da cultura. Não é nossa intenção esgotar o assunto, até mesmo porque não dispomos de informações sobre todas as ações desenvolvidas nos mais diversos lugares do território nacional. Procuraremos assim, evidenciar aqueles que nos pareceram mais relevantes.

No contexto de casos isolados da criação de instituições de pesquisa no âmbito nacional para agricultura, em especial para o algodão, merece destaque o pioneirismo do Instituto Agronômico de Campinas (IAC) ${ }^{40}$, instituto de pesquisa do estado de São Paulo, fundo em 1887 em Campinas - SP. Embora criado no final do século XIX, a execução de pesquisa para sobre o algodão só veio a ocorrer a partir da segunda década do século XX. (VINCENZI, 1944; MOREIRA; SANTOS, 1994; BRASIL, 2007; COSTA e BRUENO, 2004; LIRBÓRIO, 2014).

\footnotetext{
${ }^{39} \mathrm{O}$ aspecto da cotonicultura a qual nos deteremos está mais relacionada à lavoura propriamente dita, as outras etapas que englobam o setor, como beneficiamento, industrialização não serão aqui abordados.

40 O IAC foi criado sob pressão dos produtores de café de São Paulo. Inicialmente com o nome de Estação Imperial Agronômica de Campina. A Estação fazia parte da administração federal, só em 1891 é que passou a ser administrado pelo Governo Estadual.
} 
A partir da primeira década do século XX observa-se um conjunto de ações, com o objetivo de fortalecer a cultura algodoeira no país. A Primeira Guerra Mundial contribuiu duplamente para isso. Primeiro porque o algodão, além de ser matéria prima da indústria têxtil, possui um subproduto importante para a indústria bélica, o línter. Moreira e Santos (1994) destacam a valorização desse produto no mercado internacional no referido período:

Com a eclosão da Guerra, aumentou a procura do algodão no mercado internacional, pois o produto além de servir para a fabricação de tecidos, teve no línter que produz, um dos insumos básicos para a produção de pólvora. Em consequência, o preço desta matéria prima, vinha experimentando sensível queda após 1870, quando foi cotado na base de 10cents por libra peso, voltou, novamente a subir a partir de 1915 atingindo, em 1920, 35 cents por libra peso. Por sinal um valor bem próximo do vigente durante a Guerra de Secessão (MOREIRA e SANTOS, op.cit., p. 40).

O Segundo motivo foi o aumento da demanda interna pelo algodão, pois devido às dificuldades na importação de tecidos, as indústrias têxteis que já existiam no Brasil passaram a suprir o mercado interno de tecidos. Nesse período houve no Nordeste acelerado crescimento na produção algodoeira. Além de exportar para o mercado internacional, o Nordeste era responsável pelo fornecimento do algodão de fibra longa utilizado na indústria têxtil paulista, já que os algodões cultivados no Sudeste possuíam fibras médias (VINCENZI, 1944; IANNI, 1991; MOREIRA e SANTOS, 1994).

Em 1912 foi criada por meio do Decreto Federal N.9.803 de nove de outubro de 1912 a Estação Experimental de Coroatá, no município do mesmo nome, no Estado do Maranhão com o objetivo de cultivo intensivo do algodoeiro neste município. Primeira estação experimental de algodão no Brasil. Em 1915 é criado o Serviço Federal do Algodão, vinculado ao Ministério da Agricultura, Serviço criado para tratar do algodão brasileiro. O Serviço Federal do Algodão, teve vida efêmera e foi desativado em 1916, por falta de recursos. O mesmo foi recriado em 1921, e passou a atuar interligado com os Serviços Estaduais do Algodão (MOREIRA e SANTOS, 1994).

Embora o algodão fosse cultura importante no país, o conjunto do setor enfrentava vários problemas, desde os relacionados a qualidade das sementes, beneficiamento, manejo, entre outras. Em 1916, devido a realização da 
Conferência Algodoeira, que ocorreu no Rio de Janeiro, da qual participaram autoridades públicas, produtores, industriais etc., chegou-se ao consenso de que medidas deveriam ser tomadas para melhorar as condições técnicas de produção dessa lavoura e de sua cadeia.

Foi cobrado do Governo Federal e das outras esferas administrativas medidas que modificassem essa situação, entre elas a criação de Estações Experimentais, onde pudessem ser desenvolvidas variedades puras, seleção de sementes. Um dos maiores problemas do algodão brasileiro estava na grande mistura de sementes. Essa mistura fazia com que o algodão cultivado não tivesse uniformidade em suas características. Assim no geral os algodões brasileiros quando classificados para serem comercializado no mercado internacional, apresentavam classificação baixa e isso afetava sensivelmente 0 preço do produto (MOREIRA e SANTOS, 1994).

Segundo Moreira e Santos (op. cit.) mesmo diante dos apelos para os cuidados com a lavoura algodoeira, só a partir da década de 1920 é que surgiram os primeiros indícios de mudança. Aconteceu por conta da crise pela qual passou a indústria têxtil inglesa, consequência da praga do bicudo, que atingiu os algodoais dos EUA em 1918. Por conta dessa praga que 70 anos depois provocou grave crise na cotonicultura brasileira, o Brasil sediou dois eventos: 1) a vinda de representantes de dois agrônomos ingleses, que vieram conhecer a produção de algodão brasileira e 2) a Conferencia Internacional Algodoeira, em 1921, no Rio de Janeiro.

Destacaram-se os trabalhos dos agrônomos Arno e Normam Pearse. Esses fizeram verdadeira incursão pelo Brasil, afim de conhecer a diversidade de produção do algodão brasileiro, óbvio que com a intenção de influenciar, para que a produção nacional atendesse aos interesses da Inglaterra. Como resultado da Conferência e diante da situação de atraso na cotonicultura nacional, foi recomendada a criação da "Estação Experimental do algodão Mocó" na região do Seridó, criada somente em 1930 (MOREIRA e SANTOS, 1994).

A reativação no Serviço do Algodão, foi particularmente importante na busca pela modernização da produção algodoeira no país. Sob seu comando foi instalada uma Fazenda Experimental em Igarapé, no Pará para multiplicação de 
sementes. Foi criado nos Estados produtores de algodão, um equivalente ao Serviço Federal do Algodão. Esses Serviços Estaduais do Algodão, tinham como objetivo organizar a produção algodoeira, tentando superar os principais gargalos do setor, como: seleção de sementes, uniformização do tamanho das fibras, escolha adequada dos descaroçadores de acordo com o tipo de fibras.

Nesse período foram criadas várias sementeiras e Estações Experimentais de algodão. No Quadro 11 estão relacionados as estações experimentais criadas e o tipo de algodão que era de sua competência. Além das pesquisas desenvolvidas nas Estações Experimentais públicas que constam no Quadro 11, havia pesquisas sendo realizadas em propriedades particulares, como na Fazenda São Miguel, localizada no município de Angicos, Rio Grande do Norte. Essa propriedade foi adquirida, por iniciativa dos ingleses que de acordo com Santos e Moreira (1994, p. 135), tinham como objetivo " a implantação de um núcleo de trabalho objetivando a melhoria da qualidade do algodão de fibra longa do Nordeste brasileiro".

Quadro 11 - Estações Experimentais de Algodão no Brasil na década de 1920

\begin{tabular}{|c|c|c|c|c|}
\hline \multirow{2}{*}{$\begin{array}{c}\text { Estação } \\
\text { Experimental }\end{array}$} & \multirow[t]{2}{*}{ Município } & \multirow[t]{2}{*}{ Estado } & \multicolumn{2}{|c|}{ Tipo de Algodão } \\
\hline & & & Arbóreo & Herbáceo \\
\hline Caroatá & Caroatá & Maranhão & & $\mathrm{X}$ \\
\hline Surubim & Surubim & Pernambuco & & $\mathrm{X}$ \\
\hline Vila Bela & $\begin{array}{l}\text { Vila Bela* atual } \\
\text { Serra Talhada }\end{array}$ & Pernambuco & $X$ & \\
\hline Cruzeta & Cruzeta & $\begin{array}{c}\text { Rio Grande do } \\
\text { Norte }\end{array}$ & $\mathrm{X}$ & \\
\hline $\begin{array}{l}\text { Santo Antônio } \\
\text { de Pitaguanri }\end{array}$ & Maranguape & Ceará & & \\
\hline Quissamã & Quissamã & Sergipe & & \\
\hline Santa Luzia & Santa Luzia & Paraíba & & \\
\hline Sete Lagoas & Sete Lagoas & Minas Gerais & & \\
\hline Miguel Calmon & $\begin{array}{l}\text { Barra dos } \\
\text { Coqueiros }\end{array}$ & Sergipe & & \\
\hline
\end{tabular}

Fonte: MOREIRA e SANTOS, 1994.

Org.: LIRBÓRIO, L.F. 2016.

Ainda naquela década estava em curso no Brasil um conjunto de ações para modernizar a lavoura algodoeira. Nos diversos estados produtores havia alguma iniciativa com o objetivo de melhorar a cultura, mas o caso mais bem 
sucedido foi o das pesquisas desenvolvidas pela Seção do Algodão, criada em 1924 no Instituto Agronômico de Campinas. É importante observar que em 1924 a Seção de Algodão do IAC desenvolveu o primeiro programa de melhoramento do algodoeiro, sendo considerado pioneiro na pesquisa de melhoramento genético do algodão (Vincenzi,1944).

De acordo com Moreira e Santos (1994), nos Estados brasileiros, produtores de algodão várias medidas estavam em curso para transformação da lavoura algodoeira. Em Pernambuco, os autores destacam o trabalho desempenhado pelo Serviço Estadual do Algodão. Esse Serviço, deu orientações práticas sobre a cultura.

Foi criado por esse Serviço o Campo de Sementeira de Surubim, depois transformado em Estação Experimental. Com o objetivo alcançar a pureza das variedades cultivadas no Estado, foram criadas normas que regulavam as áreas de cultivo. Assim foi proibido o plantio de algodão herbáceo no Sertão como forma de manter a pureza do algodão mocó. Conforme os autores (op.cit., p. 129), " todas as medidas tomadas constituíram-se em providencias importantes a julgar pelo estado de atraso e abandono a que se achava relegada, na época, a lavoura algodoeira de Pernambuco".

Na Paraíba, algumas iniciativas também estavam em andamento. Vale ressaltar que na década de 1920 estava localizado no Estado um dos principais centros de comercialização de algodão do Brasil, Campina Grande. Segundo Moreira e Santos (op. cit., p. 130) funcionou no Estado citado o "Serviço de Defesa do Algodão, criado em 1921, a partir do Decreto Estadual o 117 de maio deste ano".

No mesmo ano é instalado no Estado o Serviço Oficial de Inspeção e de Classificação do Algodão, instalado em João Pessoa, primeiro da região Nordeste, posteriormente o Serviço estendeu-se para Campina Grande. A função desse Serviço era classificação do algodão. Também havia no Estado no município a Estação Experimental de Santa Luzia, mantida pelo governo estadual (MOREIRA e SANTOS, op.cit.).

No Ceará foi iniciado em 1923 Programa de Melhoramento de Algodão, conduzido pelo Estado. Nas palavras de Moreira e Santos (op.cit., p. 129), esse 
foi o primeiro Programa sério de melhoramento genético de algodão no Brasil que "objetivava a criação e produção de sementes das variedades produzidas no próprio Estado". As pesquisas foram conduzidas pelo melhorista inglês, Bernard Geofrey Bolland e que já havia desenvolvido trabalho semelhante no Egito. Segundo os autores citados, o objetivo do Governo estadual era firmar o algodão cearense no mercado nacional da fibra. Os progressos alcançados pelo respectivo Estado tiveram resultados:

Em 1924, por exemplo assinava acordo com o governo federal no sentido de melhorar e incrementar a cultura algodoeira. Em julho de 1926, com o apoio do governo estadual e a colaboração do Centro de Exportações do Ceará, era criado o 'Serviço Oficial de Inspeção e de Classificação do Algodão', com a primeira sala de classificação vindo a funcionar na Rua Boris Freres, em Fortaleza (MỎEIRA; SANTOS,op.cit, p. 131).

Em Sergipe, foi criado em 1923 o Departamento Estadual do Algodão, as pesquisas nesse Departamento ficaram a cargo do norte-americano, o Prof. Thomas Roosevelt Day. As pesquisas práticas foram desenvolvidas na Estação Experimental Miguel Calmon, no município de Barra dos Coqueiros, criada para esse fim. Posteriormente o governo estadual criou algumas subestações experimentais nos municípios de Nossa Senhora das Dores, Propriá, Estância, e Cândido Rodrigues. Além do algodão era realizada pesquisa sobre outras culturas nessas subestações (MOREIRA e SANTOS, op.cit.).

A partir do exposto até aqui, pode-se afirmar que houve grande esforço no sentido transformar a cotonicultura nordestina no primeiro quartel do século XX, mas o caso mais bem sucedido ocorreu em São Paulo. A partir dos resultados alcançados no Programa de Melhoramento de Algodão do IAC, as pesquisas desenvolvidas sob a liderança de Cruz Martins, insere o algodão brasileiro no período técnico. Mas como característica desse período proposto por Santos e Silveira (2011) as densidades técnicas ficavam concentradas em pontos quase isolados.

Segundo Vincenzi (1944), as pesquisas genéticas realizadas pelo pesquisador Cruz Martins em 1924, no IAC, que culminou em 1930 no desenvolvimento de cinco variedades de algodão, é um marco da agricultura científica no país. Ainda, para o autor, a mudança alcançada pela cotonicultura 
em São Paulo, é fruto essencialmente da ciência e o IAC é o grande responsável por tal feito. "Nos fastos das grandes realizações brasileiras, só uma a meu ver, se ombreia ao surto algodoeiro de S. Paulo. Refiro-me à obra da medicina experimental da Escola de Oswaldo Cruz. É instrutivo acentuar que tanto uma quanto outra foram, tipicamente, obras da ciência" (VINCENZI, 1944.p.26).

As variedades desenvolvidas nesse Programa de Melhoramento foram obtidas dentro da racionalidade técnica do período: obedeciam ao padrão de exigência, que vai desde a qualidade das fibras, resistência, finura, resistência à determinadas pragas, a períodos de seca, entre outros.

3.3.4. A nova racionalidade na produção algodoeira e a hegemonia de São Paulo

Conforme mencionado no item anterior, a década de 1920 foi um prenúncio de mudanças na cotonicultura brasileira. As pesquisas desenvolvidas pelo IAC e a articulação com atores públicos e privados foram essenciais para o processo de progresso da cultura algodoeira em São Paulo. Segundo Moreira e Santos (1994), a razão do progresso da cotonicultura paulista tem a ver também com a pressão exercida pelos industriais do setor têxtil daquele estado, que resultou na estatização na produção de sementes. Além disso foi desenvolvido trabalho de extensão rural e criação da Bolsa de Mercadorias na cidade de São Paulo.

No caso de São Paulo, a explicação para o inusitado progresso observado deve-se entre outros fatores, ao 'grupo de pressão' formado pela indústria têxtil paulista, por sinal já na década de 30 a mais dinâmica do país, em termos de produção, número de fusos e teares empregados. Assim sendo ela não só direcionou o esforço da pesquisa do Instituto Agronômico de Campinas (IAC), para a melhoria da qualidade da fibra do algodão paulista, como ainda teve suficiente prestígio para induzir o Estado a criar todo um aparato destinado a garantir os objetivos que tinha em mira. A prova disto foi a estatização da multiplicação, controle e distribuição de sementes de algodão e a criação da Bolsa de Mercadorias, na verdade dois importantes agentes de indução do progresso da cotonicultura paulista.

[...] Com a criação da Bolsa de Mercadorias organizou-se a comercialização e, com isto passaram a ser taxados os tipos de algodão inferiores e premiados os superiores, no que resultou na melhoria no padrão da fibra do algodão (MOREIRA e SANTOS, op.cit., 156). 
O crescimento da cotonicultura paulista está diretamente ligado à crise econômica mundial de 1929. A mencionada crise afetou os mercados de todos os países. O Brasil que na época ainda era um país de economia agrária exportadora, viu sua principal commodity, o café, ser desvalorizado a ponto de o Estado comprar e queimar café como forma de recuperar os preços desse produto no mercado, induzindo a uma redução de sua oferta.

Diante do contexto de crise apresentada, o Estado decido estimular a lavoura algodoeira. Assim segundo Ziscka em 1935 o governo brasileiro criou o "Plano do Algodão Brasileiro". O que segundo o autor citado gerou pressão por parte de alguns países da América que criaram ainda mais especulação para baixar os preços do café, com o objetivo de intimidar o Brasil. A resposta dada pelos brasileiros, por sua vez foi ainda mais audaciosa e provocou instabilidade no mercado mundial do produto.

Os brasileiros, porém, responderam com um plano mais eficaz ainda: Aumentaram de quatro vezes a produção de algodão. Em lugar das 120.000 toneladas de ontem, produziram agora 500.000. Consequência: a cotação de algodão em Nova -York baixou de 1 'cent'. Num ambiente de pânico, a 14 de março de 1935, a Bolsa de Algodão de Osaka suspendeu suas transações por causa da derrota americana. O plano algodoeiro brasileiro tinha abalado o mundo (Ziscka,op.cit., $p$. 113).

Internamente, como já mencionamos, a lavoura algodoeira também possuía mercado, especialmente devido ao crescimento da indústria têxtil nacional, concentrada em núcleos no Nordeste, mas principalmente em São Paulo. Esse contexto corroborou para que o Estado de São Paulo a partir da década de 1930, assumisse a liderança na produção nacional de algodão.

Mesmo diante do crescimento da produção algodoeira em São Paulo, onde as racionalidades da produção estavam presentes, como a disponibilidade de sementes, também aí já existia maior concentração de máquinas agrícolas, o Nordeste ainda mantinha a maior área plantada de algodão.

Nessa região, os esforços empreendidos durante a década de 1920 não haviam se consolidado e alguns problemas persistiam, principalmente os relacionados a mistura de sementes e sua consequente hibridação. A estrutura agrária e social também se constituía limite para as transformações da lavoura 
na região. A seguir serão apresentadas em escala de tempo relativamente longo, as pesquisas de melhoramento do algodão desenvolvidas na região Nordeste.

\subsubsection{A pesquisa para o melhoramento genético do algodão no Nordeste}

Desde a época do descobrimento da América até o período da Guerra de Secessão nos Estados Unidos, o Nordeste cultivava exclusivamente os algodões dos tipos "Rim-de-Boi" - Gossypium barbadense v. brasiliense, e "Quebradinho" - Gossypium barbadense, nativos do Brasil. A partir de 1860 foram introduzidas os tipos " Upland” americanos - Gossypium hirsitum var. latifolium no Nordeste, por meio de sementes importadas diretamente da América do Norte.

A seca de 1877 provocou a morte da maioria das plantações de algodão do Nordeste, restando apenas as raízes de um algodão, posteriormente conhecido como "Mocó" na região do Seridó do Rio Grande do Norte. Destas lavouras remanescentes se processou a expansão do algodão "Mocó" por toda a zona semiárida do Nordeste, a partir de 1880, chegando este tipo a ocupar já nas primeiras décadas do século $X X$, áreas ora do herbáceo, ora do Inteiro e Quebradinho, ou até mesmo, convivendo em mistura com os diversos tipos de algodoeiros em uma mesma área (FREIRE e BARREIRO NETO, 1983).

Em função do plantio de espécies diferentes em uma mesma área, ocorreu naturalmente a mistura de sementes nas usinas de descaroçamento, além de cruzamento entre espécies, surgindo um tipo híbrido de línter verde e com características intermediarias entre o algodão herbáceo Upland e os tipos arbóreos (Mocó ou Rim-de-Boi), conhecido como Verdão. Essa situação de variedades diferentes plantadas em áreas comuns permaneceu por muito tempo.

Em pesquisa realizada pelo Centro Nacional de Pesquisa do Algodão em 1979 no Estado do Ceará, foi constatada a permanência dessa prática de cultivar variedades diferentes em uma mesma área. Segundo a referida pesquisa a disposição da plantação das diversas variedades se dava na seguinte proporção: em apenas $8 \%$ dos municípios cultivava-se algodão Mocó, enquanto que a mistura destes com o Verdão eram encontrados em $47 \%$ dos municípios e o cultivo simultâneo do Mocó e Herbáceo em um mesmo município era encontrado 
em mais de $75 \%$ dos casos. Verificou-se também, que o plantio de tipos misturados (mistura não identificável), atingiu 45 \% dos municípios em 1979 (FREIRE e BARREIRO NETO, 1983).

Um dado que nos chama atenção para a produção do algodão no Nordeste é a baixa produtividade, enquanto no Centro Sul a produtividade é maior. Essa situação decorre de que no Centro Sul houve à introdução de cultivares com melhores rendimentos em virtude de melhoramento genético.

No Nordeste do Brasil temos um fenômeno inverso do que ocorre do Centro Sul com referência as estatísticas do algodão. Na região Centro-Sul no período de 1947 a 1978 a área plantada diminuiu de 373.697 ha, mas a produção de algodão aumentou em 293.679 toneladas, devido ao aumento de produtividade por área, que no mesmo período passou de $526 \mathrm{~kg} / \mathrm{há}$ para 1.265 $\mathrm{kg} / \mathrm{ha}$.

Os números para o Nordeste para o mesmo período foram os seguintes: a área plantada aumentou em 1.587.176 ha, mas a produção aumentou em apenas 22.362 toneladas em virtude de uma queda na produtividade de $306 \mathrm{~kg} / \mathrm{ha}$ para $218 \mathrm{~kg} / \mathrm{ha}$ (FREIRE e BARREIRO NETO, 1983, pág. 5).

Freire e Barreiro Neto (1983) constatam que, se por um lado houve um aumento da área e percentual da produção da variedade Mocó no Nordeste, na década de 1980, por outro o Estado e o setor privado foram ineficientes na redução das variedades consideradas indesejadas e das possíveis misturas, conforme pode ser verificado nos dados a seguir:

\begin{abstract}
Durante a safra de 1980 a área plantada no Nordeste foi de 572.456 ha de algodoeiros herbáceos e 2.543.579 ha de algodoeiros arbóreos. Entretanto, deve-se incluir dentre esses últimos 11, 3\% de tipos Verdão (265.000 ha) e 217.866 ha de tipos Barbadense do Piauí e do Maranhão, o que nos deixaria 1.862 .713 ha de algodoeiro Mocó. Feitos esses cálculos constatamos que em 1980 eram encontrados no Nordeste as seguintes proporções; 63,8 \% Mocó; 9,1\% Verdão; 7,5\% Quebradinho e Rim-de-Boi e 19,6\% Herbáceo, o que vem a demonstrar que de 1923 para 1980, a ação pública e privada foi suficiente apenas para alterar as proporções em favor do algodão Mocó, mas sem possibilitar a retirada dos campos, das variedades indesejadas como o Verdão, e/ou dos tipos antigos, como o Rim de Boi e o Quebradinho (FREIRE; BARREIRO NETO,1983, p. 5).
\end{abstract}

Para Crisóstomo e Neves (1980 apud FREIRE e BARRETO NETO, 1983, p.5) a permanência desses tipos de algodoeiros nos campos do Nordeste implicou que a qualidade da fibra produzida fosse de " $61,6 \%$ de fibras médias, $21,8 \%$ de fibras longas e extra - longas, mas apresentava ainda $18,3 \%$ de fibras 
curtas e desuniformidade de baixo valor comercial e utilização industrial marginal".

Ainda no referido estudo os autores mostram que os mesmos problemas enfrentados no Nordeste foram superados no Centro Sul a partir da integração entre pesquisa agronômica, os serviços de produção e distribuição de sementes, a assistência técnica e o marcado de fibras (Bolsa de Mercadorias), permitiram que em apenas dez anos de (1955-1965) fosse possível o Estado de São Paulo eliminar toda a fibra curta (abaixo de $30 \mathrm{~mm}$ ) produzida no Estado além de elevar a produtividade média estadual de 882 para $1.290 \mathrm{~kg} / \mathrm{ha}$.

Em relação à introdução de sementes melhoradas, os autores acima citados chamam atenção para o baixo percentual, tendo sido $44 \%$ nos campos de algodão herbáceo e 25\% nos de algodão arbóreo. Esses percentuais ainda trazem consigo problemas, algumas das sementes introduzidas eram oriundas da região Sudeste e não adaptadas para as condições climáticas do Nordeste, o que implica que as mesmas não apresentavam os mesmos rendimentos que na região de origem. Nos casos em que havia a introdução de novas sementes essas ainda se davam com um longo período de tempo, enquanto no Sudeste esse intervalo era menor.

Essa situação é resultado da falta de interesse dos Estados em investirem na modernização das práticas agrícolas, ainda que o algodão seja um importante produto econômico. Segundo Freire e Barreto Neto:

\begin{abstract}
Apenas esta constatação explica o fato da disseminação de uma tecnologia simples como a mudança de uma semente ser feita com tanta demora na região, chegando em casos extremos, em que se levou 26 anos para iniciar a substituição da SL - 9193, pela Veludo C - 71, quando se sabe que em São Paulo, tal substituição é feita a cada intervalo de 5 anos (FREIRE e BARREIRO NETO ,1983, p. 7).
\end{abstract}

A falta de assistência técnica aos produtores, também é um fato que comprometia o desempenho da atividade. Além dos fatores citados, são mencionados aspectos, relacionados ao arcaico sistema agrário, baixa escolarização dos indivíduos, baixa capitalização como entraves à modernização da cultura algodoeira na região.

As pesquisas de melhoramento genético do algodão arbóreo e herbáceo no Nordeste se iniciaram 1920 conforme analisado no item 1.3.1 desse capitulo. 
Em relação às pesquisas para o desenvolvimento de materiais genéticos de melhor qualidade para o algodão no Nordeste os autores citam, o SU 0450/8909, desenvolvido em 1968 na Estação Experimental de Surubim - PE, e que foi a principal cultivar plantada nos Estados da Paraíba e Rio Grande do Norte, e a variedade SL - 9193, desenvolvida em 1949 pela Estação Experimental de Cruzetas- RN ${ }^{41}$. Essa última é considerada responsável pela consolidação e ampliação do cultivo do algodão Mocó em bases comerciais em todo o Nordeste.

As contribuições dos pesquisadores da Estação Experimental de Cruzetas no que se refere ao trabalho de melhoramento da variedade SL - 9193 pode ser constatada na passagem descrita por Freire e Barreto Neto, $(1983$, p.8) "Pela ação dos melhoristas essa variedade foi dotada de características excepcionais de fibras, comparáveis com as dos melhores tipos de fibras longas produzidas no mundo".

Antes da criação da Embrapa Algodão em 1975, Freire e Barreto Neto (1983), enfatizam como marco de um novo período na pesquisa para cotonicultura no Nordeste a atuação da Superintendência de Desenvolvimento do Nordeste (SUDENE), no período de 1965-1975. As ações da SUDENE tiveram como objetivo tirar da situação de estagnação a produção cotonicultora da região. Para isso várias medidas foram tomadas no sentido de dinamizar os parques têxteis da região.

No Relatório do Grupo de Estudos para o Desenvolvimento do Nordeste (GNTD), de 1959 que serviu como base para as ações delineadas no sentido de atuar nos gargalos do desenvolvimento regional do Nordeste, Celso Furtado defendia que a manutenção do sistema produtivo gado-algodão-policultura, especialmente no Sertão era nefasto para o desenvolvimento dessa região.

A SUDENE procurou desenvolver suas políticas e metas no sentido de dinamizar a economia do Nordeste, preocupada com a industrialização e modernização dos setores tradicionais, como a cana-de-açúcar e a indústria têxtil, a qual o algodão é a principal matéria prima. Para isso nos primeiros anos dessa instituição há grande aproximação com as Universidades e Centros de

\footnotetext{
${ }^{41}$ As duas Estações Experimentais inicialmente pertenciam a seus respectivos estados depois passaram a fazer parte da rede pesquisa do Instituto de Pesquisas e Experimentação Agropecuárias do Nordeste -IPEANE, Instituto responsável pela pesquisa agropecuária na região, entre 1943-1973.
} 
Pesquisa, com o objetivo de conhecer quais os reais potenciais da região e como melhor explorá-los.

Segundo Freire e Barreto Junior (1983) com o objetivo de dinamizar a produção algodoeira no Nordeste a SUDENE coordenou dois projetos nesse sentido.

- Através das resoluções №s 61 e 64 do Conselho de Desenvolvimento Industrial, reservou-se para o Nordeste a responsabilidade do crescimento da indústria têxtil nacional, oferecendo subsídios às indústrias que se instalaram ou se relocalizarem naquela região, de modo a propiciar a implantação de um polo têxtil com 2.600,000 fusos;

- Passou a financiar e coordenar as pesquisas com algodão no Nordeste, através da ação da Divisão de Pesquisa e Experimentação desta autarquia.

Mesmo com as ações coordenadas pela SUDENE, a pesquisa algodoeira no Nordeste ainda era pequena e difusa no território, enquanto no Sudeste a pesquisa estava mais concentrada. Com a criação da Embrapa Algodão em Campina Grande em 1975, houve maior concentração da pesquisa, uma vez que esse instituto definia e orientava como deveria ser o manejo e as melhores práticas para a produção do algodão.

A criação desse Centro de pesquisa marca uma nova fase em relação à cultura algodoeira no Nordeste e no Brasil, especialmente por que esse Centro buscou gerar tecnologias para o algodoeiro cultivado na região e por concentrar elevado número de pesquisadores altamente qualificados.

Além das instituições públicas, o setor privado foi importante no desenvolvimento de algumas pesquisas na região, tais como: a Algodoeira São Miguel e Instituto Nordestino de Fomento ao Algodão e Oleaginosas (INFAOL). A Fazenda São Miguel, localizada em Angicos - RN desde 1924 vinha desenvolvendo ininterruptamente programas de melhoramento genético, produção de sementes e comercialização do algodão na região. Desde o início de suas atividades a Fazenda São Miguel desenvolveu os seguintes materiais, tendo como recurso genético o algodão Mocó: MF-1, MF-2, MF-3 e MF-4, dos quais distribuiu anualmente $253 \mathrm{t}$ de sementes para os agricultores do Rio Grande do Norte (Freire e Barreto Junior, 1983).

A pesquisa agrícola no Brasil toma novo rumo a partir da criação do Centro Nacional de Pesquisa do Algodão (CNPA) - Embrapa Algodão, 
localizada na cidade de Campina Grande - PB. Esse Centro de pesquisa criado em 1975, é uma das Unidades de Pesquisa de Produto da Empresa Brasileira de Pesquisa Agropecuária - Embrapa, fundada em 1973, vinculada ao Ministério da Agricultura Pecuária e Abastecimento, como parte do projeto de modernização da agricultura no país na década de 1970.

Quando foi criada a Embrapa Algodão, tinha como objetivo o desenvolvimento de conhecimento e tecnologias relacionadas ao cultivo do algodão em todo o território brasileiro. Na época o Nordeste ainda possuía a maior área plantada de algodão e maior produção, contudo baixa produtividade. Predominava a produção da variedade Gossypium hirsitum marie galante, de ciclo perene de até 4 anos, popularmente conhecido como algodão Mocó. O Sudeste liderado pelo Estado de São Paulo, possuía a segunda maior produção e a maior produtividade nacional. As regiões Norte e Centro-Oeste eram pouco representativas nessa cultura, conforme pode ser analisado na Tabela 2. 
Tabela 2 - Área Plantada, Produção Algodão em Caroço e Produtividade do Algodão em Caroço, por Região Geográfica, e Estados do Brasil na safra 1975/1976.

\begin{tabular}{|c|c|c|c|}
\hline \multirow{3}{*}{ REGIÃO/UF } & \begin{tabular}{|c|} 
Área Plantada \\
(Em mil hectares) \\
\end{tabular} & \begin{tabular}{|c|}
$\begin{array}{c}\text { Produção Algodão em Caroço } \\
\text { (Em mil toneladas) }\end{array}$ \\
\end{tabular} & $\begin{array}{l}\text { Produtivida Algodão } \\
\text { em Caroço (kg/ha) }\end{array}$ \\
\hline & \multicolumn{3}{|c|}{ Safra } \\
\hline & \multicolumn{3}{|c|}{1975 / 1976} \\
\hline NORTE & - & - & - \\
\hline $\mathrm{RR}$ & - & - & - \\
\hline $\mathrm{RO}$ & - & - & - \\
\hline$A C$ & - & - & - \\
\hline AM & - & - & - \\
\hline $\mathrm{AP}$ & - & - & - \\
\hline PA & - & - & - \\
\hline \multicolumn{4}{|l|}{ TO } \\
\hline \multicolumn{4}{|l|}{ NORDESTE } \\
\hline MA & 44,4 & 6,7 & 150 \\
\hline $\mathrm{PI}$ & 141,2 & \begin{tabular}{|l|l}
13,3 \\
1
\end{tabular} & 94 \\
\hline $\mathrm{CE}$ & $1.296,0$ & 233,3 & 180 \\
\hline $\mathrm{RN}$ & 559,9 & 100,2 & 179 \\
\hline PB & 666,7 & \begin{tabular}{|l|}
116,7 \\
\end{tabular} & 175 \\
\hline PE & 300,9 & \begin{tabular}{|l|}
83,3 \\
\end{tabular} & 277 \\
\hline$\overline{A L}$ & 99,3 & \begin{tabular}{|l|l}
20,0 \\
\end{tabular} & 201 \\
\hline SE & 15,9 & \begin{tabular}{|l|}
3,3 \\
\end{tabular} & 210 \\
\hline $\mathrm{BA}$ & 123,4 & 23,3 & 189 \\
\hline CENTRO-OESTE & 141,5 & 125,5 & 886 \\
\hline MT & - & - & - \\
\hline MS & 68,4 & \begin{tabular}{l|l}
44,9 \\
\end{tabular} & 656 \\
\hline $\mathrm{GO}$ & 73,1 & \begin{tabular}{|l|}
80,6 \\
8
\end{tabular} & 1.102 \\
\hline \multicolumn{4}{|l|}{ DF } \\
\hline SUDESTE & 416.3 & 643,2 & 1.545 \\
\hline$M G$ & 116,2 & 88,3 & 760 \\
\hline ES & - & - & - \\
\hline RJ & - & - & - \\
\hline SP & 3001 & 554.9 & 1.849 \\
\hline SUL & 290,4 & 394,1 & 1.357 \\
\hline PR & 290,4 & 394,1 & 1.357 \\
\hline SC & - & - & - \\
\hline$R S$ & - & - & - \\
\hline
\end{tabular}

Fonte: Conab, 2016.

Org.: LIRBÓRIO, L.F. 2016.

3.3. 6 - Crise na cotonicultura brasileira (1980-1995)

A cotonicultura brasileira sofreu grande golpe na década de 1980, com a introdução da praga do besouro bicudo (Anthomonus grandis Boheman), que quase dizimou a produção de algodão no país. Além da referida praga outros fatores contribuíram para acentuar a crise na cotonicultura nacional. Nesse período o Brasil, que já possuía vários núcleos da indústria têxtil consolidados, passou a importar algodão.

Entre os fatores que corroboraram para agravamento da crise se destacam: a falta de recursos financeiros dos pequenos produtores; a falta de 
crédito por parte das agencias financiadoras (bancos); a Constituição de 1988; que entre tantas contribuições reviu os direitos dos trabalhadores; o que provocou nos grandes proprietários de terras do Nordeste o temor de que os "moradores de condição" adquirissem o direito de posse das terras onde trabalhavam e moravam, provocando a expulsão de muitos desses trabalhadores.

Somado a esses fatos o Brasil vivia em plena abertura comercial, com a inserção de produtos têxteis mais baratos, provocando a desestruturação dessa cultura. Diante desse quadro o Brasil deixa de ser um grande produtor e exportador de algodão e passa a ser importador, conforme pode ser constatado nas Tabelas 3 e 4 (BRASIL, 2007; SANTOS et al., 2008). Essa situação vai persistir até a segunda metade da década de 1990. 
Tabela 3 - Os dez principais países em área colhida de algodão (ha) (1975-1976, 1980-1981, 1985-1986, 1995-1996, 2005-2006, 2010-2011, 2015-2016)

\begin{tabular}{|c|c|c|c|c|c|c|c|c|}
\hline \multicolumn{8}{|c|}{ Área Colhida (ha) } & \multirow[b]{2}{*}{ 2015-2016 } \\
\hline 1975-1976 & 1980-1981 & 1985-1986 & 1990-1991 & 1995-1996 & 2000-2001 & 2005-2006 & 2010-2011 & \\
\hline Índia & Índia & Índia & Índia & Índia & Índia & Índia & Índia & Índia \\
\hline China & EUA & China & China & EUA & EUA & China & China & EUA \\
\hline EUA & China & EUA & EUA & China & China & EUA & EUA & China \\
\hline URSS & URSS & Brasil & URSS & Paquistão & Paquistão & Paquistão & Paquistão & Paquistão \\
\hline Paquistão & Brasil & URSS & Paquistão & Uzbequistão & Uzbequistão & Uzbequistão & Brasil & Uzbequistão \\
\hline Brasil & Paquistão & Paquistão & Brasil & Argentina & Canada & Brasil & Uzbequistão & Brasil \\
\hline Turquia & Uzbequistão & Uzbequistão & Uzbequistão & Brasil & Brasil & Burkina Faso & Turquemenistão & Burkina Faso \\
\hline Uganda & Turquia & Turquia & Turquia & Turquia & Turquia & Turquemenistão & Austrália & Mali \\
\hline Egito & Egito & Egito & Turquemenistão & Turquemenistão & Austrália & Turquia & Argentina & Turquemenistão \\
\hline Nigéria & Nigéria & Tanzânia & Paraguai & Grécia & Turquemenistão & Mali & Tanzânia & Turquia \\
\hline
\end{tabular}

Fonte: Comitê Consultivo Internacional do Algodão (ICAC) - 2016

ORG. e ELAB: LIRBÓRIO, L. F, 2016. 
Tabela 4 - Os dez principais países em produção de algodão (T) (1975-1976, 1980-1981, 1985-1986, 1995-1996, 2005-2006, 2010-2011, 2015-2016)

\begin{tabular}{|l|l|l|l|l|l|l|l|l|}
\hline \multicolumn{7}{|c|}{ Produção (Toneladas) } \\
\hline $\mathbf{1 9 7 5 - 1 9 7 6}$ & $\mathbf{1 9 8 0 - 1 9 8 1}$ & $\mathbf{1 9 8 5 - 1 9 8 6}$ & $\mathbf{1 9 9 0 - 1 9 9 1}$ & $\mathbf{1 9 9 5 - 1 9 9 6}$ & $\mathbf{2 0 0 0 - 2 0 0 1}$ & $\mathbf{2 0 0 5 - 2 0 0 6}$ & $\mathbf{2 0 1 0 - 2 0 1 1}$ & $\mathbf{2 0 1 5 - 2 0 1 6}$ \\
\hline URSS & China & China & China & China & China & China & China & Índia \\
\hline China & URSS & EUA & EUA & EUA & EUA & EUA & Índia & China \\
\hline EUA & EUA & URSS & URSS & Índia & Índia & Índia & EUA & EUA \\
\hline Índia & Uzbequistão & Índia & Índia & Paquistão & Paquistão & Paquistão & Brasil & Paquistão \\
\hline Paquistão & Índia & Uzbequistão & Paquistão & Uzbequistão & Uzbequistão & Uzbequistão & Paquistão & Brasil \\
\hline Turquia & Paquistão & Paquistão & Uzbequistão & Turquia & Brasil & Brasil & Austrália & Uzbequistão \\
\hline Brasil & Brasil & Brasil & Brasil & Grécia & Turquia & Turquia & Uzbequistão & Turquia \\
\hline Egito & Egito & Turquia & Turquia & Argentina & Austrália & Austrália & Turquia & Austrália \\
\hline México & Turquia & Egito & Turkmenistan & Austrália & Grécia & Grécia & Turkmenistan & Turkmenistan \\
\hline Síria & México & Austrália & Austrália & Brasil & Síria & Síria & Argentina & Burkina Faso \\
\hline
\end{tabular}

Fonte: Comitê Consultivo Internacional do Algodão (ICAC) - 2016

ORG. e ELAB: LIRBÓRIO, L. F, 2016. 
3.3.7 - A retomada na produção algodoeira do Brasil e as novas dinâmicas (1995-2016)

A retomada da produção do algodão ocorreu na segunda metade da década de 1990, principalmente devido aos esforços da pesquisa agropecuária, que a essa época já se mostrava bem avançada, e a Embrapa Algodão foi essencial nesse processo. Com a modernização da agricultura alguns produtos que já eram importantes para a economia brasileira, tem sua produção resignificada como é o caso da produção do algodão.

Nesse processo de retomada regiões tradicionais na produção de algodão tem suas áreas e produção drasticamente reduzidas, como foram os casos do Semiárido Nordestino e do Sudeste Brasileiro. A partir da década de 1990, as áreas de Cerrado do Centro-Oeste e Nordeste se tornaram os principais locais de produção dessa lavoura. Essa situação foi possível devido ao desenvolvimento de pesquisas e de adaptação de variedades de algodão para as condições edafoclimáticas dos Cerrados brasileiro pela Embrapa Algodão; incentivos fiscais por parte do Estado que reduziu em até $75 \%$ a taxa de impostos sobre a venda desse produto, quando comercializado no mercado nacional e também por conta da infraestrutura que já existia nessa região em que o agronegócio brasileiro de grãos já estava consolidado (COSTA; BRUENO, 2004; BRASIL, 2007; BELTRÃO; AZEVEDO, 2008; SANTOS; SILVEIRA, 2011).

A produção do algodão desenvolvida no Centro-Oeste, com destaque para o estado do Mato Grosso, maior produtor nacional do algodão é completamente diferente da que era desenvolvida no Nordeste, antes da década de 1990, pois se trata de uma produção empresarial. Na Tabela 5 que foi elaborada com base em dados disponíveis no site da Associação Brasileira dos Produtores de Algodão (ABRAPA) constata-se que o Estado com maior área de produção dessa cultura é o Mato Grosso com 475,3 mil ha, seguido pelo Estado da Bahia. Esse ranking de liderança também, se verifica em relação a produtividade e para a produção de pluma de algodão. 
Tabela 5 - Brasil - Área Plantada, Produtividade e Produção de Algodão na Safra 2012/2013 e 2013/2014, segundo estados maiores produtores.

\begin{tabular}{|c|c|c|c|c|c|c|}
\hline \multirow[t]{3}{*}{ REGIÃO/UF } & \multicolumn{4}{|c|}{ Safras $2012 / 2013$ e $2013 / 2014$} & \multirow{2}{*}{\multicolumn{2}{|c|}{$\begin{array}{l}\text { Algodão em Pluma } \\
\text { Produção (em mil t) }\end{array}$}} \\
\hline & \multicolumn{2}{|c|}{ Área (em mil ha) } & \multicolumn{2}{|c|}{$\begin{array}{l}\text { Produtividade (em kg } \\
\text { há) }\end{array}$} & & \\
\hline & $\begin{array}{l}\text { Safra } \\
12 / 13 \\
\end{array}$ & $\begin{array}{l}\text { Safra } \\
13 / 14 \\
\end{array}$ & $\begin{array}{l}\text { Safra } \\
12 / 13 \\
\end{array}$ & $\begin{array}{l}\text { Safra } \\
13 / 14 \\
\end{array}$ & $\begin{array}{l}\text { Safra } \\
12 / 13\end{array}$ & $\begin{array}{l}\text { Safra } \\
13 / 14 \\
\end{array}$ \\
\hline \multicolumn{7}{|c|}{ Nordeste } \\
\hline Bahia & 271,4 & 319,4 & 1.315 & 1.552 & 357,0 & 495,8 \\
\hline Maranhão & 16,7 & 18,6 & 1.568 & 1.635 & 26,2 & 30,4 \\
\hline Piauí & 11,4 & 12,1 & 1.275 & 1.492 & 14,5 & 18,1 \\
\hline \multicolumn{7}{|c|}{ Centro Oeste } \\
\hline Goiás & 46,1 & 53,6 & 1.525 & 1.525 & 70,3 & 81,7 \\
\hline Mato Grosso & 475,3 & 643,1 & 1.559 & 1.505 & 731,3 & 967,8 \\
\hline $\begin{array}{l}\text { Mato Grosso do } \\
\text { Sul }\end{array}$ & 39,5 & 37,5 & 1.724 & 1.659 & 68,1 & 62,2 \\
\hline \multicolumn{7}{|c|}{ Sudeste } \\
\hline Minas Gerais & 20,0 & 20,9 & 1.316 & 1.353 & 26,3 & 28,3 \\
\hline São Paulo & 5,8 & 8,0 & 1.428 & 1.333 & 8,3 & 10,7 \\
\hline \multicolumn{7}{|c|}{ Sul } \\
\hline Paraná & 0,8 & 0,9 & 998 & 903 & 0,8 & 0,8 \\
\hline Total & 887 & $1.114,4$ & 1.412 & 1.440 & $1.302,8$ & $1.695,8$ \\
\hline
\end{tabular}

Fonte: ABRAPA, 2014.

Org.: LIRBÓRIO, L.F. 2014.

O modelo produtivo desenvolvido no Nordeste se caracterizava pelo baixo emprego de técnicas agrícolas; amplo emprego de mão de obra principalmente na época da colheita; os produtores eram, em geral agricultores familiares, cultivando em pequenas propriedades ou em sistema de meação na propriedade dos grandes pecuaristas da região e em associação com outras culturas de subsistência (ANDRADE, [1963] 2005; MELO, 1982).

No Centro-Oeste e no Oeste Baiano, que são os espaços da racionalidade da produção agrícola moderna, predomina uma produção altamente cientificizada, mecanizada e informatizada e com produtores altamente capitalizados. Nessa nova fase de produção, conforme mencionamos, o Semiárido que tradicionalmente tinha no algodão importante fonte de renda para grande número de agricultores familiares, deixa de participar dessa renovação da cultura.

O algodão arbóreo ou Mocó, plantado na região tem sua área reduzida drasticamente. Argumento amplamente utilizado para explicar a drástica redução na produção do algodão arbóreo produzido no Nordeste, é que como essa planta possui ciclo biológico longo seria difícil combater do a praga do bicudo. Essa 
explicação até certo ponto é contraditória, pois os produtores de algodão em sistema agroindustrial não estão livres dessa praga. Os custos com herbicidas, pesticidas para controlar essa e outras pragas são grandiosos. Por sua vez como se trata de produtores altamente capitalizados, os mesmos sem condições arcar com os custos desse processo.

No Nordeste as áreas inseridas no domínio de Cerrado responsáveis pelas maiores produções de algodão da região estão no Estado da Bahia. O município de Luiz Eduardo Magalhães, é o maior produtor de algodão do Estado citado. O Maranhão e o Piauí, também estão apresentando produção crescente de algodão em suas áreas de Cerrado.

O declínio na produção de algodão arbóreo e herbáceo no Nordeste entre 1990 e 2014 pode ser analisado no Mapa 2. Além do Semiárido Nordestino, os Estados de São Paulo e do Paraná, também áreas tradicionais no cultivo de algodão tiveram suas plantações drasticamente reduzidas (Ver, Mapa 3).

Fato que precisa ser considerado é que mesmo o Nordeste, Sudeste e Sul tendo suas produções reduzidas, não significa que os antigos produtores dessas regiões tenham abandonado a cultura. Alguns dos grandes produtores detentores de grandes capitais migraram para áreas de Cerrado e continuaram a produzir, contando com condições vantajosas, como a redução de $75 \%$ de impostos, quando o algodão se destina ao mercado nacional (SANTOS; SILVEIRA, 2011).

Já os pequenos produtores em sua maioria, não tiveram mais como se manter no setor. Com a praga do bicudo era necessário mais de uma aplicação de veneno e os custos tornaram oneroso e inviável sua permanência na atividade. Os agricultores que podiam fazer empréstimos bancários para custear suas produções também enfrentaram dificuldades, pois já não se acreditava mais na viabilidade dessa cultura na região. 
Mapa 2 - Variação na quantidade de algodão arbóreo e herbáceo no Nordeste entre 1990 e 2014.

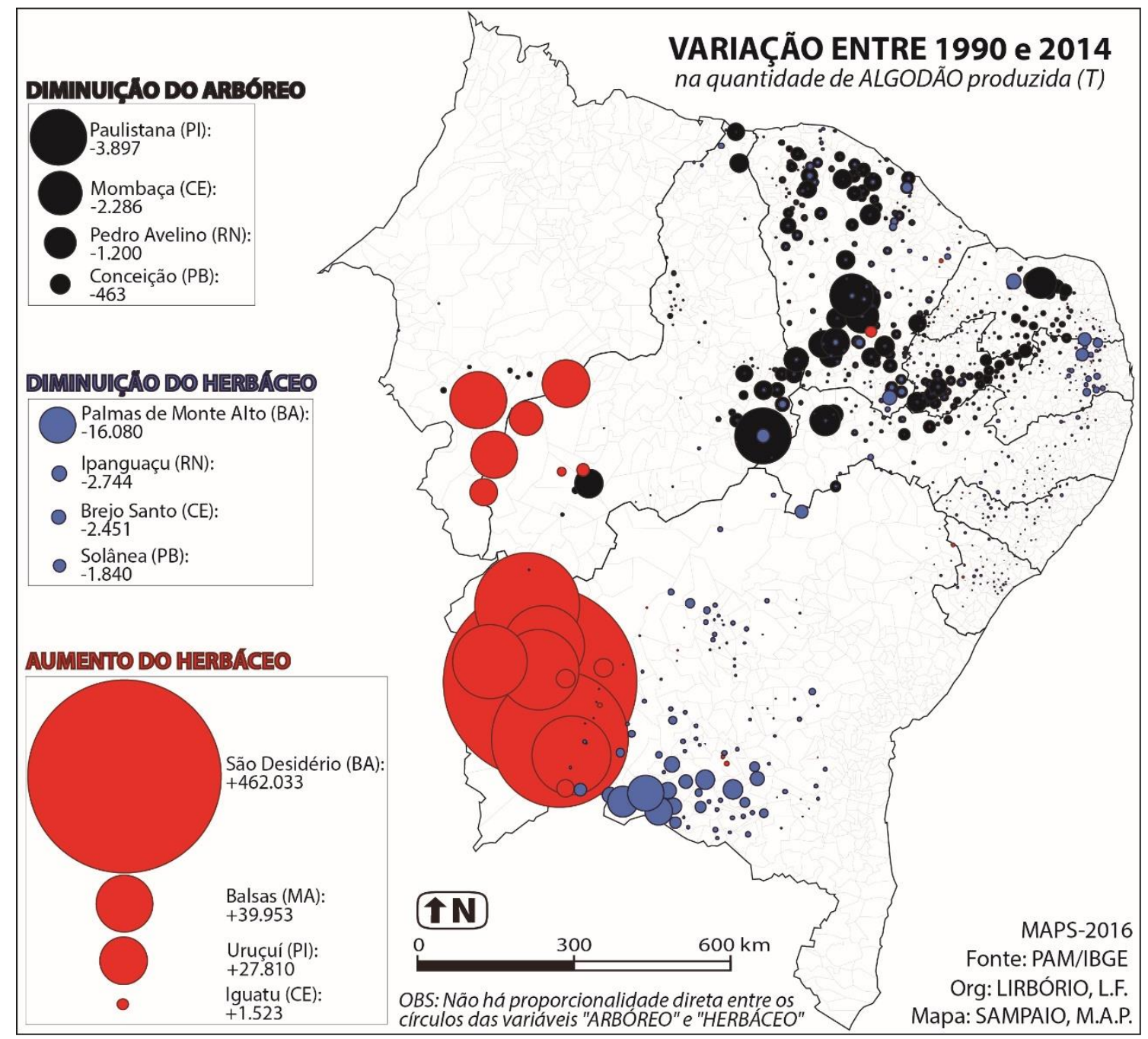


Mapa 3 - Variação na quantidade produzida de algodão herbáceo no Brasil (1990 e 2014)

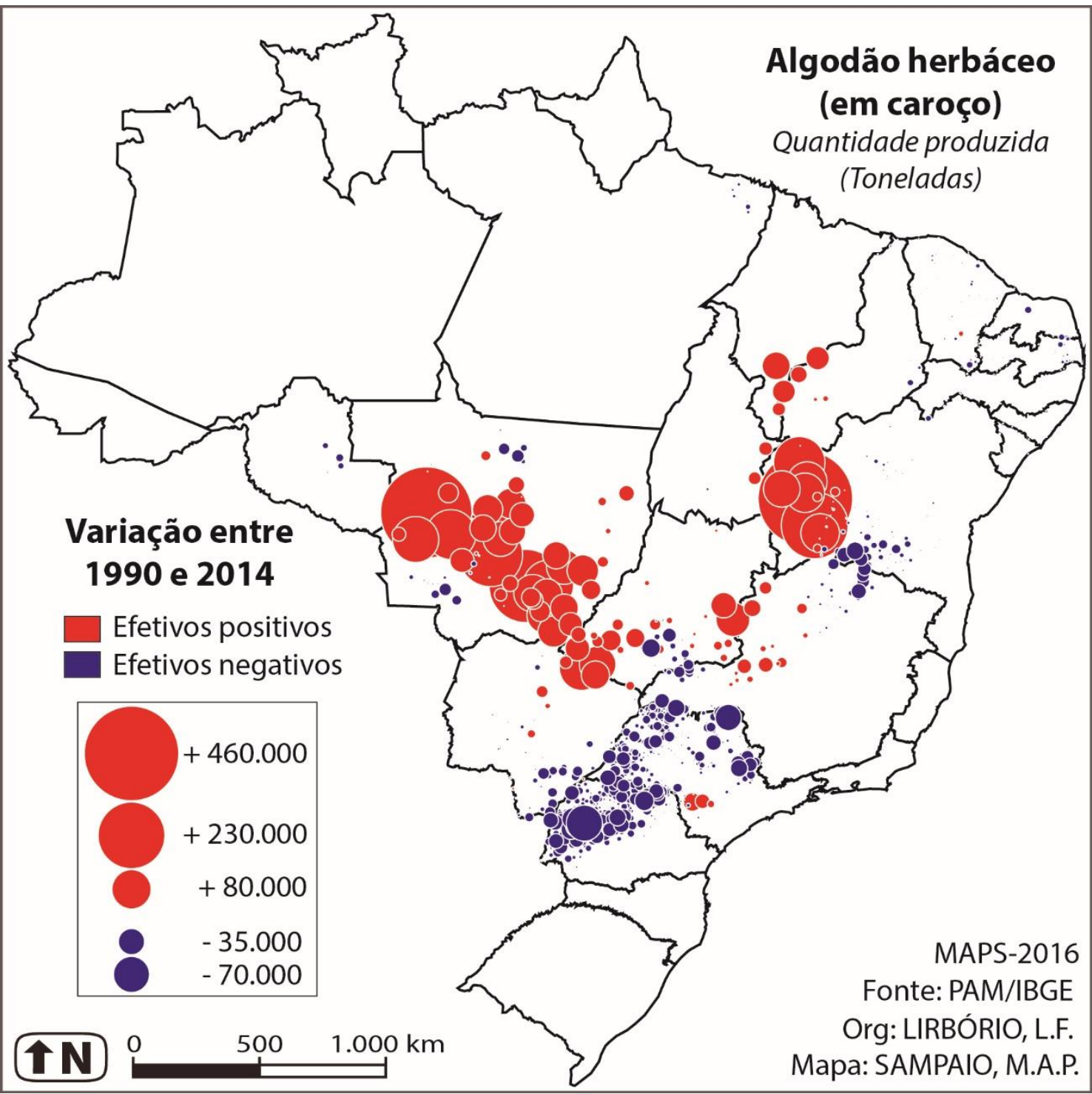

O Mapa 4 nos permite analisar a dinâmica da produção algodoeira no território brasileiro. Para elaboração do mesmo levou-se em consideração períodos que demonstram a mudança geográfica e expansão da área plantada. Assim na década de 1920 se observa que a maior área plantada está na região Nordeste. Na região Sudeste merece destaque o estado de São Paulo, lembrando que foi a partir do final da década de 1920 que a cultura algodoeira passou a ser um dos principais produtos da agricultura paulista, superando em alguns momentos inclusive a produção de café e da cana-de-açúcar, culturas 
tradicionais. Na década de 1950 o Nordeste ainda se mantém com representatividade na produção algodoeira. O estado de São Paulo respondia por mais de $45 \%$ da área plantada no país e é possível verificar a expansão da cultura para o estado do Paraná. O Mapa 4 nos permite ainda acompanhar a evolução da área plantada com a lavoura de algodão na região Centro-Oeste, na década de 1920 o estado de Goiás representava menos de $10 \%$ da área plantada dessa cultura. Na década de 1950 Goiás ainda se mantém com pequena área plantada. $O$ aparecimento da lavoura algodoeira nessa região em 1980 era pouco significativo se torna grandiosa na década de 2010 , lembrando que foram introduzidas cultivares adaptadas para as condições ambientais do Cerrado em 1992, a CNPA - ITA 90. O Mapa em questão nos permite ainda verificar o quão drástico foi a redução da área plantada com algodão no Nordeste, exceto pela Bahia. 
Mapa 4 - Evolução da área plantada com algodão no Brasil em período selecionado (1920, 1950, 1980, 2010)

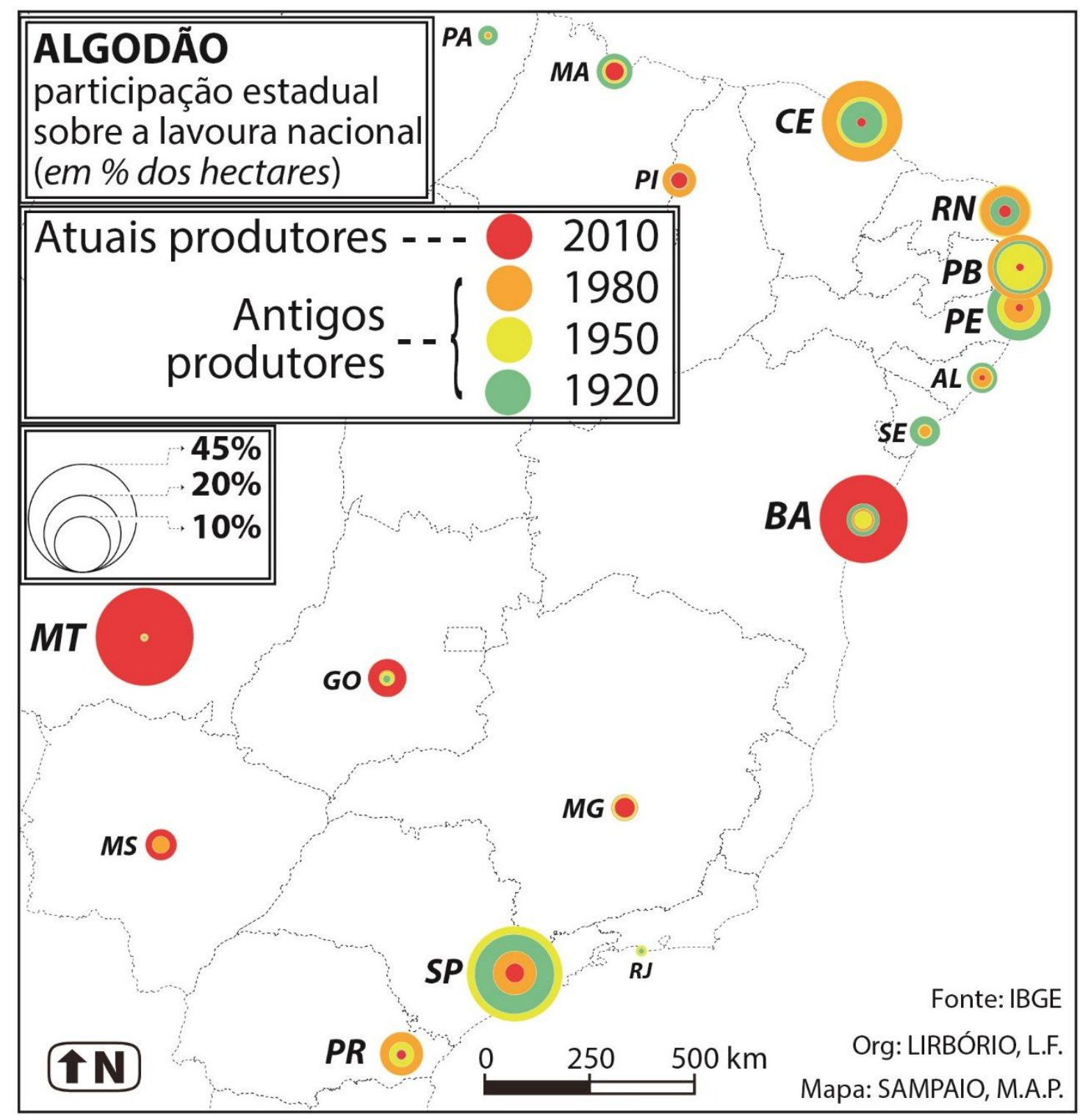

No Mapa 5 está disposto a espacialização da atual situação da produção de algodão no Nordeste Brasileiro. A análise do Mapa 5 nos permite inferir que na década de 1990 a produção de algodão arbóreo, embora reduzida se comparada a outras décadas ainda era cultivado na região e a produção de algodão herbáceo estava concentrada no Oeste Baiano. No mesmo Mapa para o ano de 2015 constata-se que o algodão arbóreo não está sendo mais produzido no Semiárido e que mesmo a produção de algodão herbáceo nessa 
região é pouco significativa, enquanto a região do Cerrado Nordestino o crescimento da quantidade produzida entre 1990 para 2015 é expressivo.

Mapa 5 - Evolução da produção do algodão na região do Semiárido e do Cerrado do Nordeste Brasileiro (1990 - 2015)

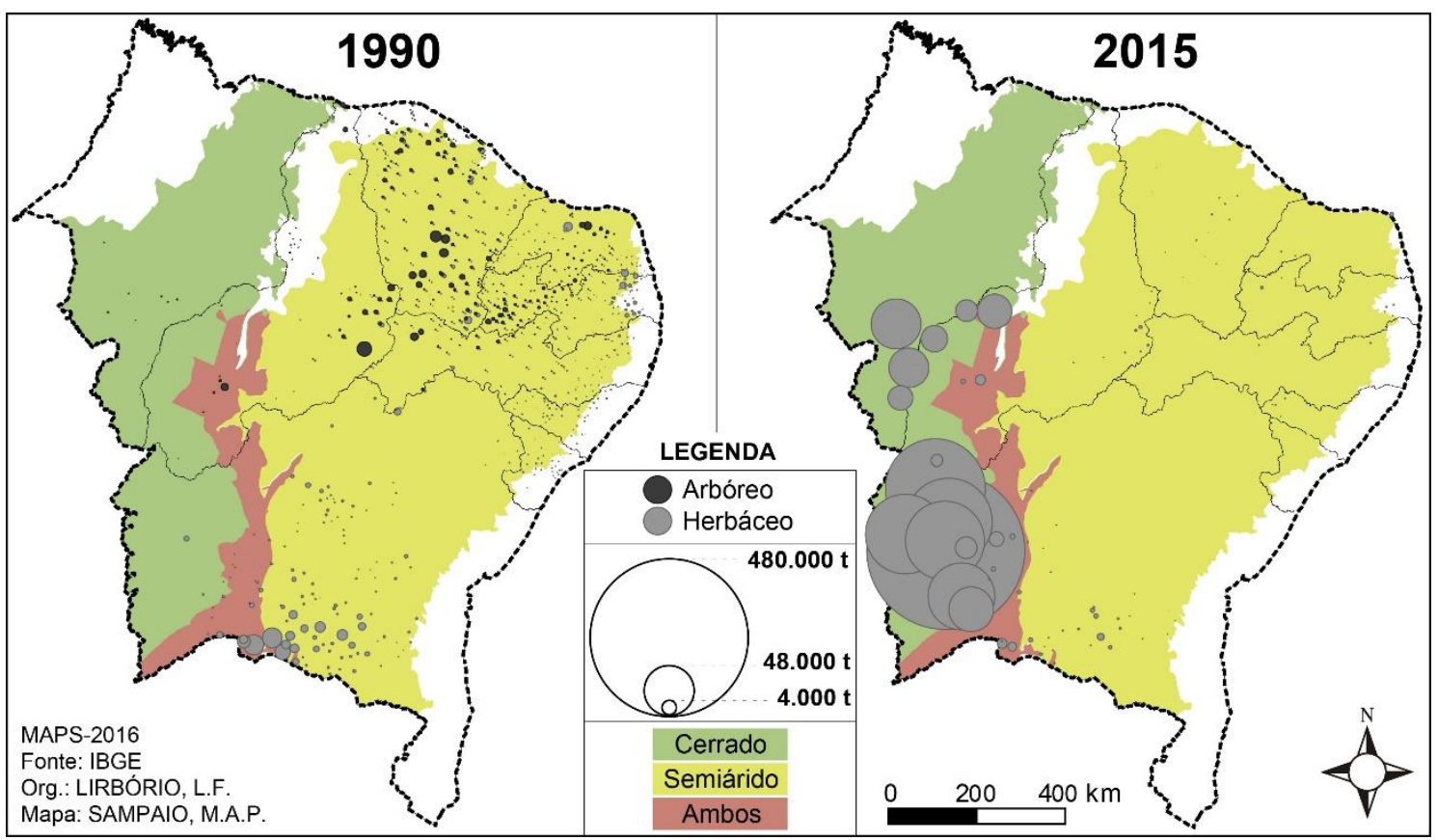




\section{O ALGOdÃo NATURALMENTE COLORIDO NA PARAÍBA: A REINVENÇÃO DA CULTURA ALGODOEIRA NO NORDESTE}

Como analisamos no capítulo anterior, a história da produção de algodão no Brasil tem início antes da colonização. Sua dinâmica variou no espaço e no tempo. Inicialmente a lavoura algodoeira era desenvolvida com base no conhecimento empírico e na utilização dos recursos naturais disponíveis na natureza onde era cultivada, sem grandes modificações nem da planta, nem do espaço. "Era uma agricultura ao sabor da natureza", conforme Silva (1981).

A partir da década de 1930, a lavoura algodoeira passou a ser desenvolvida com base em maior conteúdo científico e técnico, em decorrência da cientifização da agricultura como propõe Santos e Silveira (2011). Esta cientifização é realizada a partir da aplicação do conhecimento científico no processo produtivo. Nesse sentido as espécies são modificadas e ou aperfeiçoadas para atender aos interesses da produção e o sistema de objetos que anteriormente era natural passa a ser cada vez mais artificiais, criando verdadeiros híbridos.

Além das mudanças na área biológica, outras inovações também permitiram que de algum modo a produção agropecuária se realizasse com menor dependência dos fatores naturais de produção, tais como as inovações mecânicas e as inovações químicas. O desenvolvimento de máquinas agrícolas, como tratores, plantadeiras e colheitadeiras mecânicas, a utilização de aviões para aplicação de inseticidas e os sistemas de irrigação são objetos técnicos que modificam as condições de produção, criando um meio geográfico cada vez mais artificializado, ampliando a tecnoesfera com a fixação de objetos técnicos no espaço geográfico (SANTOS,1994).

Esses objetos mecânicos são cada vez mais resultado de uma intencionalidade, de um desejo de aumento da produtividade e, consequentemente, de aumento do lucro. Ao longo do tempo esses equipamentos foram sendo transformados e tornados mais eficientes em seus resultados. Com o desenvolvimento das tecnologias da informação a partir dos anos 1950, não raro esses meios de produção tornaram-se controlados por 
softwares que monitoram suas ações no território, elevando o nível de precisão desejada.

O desenvolvimento da indústria química, especialmente a partir do fim da Segunda Guerra Mundial, permitiu grandes avanços para esse setor da economia, pois a sintetização de elementos químicos e sua transformação em adubos e agroquímicos permitiu transformar áreas antes consideradas impróprias para a agricultura em novos celeiros de produção, como foi o caso do Cerrado brasileiro a partir da década de 1970.

As inovações biológicas, por sua vez, tem proporcionado uma verdadeira revolução no campo. A domesticação e seleção de plantas e animais são práticas milenares, contudo a manipulação de suas características genéticas de forma a obter espécies superiores é uma prática relativamente recente. De acordo com Goodmam, Sorj e Wilkson (2008):

\begin{abstract}
As origens científicas dessa convergência tecnológica devem ser buscadas na transformação da biologia e no crescimento vigoroso da teoria genética mendeliana no início do século XX (Allen, 1978). O florescimento desta pesquisa genética estabeleceu a base teórica das técnicas de melhoria vegetal utilizadas no desenvolvimento e na ampla difusão de variedades de milho híbrido nos anos 30 , de alto rendimento, sensíveis ao uso de fertilizantes e adaptados a colheita mecânica. Subsequente a pesquisa genética consolidou ainda mais o seu papel de pivô na inovação agrícola: a semente se tornou o portador do progresso técnico na biologia de plantas que, refortalecida pelos novos avanços na bioquímica e genética molecular durante os anos 60 e 70, se confirmou como foco privilegiado de apropriação industrial. De fato, a seleção de variedades e linhagens é tão antiga como a própria agricultura. Estes métodos foram sistematizados durante o longo período da primeira Revolução Agrícola, mas naquela época faltaram mecanismos adequados para controlar a difusão de linhagens biológicas melhoradas e os ganhos de produtividade daí decorrentes (GOODMAM; SORJ; WILKSON, 2008, p. 28):
\end{abstract}

Essa sucessão de inovações ocorre de forma integrada e cada vez mais é demandado o papel da pesquisa. Goodmam. Sorj e Wilkson (2008), afirmam também que, por mais que as inovações na agricultura criem as condições para que o capital industrial se realize "plenamente" no campo, essas inovações encontram obstáculos nos fatores naturais. Por mais que seja possível modificar o ciclo de produção na agricultura, a natureza ainda é relevante. A partir daí insistimos que os Centros de Pesquisa são imprescindíveis para o desenvolvimento das condições de produção no campo. 
Nesse sentido o Estado assume papel de destaque. No Brasil, se voltarmos para o caso da modernização do algodão, esta encontra bases sólidas no conjunto de ações empreendidas pelo Estado. A base de pesquisa do IAC é evidente nesse argumento. Na década de 1970 a criação da Embrapa é mais um indicativo de como o Estado é mobilizado para a criação das condições necessárias à produção moderna no campo.

Por sua vez, isso não é uma particularidade do Brasil, ocorrendo também em outros países. Nos Estados Unidos, por exemplo, que exerceu pioneirismo nos processos que transformaram as condições de produção, o financiamento público da pesquisa foi imprescindível. Consideramos a pesquisa pública na agricultura relevante, pois mesmo com o grande avanço das ciências não é suficiente apenas a introdução de plantas melhoradas e insumos, pois as condições naturais do território exigem adaptações.

No caso do algodão, reconhecemos o pioneirismo do IAC, instituição de pesquisa pública que ajudou na transformação dessa cultura beneficiavam especialmente a produção algodoeira do Sudeste para a qual tinha desenvolvido cultivares adaptadas. Ainda que as cultivares desenvolvidas em São Paulo alcançassem outras áreas de produção do país, seus resultados eram menos expressivos.

Consideramos que a criação da Embrapa em 1973 e da sua unidade de pesquisa descentralizada, a Embrapa Algodão em 1975, instalada em Campina Grande - PB, se constituiu na possibilidade de transformação dessa cultura em todo o território nacional. Esse Centro de Pesquisa constitui-se um dos principais agentes da pesquisa algodoeira do país, que como mencionado no decorrer dessa pesquisa, viabilizou a produção de algodão no Cerrado, a partir do desenvolvimento de cultivares adaptadas a esse ambiente.

A produção de algodão na região dos Cerrados se desenvolve baseada no que há de mais moderno em recursos técnicos e científicos. O Nordeste Semiárido não participou deste processo após a retomada da produção algodoeira no país e vem se inserindo nessa atividade buscando formas de se recolocar no cenário nacional da produção algodoeira. O principal motivo desta defasagem é que os produtores desta região não têm condições de competir 
com os grandes capitais investidos na região dos Cerrados do Centro-Oeste do país, do Oeste Baiano, e agora da região de fronteira formada pelos estados do Maranhão, Piauí, Tocantins e Bahia, que formam a região Produtiva Agrícola de MAPITOBA.

A reinserção do Semiárido tem sido feita a partir da produção de algodão orgânico, com características especiais, e para tal a Embrapa Algodão tem sido a grande indutora deste processo. Isso nos leva a crer que a ação de uma instituição tem diferentes rebatimentos no território que as recebe, pois as condições sociais implicam no surgimento de diferenciações. Pretende-se assim nesse capítulo elucidar como a Embrapa Algodão foi a possibilidade necessária para transformação de cultivares de algodão silvestre sem valor comercial em nova oportunidade para a cotonicultura do Semiárido e sua apropriação pelos diferentes atores do circuito espacial de produção.

A contribuição da Embrapa Algodão vai além do desenvolvimento de sementes melhoradas. Consideramos que a assistência técnica prestada aos agricultores, a orientação no manejo da cultura no campo e as parcerias com empresários e organizações públicas e privadas são essenciais para o desenvolvimento dessa atividade. A Embrapa Algodão é um Centro de excelência internacional na pesquisa de algodão, e foi responsável pela reinserção do Brasil no mercado de exportação desse produto ${ }^{42}$ (KOURI e SANTOS, 2007; BRASIL, 2007; SUZIGAN e ALBUQUERQUE, 2011; LIRBÓRIO, 2014).

Se um agricultor decidisse, dez anos atrás, plantar algodão, ele corria
o risco de ser chamado de louco. Hoje essa decisão é uma aposta com
margem mínima de risco. O que mudou na cultura do algodão
brasileiro? Mudou quase tudo, mas, principalmente, o próprio algodão.
O principal sinal de que as mudanças foram substanciais é que, a partir
de 2000 , o Brasil deixou de ser importador e passou a ser exportador
dessa commodity (PANRURAL, 2003, p. 26).

As tecnologias agrícolas desenvolvidas por essa Unidade tem rebatimento diferenciado no território, pois as condições políticas e sociais são aspectos que precisam ser considerados na análise dos resultados dos impactos

\footnotetext{
${ }^{42}$ Aqui estamos falando do algodão com fibra branca
} 
econômicos e sociais a partir da adoção de novas cultivares, ou de novos processos agrícolas.

Em relação a essa situação, de imediato podemos diferenciar as dinâmicas territoriais de algumas das áreas e grupos sociais favorecidos pelos produtos desenvolvidos pela Embrapa. No Cerrado da região Centro-Oeste, maior produtora de grãos, fibras e carnes do país, observamos que a produção está concentrada na mão de grandes fazendeiros/empresários com capital nacional e internacional e, consequentemente, com a presença crescente de empresas multinacionais como a Monsanto e a Bunge. Com isso, verifica-se que os resultados das pesquisas do Estado brasileiro para o setor beneficiou, sobretudo, o grande capital.

Essa mesma instituição, devido ao fato de estar localizada no Nordeste brasileiro, e em particular no Semiárido, se vê na necessidade de gestar soluções para atender às demandas regionais, surgindo aí a diferenciação das ações políticas territoriais. O perfil socioeconômico dos produtores do Semiárido é diferente do que predomina nos Cerrados. O predomínio de agricultores familiares demanda outra lógica de transferência de tecnologia. Assim, mesmo que haja predomínio da busca pelo aumento da produtividade nas tecnologias agrícolas desenvolvidas pela Embrapa Algodão, é preciso considerar a realidade local.

A Embrapa Algodão atualmente possui um quadro de com 209 funcionários entre técnicos, assistentes e pesquisadores. Possui quadro de recursos humanos altamente qualificado e com diversas especialidades (ver Quadro 12).

Quadro 12 - Nível de Formação dos Pesquisadores da Embrapa (2016)

\begin{tabular}{|c|c|c|c|c|}
\hline \multicolumn{5}{|c|}{ NIVEL DE FORMAÇÃO DOS EMPREGADOS DA EMBRAPA ALGODÃO } \\
\hline GRADUAÇAO & ESPECIALIZAÇÃO & MESTRADO & DOUTORADO & PHD \\
\hline 16 & 14 & 17 & 41 & 9 \\
\hline
\end{tabular}

Fonte: Embrapa Algodão, 2016.

Elaboração e Organização: LIRBORIO, L. F. 2016. 
Quando a Embrapa Algodão foi criada em 1975, a função atribuída à essa Unidade foi desenvolver pesquisas sobre $o$ algodão em todo o país ${ }^{43}$ Com a crise do algodão ocorrida nos anos 80, essa Unidade incorporou novos produtos em sua agenda de pesquisa. As novas culturas pesquisadas são produtos que já eram cultivadas na região e que apresentavam potencial econômico. São eles: o amendoim ${ }^{44}$, o gergelim, a mamona, o pinhão manso e o sisal. Atualmente as pesquisas da Embrapa Algodão são orientadas por dois núcleos principais: Núcleo de Pesquisa do Semiárido e Núcleo de Pesquisa do Cerrado.

No Núcleo de Pesquisa do Semiárido, são pesquisadas a mamona, o pinhão manso, o sisal, o gergelim e o algodão. A pesquisa sobre o algodão tem foco especial para a produção voltada para a agricultura familiar. O Núcleo de Pesquisa dos Cerrados se dedica às pesquisas do amendoim e do algodão para as condições do Cerrado. Devido ao escopo dessa pesquisa, não entraremos nas contribuições que esse centro de pesquisa proporcionou para as outras culturas além do algodão.

Com exceção do sisal, todas as outras culturas são de oleaginosas. 0 sisal é uma fibra têxtil vegetal. O gergelim tem sido bastante apreciado pelo mercado devido aos benefícios que proporciona a saúde, sendo consumido tanto em grão quanto na forma de óleo. As culturas de mamona e pinhão manso, utilizadas como matéria prima na fabricação de biodiesel, tiveram sua importância reforçada na década de 2000 devido ao Programa Nacional de Produção e Uso de Biodiesel (PNPB) ${ }^{45}$.

\footnotetext{
${ }^{43}$ As Unidades de Pesquisa de Produto da Embrapa foram criadas e instaladas nas regiões, onde naquele período (década de 1970) se concentravam a produção de determinados tipos de produto, assim de certa forma pode-se dizer que era a região produtora que definia a especialidade da pesquisa que iria ser desenvolvida pela Unidade criada. Por exemplo, a Embrapa Soja, foi localizada no Paraná, que na época era o Estado onde havia maior área plantada com essa lavoura, mas com o processo de expansão da fronteira agrícola, em direção a região Centro-Oeste, onde as vantagens oferecidas pelo Estado eram mais vantajosas para as empresas, muitos empresários migraram para a nova área. Com a migração da cultura, a sede da Embrapa Soja, permaneceu em Londrina, mas alguns campos experimentais dessa Unidade foram instalados nas áreas próximas onde estão sendo cultivadas essa oleaginosa. Essa situação demonstra que a pesquisa agrícola é realizada em base territorial. Então por mais que nos dias de hoje os recursos tecnológicos disponíveis forneçam informações que facilitem o deslocamento de informações, ou mesmo a precisão delas, a questão territorial é relevante, pois na experimentação agrícola precisa-se levar em consideração os fatores ambientais, no processo de adaptação dos sistemas agrícolas de produção.

${ }^{44}$ As pesquisas sobre o amendoim têm como foco a produção no Cerrado

${ }^{45} \mathrm{Em}$ relação as matérias primas, perfil dos produtores e regiões produtoras que deveriam fomentar a produção de biodiesel no Brasil, Freitas (2011), demonstra que não foram as
} 
Em relação ao algodão com fibra naturalmente colorida, a primeira consideração a ser feita é de que o mesmo não é uma invenção da Embrapa Algodão. Essa planta já existe na natureza há mais de 4.500 anos, sendo tão antigo quanto o algodão de fibra branca (BELTRÃO e CARVALHO, 2004; VREELAND, 1999; SINGH, SINGH e WAGHMARE, s/d.).

Como o algodão naturalmente colorido é uma planta silvestre do ponto de vista genético, quando comparado ao algodão branco possui características consideradas inferiores, tais como: resistência, comprimento e finura, sendo por isso relegado ao pouco uso e desconhecido por ampla maioria da população mundial.

Se o algodão colorido já existia na natureza qual foi então a grande inovação proporcionada pela Embrapa Algodão? Esse centro de pesquisa foi responsável pela transformação das características desejáveis para um bom algodão a partir do Programa de Melhoramento Genético do Algodão Colorido, em desenvolvimento desde 1989 e responsável pela criação de variedades de algodão colorido com fibras de boa qualidade e maciez, características exigidas pela indústria têxtil contemporânea (SANTANA, et al., 1997; FREIRE, 1999; BELTRÃO e AZEVEDO, 2008).

Viabilizou assim a transformação de plantas de algodão silvestre, sem valor comercial, através do melhoramento genético, em um produto inovador e com valor comercial. A solução tecnológica encontrada por esse centro de pesquisa é parte do "novo tempo" da agricultura, no qual cada vez mais o homem manipula as condições de produção de acordo com os seus interesses. As cultivares de algodão naturalmente colorido disponíveis para cultivo no Brasil, em particular na Paraíba, são resultado de longo processo de pesquisa. Assim, o algodão colorido naturalmente criado pela Embrapa Algodão "já nasce com uma vocação mercantil" (SANTOS, 2014).

Esse tipo de algodão que em períodos anteriores não possuía valor, a não ser o de uso, se tornou produto comercial com valor de troca a partir do

oleaginosas, como a mamona e o pinhão manso que se sobressaíram na oferta de biodiesel, nem foram os agricultores familiares, que foram os responsáveis pelo fornecimento dessas matérias primas, tão pouco foi o Semiárido a região produtora 
melhoramento genético ao qual foi submetido ${ }^{46}$ e aos atuais estilos de vida estabelecidos pela sociedade, em matéria prima excepcional. Como não precisa ser tingido, reduz o consumo de água em até $90 \%$ e também não consome corantes sintéticos, e por isso é considerado um produto agroecológico.

A capacidade de melhoramento genético do algodão colorido silvestre não foi a única condição para que o mesmo se tornasse um produto inovador e com crescente interesse no mercado têxtil e de confecções. De acordo com Farias (2012), a mudança do modelo de acumulação capitalista fordismo/keynesianismo para a acumulação flexível/neoliberalismo, também foi acompanhado pelas indústrias têxteis e confecções que buscaram formas de diferenciar seus produtos dos produzidos em série, e assim ocuparem nichos de mercado. É nesse contexto que novas possibilidades são abertas para o aproveitamento de novas fibras, entre elas a do algodão naturalmente colorido:

\begin{abstract}
Estas se valeram dos elementos da nova tecnoesfera, especialmente das tecnologias da informação e da ampliação do conhecimento científico à produção, e dos aparatos normativos neoliberais para adotar novos processos produtivos, utilizar novas fibras, flexibilizar as relações de trabalho, articularem-se em redes de empresas e atuar em escala planetária, para desse modo enfrentar a competitividade global dos mercados. Por outro lado, estas indústrias, dada a flexibilização da moda e dos gostos, passaram a investir nas marcas, na publicidade, nas embalagens personalizadas e na diluição mundial da produção para camuflar a homogeneidade dos seus produtos em série e, assim, explorar nichos de mercado ( FARIAS, 2012, p. 203).
\end{abstract}

Nessa pesquisa demos atenção para o algodão naturalmente colorido como uma das fibras têxteis utilizadas nesse contexto de abertura e procura por matérias primas sustentáveis na produção de têxteis e confecções, contudo há outras fibras naturais que são importantes nesse setor. $O$ algodão naturalmente colorido é uma especificidade do sistema dominado pelo algodão branco, principal fibra têxtil natural utilizada no mundo.

Mesmo com reduzida escala de produção, o algodão naturalmente colorido chama atenção, pelos processos técnicos e sociais do qual faz parte. No mundo capitalista sempre vai existir a busca pelo produto novo, ou a resignação do velho transformado em novo. Assim, mesmo que o algodão

\footnotetext{
${ }^{46} \mathrm{~A}$ técnica de melhoramento genético adotada pelos pesquisadores da Embrapa Algodão foi o melhoramento convencional, que consiste na seleção genealógica
} 
colorido tenha existência milenar, até a década de 1980 o seu cultivo e uso era voltado para o consumo local principalmente de comunidades indígenas da América Andina. As técnicas de cultivo e beneficiamento eram pouco desenvolvidas e ainda se mantém dessa forma (FARIAS, 2010).

De acordo com Shand (1993), grupos nativos da América Pré-colombiana que há milhares de anos faziam uso do algodão colorido realizaram domesticação, seleção, e até algum tipo de melhoramento genético nessa planta. O domínio da agricultura naquele tempo já era uma técnica complexa, pois exigia do homem conhecimento sobre o ciclo biológico das plantas. Entretanto as transformações proporcionadas por essa atividade devido ao nível do desenvolvimento técnico da época não provocava grandes transformações nem na natureza, nem nos produtos.

O autor citado chama atenção ainda para os processos recentes de melhoramento genético moderno de plantas de algodão colorido feito com origem em materiais genéticos coletados em alguns lugares da América Andina, coletados por pesquisadores de outros países e que após melhorarem as características dessas plantas patenteiam, tornando a propriedade de uso das cultivares por eles melhoradas privado, impedindo o uso deste produto pelos povos nativos.

Após séculos sendo utilizado por comunidades nativas da América Andina, a partir da década de 1980 ocorreu em escala mundial um novo período na história da produção do algodão colorido. Esse período é marcado pela necessidade de realização de pesquisas com o objetivo de melhorar as características técnicas do algodão colorido, que por ser algodão silvestre não possui fibras com o tamanho adequado para ser manipulado pela indústria têxtil moderna. Além do tamanho, outras propriedades precisaram ser transformadas, como a finura, resistência e uniformidade da cor (FREIRE, 1999; FARIAS, 2010).

A produção de algodão colorido ainda é incipiente se comparada com a escala de produção do algodão branco, principal fibra têxtil vegetal da indústria moderna. Ainda que os mercados a que se destinam os produtos derivados do algodão colorido sejam semelhantes, voltados para consumidores preocupados com as questões ambientais, sua produção difere na escala do lugar, e articula- 
se na escala mundial. Isso ocorre porque o mesmo se insere em um novo movimento na produção de fibras têxteis naturais, no qual a produção orgânica se coloca como alternativa para reduzir os impactos ambientais causados pelo setor.

Nesse contexto de mudanças, observamos que o interesse em produzir conhecimento que viabilizasse a produção de algodão colorido no estado da Paraíba a partir de 1989, embora tenha ocorrido a partir de um evento particular, está articulado com o novo movimento global. Assim entendemos que a partir do ano 2000, quando são disponibilizadas as primeiras cultivares de algodão colorido no Brasil pela Embrapa Algodão para cultivo comercial, surge um novo período na história da produção de algodão no país e em particular no Nordeste Semiárido.

O que estamos propondo como novo período se refere a forma como aconteceu a renovação da cultura algodoeira na região do Semiárido Nordestino, com a introdução de algodão de fibra colorida produzido inicialmente em sistema convencional, com o uso de fertilizantes e herbicidas, e a transição para a produção orgânica, como mais uma forma de agregar valor ao produto ${ }^{47}$.

A ênfase para o Semiárido se deve ao fato de historicamente a cultura algodoeira ter sido importante atividade econômica para essa região e no processo de retomada da exploração dessa cultura no país na década de 1990 a mesma ter sido marginalizada. Haja vista que na renovação da cotonicultura no país as novas áreas escolhidas foram as inseridas no domínio do bioma Cerrado. Além do cultivo ter migrado para o Cerrado, predomina a utilização de cultivares de algodão herbáceo, pois possuem ciclo de produção mais curto que o arbóreo, que produzia por até 8 anos. Já as cultivares herbáceas possuem ciclo precoce de 120 dias. As cultivares de algodão naturalmente coloridas cultivadas no território paraibano também são de ciclo anual, exceto pela variedade BRS 200 que possui ciclo semi perene e produz por até 3 anos.

\footnotetext{
${ }^{47}$ Nos primeiros anos de cultivo do algodão colorido, essa lavoura era desenvolvida de forma convencional, em 2006 é que tem início a experiência com o algodão orgânico. Como não havia conhecimento sobre como produzir algodão orgânico, foi necessário o desenvolvimento de uma metodologia, para inclusive saber como combater as pragas que atingem a cultura. Os próprios técnicos da Embrapa Algodão, que vem de um modelo de produção onde os insumos agrícolas são condições básicas para a produção, precisaram construir novas práticas
} 
Detalhes sobre as variedades de algodão colorido cultivados na Paraíba serão tratados no próximo tópico.

4.1 - Do algodão naturalmente colorido como "contaminação" ao algodão naturalmente colorido como inovação

O algodão de fibra naturalmente colorida, como já foi exposto não é criação do ser humano. Mesmo que o algodão branco seja mais conhecido por conta de seu uso em escala industrial, desde a segunda metade do século XVIII, estudos comprovam que o algodão colorido é tão antigo quanto o de fibra branca. O fato de ser pouco conhecido até recentemente, salvo pelas comunidades que faziam uso dos produtos derivados desse tipo de algodão e por pesquisadores, faz com que muitas pessoas imaginem que o mesmo seja resultado de biotecnologia moderna, ou transgenia.

Contudo, boa parte dos algodões com pigmentação utilizados atualmente na indústria têxtil, provém de melhoramento genético que foram realizados para aperfeiçoar as qualidades dos algodões silvestres. Os países que tem cultivo comercial de algodão colorido são: os Estados Unidos, o Brasil, a China, a Índia, a Espanha e o Peru.

Dos países citados o Peru é o único em que as espécies de algodão colorido utilizadas não passaram por nenhum melhoramento genético, coordenado nem por instituições públicas de pesquisas, nem pelo setor privado, que transformasse as características da pluma dos algodões silvestres. As espécies de algodoeiro colorido desse país continuam a ser produzido com o conhecimento e técnicas herdadas de seus ancestrais (VREELAND, 1999; ARBILDO e IPARRAGUIRRE, 2012).

Nesse país, além das características do algodão nativo com pigmentação terem sofrido poucas transformações, as outras etapas da produção também são bem arcaicas. Os povos nativos manejam o algodão manualmente em todas as etapas da produção: colheita, descaroçamento, fiação e tecelagem (Ver figuras $11,12,13,14,15$ e 16$)$. 


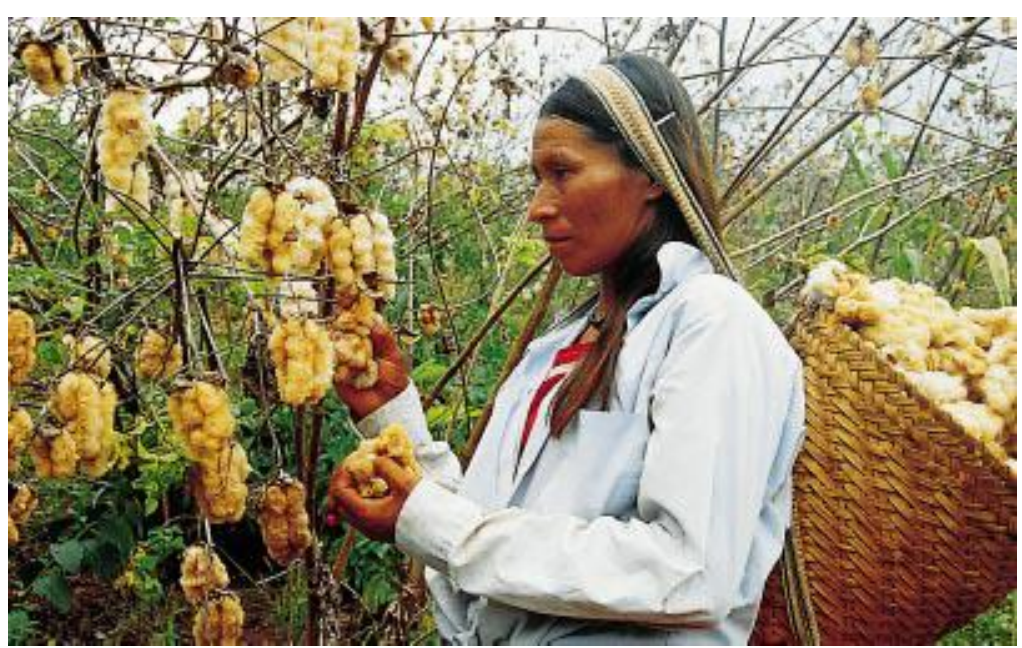

Figura 11 - Colheita manual de algodão naturalmente colorido-Peru. Fonte: VREELAND JUNIOR, 1999.

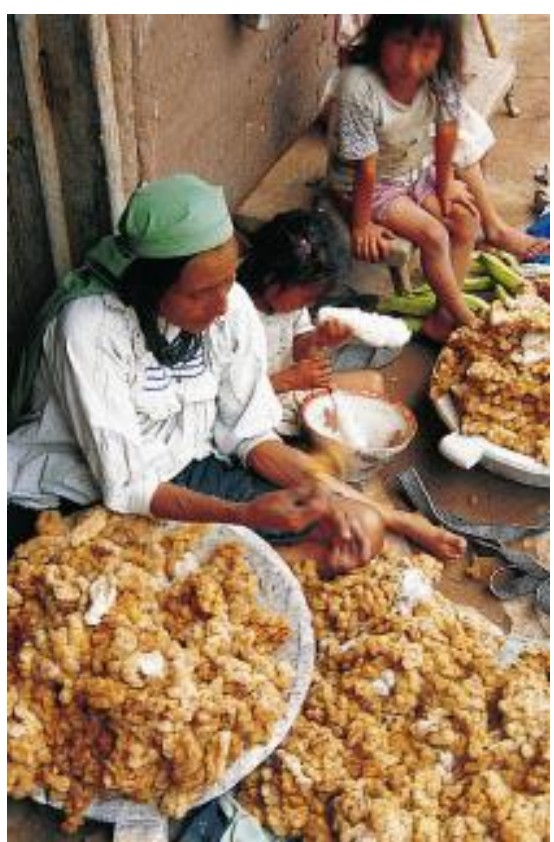

Figura 12 - Descaroçamento manual de algodão colorido - Peru. Fonte: VREELAND JUNIOR, 1999.

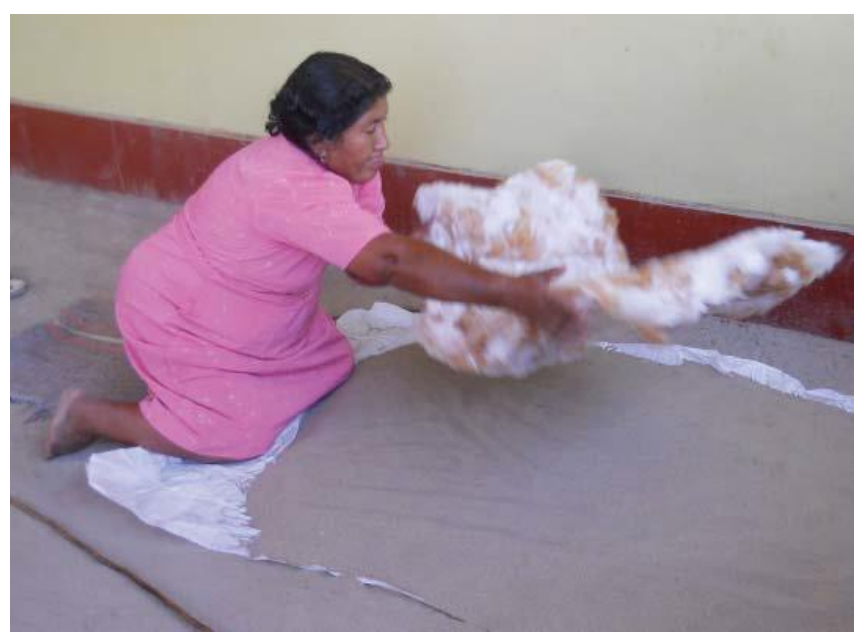

Figura 13 - acomodação de mistura de algodão para formação do rolo- Peru.

Fonte: ARBILDO e IPARRAGUIRRE, 2012. 


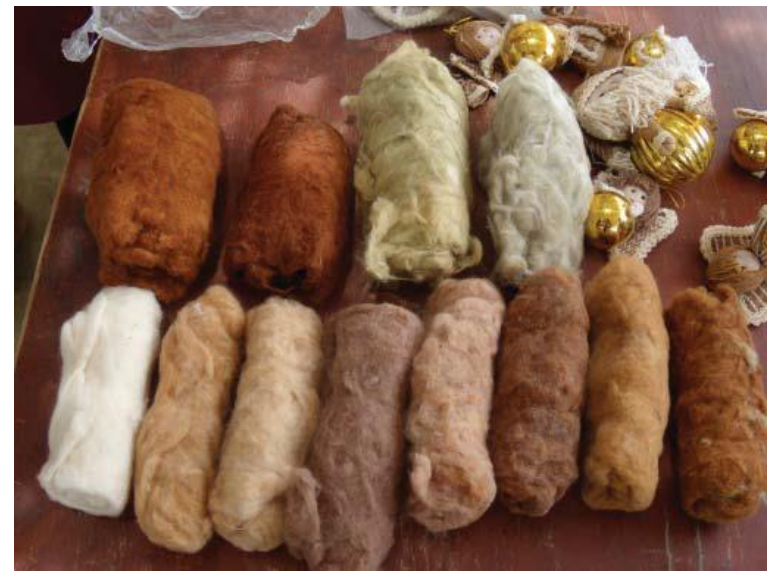

Figura 14 - Rolos de algodão colorido nativo Peru

Fonte: ARBILDO e IPARRAGUIRRE, 2012.

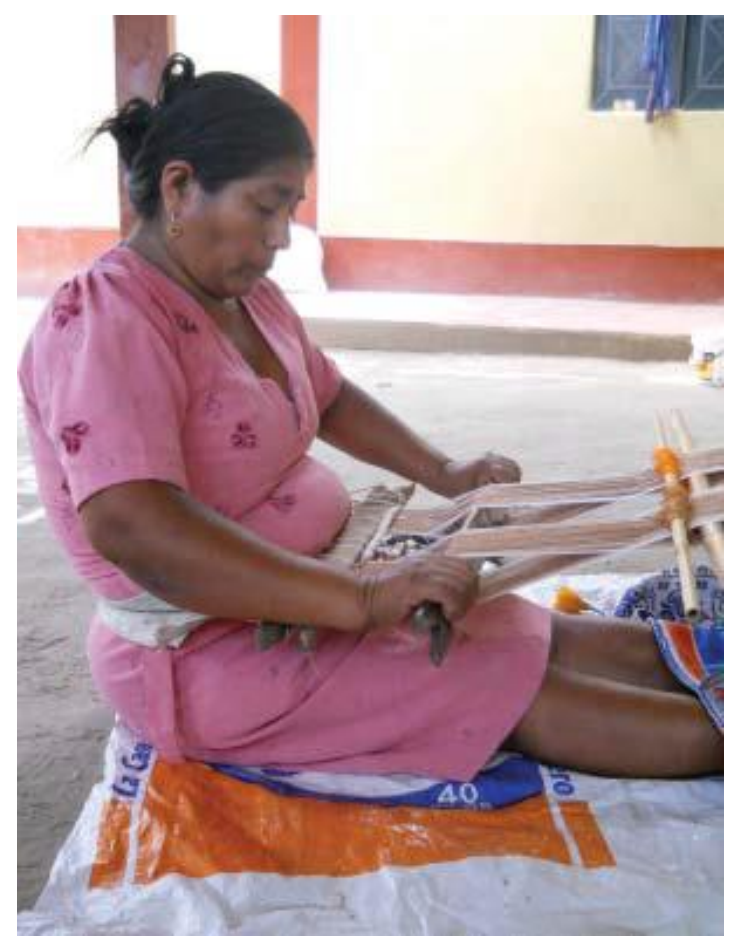

Figura 16- Tecelagem manual de algodão colorido nativo - Peru.

Fonte: ARBILDO; IPARRAGUIRRE (2012).

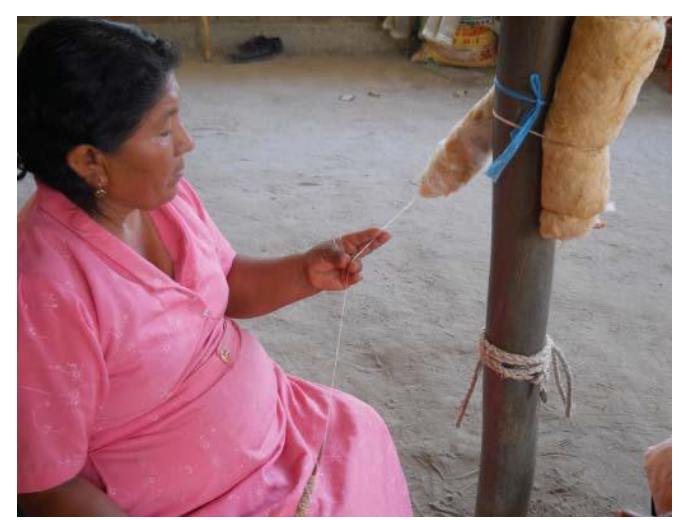

Figura 15- Fiação manual do algodão colorido nativo - Peru

Fonte: ARBILDO; IPARRAGUIRRE, 2012.

A literatura sobre o algodão naturalmente colorido é escassa. Uma contribuição para o resgate da história do algodão colorido do Peru foi feita pelo 
antropólogo James Vreeland Junior ${ }^{48}$ (1999), já citado nesse trabalho. Além de realizar pesquisas para desvendar a história do algodão naturalmente colorido no Peru, o pesquisador criou e coordenou em 1982 o Projeto Algodão Nativo, que tinha como objetivo o resgate do cultivo e uso de roupas feitas com o algodão colorido naquele país. O projeto foi desenvolvido com o apoio do Ministério do Trabalho e Turismo do Peru.

Em artigo escrito por Vreeland Júnior em 1999, ele fez uma revisão histórica, numa perspectiva antropológica, do algodão colorido nativo. Descreve como foi o seu primeiro contato com o algodão colorido por acaso, em 1977, quando examinava têxteis da civilização pré-colombiana, no Museu Nacional de Antropologia e Arqueologia de Lima no Peru. Ao analisar o tecido, observou a presença de manchas escuras nos fios do tecido, que não pareciam se tratar de pigmentação artificial. Essa descoberta ao acaso levou-o a investigar sobre a origem do algodão naturalmente colorido (Ver Figuras: 17 e 18 ).
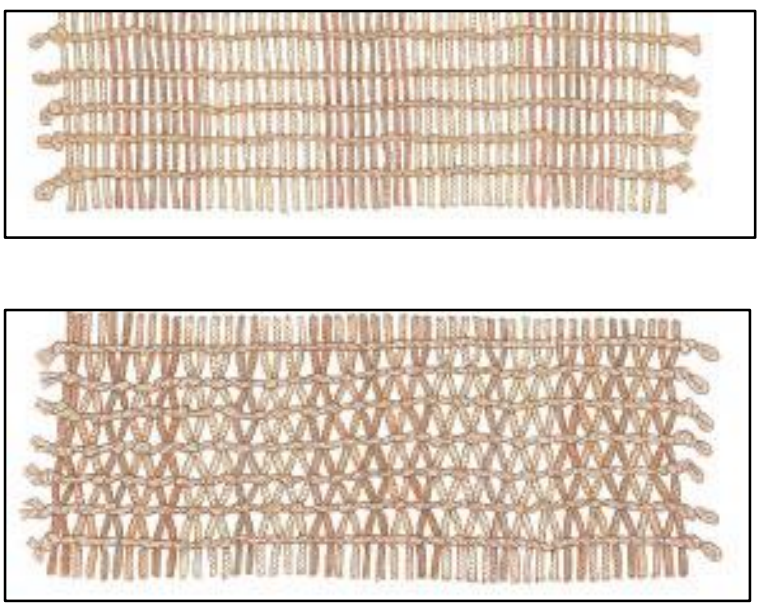

Figura 17 -Tecelagem peruana feita, por nativos pré-colombianos.

Fonte: VREELAND JUNIOR, 1999.

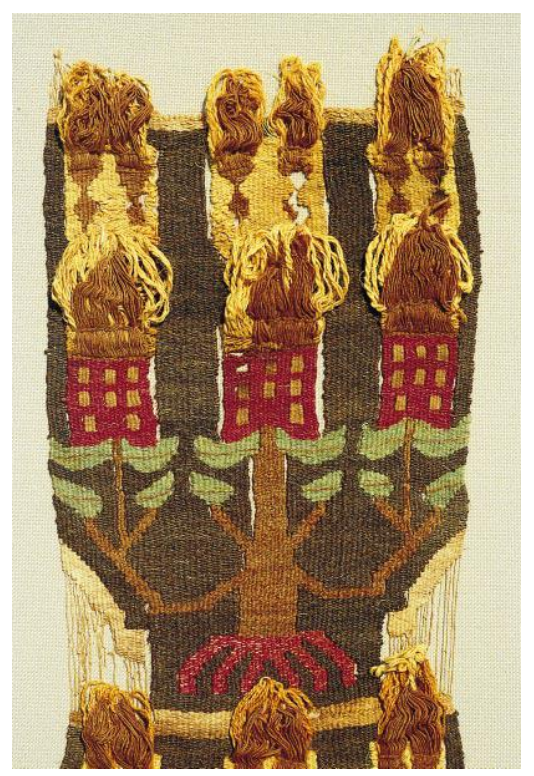

Figura 18 - Têxtil com algodão colorido

Fonte: VREELAND JUNIOR, 1999.

\footnotetext{
${ }^{48}$ James Vreeland atualmente é dono de uma empresa que explora comercialmente o algodão nativo, a Peru Naturtex. Iremos em outro momento falar sobre essa e outras empresas que comercializam derivados do algodão colorido
} 
Diante da descoberta de Vreeland Junior, ele perguntou a várias pessoas se seria possível que alguns algodões apresentassem pigmentação natural. Todos responderam categoricamente que não e que o algodão é branco. Não conformado, ele dirigiu-se à cidade de Trujillo, no Norte do Peru, onde tinha trabalhado anos antes, com o professor de antropologia Victor Antônio Rodriguez Suy Suy, da Universidade Nacional de Trujillo. Foi lá que, com a ajuda desse professor e de um descendente indígena da etnia Mochica, que ele teve o primeiro contato com campos plantados com algodão naturalmente colorido.

\begin{abstract}
Ele me encontrou no aeroporto e me informou de imediato que havia alguma coisa como algodão naturalmente colorido. Na verdade apenas saímos do aeroporto e ele já apontou para um terreno ao lado da estrada. Em tais campos, que eram claramente cultivos de origem préhispânica, pudemos ver plantas de algodão rústico agarrados ao solo arenoso. As plantas de algodão tinham fibras avermelhadas! Entusiasmado, passei os próximos meses viajando pela área, em busca de plantas e tecidos com fibras que possuíam, naturalmente, cores como a crua, o chocolate profundo e muitos outros tons de marrom, e até mesmo a malva.

He met me at the airport and informed me straightaway that there was such a thing as naturally colored cotton. In fact, he drove just outside the airport and pointed to land alongside the road. In the sunken fields, which were clearly of pre-Hispanic origin, we could see rustic cotton plants clinging to the sandy soil. Cotton plants bearing reddish fibers! Entranced, I spent the next few months traveling the area, searching for plants and textiles with fibers that were naturally ecru, deep chocolate and many other shades of brown, and even mauve (VREELAND JUNIOR, 1999, p.113).
\end{abstract}

Segundo o autor citado, sua pesquisa não foi fácil, pois os índios Mochica, que habitam o litoral Norte peruano e que haviam preservado essas plantas, tinham muito cuidado com elas. Na sua pesquisa, Vreeland descobriu que o algodão colorido era milenar, e também toda uma técnica de tecelagem executada pelos povos pré-colombianos. Ainda segundo o autor, o algodão colorido era cultivado em sistema de rotação com cucurbitáceas e culturas alimentares, semelhante ao que é praticado pelos agricultores familiares que plantam o algodão no Brasil.

De acordo com Beltrão e Carvalho (2004), o gene de cor do algodão é dominante e se não fosse a intervenção humana no processo de domesticação 
e seleção que privilegiou o algodão branco por interesses comerciais, provavelmente teríamos o algodão colorido como produto hegemônico:

\begin{abstract}
O algodão de fibra de cor (verde, amarelo, cinza, bege, creme e outros) existe há milhares de anos, sendo tão antigo quanto o branco, o de cor na realidade é o dominante do ponto de vista genético, sendo o branco o recessivo, ou seja caso não fosse a intervenção do homem, hoje teríamos somente algodão de fibra colorida e o branco seria a grande minoria em locais isolados e longe dos tipos de fibras de cor (BELTRÃO e CARVALHO,2004, p. 9).
\end{abstract}

A supremacia do algodão branco foi reforçada com as inovações técnicas da indústria têxtil moderna, na segunda metade do século XVIII. Como o algodão naturalmente colorido é geneticamente dominante, houve sistematicamente políticas de extinção do mesmo a fim de evitar a "contaminação" dos algodoais branco.

Essa imposição se deve ao fato de a polinização do algodoeiro ser espontânea e um polinizador natural, por exemplo a abelha, levar de um lugar a outro o pólen de algodão colorido. Portanto, caso existissem plantações de algodão branco próximas, poderia haver cruzamento entre espécies. Assim, era recomendado aos agricultores que quando encontrassem um pé de algodão colorido no meio da lavoura o mesmo fosse arrancado e destruído.

O Peru é o país em que há o maior número de genótipos de algodão colorido natural preservado. Os desafios para preservação dessas plantas coube aos povos nativos, contrariando o desejo dos interesses hegemônicos. Vreeland Junior (1999), aponta que partir de 1931 o governo peruano emitiu várias leis e decretos com o objetivo destruir o algodão nativo de cor, o argumento utilizado era o de proteger as variedades brancas, mais viáveis comercialmente:

Medidas de quarentena tinham sido implementadas através de uma ampla faixa do litoral peruano para erradicar pragas do algodão, eliminando todos os possíveis hospedeiros vegetais alternativos, incluindo variedades crioulas de algodão colorido, a sumaúma peruana (Bombax discolor) e até mesmo um algodão sem fiapos (G. raimondii) (VREELAND JUNIOR, 1999, p.117).

Quarantine measures had been implemented over a broad swath of the Peruvian coast to eradicate cotton pests by eliminating all the possible alternative plant hosts, including landraces of colored cotton, the Peruvian kapok tree (Bombax discolor) and even a lintless cotton (G. raimondii) (VREELAND JUNIOR, 1999, p.117). 
Além da determinação de erradicação dos algodoeiros coloridos, foi permitido o uso de pesticidas em larga escala. Diante das imposições por parte do Governo, o cultivo do algodão colorido foi abandonado, mas algumas comunidades continuavam a plantá-lo secretamente. As medidas restritivas perduraram até a década de 1980. Só em 1990, com a criação de um novo "Código Ambiental" é que a prática de erradicação do algodão colorido foi considerada ilegal. As medidas impostas contra o cultivo do algodão colorido, causou grande perda de variedades de cores (VREELAND JUNIOR, 1999).

Atualmente existem bancos de germoplasma de algodão colorido preservados nos Departamentos de Agricultura de alguns países e em Universidades. Segundo Singh; Singh e Waghmare (s/d, p. 3) na Índia há pelo menos 40 genótipos de algodão colorido da variedade upland (G.hirsitum), a maioria nas cores marrom e verde.

Esse material está preservado no Banco Nacional de Gene de Algodão, mantido no Instituto Central para Pesquisa de Algodão em Nagpur. As origens desse material são de variedades existentes no país e doações provenientes de bancos de germoplasma de outros países, como Estados Unidos, Ex-União das Repúblicas Socialistas Soviéticas (URSS), Israel, Peru, México e Egito. Além das espécies de $G$. hirsitum, o referido instituto indiano também tem 10 acessos $^{49} \mathrm{de}$ algodão com fibra colorida das espécies G. arboreum e G. herbaceum (SINGH; SINGH; WAGHMARE, s/d.).

São encontradas variedades de algodão colorido nativo na América, na Ásia, na África e na Austrália. Assim como em relação ao algodão branco, as espécies silvestres e domesticadas utilizadas pertencem às espécies Gossipium arboreum, Gossypium herbaceum, no Velho Mundo e às espécies Gossypium hirsitum e Gossypium barbadense no Novo Mundo ( ver Figura 19).

\footnotetext{
${ }^{49}$ Acesso, corresponde ao número de cultivares presentes no banco de Germoplasma
} 


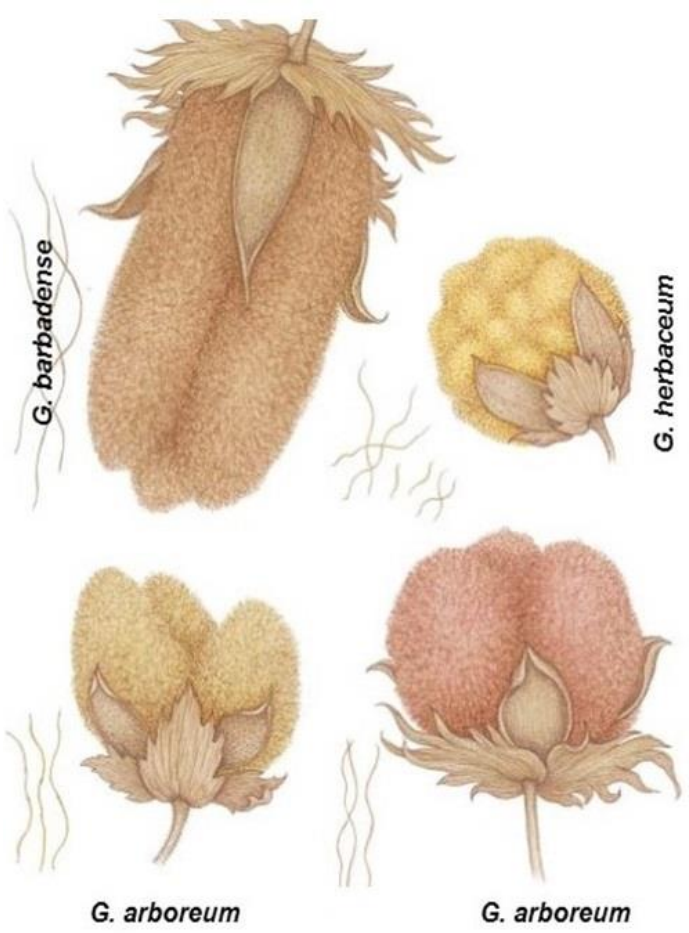

Figura 19 - Capulhos de algodão silvrestre naturalmente colorido

Fonte: VREELAND JUNIOR, 1999.

No Brasil, a existência de algodão colorido teve seu primeiro registro escrito em 1799, por Manuel Arruda da Câmara, no livro "Memória sobre a cultura dos Algodoeiros, e sobre methodos de escolher e ensacar, etc". O botânico pernambucano, ao falar das variedades de algodão existentes na colônia, citava a presença de algodões que possuíam pluma colorida.

As variedades as quais Câmara (1779) se referia eram denominadas algodão "macaco" e algodão "cor de ganga". Tratava-se de algodões com fibras curtas, ásperas e com línter, por isso possivelmente eram variedades da espécie G. barbadense. Arruda Câmara, fala ainda que esse algodão era apreciado para o artesanato, mas que em caso da necessidade de tingir não seria possível, devido à resistência desses algodões ao processo de branqueamento.

Algodão macaco, que os Francezes chamam verdadeiro algodão de Sião Cotonier de Sian franc. Xilon sativun filo croceo: os galhos são prostrados, a lã é de cor ganga, e ainda mais fechada, macia, fina e estimada para certas obras pela sua cor natural. Há outra variedade de algodoeiro bravo, com o fruto maior, com a lã da mesma cor de gânga: tanto esta, como a variedade chamada de macaco, não pode servir 
para chitas, nem outras obras, que levem tinta; porque está côr parda he tão adherente, que resiste à operação do embranquecimento, e nem aceita outra côr artificial, sem se the tirar aquela natural (CAMARA, 1799, p.15).

Segundo Carvalho (1999), no mundo já foram identificadas 39 espécies silvestres de algodão colorido. As cores mais comuns são tons de marrom e verde. Segundo Singh; Singh e Waghmare (s/d) nas coleções de germoplasma de algodão colorido dos Estados Unidos e da Rússia há genótipos de algodão nas cores amarela, cinza, preto etc. As espécies, cor da fibra e região geográfica podem ser identificadas no Quadro 13:

Quadro 13 - Espécies silvestres de algodão colorido e sua distribuição geográfica

\begin{tabular}{|c|c|c|c|}
\hline Símbolo do gene & Coloração da fibra & Espécie de Gossypium & Região \\
\hline Ld1k & Caqui & Arboreum e herbaceum & $\begin{array}{l}\text { África e } \\
\text { Ásia }\end{array}$ \\
\hline Lc2B & Marrom claro & Arboreum e herbaceum & $\begin{array}{l}\text { África } \mathrm{e} \\
\text { Ásia }\end{array}$ \\
\hline Lc2k & caqui & Arboreum e herbaceum & $\begin{array}{l}\text { África e } \\
\text { Ásia }\end{array}$ \\
\hline Lc2M & Marrom médio & Arboreum e herbaceum & $\begin{array}{l}\text { África e } \\
\text { Ásia }\end{array}$ \\
\hline Lc2v & Marrom muito claro & Arboreum e herbaceum & $\begin{array}{l}\text { África e } \\
\text { Ásia }\end{array}$ \\
\hline Lc3B & Marrom claro & Arboreum e herbaceum & $\begin{array}{l}\text { África } \mathrm{e} \\
\text { Ásia }\end{array}$ \\
\hline Lc4k & Caqui & Arboreum & Ásia \\
\hline Dw & Branco sujo & Raimondii & América \\
\hline Lg1 & Verde & Hirsutum & América \\
\hline Lc2 & Marrom & Hirsutum & América \\
\hline LC & Marrom & $\begin{array}{l}\text { Barbadense, Darwinii e } \\
\text { Tomentosum }\end{array}$ & América \\
\hline
\end{tabular}

Fonte: FREIRE, 1999 (Apud Endrizzi et al , 1984).

4.2 - Panorama da Pesquisa e Melhoramento Genético do Algodão Colorido Natural

Conforme mencionamos, as variedades de algodão colorido até a história recente sofreram poucos melhoramentos genéticos. Os melhoramentos feitos nas variedades de algodão com fibra colorida até os anos 1980 foram realizados 
por alguns povos nativos das áreas onde existem. Com as transformações técnicas e científicas da indústria química após a Segunda Guerra Mundial, a variedade de cores produzidas artificialmente foi substancialmente elevada, criando grandes possibilidades para o setor têxtil. Diante desse contexto o cultivo e consumo dos algodões naturalmente colorido ficaram ainda mais restritos à comunidades tradicionais isoladas (VRRELAND JUNIOR, 1999; FARIAS, 2010).

Ao contrário do que ocorreu com o algodão branco, que desde o século XIX tem sido sistematicamente pesquisado e modificado geneticamente, inclusive com a criação do chamado algodão transgênico, lançamento $1996{ }^{50}$, pelos Estados Unidos, o algodão colorido em raros momentos da história despertou o interesse dos pesquisadores (FARIAS, 2010).

De acordo com Vreeland Junior (1999), o primeiro procedimento com o objetivo de saber sobre as propriedades e potencialidades de uso do algodão de cor, foi realizado durante a Segunda Guerra Mundial, por uma equipe de agrônomos do Departamento de Agricultura dos Estados Unidos (USDA).

Essa iniciativa surgiu diante da dificuldade de acesso a corantes sintéticos, pois durante os conflitos muitas fábricas foram destruídas e o acesso à matéria prima não era fácil. De acordo com Vreeland Junior (op. Cit.), o governo dos Estados Unidos tomou conhecimento de que na Rússia algodão com pigmentação natural estava sendo cultivado e utilizado para confecção de tecidos.

Então, o governo americano, através da USDA, determinou que uma equipe de pesquisadores, liderada pelo agrônomo J.O. Ware, investigasse a viabilidade de produção desse tipo de algodão. Os resultados da pesquisa chegou à conclusão de que, comparado ao algodão branco, as características desse tipo de algodão eram muito inferiores, e assim não houve grande interesse pelo produto.

\footnotetext{
${ }^{50} \mathrm{O}$ desenvolvimento de cultivares transgênicas, não só de algodão, mas de outras culturas tem suscitado muitos questionamentos sobre os eventuais problemas que esse tipo de produto pode causar a saúde humana e a perda da biodiversidade. A manipulação genética tornou a planta mais resistente ao calor, a pragas e a venenos como o glifosato, herbicida criado para matar todo o tipo de planta, com exceção daquela geneticamente modificada. Alguns países possuem restrições para o cultivo desses organismos. No Brasil a liberação para produção de algodão transgênico foi ocorreu em 1998.
} 
Diante dessa situação, com o fim da Guerra e com o desenvolvimento ainda mais acentuado da indústria química, o material estudado por J. O. Ware ficou guardado na coleção de germoplasma de algodão do USDA, sem que tenha acontecido nenhum tipo de melhoramento:

\begin{abstract}
During World War II, green and brown cottons were produced for a limited time because dyes were not available. Because Soviet farmers were producing colored-cotton products, the U.S. government also instructed a famous agronomist, J. O. Ware, to study the Soviet cotton plants to determine whether they were commercially viable in the U.S. Ware and his colleagues concluded that the green and brown cotton plants yielded too little lint that was too short in staple length (VREELAND, 1999, p. 4-5)
\end{abstract}

A pesquisa iniciada por Ware durante o período da Segunda Grande Guerra foi a base para os estudos realizados quarenta anos depois pela entomologista californiana Sally Fox. Fox foi a responsável pela viabilização do algodão naturalmente colorido em escala mundial, a partir de seu pioneirismo na pesquisa e melhoramento genético do algodão naturalmente colorido. $O$ interesse em pesquisar o algodão colorido por essa pesquisadora ocorreu em 1982, quando ela voltou de uma viagem de trabalho realizada na África, especificamente na Zâmbia, país em que há grandes plantações de algodão.

Nesse país ela teria ficado impressionada com a quantidade de agrotóxicos utilizados nas plantações de algodão. A pesquisadora teria ainda tido contato com um trabalhador que estava com a saúde profundamente afetada devido ao contato direto com os produtos químicos. Diante da situação, ela voltou para os Estados Unidos, onde desenvolvia seu Mestrado na Universidade da Califórnia, e teve acesso ao algodão colorido.

Em relato da empresa Fox Fibre, empresa espanhola que também comercializa produtos derivados de algodão, desde têxteis, cosméticos e objetos de decoração, Salley Fox teria tido contato com o algodão colorido a partir de um encontro com um índio nativo do México, que lhe mostrou sementes e pluma de algodão colorido e a partir daí ela teria iniciado as pesquisas de melhoramento do algodão colorido, e em 1989 chegou a cultivares de algodão colorido comerciais: 
Sally disse-nos como um dia, enquanto trabalhava em seu laboratório na Califórnia, apareceu um índio do México com um saco de sementes em uma mão e na outra um outro saco cheio de algodão colorido. Ela ficou tão cativada pela magnificência deste algodão colorido que a partir de então dedicou todos os seus esforços para recuperar essa cultura (FOX FIBRE, 2016 - http://www.foxfibrecolorganic.com/sallyfox-5/)

Sally Fox realizou trabalho de melhoramento em variedades de algodão com coloração marrom e verde. O método utilizado no melhoramento das plantas foi o convencional, baseado no cruzamento e seleção das melhores linhagens. Em 1989, ela conclui suas pesquisas e abriu uma empresa denominada Fox Fibre - Colorganic, na Califórnia. A empresa de Sally Fox controla as etapas de produção desde a plantação na fazenda, passando pela colheita, descaroçamento, fiação, tecelagem e confecção das roupas. Para agregar valor ao produto o mesmo tem certificação de orgânico ${ }^{51}$.

Além do trabalho de melhoramento genético realizado por Sally Fox, outra empresa privada nos Estados Unidos também realizou trabalhos de melhoramento genético de variedades de algodão colorido, a BC Cotton Inc de Braskerfield, na Califórnia. A empresa citada começou os trabalhos de melhoramento do algodão colorido no início da década de 1990. O método adotado é o mesmo utilizado por Sally Fox, o material genético utilizado para desenvolver as novas variedades coloridas são provenientes da coleção de germoplasma da universidade Texas A\&M da Califórnia (SHAND, 1993).

Segundo Shand (1993, p. 3), em 1993 a BC Cotton Inc. plantou 2000 hectares de algodão colorido nos estados da Califórnia, do Texas e do Arizona. Ainda segundo o autor citado, diferentemente de Salley Fox, que tem como público consumidores de produtos orgânicos, a BC Inc. não tem essa preocupação e o seu mercado é principalmente formado por consumidores dos Estados Unidos, Japão e Europa, contudo o cultivo é realizado de modo convencional.

Além da BC Cotton Inc. outras empresas privadas também têm realizado pesquisas com o algodão colorido a exemplo da Empresa Monsanto de Biotecnologia responsável pela Pesquisa e Desenvolvimentos da multinacional do setor agrícola dos EUA (Farias, 2010, p. 201). Embora a Monsanto não

\footnotetext{
${ }^{51}$ Voltaremos a falar da Empresa criada por Salley Fox, especialmente para mostra a diferença entre a produção norte americana de algodão colorido e a brasileira.
} 
produza algodão colorido, pois até o momento não é de interesse dela, nem de grandes empresas do setor de fibras produzirem o algodão colorido, o fato de a mesma desenvolver pesquisas para essa variedade de algodão assegura que caso haja necessidade e oportunidade no mercado para esse produto, a empresa estará apta a competir. Na Índia, maior produtora mundial de algodão branco, as pesquisas de melhoramento do algodão colorido são realizadas pelo Instituto Central de Pesquisa para o Algodão - em Nagpur. No Brasil, as pesquisas para 0 algodão naturalmente colorido inicialmente foram desenvolvidas pela Embrapa Algodão, e mais recentemente pelo Instituto Agronômico de Campinas.

\section{3 - A trajetória tecnológica do Algodão Colorido no Brasil}

No Brasil, as pesquisas com o algodão colorido têm início em 1989 pela Embrapa Algodão. O método utilizado pela equipe de melhoristas de plantas do programa de melhoramento do algodão colorido foi o convencional. O material genético que serviu de base para o cruzamento e melhoramento utilizado foi o algodão mocó, que possui fibras com excelentes características e resultaram em cultivares superiores ${ }^{52}$. As cultivares desenvolvidas por Sally Fox tiveram por base material de algodão do tipo G. hirsitum, de fibra média (SANTANA, el al.,1997).

A referência ao método utilizado pelos pesquisadores é importante, pois no mercado de produtos orgânicos, não é permitido o uso de organismos geneticamente modificados. Isso é relevante, pois na China, atualmente o país em que há maior área e quantidade produzida de algodão colorido, as cultivares utilizadas são resultado de transgenia. Essa situação projeta a produção de algodão naturalmente colorido brasileiro no mercado, já que este foi desenvolvido com método aceitável pelo mercado de orgânicos, e ainda possui fibras de boa qualidade.

\footnotetext{
${ }^{52} \mathrm{O}$ que estamos denominando como cultivares superiores são as plantas que devido ao processo de melhoramento genético fornecem um algodão com fibra de melhor qualidade em relação à planta de algodão colorido silvestre.
} 
A pesquisa do algodão colorido no Brasil surge no contexto da crise na cotonicultura tradicional existente no país nos anos 1980. Após a derrocada da cultura algodoeira na região Nordeste, o algodão mocó correu o risco de entrar em extinção, conforme relatado por Beltrão, et al. (1989):

Por mais paradoxal que possa parecer, é exatamente este algodoeiro, único espécime perene, produtor de fibras longas, adaptado a região semi-árida nordestina, que irá pagar com 0 seu provável desaparecimento, o tributo da desorganização secular em que se vem apoiando a exploração algodoeira no Nordeste (BELTRÃO, et al. 1989, p.12).

A origem do material que viabilizou as pesquisas do algodão colorido pela Embrapa Algodão teve princípio na necessidade de preservar o algodão mocó. Para isso, foi realizada coleta pelos pesquisadores da Embrapa Algodão em 1984, que inicialmente tinha como objetivo coletar amostras de cultivares de algodão mocó. Nessa coleta foram encontradas diversas amostras de algodão, entre elas algumas que possuíam fibra colorida, e como o algodão colorido naquela época não era de interesse do mercado, esse material foi guardado para preservação e posterior estudos (SANTANA, et al., 1997).

A partir de uma demanda externa é que tem início as pesquisas com o algodão colorido no Brasil. O evento responsável por tal demanda foi a visita de empresários japoneses do setor têxtil, que vieram conhecer as instalações da Embrapa Algodão em Campina Grande no ano de 1989. Segundo o Pesquisador Luiz Paulo de Carvalho, agrônomo com especialidade em melhoramento de plantas, os referidos empresários demonstraram interesse em adquirir aquele tipo de algodão, que seria utilizado para a confecção de roupas para recém nascidos e pessoas alérgicas, caso a instituição conseguisse transformar as características da fibra tornando-as viável para fiação e tecelagem moderna.

Embora a gente esteja aqui há muito tempo (Embrapa Algodão), a gente nunca pensou em trabalhar com esse tipo de algodão (colorido), mas na década de 1980 os pesquisadores que trabalhavam com o melhoramento do algodão viajaram o Nordeste inteiro coletando plantas de algodão abandonadas que ficavam em restos de cultura, para conservar no banco de Germoplasma para futuras gerações, é uma fonte de variabilidade, porque quando precisar de fazer novas variedades, tem sementes para fazer novas variedades. Então os pesquisadores observaram que algumas plantas que eles coletaram não eram totalmente brancas, era como se estivessem empoeiradas, então eles viram que era uma cor que tinha. Eles beneficiaram isso, tiraram as sementes e guardaram e um pouco da pluma ficou na sala 
da chefia, coincidentemente um grupo de empresários japoneses vieram aqui conhecer a Embrapa, não estavam nem pensando em algodão colorido nem nada, aí viram aquilo ali e disseram para o chefe da época que era o Eleusio que estavam interessados nesse tipo de tecido, e que se eles fizessem tecidos com aquele algodão eles comprariam para recém nascidos. Isso teria dado um estalo na cabeça do pesquisador, que começou a fazer melhoramento e dois ou três anos depois lançou a primeira variedade, marrom claro (algodão mocó) (Luiz Paulo de Carvalho, realizada durante trabalho de campo em: julho de 2015).

A visita dos empresários japoneses é então o evento que marca o início do interesse pelo melhoramento e desenvolvimento do algodão naturalmente colorido no Brasil. Então, quando os pesquisadores da Embrapa começaram o trabalho de melhoramento do algodão colorido, o desafio era melhorar essas características (FREIRE,1999).

Estava dado ali o input para o novo período de produção de algodão no território paraibano e brasileiro. E coube a Embrapa Algodão, que já possuía uma expertise no setor, solucionar esse problema tecnológico. Então o desenvolvimento do algodão colorido no país surge inicialmente como demanda internacional.

Assim, em 1989, dois programas de melhoramento de algodão tiveram início no âmbito da competência das pesquisas realizadas pela Embrapa Algodão. Um voltado para recuperação do setor algodoeiro no país, que tinha como foco o desenvolvimento de cultivares de algodão herbáceo adaptado para as condições edafoclimaticas do Cerrado brasileiro, área que já despontava como grande celeiro na produção de commodities agrícolas e precisava de uma outra cultura para fazer rotação, ou seja plantar na entressafra da soja. E outro programa preocupado em atender as demandas de produção do Semiárido, especialmente relacionada ao algodão mocó (FREIRE e BELTRÃO, 2008).

Quando a Embrapa Algodão formalizou a parceria com o Grupo Itamarati, de propriedade de Olacir de Moraes, em 1989, buscavam-se alternativas econômicas para a rotação com a soja [Glycine max (L.) Merrill], como estratégia para garantir os grandes investimentos realizados para a abertura do Cerrado do Mato Grosso, ameaçado por seqüências de safras com baixa rentabilidade para a soja, bem como pelo aumento dos problemas fitossanitários, especialmente pelo cancro-da-haste e nematóide-de-cisto. A tecnologia utilizada nessa época para o plantio de algodão no Cerrado incluía a importação de sementes de Israel, dos Estados Unidos da América e da Austrália; o plantio das lavouras no mês de fevereiro; o uso de fileiras duplas, 
espaçadas de 1,20 m; o controle apenas de lagartas; o uso de solos marginais do Cerrado para o plantio do algodoeiro, que era considerada lavoura experimental; e a inexistência de controle de doenças. Essas tecnologias foram aperfeiçoadas ao longo de 16 safras de algodão e, hoje, pouco daquela tecnologia inicial ainda persiste. As cultivares importadas estavam adaptadas a sistemas de produção irrigados em ambientes semi-áridos e, nas condições climáticas do Cerrado no Mato Grosso, de altas altitudes, associadas à temperatura, umidade e precipitação elevadas, resultaram em alta incidência de pragas e de doenças foliares (bacterianas e fúngicas) e viroses (FREIRE e BELTRÃO, 2008, p.640).

As pesquisas para o melhoramento do algodão colorido inicialmente foram realizadas com base em onze acessos disponíveis no Banco ativo de Germoplasma da Embrapa Algodão, localizado em Patos - PB, proveniente da coleta feita em 1984 no Nordeste (FREIRE, 1999). A primeira cultivar desenvolvida foi a BRS 200 (cor marrom claro), disponibilizada para cultivo comercial em 2000. A BRS 200 é uma variedade semiperene, com ciclo produtivo de até três anos e altamente resistente à seca. $\mathrm{O}$ material genético utilizado foi o algodão mocó, que possuía fibra marrom clara (ver Figura 20). É a única cultivar de algodão colorido perene desenvolvida no país.

Todas apresentaram fibras curtas, de baixa resistência, sem uniformidade e grossas e o trabalho do melhoramento foi selecionar a variabilidade existente para produtividade e qualidade da fibra, culminando com a obtenção de três linhagens fenotipicamente semelhantes, que foram misturadas para dar origem a cultivar BRS 200 Marrom, lançada em 2000, sendo a primeira cultivar de fibra de cor lançada no Brasil e derivada diretamente do algodão mocó, sendo a cultivar de fibra de cor de melhor performance industrial (BELTÃO; CARVALHO, 2004, p. 11). 


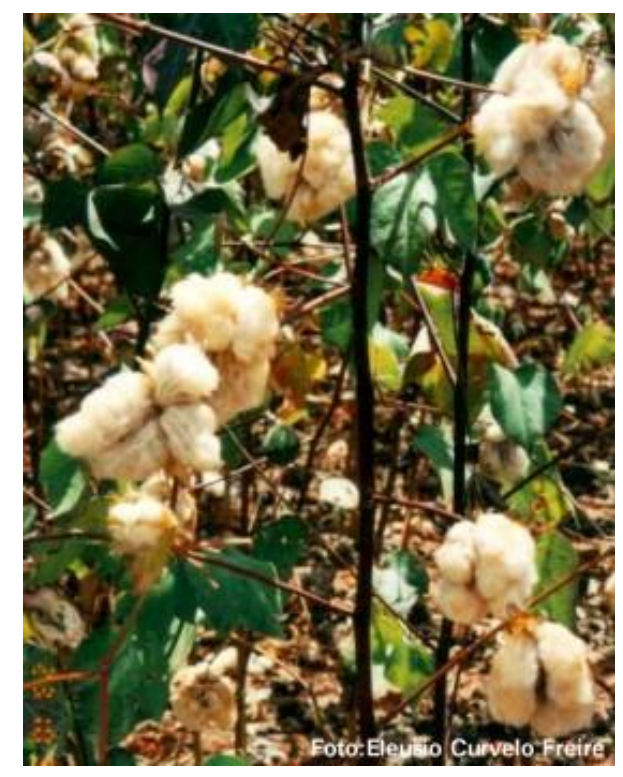

Figura 20: Cultivar BRS 200

Fonte: FREIRE, Eleusio Curvelo

Acessado em: janeiro de 2015

Disponível em: http://ccw.sct.embrapa.br/?pg=bloguinho default\&codigo=146

Essa cultivar foi obtida a partir da seleção de linhagens mais produtivas. Segundo Santana et al., 1997 a cultivar BRS 200 se constitui a partir de um bulk (mistrura) de partes iguais. A fase de experimentação dessa cultivar foi feita no Campo Experimental de Patos e as multiplicações de sementes foram feitas inicialmente em áreas da Embrapa nos municípios Touros-RN, Patos-PB e Missão Velha-CE. No segundo semestre de 2000 as multiplicações de sementes foram feitas em campos cooperados da Embrapa Transferência de Tecnologia (Embrapa STN) nos municípios de Catolé do Rocha-PB e Piancó-PB. Para se chegar a cultivar BRS 200 marrom, os pesquisadores precisaram de 7 anos de pesquisa (BELTRÃO; ARAÚJO, 2004).

De acordo com Freire (1999, p. 4), as pesquisas para o desenvolvimento da cultivar BRS 200 marrom foi financiada com recursos do Conselho Nacional de Desenvolvimento Científico e Tecnológico (CNPq), no valor de aproximadamente $R \$ 60.000,00$ e recursos da Embrapa, com aproximadamente $\mathrm{R} \$ 100.000,00$ num total de $160.000,00$ referentes ao custeio da pesquisa. Além dos valores citados, o autor acrescenta 0 valor dos salários pagos aos pesquisadores da Embrapa nos anos de pesquisa, somando um custo total de 
$R \$ 355.000,00$. Isso denota que o projeto de pesquisa sobre o algodão colorido é fruto de uma política pública, e o Estado financiador.

As demais cultivares de algodão com fibra colorida foram desenvolvidas com material genético de variedade herbácea de ciclo anual. Em 2002 foi lançada outra cultivar, a BRS Verde (verde água). Foram utilizadas as cultivares CNPA 7H, desenvolvida pela Embrapa Algodão e a Arkansas Green, de origem norte-americana (ver Figura 21).

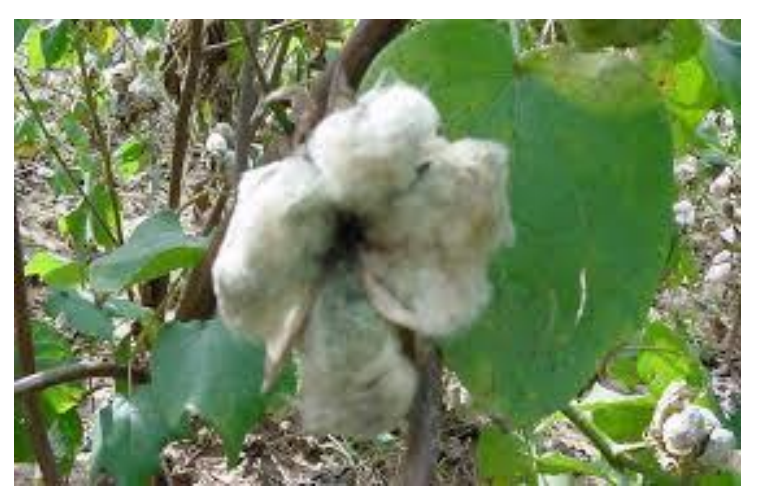

Figura 21: Cultivar BRS Verde

Fonte: CARVALHO, 2006.

Mesmo com os pesquisadores tendo conseguido estabilizar as cores do algodão colorido, foi necessário que os agricultores adotassem novas práticas para alcançar bons resultados, como colher o algodão quando os capulhos estivessem maduros. Isso acontece especialmente no caso da BRS Verde, pois como não pode ficar muito tempo exposto ao sol, precisar ser colhido à medida que for surgindo, para evitar o embranquecimento dessa cultivar.

As outras cultivares desenvolvidas pela Embrapa Algodão foram: a BRS Rubi (marrom escuro ou avermelhado), a BRS Safira (marrom telha) e a BRS Topázio (marrom clara) lançadas nos anos 2003, 2004 e 2010, respectivamente, e tiveram como doadores material genético introduzido de outros países e cultivares de algodão branco já adaptados as condições ambientais da região. ${ }^{53}$ Além das cultivares citadas, está em andamento por essa instituição uma

\footnotetext{
${ }^{53}$ É importante destacar que mesmo recomendada para ser plantadas na região zoneada para produção de algodão no Semiárido nordestino, as cultivares de algodão colorido pode ser plantada em outras regiões do país, a exemplo da região Centro Oeste e Sudeste, mas é preciso que alguns cuidados no manejo sejam tomados, pois devido as características particulares do clima essas plantas estão vulneráveis a algumas doenças e pragas mais comuns a essas regiões.
} 
pesquisa para desenvolver cultivar na cor violeta ${ }^{54}$ (FREIRE, 1999; CARVALHO; ANDRADE, SILVA FILHO, 2011).

No que se refere à BRS Safira, trata-se de uma variedade herbácea de algodão de cor, de ciclo anual (140 a 150 dias) resultante do cruzamento genético de material de fibra marrom escuro com a CNPA Precoce 3 (herbácea branca). A BRS Safira possui coloração marrom escuro, porém mais clara que a BRS Rubi (CARVALHO, 2006). (Ver Figura 22)

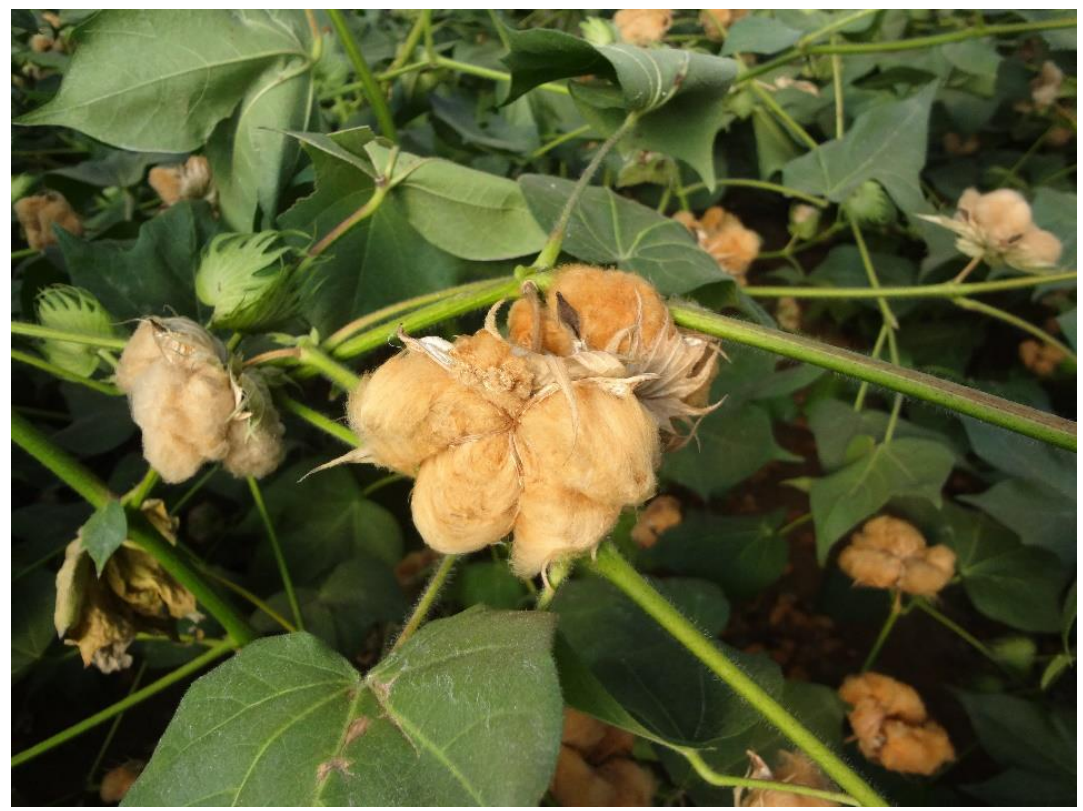

Figura 22- Cultivar BRS Safira Foto: LIRBÓRIO, L.F. 2015.

Local: Embrapa Algodão - Campina Grande - PB

A BRS Rubi constitui-se em uma variedade de cultivar herbácea de ciclo anual (140 a 150 dias), resultante do cruzamento de espécies de fibra marrom

\footnotetext{
${ }^{54}$ Em março de 2017 quando já havíamos concluído essa pesquisa foi lançada pela Embrapa Algodão mais uma nova cultivar de algodão naturalmente colorido a BRS Jade. Essa cultivar possui fibras na cor marrom claro. Entre as características da BRS Jade são destacadas: alta produtividade, qualidade da fibra e o principal diferencial em relação às outras cultivares de algodão naturalmente colorido desenvolvidas pela Embrapa Algodão é que essa cultivar tanto pode ser produzida no ambiente Semiárido quanto no Cerrado. A cultivar BRS 200 era recomendada para ambientes secos uma vez que possuía elevada resistência à seca. As cultivares BRS Verde, BRS Rubi, BRS Safira e BRS Topázio, embora pudessem ser plantadas em outras regiões fora do Nordeste estavam vulneráveis a inúmeras pragas devido as diferenças de clima. Ainda no início de 2017 foi noticiado pela Embrapa Algodão o interesse de um grupo de agricultores familiares do estado do Mato Grosso em plantar o algodão naturalmente colorido.
} 
escuro com a variedade herbácea branca CNPA 7H (CARVALHO, op. cit.) (Figura 23).

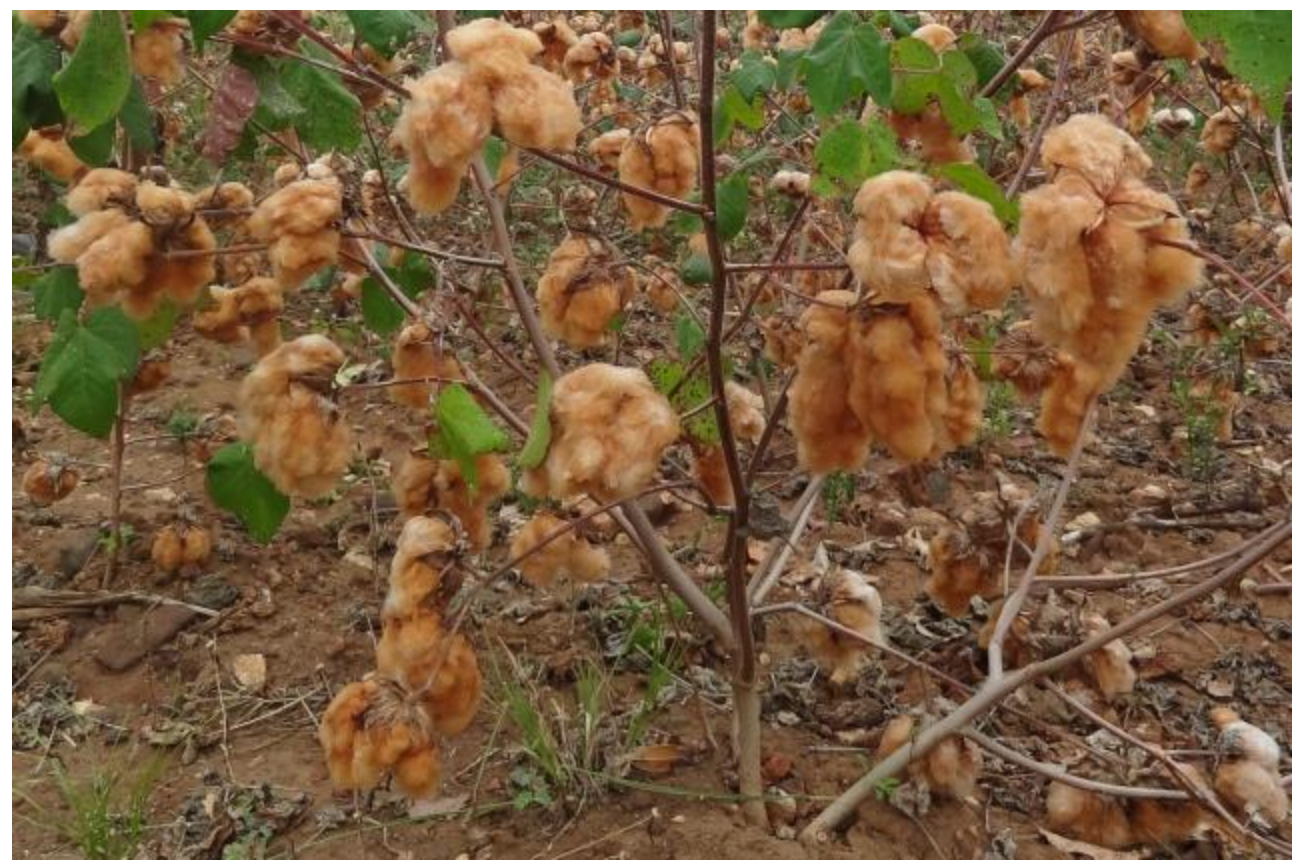

Figura 23 - Cultivar BRS Rubi

Foto: SANTOS, Edna Maria Cosme dos

Acessado em: julho de 2015

Disponível em: https://www.embrapa.br/busca-de-imagens//midia/1358004/algodao-colorido

A BRS Topázio, deriva do cruzamento entre as cultivares Suregrow e Delta Opal. Entre as cultivares com fibra colorida é a que apresenta melhor desempenho, chegando em termos de produção a superar cultivares de algodão branco herbáceo. Como possui cor semelhante a BRS 200, atualmente essa variedade tem substituído a cultivar de ciclo semiperene (Ver Figura 24). Ainda sobre as vantagens da BRS Topázio, Vale et al. (2011) destacam:

Esta cultivar se destaca por possuir alta percentagem de fibra $(43,5 \%)$, alta uniformidade $(85,2 \%)$ e alta resistência $(31,9 \mathrm{gf} / \mathrm{tex})$, conferindo excelentes características, superiores as demais fibras brancas. A produtividade média é de $2.825 \mathrm{~kg} / \mathrm{ha}$, superior às cultivares BRS Safira e BRS Rubi (Vale, et al., 2011, p.6). 


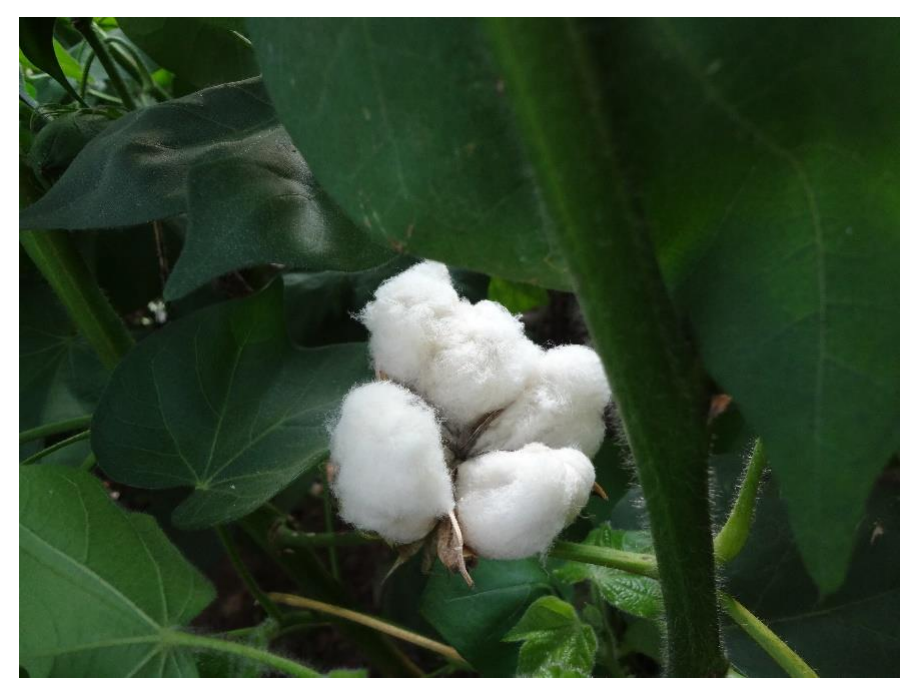

Figura 24 - Cultivar BRS Topázio

Foto: LIRBÓRIO, L.F. 2015.

Local: Embrapa Algodão - Campina Grande - PB

As principais características das cinco primeiras cultivares de algodão com fibra colorida podem ser verificadas no Quadro 14. A referência para comparação do desempenho das mesmas foi uma cultivar herbácea branca a BRS $1878 \mathrm{H}$. Mesmo que não tenha sido feita a comparação com o algodão Mocó, este apresenta produtividade muito menor, embora possuísse comprimento, resistência e finura superiores às apresentadas por essas novas variedades.

Quadro 14 - Características das Cultivares de Algodão Colorido: BRS 200 Marrom, BRS Verde, BRS Rubi, BRS Safira, BRS Topázio em comparação a cultivar branca BRS $1878 \mathrm{H}$

\begin{tabular}{|c|c|c|c|c|c|c|c|}
\hline Cultivares & $\begin{array}{l}\text { Cor da } \\
\text { Pluma }\end{array}$ & $\begin{array}{l}\text { Ciclo } \\
\text { (dias) }\end{array}$ & $\begin{array}{l}\text { Produtividad } \\
\text { e }(\mathrm{kg})\end{array}$ & $\begin{array}{l}\text { Rendimento } \\
(\%)\end{array}$ & $\begin{array}{l}\text { Comprimento } \\
(\mathrm{mm})\end{array}$ & $\begin{array}{l}\text { Resistencia } \\
\text { (gf/tex) }\end{array}$ & Uniformidade \\
\hline $\begin{array}{l}\text { BRS } 200 \\
\text { Marrom }\end{array}$ & $\begin{array}{l}\text { Marrom } \\
\text { Claro }\end{array}$ & $\begin{array}{l}\text { Até } 3 \\
\text { anos }\end{array}$ & 1.300 & 35,9 & 28 & 24,3 & 83 \\
\hline BRS Verde & Verde & $\begin{array}{l}120- \\
140\end{array}$ & 2.146 & 28 & 29,56 & 25,86 & - \\
\hline BRS Rubi & $\begin{array}{l}\text { Marrom } \\
\text { Escuro }\end{array}$ & $\begin{array}{l}120- \\
140\end{array}$ & 1.848 & 35,6 & 25,4 & 24,5 & 81 \\
\hline BRS Safira & $\begin{array}{l}\text { Marrom } \\
\text { Escuro }\end{array}$ & $\begin{array}{l}120- \\
140 \\
\end{array}$ & 1.915 & 36,6 & 24 & 24,2 & 80,1 \\
\hline BRS Topázio & $\begin{array}{l}\text { Marrom } \\
\text { Claro }\end{array}$ & $\begin{array}{l}120- \\
140\end{array}$ & $2.825^{*}$ & 43,5 & 30,4 & 31,9 & 85,2 \\
\hline BRS $1878 \mathrm{H}$ & Branco & $\begin{array}{l}120- \\
140 \\
\end{array}$ & 1990 & 38,6 & 28 & 20,8 & 50,5 \\
\hline
\end{tabular}

* Média obtida em cultivo irrigado no Cariri cearense

Fonte: VALE, et al. (2011). 
Os versos extraídos do Cordel, "O Milagre do Algodão Colorido", transcrito abaixo, é expressivo da novidade que foi o desenvolvimento/melhoramento do algodão naturalmente no início do século XXI:

\title{
O Milagre do Algodão Colorido
}

\author{
01 - O algodão brasileiro \\ Do Litoral ao Sertão, \\ Na Paraíba, inclusive, \\ Vive uma transformação \\ lluminando o presente, \\ Eis que chega finalmente \\ A GRANDE REVOLUÇÃO. \\ 02 - Mas desta revolução \\ Não sai guerreiro ferido, \\ Parque fabril devastado, \\ Monumento destruído, \\ Nela, um "mago sem condão" \\ Transmuta o BRANCO ALGODÃO \\ Em CAPULHO COLORIDO.
}

03 - Este colorido novo De mutações singulares Não é recente pois já Foi visto em outros lugares Mas no Brasil vem crescendo Pois estão desenvolvendo excelentes cultivares.

04 - Verde, marrom e mais outras

Tonalidades e cores

Nascem, como por encanto, Das mãos dos pesquisadores, Essa dança colorida Enche de esperança e vida Os nossos agricultores (Manoel Monteiro, 2003).

A produção comercial do algodão colorido na Paraíba - Brasil teve início em 2001. Houve por parte da Embrapa Algodão e da EMATER-PB mobilização para incentivar os agricultores a plantarem o algodão colorido, pois devido ao desmonte da plantação de algodão na região nos anos 1980 os agricultores familiares que inclusive foram pressionados para arrancar e queimar o algodão branco, para erradicar o bicudo tinham medo de investirem novamente na cultura algodoeira. Além das instituições citadas, grupos de empresários locais se mobilizaram para assegurar o fornecimento dessa matéria prima. 
Como forma de atrair os agricultores foi oferecido um valor superior ao que era pago no mercado pelo algodão branco. Inicialmente o algodão era vendido em rama ${ }^{55}$ e o comprador ia até a própria Embrapa, que tinha como objetivo a multiplicação de sementes ${ }^{56}$ para posteriormente ser vendida ao Governo do Estado da Paraíba, que depois distribuiu para os agricultores (QUEIROGA; JERÔNIMO; MELEÁN, 2010).

Inicialmente as áreas escolhidas para plantio o algodão foram os municípios de Patos e Pombal, no Seridó Paraibano, e depois da distribuição de sementes por parte do Governo do Estado em 2006 o cultivo se ampliou por vários municípios do Sertão e do Agreste paraibano. O cultivo é feito por agricultores familiares em propriedades de até 5 ha, produzido tanto em sequeiro, como irrigado. Nos primeiros anos a produção foi convencional com uso de pesticidas e herbicidas para o controle das pragas, contudo devido a suas características, foi estimulado a produção de forma orgânica, o que agrega mais valor a esse produto (FARIAS, 2010).

Essa grande novidade no mercado têxtil brasileiro foi amplamente divulgada na mídia e fez com que as atenções se voltassem para essa instituição e esse novo produto, pois a maioria das pessoas, não somente brasileiras, desconheciam a existência do algodão colorido na natureza (FREIRE, 1999; FARIAS, 2010; LIRBÓRIO, 2014).

O algodão naturalmente colorido, conforme mencionado, faz parte do Programa de Melhoramento Genético do Algodão da Embrapa Algodão. Este Centro de Pesquisa possui dois macro programas de melhoramento genético do algodoeiro distintos.

Um dos programas é voltado para a agricultura familiar, especialmente do Semiárido brasileiro, tendo como foco o desenvolvimento de cultivares com características especiais, como o algodão de fibra naturalmente colorida e algodão branco de fibra extralonga. Ele foi pensado para a agricultura familiar, que forma a maior parte dos agricultores da região semiárida e que quando havia

\footnotetext{
${ }^{55} \mathrm{~A}$ comercialização do algodão em rama era a forma mais comum de comercialização do algodão branco pelos agricultores do semiárido. Chama-se algodão em rama quando o algodão a pluma do algodão não está separada do caroço.

${ }^{56} \mathrm{~A}$ multiplicação de sementes, ocorre no mesmo ano em que os empresários da associação de confecções participam da FENIT, assim acreditamos que a demanda pela multiplicação veio desses empresários, que precisavam da fibra com as novas características tecnológicas, conforme será analisado ainda neste capítulo
} 
o cultivo do algodão branco na região formava a maior parte dos produtores de algodão. A perspectiva é de que os agricultores familiares desenvolvam esses sistemas de produção com base na agricultura orgânica, de forma a atingir mercados onde esses produtos são valorizados, devido ao crescente interesse por produtos que não agridem o meio ambiente.

O outro Programa de Melhoramento do Algodão da Embrapa Algodão é relacionado ao algodão branco herbáceo, voltado para os Cerrados. As pesquisas são desenvolvidas tanto na sede da Embrapa Algodão, como há pesquisadores lotados em Campos Experimentais, localizados nas principais áreas produtoras. Com o propósito de desenvolver cultivares adaptados para as diferentes condições ambientais, a Embrapa Algodão possui oito Campos Experimentais localizados nos municípios de Monteiro e Patos (Paraíba), Barbalha e Missão Velha (Ceará), Luiz Eduardo Magalhães e Irecê (Bahia), Sinop (Mato Grosso) e Santo Antônio de Goiás (Embrapa Arroz e Feijão), além de diversos pontos de pesquisa no Brasil e no exterior (ver Mapa 6).

A presença desses Campos Experimentais nas áreas produtoras, demonstram que, por mais que existam avanços técnico-científicosinformacionais, os elementos naturais dos territórios são relevantes, especialmente no processo de adaptação de produtos agrícolas. 
Mapa 6 - Sede da Embrapa Algodão e Campos Experimentais na região Nordeste e Centro-Oeste

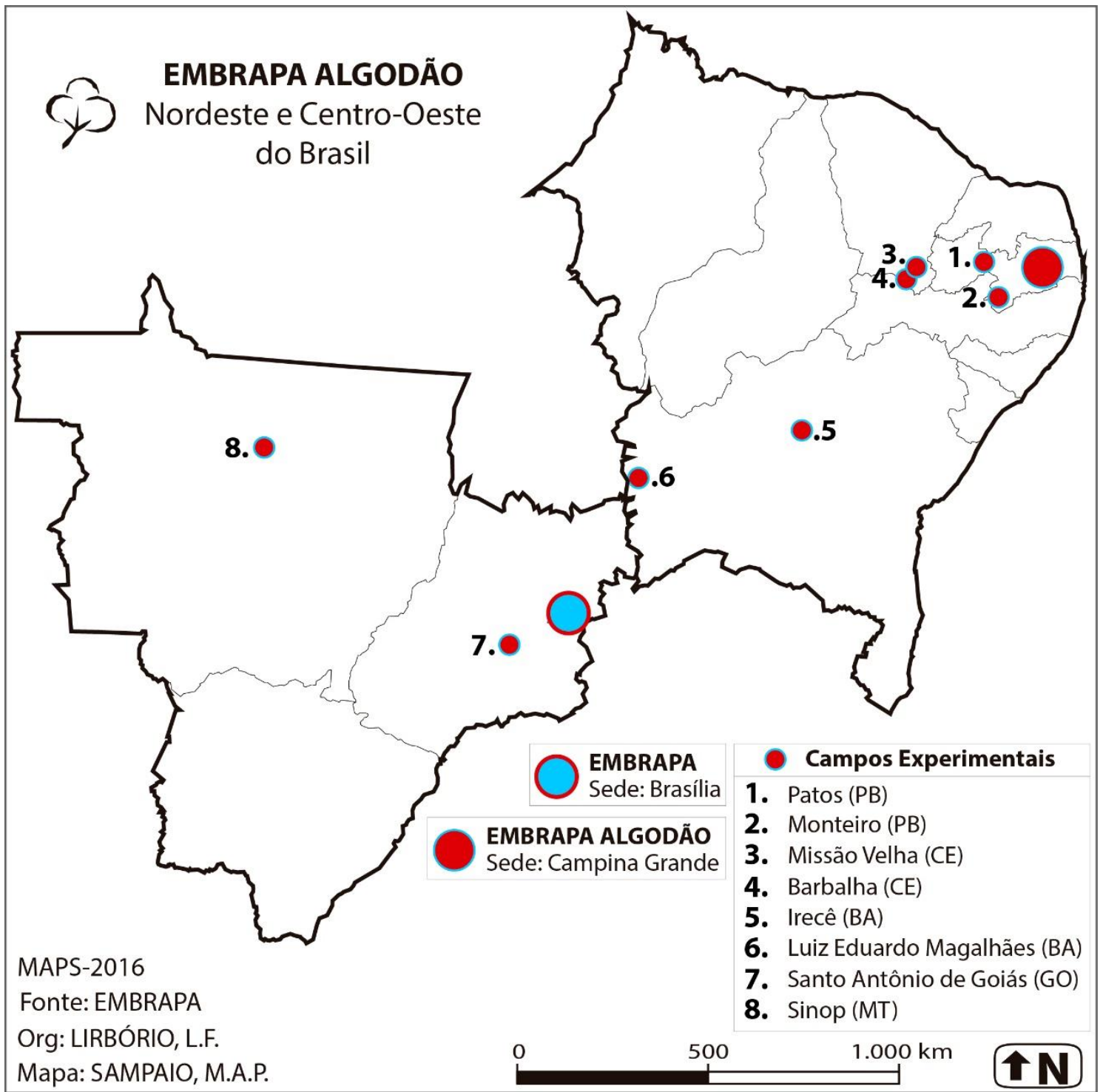

4.4. O processo de territorialização do algodão colorido na Paraíba

As atividades ligadas ao circuito espacial de produção do algodão colorido no Brasil é recente. Contudo em pouco mais de quinze anos de existência desse produto observa-se algumas metamorfoses pelas quais o mesmo passou. Algumas destas transformações são: as áreas onde eram cultivadas nos 
primeiros anos de exploração da cultura; modificação no sistema de cultivo, inicialmente o cultivo era realizado nos moldes da agricultura convencional, com o uso de agrotóxicos e fertilizantes; predomínio de cultivares de ciclo precoce, tendo em vista que a cultivar BRS 200 de ciclo semi-perene, atualmente essa variedade não é mais plantada, pois já foram desenvolvidas outras cultivares, com cor semelhante e com melhores rendimentos.

Inicialmente, só o fato de ser naturalmente colorido já chamava atenção, mas para ganhar visibilidade no mercado a forma de produção desse produto precisou se adequar as exigências do mercado consumidor de exportação. A opção pelo sistema de produção orgânico foi mais um elemento para adentrar nesse mercado, pois em países da Europa para onde foram direcionados os produtos há crescente público interessado por produtos considerados ecologicamente corretos.

A preocupação com a origem social desse produto é outro item que passa a ter valor na cadeia, pois o consumidor final cada vez mais se preocupa com as condições de produção em todas suas fases. Nesse sentido, a agricultura familiar passa a ter papel relevante. O marketing pelo social acaba sendo elemento estratégico para a venda, pois não está só sendo vendido um produto, mas um "modo de vida", valores culturais.

Esses novos valores sociais acontecem no âmbito da "psicoesfera" e ocorre em escala global, na forma de fluxos, ideias, valores. Segundo Santos (1994, p. 14) a pisicoesfera "é o resultado das crenças, desejos, vontades e hábitos que inspiram comportamentos filosóficos e práticos, as relações interpessoais e a comunhão com o Universo".

No Brasil, o cultivo do algodão colorido até recentemente estava territorializado ${ }^{57}$ no Estado da Paraíba. Essa territorialização se deve ao poder exercido por grupos empresariais locais que se articularam para manter o domínio sob esse produto, e criaram as condições para manutenção dessa matéria prima nesse estado. Não só o cultivo do algodão está territorializado no estado da Paraíba, mas as outras etapas da produção, como fiação, tecelagem, a criação das peças, confecção e comercialização. Por sua vez, a circulação do

\footnotetext{
${ }^{57}$ A ideia de territorialização aqui empregada está articulada com o conceito de territorialidade, no sentido de uma organização territorial.
} 
produto final acontece de forma globalizada e as ações durante as etapas anteriores são feitas e pensadas por esse mercado mundial ${ }^{58}$.

Foi o interesse demonstrado por empresários japoneses do setor têxtil que criou a necessidade da Embrapa Algodão a partir do conhecimento científico aplicado a agricultura para modificar a estrutura do algodoeiro e torná-lo possível de exploração econômica. Embora a demanda inicial tenha partido do exterior, foram os grupos locais que se apropriaram dessa inovação.

O fato de ter sido utilizada por grupos locais foi positivo, na medida que diante da possibilidade de fornecer esse tipo de algodão como matéria-prima para o mercado externo, o mesmo passou a ser comercializado como produto pronto para o consumo, o que agrega valor à produção e contribui para 0 desenvolvimento econômico local.

Contudo, o lucro gerado por essa matéria prima não é distribuído proporcionalmente entre os diferentes atores envolvidos no circuito espacial de produção. $O$ aspecto relacionado a equidade no circuito espacial de produção é relevante, pois parte do marketing que envolve a venda de produtos derivados do algodão colorido orgânico está vinculado ao fato desse produto ser cultivado pela agricultura familiar, agregar rudimentos do artesanato regional e ser socialmente justo ${ }^{59}$.

Farias (2010) considera que devido a diferença de poder político e econômico que possuem os diversos atores que compõe o circuito espacial de produção do algodão colorido e derivados da Paraíba, o mesmo não se caracteriza como fair trade (socialmente justo). Nesse sentido, o apelo ambiental e socialmente justo é um "marketing forjado" pelos empresários do setor de confecção que procuravam um diferencial para sua produção.

Assim, em um ciclo de produção como o do algodão colorido e derivados, no qual se inscrevem desde agricultores pobres que, em

\footnotetext{
${ }^{58}$ Recentemente o cultivo de algodão naturalmente colorido também está acontecendo em outros estados do Nordeste, a exemplo do Rio Grande do Norte, sobre esse tema trataremos no capítulo seguinte.

59 Para esse assunto consultar a tese de Paulo Sergio Cunha Farias, intitulada: " Os circuitos Espaciais de Produção e os Círculos de Cooperação do Algodão Colorido e Derivados da Paraíba (2000-2008): uma dimensão geográfica da flexibilização do produto, da produção e do consumo de moda, fibras, têxteis e confecções".
} 
sua imensa maioria, nem sabem o sentido e o destino da sua produção, até representantes das oligarquias políticas e econômicas do Estado, que se situam na ponta superior, comandando o ciclo e subordinando todas as demais etapas e atores aos seus interesses, não é possível a sustentabilidade social e ambiental, a solidariedade econômica e o intercâmbio marcado por trocas justas e benefícios compartilhados entre todos os atores sociais que dele participam (FARIAS, 2010, p. 23).

O aproveitamento industrial e artesanal dessa matéria-prima teve início na cidade de Campina Grande - PB, mesma cidade onde está localizada a Embrapa Algodão. E se não fosse pelo contexto de crise pelo qual o setor de confecção da Paraíba enfrentava, talvez esse produto inovador tivesse passado desapercebido pelo grupo de pequenos empresários do setor de confecção daquela cidade. Algumas situações contribuíram para que o algodão colorido brasileiro se tornasse conhecido fora do país, e hoje seja considerado exemplo de sucesso, tanto do ponto de vista tecnológico, como pelas questões sociais que lhe são inerentes.

Segundo a Presidente do Sindicato das Indústrias do Vestuário da Paraíba (SINDIVEST) ${ }^{60}$ quando os pesquisadores da Embrapa Algodão começaram a divulgar nos meios de comunicação que haviam concluído a pesquisa que levou a criação da primeira cultivar de algodão colorido do Brasil, a BRS 200, em 2000, o setor de confecção da Paraíba estava em crise devido à concorrência que o Polo Têxtil e de Confecção de Pernambuco, formado pelas cidades de Caruaru, Santa Cruz do Capibaribe e Toritama, e também pela invasão no mercado nacional de confecções chinesas, ocasionada pela abertura da economia brasileira na década 1990 (BRASIL, 2011).

O polo de confecções do Agreste pernambucano possuía vantagens competitivas, como a isenção de impostos, situação comum na chamada "guerra dos lugares" na qual as empresas se instalam nos lugares onde o Estado oferece as melhores condições, a exemplo da isenção de impostos ${ }^{61}$. O que, nas

\footnotetext{
${ }^{60}$ Informação obtida em entrevista, durante trabalho de campo, realizado em Campina Grande, em julho de 2016. Informação semelhante está disponível em: BRASIL, Ministério da Cultura. Pesquisa - Economia e Cultura da Moda no Brasil.(pág. 96-97) 2011.A presidente do SINDVEST é também a presidente da COOPNATURAL.

Disponível em: http://www.iniciativacultural.org.br/wp-content/uploads/2011/01/PesquisaEconomia-e-Cultura-da-Moda-2012.pdf> Acessado em: 10/08/2016.

61 A partir dos anos 1970 houve no Brasil uma intensa politica de industrialização no país, especialmente nas regiões onde o fenômeno industrial era mais raro. Como forma de atrair
} 
palavras da Presidente da SINDIVEST, significava ter uma "China ao seu lado", no sentido de que não era possível competir em igualdade de condições.

Somado a crise no setor de confecção, o estado da Paraíba ia participar da Feira Nacional da Industria Têxtil (FENIT) no ano de 2000 e não tinha nenhuma perspectiva do que apresentar como novidade nesta feira. Ao tomar conhecimento do algodão colorido, a presidente do SINDVEST vislumbrou que esse produto poderia ser a grande novidade que os empresários do setor de confecção apresentariam na ocasião. Foi nesse contexto que o algodão colorido foi inserido como inovação no mercado têxtil do país.

Como o cultivo de algodão colorido em escala comercial não havia começado, pois só depois da apresentação desse produto na FENIT é que surgiu a demanda, o algodão utilizado pelo SINDVEST para confeccionar as peças apresentada na feira foi o que havia sido acumulado das pesquisas realizadas nos campos experimentais da Embrapa Algodão62. A Embrapa Algodão, atendendo a demanda da Associação, repassou para essa cooperativa $300 \mathrm{~kg}$ de pluma de algodão naturalmente colorido (BELTÃO e ARAÚJO, 2008).

Como nos adverte Santos (1996), os eventos acontecem de forma a modificar uma dada situação, e surge em um contexto específico. É preciso que as condições necessárias existam para dar possibilidade real do evento acontecer. Dessa forma o fato de o algodão colorido ter sido apresentado no período em que havia sido recém criada a Agência Brasileira de Promoção de Exportações e Investimentos (APEX - Brasil) ampliou a possibilidade de o algodão colorido brasileiro "ganhar o mundo".

Entrevistadora"3: "Fale como foi o primeiro contato de vocês com o algodão colorido".

Presidente da COOPNATURAL: "Eu era presidente do Sindicato das Indústrias do Vestuário aqui na Paraíba e no ano de 2000 nós estávamos organizando um grupo para participar de uma feira em São Paulo, a Fenit, que é a Feira Nacional da Indústria Têxtil, mas as

\footnotetext{
empresas da região Concentrada do país, especialmente as do estado paulista foi concedido inúmeros benefícios por bancos públicos e agências de planejamento do Estado para que as mesmas se instalassem nos diferentes estados no Nordeste, Norte e Centro Oeste.

${ }^{62}$ Sobre a fase de multiplicação de sementes ler: QUEIROGA, Vicente de Paula; JERÔNIMO, Jeane Ferreira; MELEÁN, Jesús Ávila. Experiência sobre a produção de algodão de fibra colorida por duas cooperativas do Estado da Paraíba. Rev. Agronomia Trop.

${ }^{63}$ Entrevista realizada pela pesquisadora em 12 de julho de 2016, em Campina Grande-PB.
} 
empresas estavam todas em crise porque nós temos aqui perto da gente a "China", que é Toritama, Santa Cruz e Caruaru, então, estávamos passando por um período muito difícil e para essa feira a gente conseguiu com parceira do SEBRAE, da Prefeitura de Campina, mas a gente não queria chegar lá com o que todo mundo já tinha e já tinha saído nos jornais aqui que a EMBRAPA tinha terminado a pesquisa da primeira cor de algodão colorido que era o BRS 200 Marrom, o café com leite. Então, quando a gente estava se organizando para ir para essa feira, buscando um diferencial, a gente estava num brainstorming".

Entrevistadora: "Nesse primeiro momento vocês já tinham em vista essa questão do mercado ecológico ou vocês queriam apenas um diferencial?".

Presidente da COOPNATURAL: "A gente queria um diferencial, então, nós fomos na EMBRAPA e na época eles tinham lá 300 quilos de pluma de algodão colorido e nos deu tudo. Então, nós fomos na Coteminas, eles concordaram em fazer o fio para gente, nós fizemos $o$ fio, o SENAl entrou também de parceria e nós fizemos uma coleção muito bonita com o fio que nós tínhamos, feita pelo estilista Ângelo Rafael.

Então, nós fomos para a feira, mas como um teaser para ver o que é que o mercado achava do produto, mas nós não tínhamos preço, não tínhamos produto e nem produção daquilo... Nós só tínhamos aquilo para saber o que o mercado acharia e foi um sucesso absoluto lá na Fenit: A gente saiu em todas as redes de jornal e revistas de São Paulo, era entrevista no Bom Dia São Paulo e aquela coisa toda.

Na época, várias autoridades visitavam a Fenit e fomos procurados pela Doutora Dorotéia Werneck porque ela tinha acabado de criar a APEX, a Agência de Promoção à Exportação e ela falou: 'O produto de vocês é para exportacão, então, eu aconselho vocês a criarem um consórcio'. Nós já éramos 10 empresas lá dentro do estande e a partir daí nós fizemos o projeto e criamos o consórcio Natural Fashion". (Grifo da autora) ${ }^{64}$

A partir do trecho da entrevista acima citado, podemos perceber como a atuação da Apex- Brasil foi estruturante na inserção dos produtos derivados do algodão colorido no mercado internacional. Ainda no âmbito das ações dessa agência, foi recomendado aos cooperados da COOPNATURAL que a associação deveria se tornar um consórcio de exportação, pois assim poderia acessar a determinados incentivos, inclusive financeiros. Além dessa orientação, a Apex-Brasil, deu apoio estrutural para divulgação do produto, na medida em que parte dos custos para participação em feiras e eventos internacionais foram e ainda são subsidiados por essa Agência.

\footnotetext{
${ }^{64}$ Entrevista realizada durante trabalho de campo em 12 julho de 2016, em Campina Grande.
} 
Diante da boa aceitação desse novo produto, ao retornar da Fenit os empresários paraibanos constataram que uma possibilidade de recuperação do setor de confecções de Campina Grande poderia ser a partir de produtos derivados do algodão colorido. Surgiu o primeiro desafio, organizar a produção no campo, pois em função da praga do bicudo o cultivo do algodão havia declinado no estado, e os agricultores estavam desmotivados com essa cultura (PICCIOTTO e SHEWCHENKO, 2006, BRASIL, 2011).

A organização espacial dessa atividade contou com a participação de diversos atores, tanto da esfera pública, quanto privada. O poder público municipal de Campina Grande teve papel central na indução do desenvolvimento da cadeia produtiva do algodão naturalmente colorido. Devido à crise econômica, causada pela crise do algodão, e consequente migração de indústrias do setor têxtil desse município para outros estados, grande número de pessoas, tanto da zona urbana, quanto da zona rural, ficaram sem emprego. Diante dessa situação os agentes políticos se viram na necessidade de criar instrumentos que viabilizassem e incentivassem as potencialidades locais, de forma a reduzir os problemas econômicos (PICCIOTTO e SHEWCHENKO, 2006).

Assim foi criada em 1999 a Agência Municipal de Desenvolvimento Econômico (AMDE). Naquela década estava em ascensão no Brasil a política de desenvolvimento econômico que tinha como referência a escala local, com base em Arranjos Produtivos Locais (APL's) ${ }^{65}$. Então a AMDE investiu em identificar quais os setores que apresentavam potencialidades, e os setores que mais se destacavam eram o de calçados de couro e o de confecção (PICCIOTTO e SHEWCHENKO, 2006; MOUTINHO e CAMPOS, 2007).

Dentre os diversos programas da Agência, o Programa Multissetorial envolve a organização de segmentos sociais, qualificação profissional

\footnotetext{
${ }^{65} \mathrm{O}$ conceito de Arranjo Produtivo Local, tem como referência os estudos desenvolvidos por Alfred Marshall, sobre os distritos industriais italianos, onde esse autor observou que em contexto de crise pequenas empresas de um mesmo setor e que estavam localizadas próximas haviam conseguido um desempenho excepcional para o contexto no qual estavam inseridos. Foi pensando nesse modelo de desenvolvimento econômico que no Brasil, a partir da década de 1990, houve forte debate e estabelecimento de políticas públicas preocupadas com as potencialidades territoriais. Brandão (2004) faz sérias críticas a escala de planejamento escolhido, pois segundo o mesmo não é só a escala local que é relevante, a escala nacional também precisa ser considerada
} 
e microcrédito. Neste último componente, a equipe da AMDE começou a identificar uma forte tendência dos pequenos empreendedores de se dirigirem para o setor de têxtil. De acordo com o relatório da AMDE (2000), entre 1999 e 2000 foram apoiados mais de 100 pequenos empreendimentos relacionados ao setor (PICCIOTTO e SHEWCHENKO, 2006, p. 5).

Para o setor de confecção, foi criado o Programa de Fortalecimento do Setor Têxtil de Campina Grande. Com a demanda específica apresentada em relação ao algodão colorido. A AMDE foi a principal articuladora para que fosse montado o circuito espacial desta produção. Segundo Picciotto e Shewchenko, (2006) o poder da AMDE extrapolou os limites do território campinense:

O programa, dessa forma, possuía abrangência regional, envolvendo atores de diversos municípios (com partidos diferentes), com escala comparável à de uma iniciativa estadual. Vinte e oito municípios da região estavam envolvidos na proposta, plantando o algodão colorido. Para concretizar esse trabalho fora dos limites de Campina Grande, a AMDE desenhou e implementou uma engenharia institucional com envolvimento de entidades sem fins lucrativos (PICCIOTTO e SHEWCHENKO, 2006, p. 8).

A cadeia produtiva do algodão colorido em 2006 era formada pela Embrapa Algodão, EMATER, Secretaria de Agricultura do Estado da Paraíba, agricultores familiares, indústria de fiação (Malharia Limoeiro), Cooperativa Mista dos Produtores de Algodão de Patos LTDA (CAMPAL), indústria tecelagem ( MATESA e Malharia Limoeiro), Coopnatural, Associação de mães e cooperativas de artesãs (ver Fluxograma -1) (PICCIOTTO; SHEWCHENKO, 2006) 
Fluxograma 1 - Atores da Cadeia Produtiva do Algodão Colorido (2006)

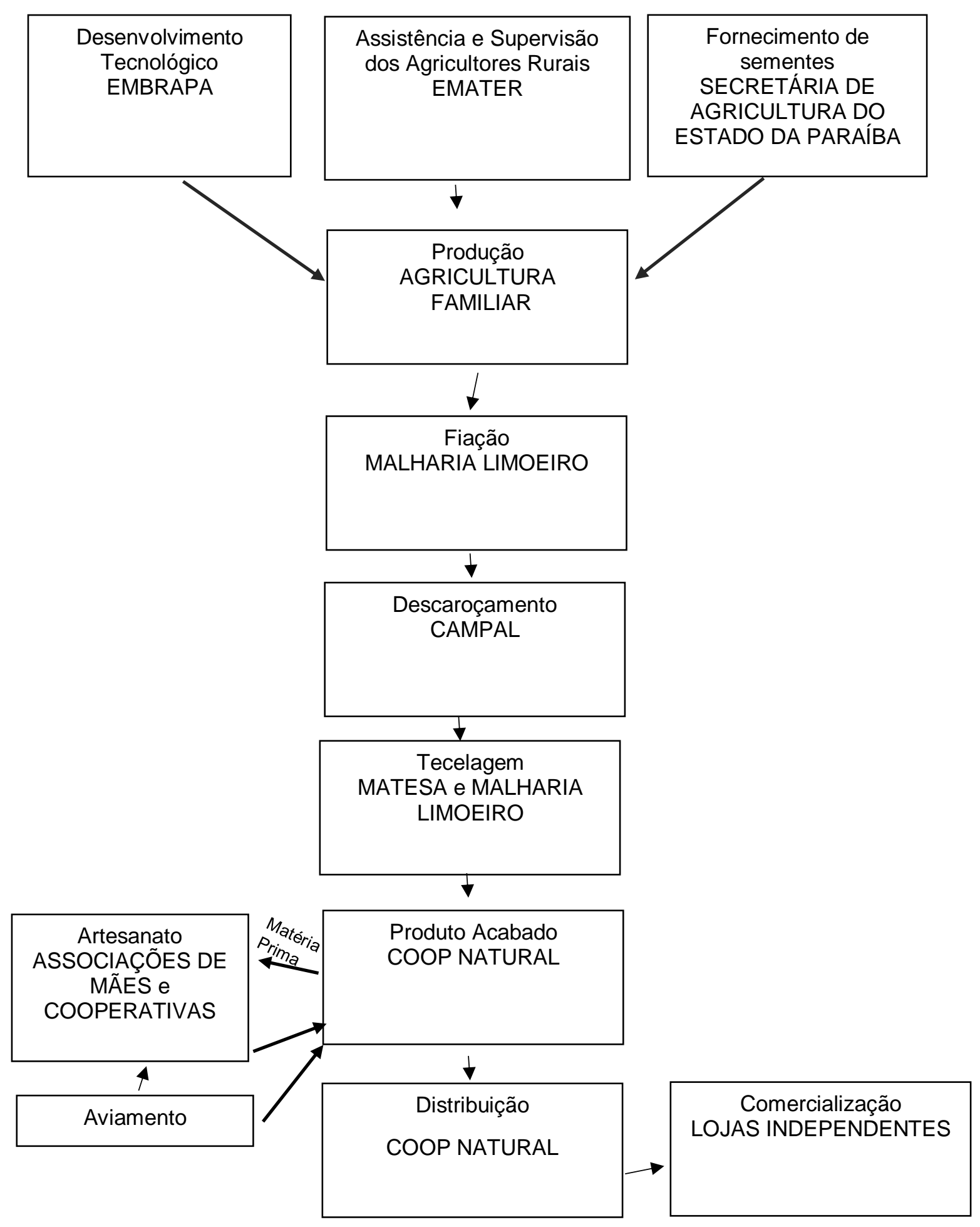

Fonte: PICCIOTTO e SHEWCHENKO (2006). 
Ainda como medida que caracteriza a territorialização do algodão colorido por força de atores locais da Paraíba, pode-se destacar a compra de todas as sementes postas em leilão pela Embrapa Algodão pela COOPNATUAL. Segundo Farias (2010), no início da utilização do algodão colorido na Paraíba, houve um acordo entre a Embrapa Algodão e os produtores locais, para que o cultivo não se expandisse para outras áreas. O monopólio no acesso à semente perdurou até o ano de 2006, quando outros grupos de fora de Campina Grande, mas do mesmo estado, pressionaram a Embrapa Algodão para que o acesso às sementes fosse livre para todos que desejassem trabalhar com essa matéria prima.

No próximo capítulo são analisadas as dinâmicas da produção do algodão colorido no decorrer de quase duas décadas de existência; os atores envolvidos; as vantagens e limites para seu desenvolvimento e como os atores se articulam para fortalecer o circuito espacial de produção do algodão colorido e derivados. 


\section{O CIRCUITO ESPACIAL DE PRODUÇÃO DO ALGODÃO NATURALMENTE COLORIDO DA PARAÍBA}

A escala de produção de algodão naturalmente colorido no Brasil ainda é reduzida. Ao longo de 16 anos de existência do cultivo de algodão colorido no país, não há registros oficiais da área plantada, quantidade produzida e dos municípios que plantam essa variedade de algodão. Também não há informações oficiais sobre quais são as cores mais plantadas, e nem mesmo, em quais locais a produção é orgânica ou convencional. Nos trabalhos de campo realizados constatamos o predomínio de cultivo orgânico na Paraíba.

A escassez de dados referentes a produção de algodão naturalmente colorido está diretamente relacionada ao fato de se tratar de produção recente e pouco representativa do ponto de vista quantitativo. O Instituto Brasileiro de Geografia e Estatística (IBGE), órgão responsável pela elaboração de dados estatísticos dos produtos agrícolas, apenas fornece informações do algodão por tipo de lavoura. No caso do algodão há informações disponíveis para lavoura permanente (algodão arbóreo) e lavoura temporária (algodão herbáceo). Como até o ano 2000 não existia no país algodão com essa especificidade da cor, a distinção por ciclo de produção da cultura era suficiente.

Dessa forma, as informações que elaboramos sobre as estatísticas da produção de algodão colorido foram coletadas durante as pesquisas de campo realizadas em 2014, 2015 e 2016, e pesquisas secundárias em artigos científicos, dissertações, teses e notícias divulgadas na internet.

Na coleta de dados primários nossos informantes foram os agricultores do Assentamento de Reforma Agrária Margarida Maria Alves, localizado no município de Juarez Távora - Paraíba; pesquisadores e técnicos agrícolas da Embrapa Algodão e da Empresa de Extensão Rural da Paraíba (EMATER-PB); os dois principais grupos que trabalham com algodão colorido e derivados: a Cooperativa de Produção Têxtil e Afins do Algodão do Algodão do Estado da Paraíba (COOPNATURAL), localizada em Campina Grande e a Natural Cotton Color66, situada em João Pessoa ; e artesãs da Vila do Artesão de Campina

\footnotetext{
${ }^{66} \mathrm{~A}$ Natural Cotton Color é uma marca pertencente à empresária Francisca Vieira. Essa marca hoje também dá nome a um grupo de pequenos empresários do setor de confecções e têxteis, o grupo Natural Natural Cotton Color. As empresas que fazem parte desse grupo e que serão
} 
Grande ${ }^{67}$. Os dados levantados, embora não deem conta da totalidade, nos ajuda a compreender a dinâmica da produção de algodão colorido ao longo de quase duas décadas.

A escolha do Assentamento de Reforma Agrária Margarida Maria Alves, se deu pelo fato de que, ao iniciarmos nossa pesquisa em 2013, a área de plantação de algodão colorido no estado da Paraíba tinha sofrido uma redução drastica e o assentamento citado era o que possuía maior área plantada, e consequentemente, a maior produção. Posição esta que o assentamento mantém até os dias de hoje (2016); ter passado pela transição do sistema de produção convencional para a produção orgânica e por participar desde o início da história do algodão colorido no estado. Assim, o assentamento Margarida Maria Alves pode ser considerado uma experiência exitosa de transferência de tecnologia e modelo na produção de algodão orgânico desenvolvido pela agricultura familiar.

A Embrapa Algodão é considerada nessa pesquisa ator central desse circuito espacial de produção, pois além de ter sido a instituição responsável pelas pesquisas e desenvolvimento das cultivares de algodão colorido, vem atuando sistematicamente na transferência de tecnologia para os agricultores deste assentamento e de outras áreas que demonstrem interesse em produzir este tipo de algodão. Temos também a participação desta no Comitê Gestor do Arranjo Produtivo Local de Confecções e Artefatos de Algodão Colorido da

doravante aqui tratados como grupo Natural Cotton Color são: Natural Cotton Color (confecção e moda), Comparoni (bolsas e sapatos), Coco Brasil (confecção masculina), Z - AZ (bolsas), Maria Xique (confecção feminina), Casulo arte natural (bolsas e acessórios), Pé de Algodão (calçados), Petit Coton (roupa infantil), Rubra Rosa (roupa infantil), Terra do Sol (Têxtil e decoração), Santa Luzia Redes e Decorações (Têxtil e decoração). No caso da Santa Luzia Redes e Decorações devido à mesma ter participado desde o início do uso do algodão colorido como matéria prima da industrial têxtil paraibana, teceremos alguns comentários em específico, assim como a própria Natural Cotton Color, enquanto empresa. Portanto, quando nos referirmos ao grupo estaremos considerando todas as empresas e quando falarmos só Natural Cotton Color estaremos fazendo referência a empresa.

${ }^{67} \mathrm{Na}$ Vila do Artesão estão concentrados 15 boxes com artesões que trabalham exclusivamente com produtos feitos com algodão naturalmente colorido. Em sua maioria geridos, por mulheres, as próprias artesãs. Apenas a Casulo Arte nos clama atenção, pois se trata de uma empresa de confecção de bolsas e acessórios de algodão colorido, e possui CNPJ com a razão social: Casulo Arte Natural Confecção de Produtos Naturais. Essa empresa faz parte do grupo Natural Cotton Color destoando do perfil das demais. Atribuímos isso ao fato de a Vila do Artesão ser o local de concentração de grande número de artesão, inclusive os que trabalham com algodão colorido e consequentemente local para onde converge elevado número de turistas, especialmente durante o mês de junho quando, em função das festas de São João, a cidade recebe elevado número de pessoas de todo o país. 
Paraíba (CGAPLCAACP) ${ }^{68}$, além do fato dessa instituição ser referenciada nas propagandas das marcas que fazem uso do algodão colorido, como estratégia para garantir aos clientes confiança, quanto a qualidade e originalidade do produto.

A relação da Embrapa Algodão com o assentamento Margarida Maria Alves vai além da transferência de tecnologia. Durante os trabalhos de campo observamos que ao longo de mais de uma década de acompanhamento dos técnicos da Embrapa nas atividades ligadas ao cultivo de algodão colorido, no referido assentamento, foi construída uma relação de confiança entre agricultores, pesquisadores e técnicos de campo.

Conforme será analisado adiante na tese, percebemos que não ocorre apenas a transferência de tecnologia, já que os próprios pesquisadores e técnicos da Embrapa Algodão aprendem com as práticas dos agricultores do assentamento e estes, por sua vez, dão um feedback para os pesquisadores em relação aos problemas encontrados no manejo do algodão colorido orgânico. Do mesmo modo que há sistematicamente uma troca de experiências e aperfeiçoamento das técnicas de produção entre os envolvidos.

A EMATER - PB foi relevante para compreendermos como, no âmbito estadual, ocorrem as políticas de incentivo dessa cultura no estado. Essa instituição foi apontada por Piccioto e Shewchenko (2006) e Farias (2010), como importante para organização espacial na fase de introdução da cultura de algodão colorido no território paraibano. Entendemos também que, por se tratar de empresa de assistência técnica e extensão rural, a mesma se constituí ator importante nesse processo, haja visto que historicamente o serviço de extensão rural é escasso no país, embora seja considerado pilar necessário a difusão de inovação e modernização no campo ${ }^{69}$.

Mesmo existindo número maior de pequenos empresários que fazem uso do algodão colorido na fabricação de seus produtos, identificamos a partir dos

\footnotetext{
${ }^{68}$ O Comitê Gestor do Algodão Colorido, foi criado em 2010 com o objetivo de fortalecer o circuito espacial de produção do algodão colorido e derivados no Estado. É o que há de mais recente no sentido de promover articulação dos diversos atores envolvidos no circuito espacial de produção do algodão colorido.

${ }^{69}$ A política de modernização da agricultura a partir da 1970 teve como tripé a pesquisa, a extensão e o credito rural. As inovações a que nos referimos se trata no acompanhamento para verificar a adaptação de novas culturas, manejo, organização dos agricultores, etc.
} 
dados de trabalhos de campo, duas organizações que se destacam na cadeia de derivados do algodão colorido: a COOPNATURAL e o grupo Natural Cotton Color. A COOPNATURAL é pioneira no uso dessa matéria prima. Conhecer essa Cooperativa nos ajudou a compreender as características técnicas e organizacionais e as estratégias territoriais (topologia) utilizadas para a dinâmica desse produto no espaço paraibano.

A Natural Cotton Color $^{70}$ é uma empresa do ramo de confecção e moda localizada na cidade de João Pessoa. Essa empresa tem poder de articulação entre alguns empresários do setor de confecção de produção de têxteis e decoração, que fazem uso da referida marca para promover seus produtos no mercado internacional. A empresa citada investe em moda e design, utiliza como matéria-prima para suas criações o algodão colorido orgânico e o uso do artesanato regional tem projetado o algodão naturalmente colorido no nicho de mercado com a categoria de moda de luxo sustentável. Na Figura 25 é possível observar uma das peças da coleção da referida empresa com detalhe feitos com renda renascença. No decorrer desse capítulo procuraremos destacar que as duas organizações citadas exercem controle do circuito espacial de produção do algodão colorido e derivados.

70 O nome da marca Natural Cotton Color em inglês foi uma estratégia da empresa para ajudar na divulgação dos produtos nos eventos internacionais. 


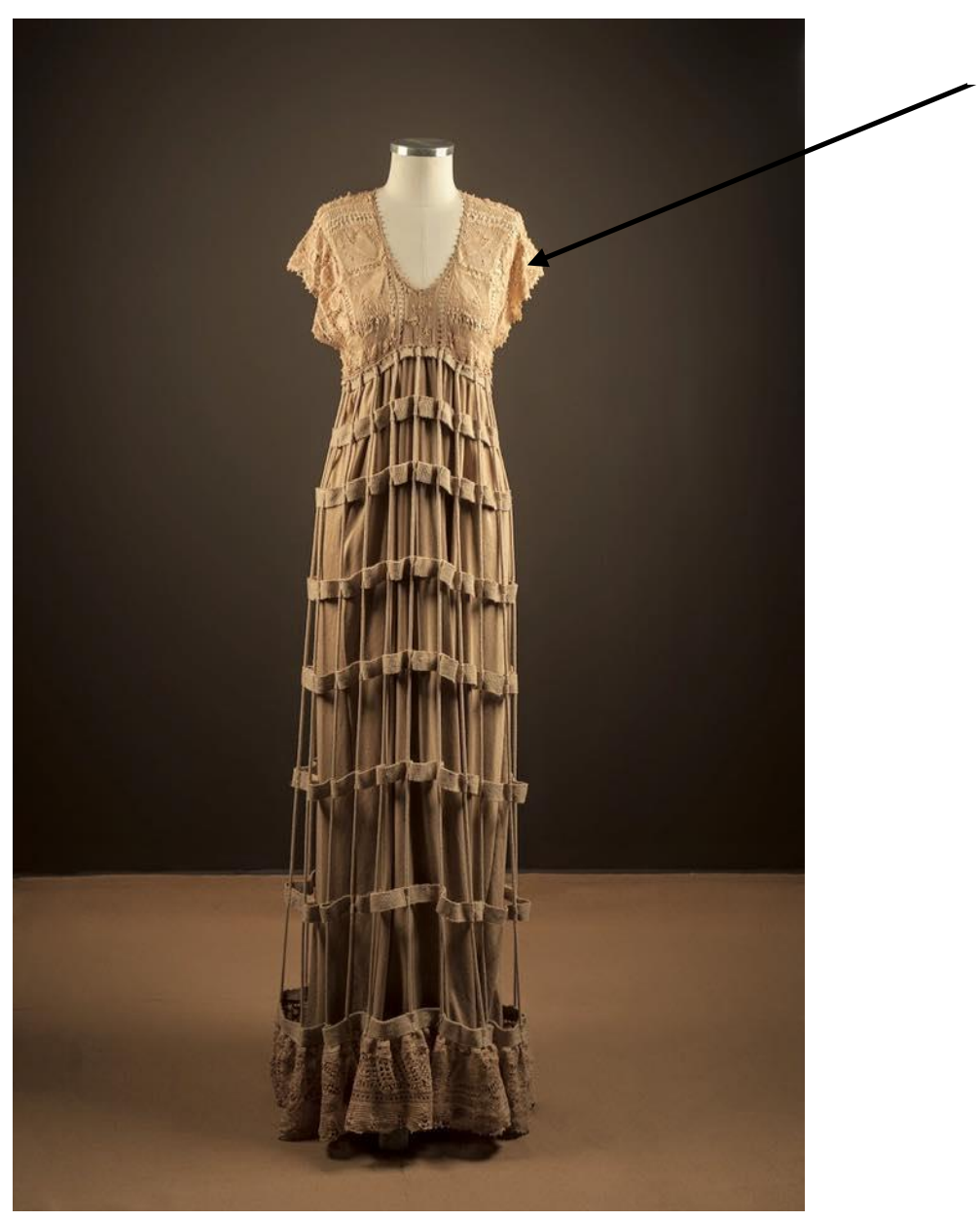

Detalhe em renda renascença

Figura 25 - Vestido de algodão naturalmente colorido com detalhe em renda renascença Fonte - Natural Cotton Color, 2016

Disponível em: https://www.facebook.com/NaturalCottonColor/photos/

Acessado em: 21 de setembro de 2016

As artesãs entrevistadas desenvolvem suas atividades na Vila do Artesão em Campina Grande. As informações obtidas ajudaram a identificar como os atores possuem poderes diferentes, dentro do circuito espacial de produção do algodão colorido. Estas permitiram identificar e analisar as estratégias encontradas pelo grupo de artesãs para se manterem no negócio, fortalecendo as relações de solidariedade orgânica. Santos e Silveira (2011, p. 306), definem solidariedade orgânica como:

A solidariedade orgânica resulta de uma interdependência entre ações e atores que emana sua existência no lugar. Na realidade, ela é fruto do próprio dinamismo de atividades cuja definição se deve ao próprio lugar enquanto território usado. É em função dessa solidariedade orgânica que as situações conhecem uma evolução e reconstrução locais relativamente autônomas e apontando para um destino comum (Santos e Silveira 2011, p. 306). 
Além da solidariedade orgânica, observou-se a prática da solidariedade organizacional, na medida em que os empresários, se reúnem com o objetivo de se fortalecerem no mercado, nacional e sobretudo no internacional. Para Santos e Silveira (2011, p.307) a solidariedade organizacional:

Supõe uma interdependência até certo ponto mecânica, produto de normas presididas por interesse de modo geral mercantis, mutáveis em função de fatores de mercado. Nesse último caso, os 'organizadores' prosperam à custa da solidariedade interna e, frequentemente, também à custa da solidariedade no sentido ético (Santos e Silveira 2011, p. 307).

A produção propriamente dita do algodão colorido, beneficiamento, fiação, tecelagem, confecção de roupas, produto final, circulação e comércio, são dados que revelam o movimento geográfico da produção no tempo e no espaço. Assim, o conceito de circuito espacial de produção, proposto por Santos (2008 [1985]); (2014 [1988]), é basilar para entendimento das etapas de produção e suas dinâmicas especificas.

Concordamos com Santos (2008 [1985], p. 14), sobre a necessidade de incorporar outros elementos na análise do circuito espacial de produção, de acordo com os objetivos da pesquisa. Assim além das tradicionais etapas do circuito espacial (produção propriamente dita, circulação, distribuição, consumo), demos destaque para a fase que precede o cultivo, isto é, a pesquisa científica.

A própria segmentação tradicional do processo produtivo (produção propriamente dita, circulação, distribuição, consumo) muito ganharia em ser corrigida para incluirmos, em lugar de destaque, como ramos automatizados do processo produtivo, propriamente dito, a concepção (pesquisa), o controle a coordenação, a previsão, paralelamente à mercadologia (marketing) e a propaganda (SANTOS 2008 [1985], p. 14).

5.1. Dinâmicas espaciais das áreas de cultivo de algodão colorido da Paraíba (2000-2016)

O algodão naturalmente colorido se insere na dinâmica do espaço agrícola do Semiárido Nordestino como inovação, e a semente selecionada talvez seja o que exista de mais moderno nessa fase da produção, já que os instrumentos técnicos utilizados no campo para realização do trabalho agrícola 
se mantêm quase inalterados, diante da evolução técnica que os tempos atuais têm proporcionado.

Entretanto, o fato da produção do algodão naturalmente colorido atualmente estar sendo realizada de forma orgânica traz consigo outros imperativos do atual período histórico e geográfico, como a normatização da produção agrícola para atender ao mercado consumidor, ou seja, o lugar de produção propriamente dito do algodão colorido também é espaço das verticalidades e horizontalidades. As verticalidades são as demandas externas que induz a forma de produzir, assim o campo é também o lugar onde as relações na escala mundial acontecem. É também o espaço das horizontalidades, onde os atores se organizam e reorganizam. Consequentemente, é o espaço das possibilidades.

Chamamos atenção para este debate acima porque, a produção de algodão colorido é um subsistema da produção algodoeira, que tem como finalidade atender a demanda especifica de uma fatia do mercado, a de produtos orgânicos. Por um lado, ainda que os instrumentos de trabalho no campo, para esse caso especifico, não sejam os mais sofisticados, o mesmo obedece a lógica de produção capitalista, de produção diferenciada do espaço.

Por outro lado, a presença de diferentes atores articulados para que essa produção aconteça cria possibilidades de mudança. É o que ocorre, por exemplo, quando os agricultores envolvidos na produção de algodão orgânico, seja o colorido ou o branco, começam a trocar entre si suas experiências. Não apenas experiências de como melhor produzir, mas de como se organizar para exigir um preço mais justo pelo seu trabalho.

Ainda em relação à produção do algodão colorido no campo, é perceptível que, como os dados do novo período geográfico propostos por Santos (1994,1996, 2001), o meio técnico-científico -informacional não atinge todos os lugares e atividades com a mesma intensidade. Santos e Silveira (2011) definem os lugares em que há maior presença de sistemas técnicos e potencialmente dos fluxos de informação e dinheiro, pontos luminosos do território e os espaços onde a ausência ou diminuta existência desses meios são considerados pontos opacos. 
A primeira observação a se fazer é que há elementos do meio técnicocientífico - informacional presente no cultivo do algodão colorido orgânico, mas não na mesma intensidade existente nos sistemas técnicos de produção agrícola dos principais centros produtores de commodities do território nacional. A segunda advertência é que, mesmo do ponto de vista técnico científico, as cultivares de algodão desenvolvidas pela Embrapa Algodão possuem conteúdos científicos semelhantes, no entanto, o fato de ser destinado a atores sociais com poderes econômicos e sociais diferentes (grandes empresários, médios produtores e agricultores familiares) os resultados são distintos.

Mesmo que ao longo do circuito espacial de produção do algodão colorido haja contradições, buscamos enxergar também as possibilidades que o acesso a transferência de tecnologia através de instituições públicas - como é o caso da Embrapa Algodão - pode proporcionar o desenvolvimento dos lugares opacos, como o que vem ocorrendo com os agricultores familiares envolvidos no cultivo do algodão colorido, tecnologia social desenvolvida e difundida pela instituição citada.

Segundo Santos (2008 [1985], p.14) a produção propriamente dita é, das fases de produção, a que tem relação direta com o lugar. Assim, a organização espacial, disponibilidade de fatores de produção, e os dado sociais do lugar convergem para que os lugares possuam especificidades. Os lugares onde foram implantadas as lavouras de algodão colorido, ao longo do tempo, passaram por algumas alterações. Em 2000, quando teve início os primeiros plantios e a única variedade disponível era a BRS 200, que apresenta como uma de suas características a resistência à seca, os lugares indicados para o cultivo foi a região do Seridó paraibano.

Entre as vantagens para o cultivo nessa região, Santana et. al. (1997) apontam o fato das condições ambientais serem consideradas ideais para o desenvolvimento das características intrínsecas do algodão, a baixa incidência de insetos, o que dispensaria ou reduziria sensivelmente o uso de agroquímicos. Naquela época, os pesquisadores já vislumbravam a inserção do algodão 
colorido no mercado de produtos ecológicos, ou orgânico, destinado ao mercado europeu e também para o nacional ${ }^{71}$.

Com a formação de um mercado de produtos orgânicos em ascensão, a produção de algodão orgânico no Nordeste tem possibilidades de preencher esse mercado em formação. Vale destacar que para um produto ser considerado orgânico, não é suficiente apenas a não utilização de produtos químicos, ou equipamentos agrícolas mais modernos que possa impactar o uso do solo. Para ser orgânico é necessário que a produção no campo obedeça a algumas regras na produção e ser certificada, por instituição habilitada para esse procedimento.

De acordo com Souza (1998), a primeira certificação de algodão orgânico realizada no Brasil, ocorreu em 1970 pelo Instituto Biodinâmico de Botucatu (IBD). Isto demonstra que a produção de algodão orgânico no Brasil não é tão recente e acompanha a tendência mundial, já que muitas das questões sobre a produção orgânica vão surgir a partir dos movimentos ambientalistas dos anos $1960^{72}$.

O cultivo do algodão colorido se restringiu até recentemente ao território paraibano. Segundo Amaral, Beltrão e Silva (2004) os municípios indicados no zoneamento agrícola para o cultivo da variedade BRS 200 são: Areia de Baraúnas, Nova Palmeira, Santa Luzia, Baraúna, Passagem, São José dos Espinharas, Cubatí, Patos, São Mamede, Cacimba de Areia, Pedra Lavrada, São Vicente do Seridó, Frei Martinho, Picuí, Santa Terezinha, Juazeirinho Quixadá São José do Sabugi, Junco do Seridó, Salgadinho, Tenório, Mãe D'água, São José do Bonfim e Várzea.

A recomendação em relação ao tamanho da área a ser cultivada com o algodão colorido é que o mesmo deve ser plantado em área de até 2 ha. Isso tendo como referência que o trabalho que será desenvolvido por agricultores familiares e que, como a maior parte do trabalho é feito manualmente, se for

\footnotetext{
${ }^{71}$ Os autores citados apontam a empresa paulista de confecções YD Confecções, referência no consumo de algodão orgânico no país. Essa empresa atualmente compra algodão orgânico produzido em alguns estados do Nordeste, a exemplo da Paraíba. Essa mesma empresa foi estudada por Maria Celia Sousa em 2002, quando escreveu sua dissertação intitulada: "Algodão Orgânico: O Papel das Organizações na Coordenação e Diferenciação do Sistema Agroindustrial do Algodão".

${ }^{72}$ Em resposta aos impactos no meio ambiente, decorrentes do uso em escala industrial de insumos agrícolas preconizados pela RevoluçãoV iniciada na década de 1950.
} 
realizado em grandes áreas o agricultor não terá tempo para os devidos cuidados com a lavoura.

Farias (2010) identificou propriedades com plantações de até 20 hectares e pertencente a um único dono, só que a produção era realizada por vários agricultores e o regime de trabalho apresentava diferentes organizações, como a parceria e o trabalho assalariado. A permanência do trabalho em regime de parceria se apresenta como uma rugosidade ${ }^{73}$ no espaço geográfico do Nordeste, para este tipo de cultivo,

[...]embora inexistam dados sobre a quantidade de propriedades, a extensão média das áreas cultivadas por cada agricultor é de 1 hectare. No entanto, encontramos, nas pesquisas de campo, áreas com 14 ha (como verificamos no sítio Santa Maria, no município de Pombal) e até 20 hectares (como verificamos no sítio União, em São Bento, e na fazenda Santo Antônio, em Bom Sucesso), ocupadas com o cultivo irrigado de espécies do algodão colorido. Todavia, a área de 14 hectares ocupada com o cultivo do algodão colorido BRS Safira no Sítio Santa Maria, em Pombal, corresponde à soma do total das áreas das propriedades entregues, pelo proprietário, para o cultivo desse algodão, em sistema de parceria, a 10 parceiros. Portanto, a média do tamanho da área usada por cada agricultor/parceiro é inferior a 1 hectare. (FARIAS, 2010, p. 231).

Ainda que a média seja de 2 ha por agricultor, há aqueles que plantam até 5 ha, como constatamos no assentamento Margarida Maria Alves. Não há um impedimento sobre o tamanho da área a ser cultivada, isso vai depender da disponibilidade do agricultor para cuidar de sua lavoura sem colocar em perigo a dos demais.

Em relação a situação da propriedade das terras onde o algodão colorido é cultivado há registro de produção em propriedades particulares de até 5 ha, mas a maioria das áreas cultivadas estão nos assentamentos rurais de reforma agrária. Nos primeiros anos de cultivo, como ressaltado por Farias (2010) e na presente tese, houve cultivo em áreas maiores de produtores que já possuíam histórico na cultura do algodão branco convencional, como foi o caso da Fazenda Santo Antônio pertencente à família Gadelha.

\footnotetext{
73 As rugosidades segundo Santos (2008[1978], p. 173), são: Espaços construídos, tempo histórico que se transformou em paisagem, incorporado ao espaço. As rugosidades nos oferecem, mesmo sem tradução imediata, restos de uma divisão do trabalho internacional, manifestada localmente por combinações particulares do capital, das técnicas e do trabalho utilizados.
} 
Os locais onde são cultivados o algodão naturalmente colorido na Paraíba variam a cada ano há lugares que participaram da fase inicial de cultivo desse produto e atualmente não cultivam mais ou tiveram sua produção reduzida. $\mathrm{O}$ Seridó paraibano na primeira década de cultivo concentrava a maior área de plantação, como por exemplo, os municípios de Pombal, Patos, Sousa. Farias (2010, p. 228) já apontava que, entre o ano de 2000 a 2008, tinha ocorrido mudanças nos lugares de cultivo de algodão colorido. Segundo o autor citado, as regiões do Curimataú e do Seridó, onde inicialmente havia sido plantado o algodão colorido, em 2008 não exerciam mais a função de produtora dessa matéria-prima. A microrregião de Patos, que havia ocupado lugar de destaque no cultivo desse produto, também já não tinha a mesma representatividade. Em trabalho de campo realizado em 2014 constatamos que os lugares onde havia cultivo de algodão colorido foi ainda mais reduzido. O município de Patos atualmente não está produzindo algodão colorido.

A principal justificativa para essa situação é um fator do meio geográfico, isto é, o longo período de seca que vem afetando a região desde o ano de 2010. Além da seca, muitos agricultores enfrentaram problemas para vender suas produções, principalmente nas safras de 2003/2004 e 2004/2005. Nas referidas safras, o governo do estado, visando atender aos interesses das empresas de confecção e fazer o território paraibano ser reconhecido como estado onde se produz o algodão naturalmente colorido, distribuiu aos agricultores de vários municípios sementes de algodão colorido sem o devido planejamento do mercado. Por estar inserido em um nicho de mercado, a escala de produção foi superior a capacidade de consumo dos empresários locais.

De acordo com Piccioto e Shewhenko (2006), o excesso da produção a partir da safra de 2003 provocou a estagnação desse cultivo até o ano de 2005. Ainda conforme as autoras (op. cit., p.9), no período em questão, a produção do cultivar BRS 200 "sofreu um aumento considerável, passando de 21 para 65 toneladas". Como forma de amenizar o problema, o governo do estado teve que intervir e comprou parte do excedente da produção para diminuir os prejuízos dos agricultores.

Como até o ano de 2006 o acesso ao algodão colorido era monopolizado pelo grupo de pequenos empresários de Campina Grande, vinculados a 
COOPNATURAL, os agricultores acabaram sendo muito prejudicados. Diante do excesso da matéria-prima faltou compradores e os que compravam, pagavam preços muito baixos desestimulando a produção. No Quadro 15, é possível analisar a evolução na área plantada com algodão naturalmente colorido entre o ano de 2000 a 2006.

Quadro 15 - Evolução da área plantada de algodão colorido na Paraíba (20002006)

\begin{tabular}{|c|c|}
\hline Safra/Período & Área (hectares) \\
\hline $2000 / 2001$ & 10 \\
\hline $2001 / 2002$ & 60 \\
\hline $2002 / 2003$ & 600 \\
\hline $2003 / 2004$ & 600 \\
\hline $2004 / 2005$ & 2.000 \\
\hline $2005 / 2006$ (estimativa) & 2.000 \\
\hline
\end{tabular}

Fonte: CARVALHO (s/d) apud (FARIAS, 2010, p.248).

Desde o ano 2006, quando a estimativa da área a ser plantada no estado da Paraíba foi de 2.000 ha houve redução expressiva da área plantada. Ainda sobre a evolução da área plantada com essa cultura, o Quadro 16 é revelador da queda na produção do algodão colorido no estado nos últimos anos.

Quadro 16 - Evolução da área plantada com algodão colorido na Paraíba (20022014)

\begin{tabular}{|l|l|l|l|l|l|l|l|l|l|l|l|l|}
\hline \multicolumn{10}{|c|}{ Ano } \\
\hline $\mathbf{2 0 0 2}$ & $\mathbf{2 0 0 3}$ & $\mathbf{2 0 0 4}$ & $\mathbf{2 0 0 5}$ & $\mathbf{2 0 0 6}$ & $\mathbf{2 0 0 7}$ & $\mathbf{2 0 0 8}$ & $\mathbf{2 0 0 9}$ & $\mathbf{2 0 1 0}$ & $\mathbf{2 0 1 1}$ & $\mathbf{2 0 1 2}$ & $\mathbf{2 0 1 3}$ & $\mathbf{2 0 1 4}$ \\
\hline \multicolumn{10}{|c|}{ Área Plantada (hectares) } \\
\hline 54 & 1.003 & 1.812 & 428 & 328 & 429 & 571 & 286 & 214 & 500 & 450 & 65 & 80 \\
\hline
\end{tabular}

Fonte: (SEBRAE, 2015 apud Embrapa, 2014, p. 15).

A análise dos dados obtidos no Quadro16 sobre a área plantada com cultivares de algodão colorido em comparação ao Quadro 15 para a safra de 2003 apresenta grande diferença na indicação da área total plantada. Os dados do Quadro 15 indicam aumento de 1000\% na safra de 2003 em relação à safra 
de 2002. E no Quadro 16, para o mesmo período, o aumento teria sido de mais de $2.000 \%$. Embora com dados divergentes ambos os quadros demonstram aumento expressivo da área plantada a partir da safra de 2002.

A análise do Quadro 16 demonstra ainda que, a partir da safra de 2005, houve queda na área plantada com o algodão colorido. A situação dos lugares onde o algodão colorido vem sendo modificado a partir de novas demandas pelo produto, inclusive de compradores de fora do país, como será analisado em outro momento.

O IAC lançou em 2015 as duas primeiras cultivares de algodão naturalmente colorido, a IAC FC ${ }_{1}$ e IAC FC $\mathrm{FC}_{2}$, adaptadas para as condições edáficas do estado de São Paulo. O cultivo ainda se encontra em fase de multiplicação de sementes, por isso não será tratada nas estatísticas de produção desta tese. As cultivares desenvolvidas pelo IAC possuem cores da fibra caqui e bege claro, semelhantes às tonalidades já existem no Nordeste (Figura 26).

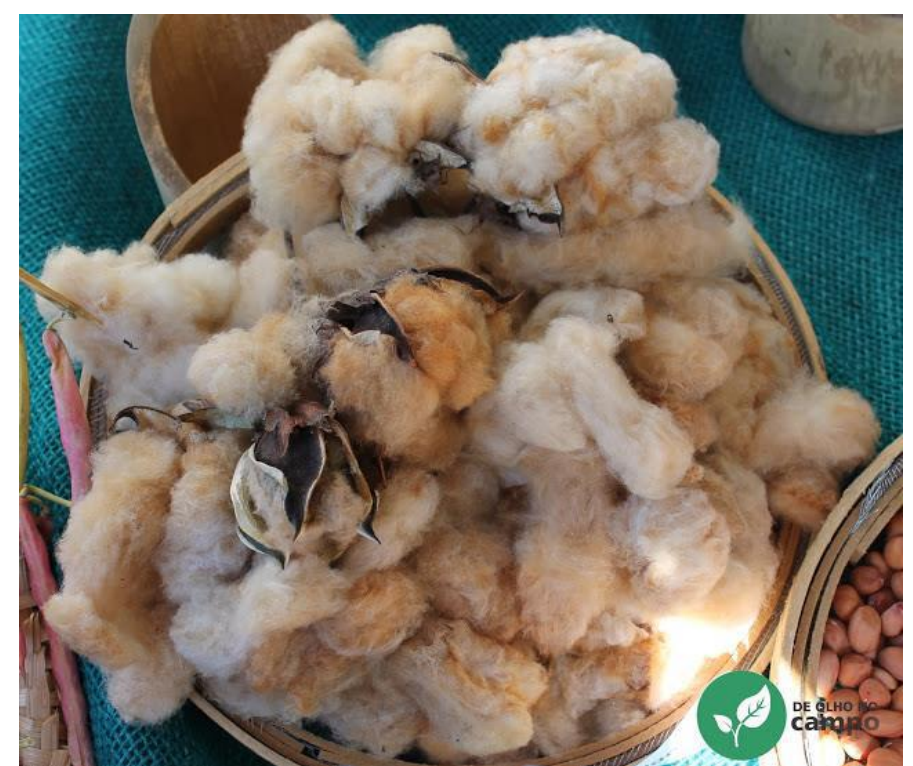

Figura 26 - Cultivares de algodão colorido desenvolvidas pelo IAC.

Fonte: Disponível em:

$<$ http://www.deolhonocampo.com.br/2015/08/instituto-agronomicocampinas-iac-agrifam-cultivares-milho-pipoca-hibrido-feijaoalgodao-colorido.html>. Acessado em: setembro de 2016.

O fato de o IAC também ter desenvolvido cultivares de algodão colorido, demonstra que esse tipo de fibra tem potencial no mercado, ao mesmo tempo que reforça o papel da pesquisa pública no desenvolvimento de tecnologias 
agrícolas adaptadas às condições geográficas do lugar. Sobre as características técnicas das cultivares IAC FC 1 e IAC FC 2 , os pesquisadores destacam a alta produtividade que pode chegar até $2.800 \mathrm{~kg} / \mathrm{ha}$ e são resistentes a nematoides (APTA, 2015).

Atualmente, a área plantada com o algodão colorido na Paraíba, como já mencionado, encontra-se reduzida. Entre os lugares onde há cultivo de algodão naturalmente colorido orgânico, merece destaque o município de Juarez Távora (Assentamento Margarida Maria Alves), o município de Remígio (Assentamento Queimadas), Salgado de São Felix (Fazenda Campos), Itabaiana, Gurinhém, Campina Grande, Ingá, Caiçara, Pedra Lavrada, Areia de Baraúna, Picuí, Catingueira, São José das Espinharas ${ }^{74}$.

A partir da análise dos mapas 7,8 e 9 constata-se que a maioria nos municípios que plantavam algodão na fase inicial hoje não plantam mais, enquanto novos municípios passaram a adotar a cultura. Entre os fatores que explicam a queda no cultivo nessa região, pode-se citar os problemas com a falta de chuvas; a escolha pelas cultivares de ciclo anual, menos resistentes à seca; a produção em grande quantidade nos primeiros anos, fruto de uma política de incentivo por parte do governo estadual.

Esse último evento certamente teve grande impacto, já que tal situação fez com que muitos agricultores que investiram na cultura ficassem com o algodão estocado em suas propriedades e compradores ou atravessadores se aproveitassem da situação para comprar o algodão à preços muito baixos, desestimulando a produção. Essa situação contribuiu para que hoje os agricultores só plantem mediante o contrato de garantia de compra de sua produção.

\footnotetext{
${ }^{74}$ Informações obtida durantes as pesquisas de campo.
} 
Mapa 7 - Municípios que cultivavam algodão naturalmente colorido em 2000.

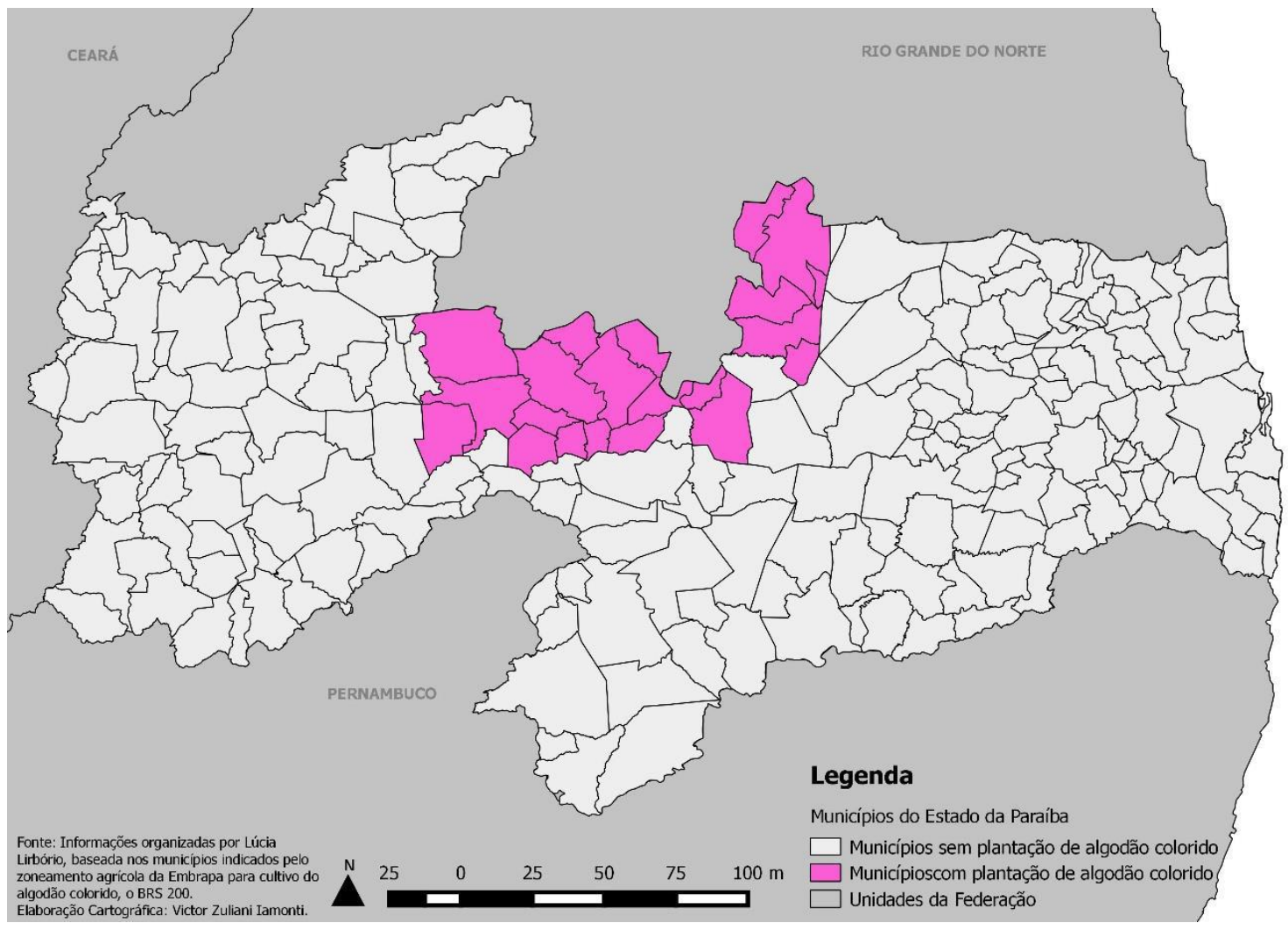

Mapa 8 - Municípios que cultivavam algodão naturalmente colorido em 2008

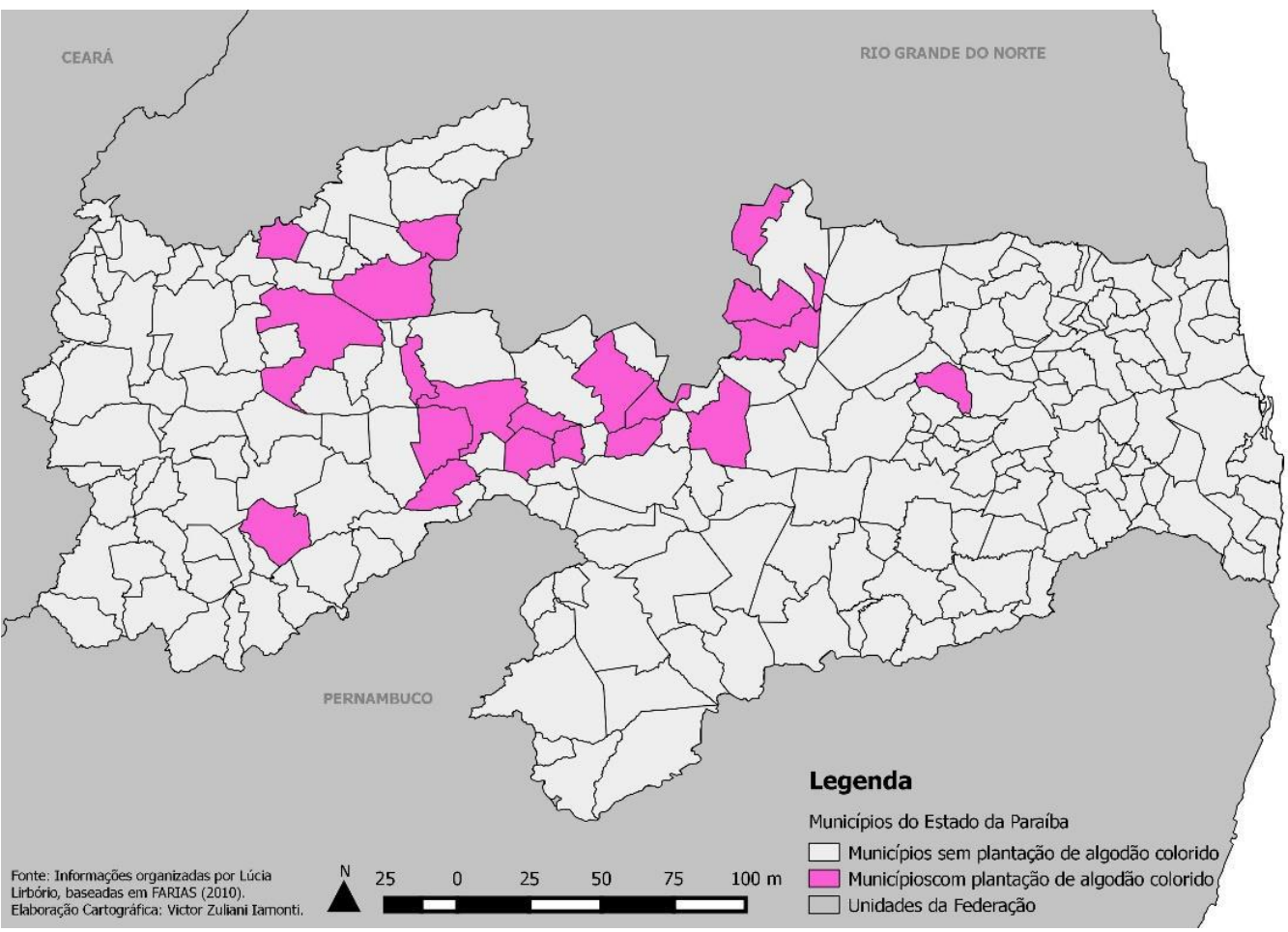


Mapa 9 - Municípios que cultivavam algodão naturalmente colorido em 2016

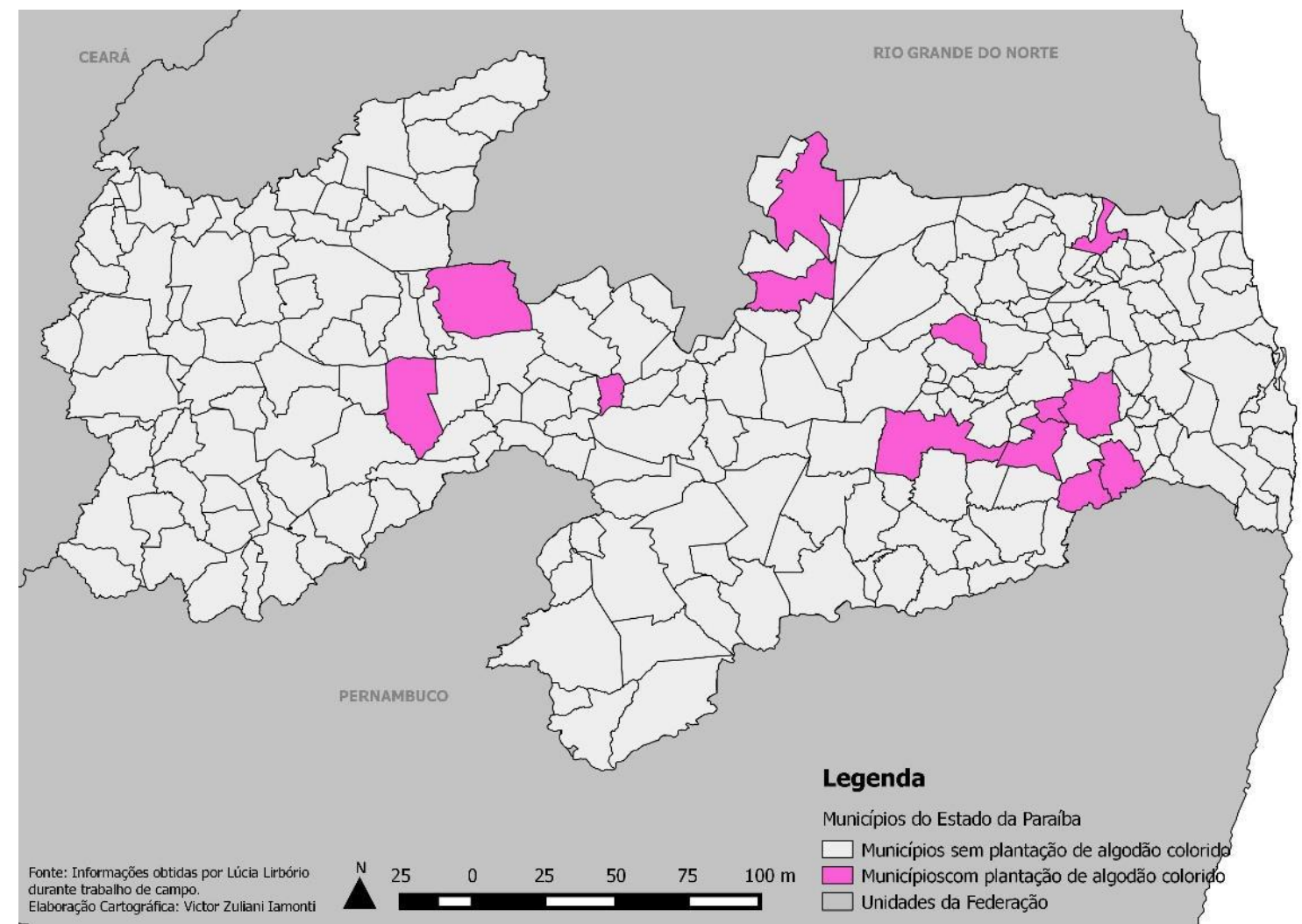

Em relação ao período inicial, observa-se que o deslocamento da área de produção caminhou do Sertão em sentido à região Agreste. Três motivos principais podem explicar isso: 1) maiores possibilidades de chuvas nessa região; 2) proximidade da área de beneficiamento, já que atualmente 0 beneficiamento dessa cultura é feito no Assentamento Margarida Alves e 3) proximidade dos compradores dessa matéria prima, Campina Grande e João Pessoa.

5.1.1. As Inovações no cultivo do algodão colorido

Se no sistema técnico agrícola houve poucas mudanças em relação à forma como se produzia o algodão branco na agricultura familiar, a introdução do algodão colorido no território paraibano veio acompanhado de outras inovações, pois, para o bom desempenho produtivo das cultivares desenvolvidas, foi necessário também a adoção de novas práticas pelos 
agricultores. Um exemplo disto é seguir as orientações do zoneamento agrícola com o objetivo de minimizar os riscos da cultura ${ }^{75}$.

Por muito tempo a principal orientação que o pequeno agricultor seguia no planejamento de sua produção agrícola era o calendário que a natureza the oferecia. O plantio do algodão geralmente era feito nos primeiros meses de chuva que, no Nordeste, ocorre entre os meses de fevereiro e março. Embora não exista muita precisão no período de chuvas devido as irregularidades pluviométricas da região ${ }^{76}$.

Conforme ilustrado por Andrade (2011 [1965]), a semeadura do algodão na região Agreste, tinha início no mês de março e sua colheita era realizada nos meses de novembro e dezembro, coincidindo com o período de seca (Figura, 27). Devido ao período em que o algodão era colhido - no final do ano -, essa cultura representava para muitos agricultores uma "poupança" que, somado a venda de algum animal, ajudava na compra de bens ao final da safra.

\footnotetext{
${ }^{75}$ Uma das primeiras preocupações da Embrapa Algodão, quando foi instalada no Nordeste, foi a partir dos problemas identificados na cadeia de produção do algodão, do campo a fase de beneficiamento estimular a adoção de novas práticas que modificassem as condições vigentes e que como consequência fazia com que a produção de algodão na região não apresentasse bons resultados. Embora tenhamos feito referência ao fato de que o cultivo do algodão colorido passou a contar com um zoneamento para sua produção, isso também ocorreu para o caso do algodão branco produzido no Nordeste, principalmente a partir dos estudos encomendados pela SUDENE que muito contribuiu para que os recursos naturais do Nordeste fossem melhor conhecidos.

${ }^{76}$ É preciso destacar que o calendário acima citado tem como referência o cultivo do algodão arbóreo Mocó, que possuía ciclo vegetativo sete meses. As cultivares de ciclo precoce, foram desenvolvidas pela Embrapa Algodão, entre as vantagens que essas cultivares apresentam e a possibilidade de $\mathrm{o}$ agricultor conseguir controlar melhor as pragas que afetam a cultura, já que 0 período de floração dessas cultivares são menores. As cultivares desenvolvidas foram: CNPA PRECOCE 1, CNPA PRECOCE 2 e CNPA PRECOCE 3 (SILVA; GUIMARAES FILHO, 2006, p. 134).
} 


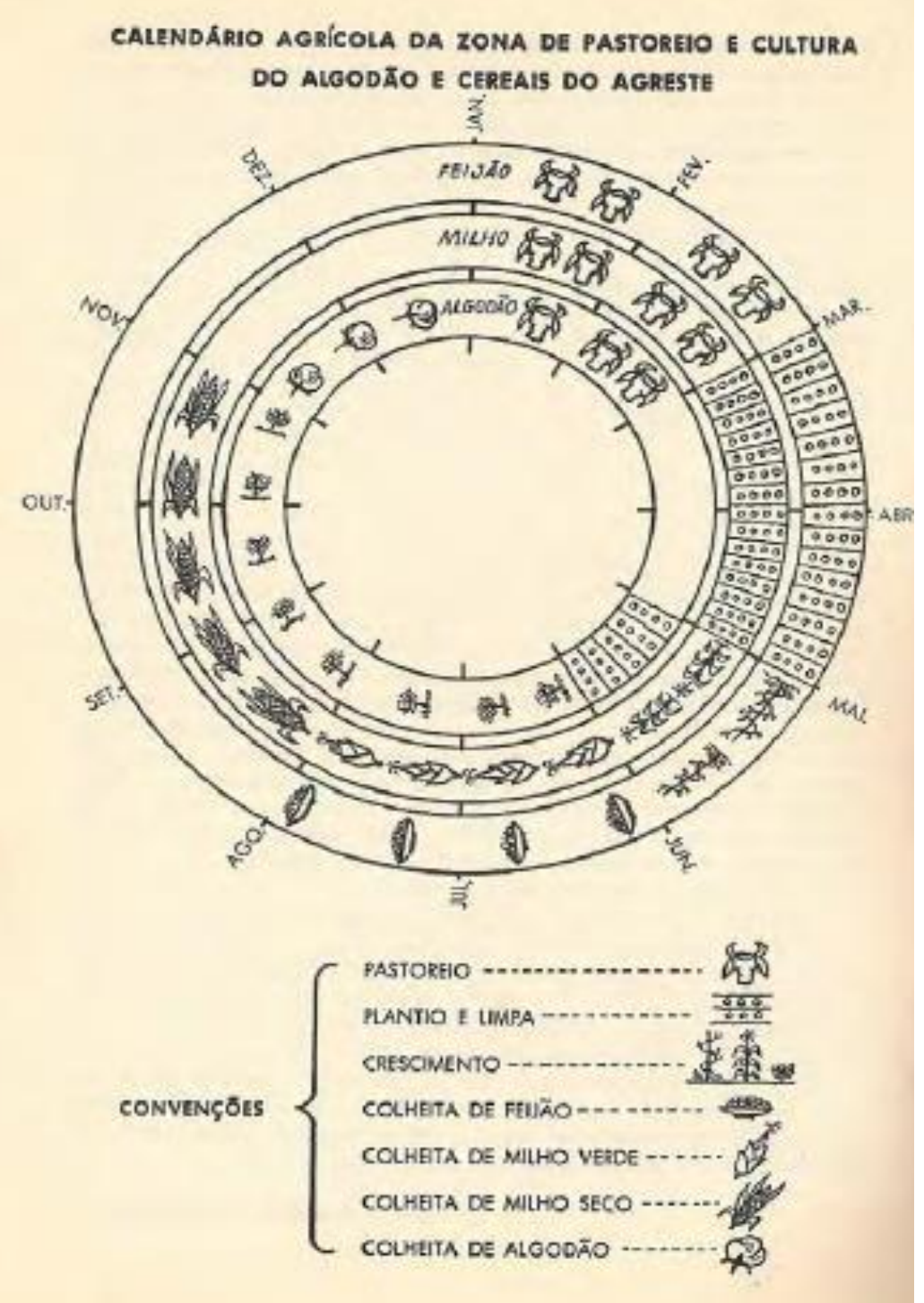

Figura 27 - Calendário Agrícola do Agreste Fonte: ANDRADE (1973, p. 172).

A análise do calendário agrícola apresentado na Figura 27 nos permite, ainda, verificar que, como o ciclo de produção do algodão era maior em relação as culturas como o milho e o feijão, era possível o cultivo em consórcio, considerado uma das maiores vantagens da cultura algodoeira no Nordeste. $\mathrm{Na}$ mesma figura é possível observar que o período de pastoreio do gado coincida com o período em que já havia sido feita a colheita do algodão e sua rama servia para a alimentação do gado.

Mesmo tendo como referência para plantio os primeiros meses de chuva, era comum que os agricultores não plantassem, todos, na mesma época. Com 
o surgimento da praga do bicudo, esse tipo de prática acabou por prejudicar no combate ao inseto, haja visto que a referida praga se reproduz no período de floração do algodão. A existência de campos de cultivo em fases de desenvolvimento diferentes permitia que o bicudo migrasse de uma lavoura à outra, tornando impossível seu controle.

Como forma de conter a infestação das lavouras pelo bicudo, os pesquisadores e técnicos passaram a recomendar que os agricultores plantassem na mesma época. Além disso, outros tratos culturais precisaram ser adotados tais como: catação das maças ${ }^{77}$ e botões florais atacados pelo bicudo, e depois de colhido o algodão, pastoreio do gado, a raiz da planta deve ser arrancada. Esse conjunto de ações faz parte do Manejo Integrado de Pragas $(\mathrm{MIP})^{78}$. A importância deste procedimento se deve ao alto poder de reprodução do bicudo conforme podemos constatar a seguir:

\begin{abstract}
O bicudo macho somente produz o hormônio sexual e de agregação após se alimentar do pólen do algodão. É justamente o próprio botão floral do algodoeiro que depois de um certo tamanho (grossura de um lápis), produz 10 substâncias aromáticas que atraem o bicudo, em geral o macho, no início da colonização no campo. Desta forma, destruindo-se os botões florais atacados (a fêmea coloca somente um ovo em cada botão floral, com média de 8 por dia e 150 durante 0 período fértil), reduz-se a população de bicudos, e assim se reduzem os danos e o uso de inseticidas (EMBRAPA ALGODÃO, 2002).
\end{abstract}

O uso de conhecimento técnico é cada vez mais necessário na agricultura, mesmo na produção da agricultura familiar, que historicamente tem dificuldade de acesso as principais inovações desenvolvidas para o setor. Essa situação é ainda mais agravada pela falta de políticas públicas em nível federal, estadual e municipal, que levem a sério o desenvolvimento no campo ${ }^{79}$. No caso especifico

\footnotetext{
77 A catação dos botões florais atacados pelo bicudo, é considerado uma das formas mais eficientes no controle da referida praga. Esta pode ser feita tanto à mão, como com a utilização de um catador mecânico. A catação manual é a forma mais corriqueira. O agricultor caminha em seu roçado e ao constatar que há um botão floral no chão imediatamente faz o recolhimento do mesmo. Após a coleta dos botões infectados o agricultor precisa destruí-los. As formas recomendadas para o aniquilamento dos botões infectados são: queimar, enterrá-lo a uma profundidade maior que $30 \mathrm{~cm}$ ou ainda os utilizar na ração animal misturada ou não com alguma substância.

${ }^{78} \mathrm{O}$ MIP é uma metodologia de controle fitossanitário da agricultura convencional, que tem por objetivo manter os insetos sempre abaixo de um nível que cause danos de forma a reduzir o uso de agrotóxicos, uma das formas utilizadas nesse processo é o uso inimigos naturais no controle das pragas.

${ }^{79}$ Contudo no Brasil desde o ano 2000 tem ocorrido esforços no sentido de mudar as condições de produção da agricultura familiar e sua inserção na oferta de produtos no mercado, através das ações do Ministério de Desenvolvimento Agrário (MDA) e em especial da Secretária da
} 
do algodão colorido, é preciso que se diga houve toda uma mobilização por parte de agentes - públicos, privados e ONGs - empenhados para que a produção do algodão colorido fosse exitosa.

De acordo com o contexto descrito acima, se disponibilizou um conjunto de instrumentos técnicos normativos que passou a ajudar no planejamento da cultura. Nesse processo de transferência de tecnologia, os "dias de campo" 80 promovidos tanto pela Embrapa Algodão, como pela EMATER-PB, se constituem de grande relevância na divulgação de informações entre agricultores, empresários, técnicos agrícolas e pesquisadores. Nos "dias de campo" são compartilhadas informações sobre aspectos relacionados ao trato da cultura no campo, colheita, beneficiamento e comércio, conforme podemos verificar na divulgação de um desses eventos a seguir:

A Embrapa Algodão, em parceria com a Empresa de Assistência Técnica e Extensão Rural (Emater/PB) e a Associação do Assentamento Margarida Maria Alves, promove nesta sexta-feira (31), o um dia de campo sobre algodão colorido (...). O dia de campo contará com palestras sobre a conservação de solos, manejo cultural do algodão orgânico, colheita, beneficiamento, comercialização e aspectos econômicos, ministradas por pesquisadores e técnicos da Embrapa Algodão (...). 'Essa será uma ótima oportunidade para os agricultores obterem mais conhecimentos sobre o plantio e comercialização do algodão colorido orgânico, uma excelente alternativa para geração de emprego e renda, em especial, para o pequeno produtor, que planta, cuida e colhe com a mão de obra da sua família', afirma o supervisor de Transferência de Tecnologia da Embrapa Algodão, Odilon Reny Ribeiro (EMBRAPA ALGODÃO, 2014).

Os "dias de campo" também são momentos em que os próprios agricultores compartilham seus conhecimentos, pois, mesmo recebendo orientações técnicas há situações com as quais eles se deparam no dia a dia, que ajudam a construir seu aprendizado (Figuras 28 e 29). Ainda conforme destacado por Piccioto e Shewhenko (2006), na fase inicial de implantação do sistema de produção do algodão colorido na Paraíba, o Serviço Nacional de Aprendizado Rural (SENAR) também atuou para assegurar a boa qualidade do algodão produzido:

Agricultura Familiar e do Desenvolvimento Agrário. Além das políticas federais no Brasil há muitas experiências exitosas, promovidas por iniciativas dos próprios agricultores, ONGs entre outros, mas de uma forma mais ampla ainda há muitos problemas.

80 Os dias de campo é uma metodologia de transferência de tecnologia. É organizada em uma determinada propriedade rural onde são montadas estações, nas quais há informações sobre as várias etapas de produção. 
Os produtores foram acompanhados pelos técnicos da EMATER e da Embrapa e mais intensamente pelos agentes multiplicadores durante o processo de cultivo, colheita, dispondo, assim, de insumos e informações para plantar o algodão colorido e obter bons resultados (Piccioto; Shewhenko, 2006, p. 7).
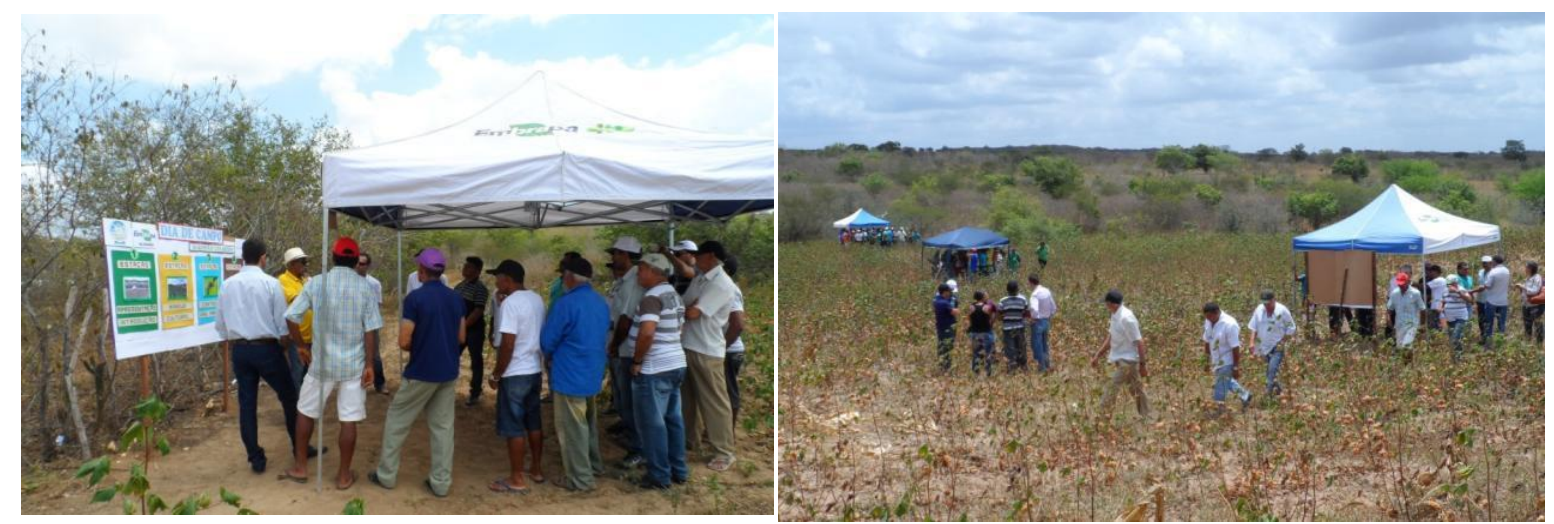

Figuras 28 e 29 - Dia de Campo de Algodão Colorido na Fazenda Campos, no município de Salgado de São Felix - PB. Fotos: Alberto Junior

Fonte: Disponível em: <https://www.embrapa.br/web/portal/busca-de-noticias/Inoticia/5417737/dia-de-campo-apresenta-vantagens-de-cultivar-algodao-coloridoagroecologico > Acessado em: 31 de agosto de 2016.

Além da troca de experiências durante esses eventos promovidos pelos agentes públicos, merece atenção a criação da Escola Participativa do Algodão (EPA). A Escola Participativa do Algodão foi criada em 2005 no assentamento Queimadas, localizado no município de Remígio a partir da ação cooperada entre a Embrapa Algodão e a ONG ARRIBAÇAN.

A Escola do Algodão, como passou a ser chamada pelos agricultores, é inspirada na metodologia norte americana da Escola de Campo Participativa. $\mathrm{Na}$ Escola do Algodão os agricultores são, de alguma forma, colocados como protagonistas do conhecimento, é o "agricultor pesquisador" (WANDERLEY JUNIOR, 2006).

O objetivo da Escola do Algodão é que os agricultores aprendam como fazer a transição da agricultura convencional para a agricultura orgânica. Faz parte da metodologia da aprendizagem: unidade de demonstração de boas práticas dentro da propriedade, visitas de intercâmbio em outras propriedades, visitas de campo, seminários e "dias de campo". Como resultado da Escola do 
Algodão o assentamento Queimadas foi o primeiro do estado da Paraíba a ter a produção de algodão orgânico certificado pelo o IBD (ALMEIDA, 2011).

O algodão orgânico certificado no assentamento Queimadas foi o de fibra branca, o mesmo foi comercializado com a empresa paulista YD Confecções, que também se responsabilizou pelo pagamento do selo IBD. Só em 2007 é que tem início no referido assentamento o cultivo de algodão colorido, também produzido de forma orgânica e comercializado com a COOPNATURAL (ALMEIDA, 2011).

No decorrer desses 16 anos de produção de algodão colorido, não foi só a área geográfica de cultivo que mudou, a forma de produzir também. Inicialmente a produção de algodão colorido era desenvolvido adotando os mesmos princípios do algodão branco convencional, ainda que a escala de insumos químicos utilizados fosse reduzida, pelo fato inclusive dos pequenos produtores não terem recursos financeiros para comprarem tais insumos.

Como os produtos derivados do algodão colorido, principalmente as roupas são exportadas para outros países, os empresários do setor precisaram readequar o sistema de produção no campo para assegurar um produto final nos padrões desejados pelo mercado. Desde o início já havia o apelo de que o algodão colorido era menos agressivo ao meio ambiente por dispensar o uso de insumos na fase de tinturaria, mas no campo a produção era feita ainda nos moldes tradicionais.

Essa demanda apresentada pelos compradores, que buscavam produtos ecológicos do campo à fase final de produção, não impediu que os empresários continuassem a ofertar seus produtos, mas, para se manter no mercado que se mostrava lucrativo, medidas foram tomadas para mudar a produção no campo.

A mudança para a produção de algodão colorido orgânico iniciou-se em 2007. Segundo a presidente da COOPNATURAL ${ }^{81}$, na época ainda não existia uma metodologia de produção de algodão orgânico no estado. Como já mencionado, a produção orgânica segue determinadas normas baseadas nas exigências estabelecidas nos países desenvolvidos como Estados Unidos, países da Europa e Japão. Esse tipo de exigências para exportação de um

\footnotetext{
81 Informação obtida durante entrevista realizada em 12 julho de 2016, em Campina Grande.
} 
produto faz parte das barreiras não tarifarias, ou seja, se o produto não estiver de acordo com as normas de aceitação daqueles países, este é vetado.

Assim, a produção local de algodão colorido precisou se adequar as normas globais de produção agrícola orgânica. O agricultor, por sua vez, é reorientado na sua forma de produzir. Mesmo sem dispor de recursos financeiros para comprar produtos químicos utilizados na agricultura, esse agricultor vem de um modelo de produção no qual os insumos agrícolas parecia ser a certeza da garantia da safra em relação ao bicudo, a lagarta curuquerê (Alabama argillacea) e outras doenças que afetam o algodoeiro. A princípio, esses agricultores não viam outra forma de controlar a praga a não ser com o uso de venenos.

Se, por um lado, o pequeno agricultor se deparou com a mudança na forma de manejo do algodão colorido, por outro, não resta dúvida dos benefícios que a produção orgânica ou agroecológica ${ }^{82}$ traz à qualidade de vida desses agricultores que antes estavam expostos aos danos que o veneno utilizado na pulverização da agricultura causava à sua saúde e de sua família. Isto porque não é raro os relatos de agricultores que levavam para casa o recipiente vazio de veneno e depois utilizava-o para armazenar água provocando os mais variados problemas de saúde.

A mudança na forma de produzir não atingiu apenas os agricultores. As instituições de pesquisa e a assistência técnica, que vem de um modelo baseado no uso intensivo de produtos químicos na agricultura, também precisaram pensar formas de manter a produtividade de uma cultura e reduzir o uso de insumos industriais ${ }^{83}$.

Segundo a empresaria e presidente da COOPNATURAL ${ }^{84}$, Maysa Gadelha para demonstrar que a produção de algodão colorido orgânico era possível e convencer os agricultores a plantarem deste modo, ela utilizou uma

\footnotetext{
${ }^{82} \mathrm{Na}$ agroecologia a forma de produção é igual a orgânica, a diferença está no fato de a produção agroecológica o produto não ser certificado pelas instituições devido em muitos casos os agricultores não terem condições de pagar os custos da certificação.

83 Os esforços das instituições de pesquisa para acompanhar as novas demandas do mercado consumidor que influenciam diretamente na forma de produção e organização dos atores sociais tem sido uma constante, devido inclusive a políticas externas que exigem a incorporação de práticas sustentáveis, especialmente na agricultura que causa tantos impactos ao meio ambiente. Ainda assim há longo caminho a ser perseguido pelas instituições e pela sociedade para redução dos impactos ambientais nas produções agrícolas.

${ }^{84}$ Entrevista realizada durante trabalho de campo em Campina Grande em 12 de julho de 2016.
} 
área de 100 ha de sua propriedade na fazenda Santo Antônio no município de Bom Sucesso, na região do Cariri Paraibano, para plantar algodão orgânico.

No excerto da entrevista a seguir é possível acompanhar como foi executada a primeira mobilização para cultivo de algodão colorido orgânico na Paraíba e como a interação entre o setor privado e o Estado foi essencial nesse processo:

Presidente da COOPNATURAL: (...) Primeiro, os técnicos da EMATER não tinham a mínima sensibilidade para nenhum produto orgânico e a Paraíba já tinha perdido todo um mercado de algodão por causa do bicudo, então, estava todo mundo realmente traumatizado. Eu andava pelo estado fazendo dias de campo tentando convencer o pessoal e eles dizem: 'Não, sem veneno não dá certo. A gente vai perder tudo'.

(...). Então, para conseguir agricultores para plantar na nossa terra, eu falei assim: 'Olha, nós vamos plantar um negócio aqui que vai dar um programa de Globo Rural. Se vocês plantarem todo mundo aqui vai sair no Globo Rural'

(...) Na época eu tive contato com um grande consultor de plantio de algodão no mundo que é um brasileiro que mora na Alemanha e ele tinha vindo aqui e falou: 'Quando vocês quiserem plantar orgânico você me avisa que eu vou te dar o suporte técnico sem custo algum' - e a EMBRAPA também não tinha tecnologia nenhuma. Nós plantamos 100 hectares e eu enviava para ele as fotos do que estava no campo. Era um monitoramento permanente".

Eu mandava as fotos e ele me mandava a receita da aplicação. (...) $E$ a EMBRAPA foi acompanhando e escrevendo a história: apareceu isso, nós usamos aquilo" criando uma metodologia que até então não existia.

E aí o técnico da EMBRAPA ia lá toda semana. Depois nós contratamos um agrônomo para ficar na fazenda e ele ficava mandando as fotos e a coisa foi caminhando.

A safra foi muito boa e o Globo Rural veio. (...). Então, quando foi divulgado o algodão colorido orgânico da Paraíba, a gente teve discurso para dizer: 'Vamos plantar que vai dar certo!' '. Se teve uma conviç̧ão, uma certeza que a gente tirou de lá desse plantio foi de que tinha que ser agricultura familiar".

A mão de obra utilizada para cuidar da lavoura de algodão orgânico, localizada na propriedade da empresaria Maysa Gadelha foi de trabalhadores assalariados. Segundo a empresária, para esses agricultores não poderia haver riscos, já que se tratava de uma fase experimental. Então, se por ventura houvesse perdas na produção, o prejuízo não poderia ser repassado para o agricultor. Em 2008, a Embrapa Algodão disponibilizou um manual que orientava a produção de algodão colorido orgânico baseado nessa experiência de campo e nas recomendações técnicas sobre a produção de algodão orgânico exigidas pelas empresas de certificação (QUEIROGA; CARDOSO; CARVALHO, 2008). 
O cultivo do algodão colorido tanto pode ser feito em regime de sequeiro, quanto com o uso de irrigação. Em 2000, algumas áreas foram plantadas fazendo uso de irrigação, mas para se fazer uso desse sistema técnico é preciso dois elementos, água e recursos financeiros. Considerando que se trata de uma região onde os problemas hídricos são severos e que os pequenos agricultores não dispõem de sistema técnico de irrigação, a primeira é a mais utilizada.

Farias (2010, p. 230) identificou áreas de cultivo de algodão colorido da cor BRS Safira no Sítio Santa Maria, no município de Pombal, que utilizava a técnica de pivô central, no Sítio União município de São Bento (ver Figura 30). O uso de irrigação nos casos citados foi possível devido a presença de sistemas de engenharia agrícola, propiciado pela presença de macro sistema hidráulico "composto pelo Complexo Mãe D"água Coremas e pelos rios perenizados Piancó e Piranhas". O autor (op. cit,. p. 230) menciona, ainda, a produção com uso de irrigação na Fazenda Santo Antônio no município de Bom Sucesso, pertencente à família Gadelha.

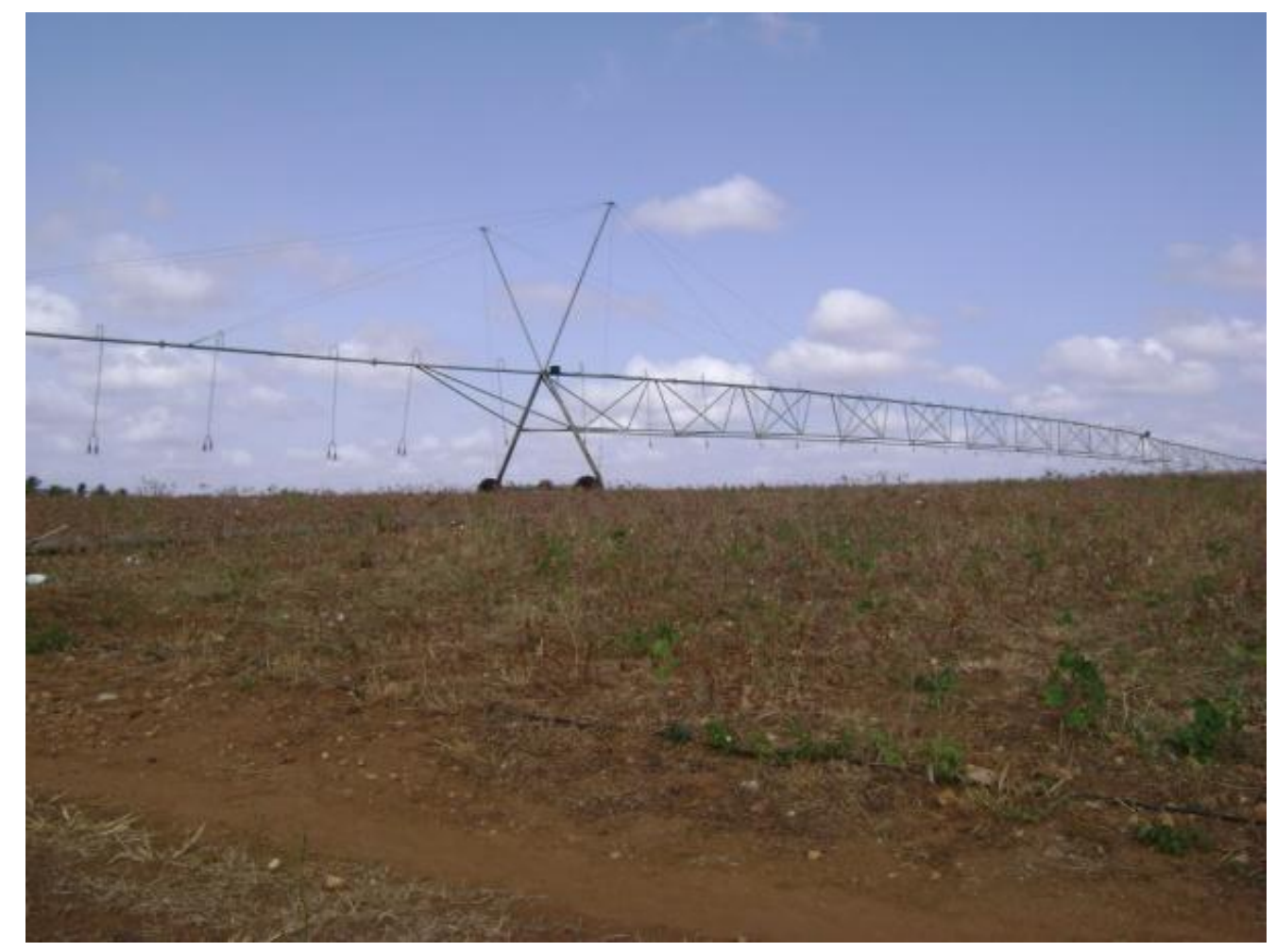

Figura 30 - Pivô Central utilizado no cultivo de Algodão Colorido BRS Safira no Sítio União - São Bento - PB

Fonte: FARIAS, 2010, p. 231. 
No período da colheita, os agricultores precisam de mais atenção para evitar que o algodão seja colhido sem que o mesmo esteja com seus capulhos completamente abertos e secos. Evitar mistura de cores, plantar as cultivares de cores diferentes com uma distância de 300 metros entre uma cultivar e outra. É comum a formação de barreiras de 50 metros com milho. No caso do algodão de fibra verde, os cuidados são ainda maiores, pois como essa variedade não possui boa estabilização na cor, depois que o capulho estiver aberto e seco precisa ser colhido, para evitar que sua exposição ao sol danifique sua cor. São utilizados alguns corantes naturais para ajudar na fixação da cor do algodão verde. Atualmente a empresa paulista Etno Botânica - Corantes e Pigmentos Naturais é quem tem feito esse tipo de trabalho. Além dessa empresa também é feito alguns tingimentos com cascas de plantas da região pelas funcionárias das empresas da Paraíba que manufaturam o algodão naturalmente colorido.

Por requerer mais cuidados e ser a cor mais inusitada, a pluma verde é mais valorizada e escassa. Nos trabalhos de campo constatamos que há alguns anos essa cultivar não tem sido plantada e que os tecidos que apresentam essa cor são de safras anteriores. Como estratégia para ofertar peças com a cor verde natural, os empresários a utilizam apenas em detalhes das peças, conforme mencionado por artesãos e empresários:

Presidente da Natural Cotton Color ${ }^{85}$ : (...) acho que eu nem tenho... $O$ verde é o que eu menos trabalho, a gente faz apenas alguns detalhes (...) (artesã de Campina Grande-PB).

Nós, temos apenas 4 cores, das quais, uma delas a gente está sem produzir, há uns 4 anos, desde 2011, que foi quando começou realmente a seca, que é o verde. Então, isso é o que nós temos. (...)E o verde, por exemplo, não se trabalha com menos de 1 ano. Ou seja, se esse grupo quer comprar peça verde, ele tem que comprar hoje para daqui há um ano ele estar recebendo. Então, a gente tem que ter sempre esse cuidado porque, afinal de contas, esse prazo é de nossa responsabilidade e de nosso controle. Então, não adianta eu dizer que vou vender verde e vou sair procurando verde que não vai ter verde

Como o material genético utilizado para gerar as variedades coloridas é proveniente da mistura de algodões de fibra colorida e branca, é possível que, eventualmente, surja na plantação do algodão colorido alguma planta com fibra

\footnotetext{
${ }^{85}$ Entrevista realizada em 17 de julho de 2016, em João Pessoa.
} 
branca. Quando isso acontece, o agricultor é orientado a arrancar a planta com capulho branco para evitar hibridações e consequente perda da pureza genética da variedade colorida (Figuras 31 e 32).

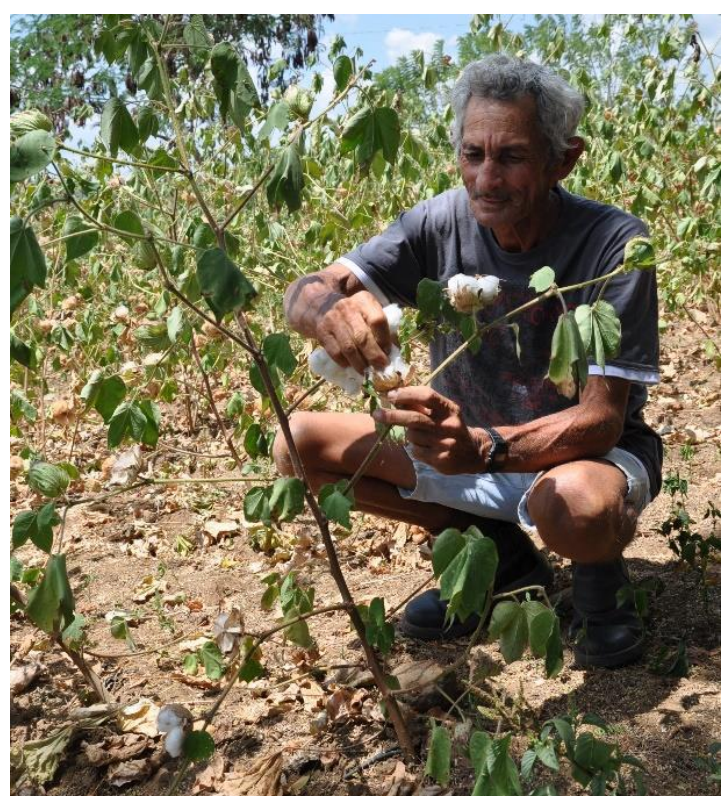

Figura 31 - Agricultor retirando o algodão branco do meio do algodão colorido Foto: Joacy Santos - 2015 .

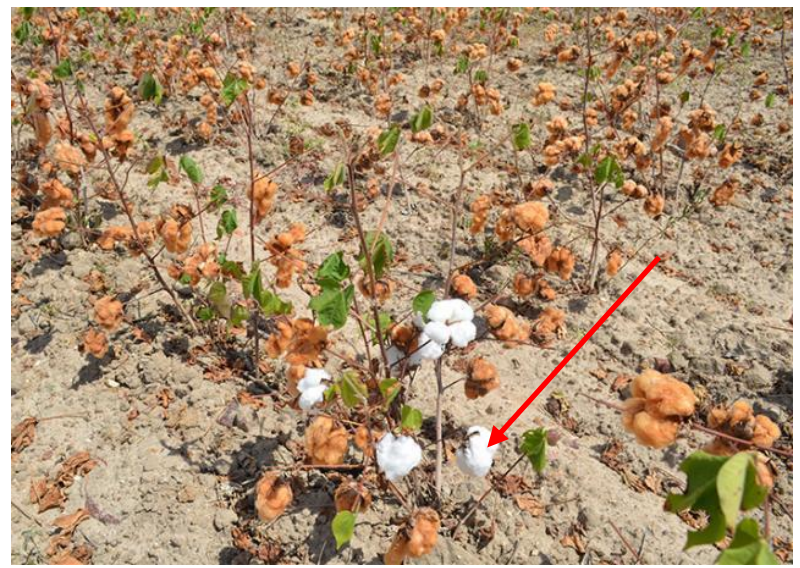

Figura 32 - Algodão com fibra branca entre o algodão colorido.

Foto: Joacy Santos - 2015

A partir do exposto observa-se que o bom desempenho da cultura do algodão colorido se dá a partir de um conjunto de práticas e não apenas pelo fato de possuir uma variedade mais produtiva e com cores inusitadas. Então, mesmo que o preço pago ao agricultor pelo algodão colorido seja superior ao valor pago pelo algodão branco, o tempo de trabalho exigido para cuidar da lavoura também é maior.

Na pesquisa realizada pela Embrapa Algodão em 2014 - em parceria com a Companhia Nacional de Abastecimento (CONAB) -, numa tentativa de inserir o algodão colorido dentro da política de preço mínimo como forma de incentivar a produção desse tipo de algodão, foi feito o cálculo dos custos de produção do algodão colorido orgânico no campo e se chegou à conclusão de que os valores pagos aos agricultores estão aquém do que deveria ser. $O$ tempo total de produção do algodão colorido, entre a fase de preparo do solo à colheita $\mathrm{e}$ beneficiamento, é de 5 meses e os cálculos demonstraram que os trabalhadores 
recebiam apenas $R \$ 5,38$ (cinco reais e trinta e oito centavos) por dia de trabalho, conforme pode ser constatado a seguir (SEBRAE, 2015):

\begin{abstract}
A CONAB e a Embrapa Algodão fizeram um levantamento conjunto sobre custos de produção na safra 2013/2014 e chegou-se à conclusão que o pagamento diário dos cotonicultores paraibanos do algodão colorido, durante os 5 meses do ciclo cultural, é de $R \$ 5,38$ (cinco reais e trinta e oito centavos)! Isso quando se leva em conta 02 (dois) trabalhadores por hectare e a pluma e o caroço, certificados como "orgânicos" são vendidos pelos melhores preço do mercado na presente conjuntura; ou seja, $R \$ 10,00$ (dez reais) por quilograma de pluma e $R \$ 1,04$ (um real e quatro centavos) por quilograma de caroço (cotações de 30/05/2015, da Fundação Bahia).
\end{abstract}

(...) Assim, aquele técnico teria que convencer os adquirentes do caroço e da pluma naturalmente colorida "orgânicos" a pagar, no mínimo, o preço de $R \$ 24,91$ (vinte e quatro reais e noventa e um centavos) por quilograma de pluma, e $R \$ 1,04$ (um real e quatro centavos) por quilograma de caroço de algodão. Isso porque são necessários, no mínimo, 02 (dois) trabalhadores para dar conta de produzir 01 (um) hectare de algodão colorido "orgânico". Há de se considerar verdadeiramente essa situação dos preços pagos pela pluma "orgânica" como um gargalo do desenvolvimento sustentado da cadeia produtiva, esforçando-se por eliminá-lo, se se quiser que ela continue sendo construída e se desenvolva. (SEBRAE, 2015, p. 16).

Isto implica que o agricultor recebe menos de um salário mínimo por mês, no período em que está dedicado a essa cultura. E essa situação ainda não é pior porque sistematicamente foi sendo estimulada a política de que os empresários do setor de confecção devem comprar a pluma do algodão e não o algodão em caroço, já que o beneficiamento agrega valor ao produto. O incentivo para que o algodão seja comercializado em pluma também tem como objetivo eliminar o atravessador que historicamente tem papel negativo na economia do algodão na região.

Mesmo incentivando a venda do algodão em pluma, não se pode garantir que não exista comercialização de algodão em rama. Essa orientação de vender o algodão em pluma tem sido para toda a cadeia de algodão orgânico, tanto o colorido, quanto o branco. O beneficiamento do algodão colorido é possível devido a existência de miniusinas de beneficiamento de algodão instaladas em alguns pontos do território nordestino. A importância desse objeto técnico na reorganização da produção do algodão no Semiárido será detalhada quando tratarmos da etapa de beneficiamento.

Até o ano de 2009 era comum os agricultores venderem o algodão colorido em rama. A produção era levada até a CAMPAL, onde era beneficiada 
e depois vendida para COOPNATURAL. Para se ter uma ideia, em 2000, quando começou a ser comercializado, se pagava pelo algodão em rama $R \$ 1,00 . \mathrm{Na}$ época esse valor era $30 \%$ mais caro que o algodão branco em caroço. A pluma era comercializada por $R \$ 3,90$. Em 2015 o algodão colorido orgânico em caroço foi comercializado a $R \$ 3,00$ e a pluma por $R \$ 10,00$. Por isso, é mais interessante que $o$ agricultor comercialize a pluma.

Ainda em relação a economia do algodão na agricultura familiar, cabem algumas ponderações. Os agricultores não dependem exclusivamente desse produto para compor sua renda, o que não minimiza o fato de que é imprescindível que seja pago o preço justo pelo mesmo. Pelo fato de desenvolver outras atividades, como a produção de alimentos (o milho, o feijão, a fava, macaxeira, etc.), como já era feito no antigo sistema de produção do algodão branco convencional (Figura 33).

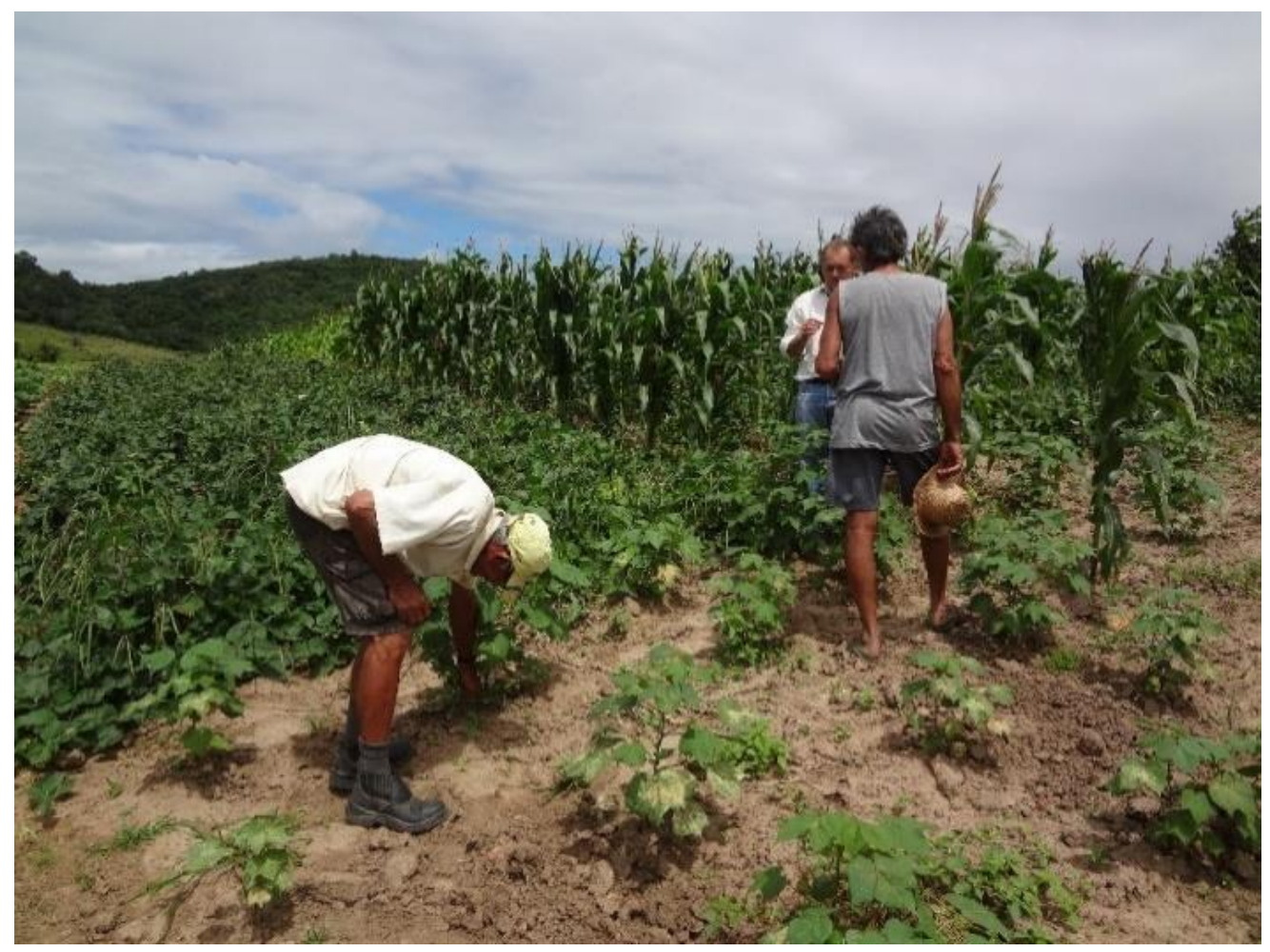

Figura 33 - Cultivo de algodão colorido consorciado com milho e feijão no Assentamento Margaria Maria Alves - Juarez Távora-PB

Foto: LIRBÓRIO, Lucia Ferreira, 2015.

Além de desenvolver agricultura de subsistência, os agricultores desenvolvem a pecuária, como a criação de bovinos, que tem duas funções: 
alguns desses animais são utilizados como fator de produção, na medida em que sua força é utilizada para movimentar o arado; para ser vendido no final do ano. Além de bovinos é comum no agreste e, sobretudo, no Semiárido, a criação de caprinos e de ovinos.

Conforme já mencionado, a crise causada com o excesso de produção dos primeiros anos de cultivo do algodão colorido e o baixo preço pago aos agricultores desmotivou os mesmo de investirem nessa cultura. A partir da situação estabelecida, foi necessário que os diversos atores da cadeia se articulassem para assegurar a matéria-prima. Nesse sentido a partir de 2010, como forma de garantir aos agricultores retorno pelo seu trabalho, o plantio do algodão passou a se condicionado pelo contrato de compra antecipada do produto por parte das empresas interessadas.

Nesse contexto de crise no fornecimento da matéria-prima e com o objetivo de revitalizar o circuito de produção do algodão colorido da Paraíba, foi criado em 2012 o Comitê Gestor do Arranjo Produtivo Local de Confecções e Artefatos de Algodão Colorido da Paraíba. Esse Comitê é formado por agentes dos setores público e privado.

Participam atualmente do Comitê Gestor a Associação da Indústria do Vestuário da Paraíba (AIVEST) ${ }^{86}$, o grupo Natural Cotton Color, as Associações dos Agricultores de Juarez Távora, de Queimadas e de Remígio, o SEBRAE-PB, o SENAI-PB, a Associação Brasileira da Indústria Têxtil (ABIT), o Governo do Estado da Paraíba e alguns órgãos federais: Embrapa Algodão, Superintendência Federal de Agricultura Familiar e Conab, além dos Banco do Brasil, Banco do Nordeste do Brasil (BNB) e Bradesco ${ }^{87}$.

Mesmo diante das medidas mencionadas, a produção de algodão colorido na Paraíba encontra-se muito limitada. Na safra de 2015 estima-se que a área plantada tenha sido de apenas 80 ha, o que dará aproximadamente 80 toneladas

\footnotetext{
${ }^{86}$ Atualmente a AIVEST representa quase exclusivamente os interesses dos empresários envolvidos com a produção de algodão colorido, particularmente o grupo Natural Cotton Color. 87 A presença dos bancos mencionados está relacionada ao apoio às pequenas empresas. Atualmente não há nenhuma linha de crédito disponível para a produção do algodão orgânico, pois geralmente os empréstimos concedidos pelos bancos para produção agrícola estão associados a um pacote tecnológico, que no caso especifico do algodão colorido não é utilizado, por ser produção orgânica e também historicamente o agricultor familiar tem mais dificuldades de acessar linhas de financiamento agrícola, porque na maioria das vezes não possui bens que possam dar como garantia.
} 
de algodão. Isso porque, embora a produtividade das cultivares de algodão colorido sejam superiores a $1.000 \mathrm{~kg} / \mathrm{ha}$, a falta de chuvas prejudica muito os rendimentos da cultura. Por ser plantado com espaçamentos maiores entre uma fileira e outra do algodão, o número de plantas de algodão é menor o que também interfere na quantidade produzida por hectare.

Com o objetivo de revitalizar a produção do algodão na Paraíba o governo do estado criou, em 2015, o Projeto Algodão Paraíba. Esse projeto não é voltado exclusivamente para o algodão colorido, mas sim para a produção de algodão orgânico pela agricultura familiar. Isso porque os pequenos agricultores do Semiárido não tem condições técnicas e financeiras de competir com os grandes produtores dos Cerrados, assim o investimento em nichos de mercado tem sido a alternativa encontrada para reinserção do algodão no Semiárido.

Ainda em 2015, o governo da Paraíba, através da Gestão Unificada (EMATER, EMEPA e INTERPA), distribuiu sementes de algodão branco para serem plantadas de forma orgânica em uma área de 150 ha e envolvendo aproximadamente 300 agricultores. Mesmo o algodão colorido hoje plantado no Nordeste possuindo características tecnológicas similar à de cultivares de algodão branco, a verdade é que o mercado para esse tipo de algodão é ainda muito restrito devido, principalmente, ao pouco número de cores disponíveis.

O projeto citado atraiu inclusive o interesse do Instituto C\&A, instituição corporativa da área social de uma das maiores redes varejistas de confecção do mundo, a $C \& A^{88}$. Representantes desse instituto foram até à Paraíba em junho de 2016 e sinalizaram interesse em estimular a produção de algodão branco orgânico. Essa empresa possui uma linha de produção de têxteis orgânicos que corresponde a $10 \%$ de sua produção, a meta da empresa é que até $2020,100 \%$ do algodão utilizado em suas confecções sejam com algodão orgânico.

Como forma de incentivar a produção mundial de algodão orgânico, que hoje não chega a $1 \%$ do total de pluma de algodão consumida, o Instituto $C \& A$ financiou o documentário "For the Love of Fashion" (Por amor a moda) exibido pelo canal de TV National Geographic. Esse documentário inclusive teve uma

\footnotetext{
${ }^{88}$ Segunda a Textile Exchange a C\&A é a empresa que mais consome algodão orgânico do
} mundo. 
pré-estreia no Brasil em maio de 2016. Os dados da produção mundial de algodão orgânico podem ser vistos no Quadro 17.

O Quadro 17 foi elaborado com base em dados disponíveis no site da ONG TEXTILE EXCHANGE, que vem incentivando a produção de algodão orgânico no mundo. Na compilação de dados sobre a produção de algodão orgânico disponível as regiões apontadas são: África, América Latina, China, Europa, Oriente Médio, Norte da África e Ásia Central, Sul da Ásia e Estados Unidos. Entretanto, nos dados do Quadro 17, no que se refere as características da fibra, só há menção da produção de algodão colorido na América Latina, cujas produções provavelmente são as do Brasil e do Peru. Contudo, também há produção de algodão colorido orgânico na Califórnia. As fibras do algodão colorido peruano são curtas, nos EUA o tamanho das fibras de algodão colorido é médio e no Brasil o algodão colorido possui fibras longas. No caso das fibras extralongas orgânica nessa região merece destaque a produção de algodão branco Pima do Peru.

$\mathrm{Na}$ região autônoma da China, Xinjiang responde por um terço da produção de algodão branco convencional da China. Além da produção de algodão orgânico branco, também há campos de cultivo de algodão colorido ${ }^{89}$. De acordo com Xiog-ming et. al $\mathrm{s} / \mathrm{d}$, nos últimos 20 anos a China obteve resultados consideráveis na pesquisa e criação de novas variedades de algodão colorido a partir do uso de biotecnologia.

Segundo os autores (op. cit., p.1), nos anos recentes foram criadas 21 novas cultivares de algodão colorido entre tons de marrom e verdes, além de 51 novas linhagens selecionadas. Pelo fato de o algodão colorido da China ser transgênico o mesmo não pode ser considerado orgânico, inserindo-se na produção de algodão convencional.

Conforme pode ser analisado no Quadro 17, a maior área plantada com algodão orgânico corresponde ao Sul da China, lembrando que a produção de algodão orgânico indiano não foi considerada, mas sabe-se da existência de grande área plantada com algodão nesse país, que é o segundo maior produtor mundial de algodão branco em sistema agrícola convencional. O Sul da China

${ }^{89}$ Segundo o pesquisador da Embrapa Algodão Gilvan Ramos a produção de algodão colorido na China seria algo em torno de 46 mil hectares. 
também responde pela maior área plantada (253. 161 ha), quantidade colhida (312.131 mil toneladas) e quantidade de pluma produzida (103.004 mil toneladas).

Em segundo lugar no ranking de produção de algodão orgânico no mundo, está o conjunto formado por países da África. A produção de algodão orgânico na América Latina é pouco expressiva com 1.644 ha e com uma produção de algodão em caroço de 2.442 toneladas. 


\begin{tabular}{|c|c|c|c|c|c|c|c|c|c|}
\hline \multicolumn{10}{|c|}{ Algodão orgânico no mundo (2011-2012) } \\
\hline Posição & Região & Países & $\begin{array}{l}\text { Características } \\
\text { gerais da fibra }\end{array}$ & $\begin{array}{c}\text { N. de Grupo } \\
\text { de } \\
\text { Produtores }\end{array}$ & $\begin{array}{c}\text { N. de } \\
\text { Agricultores }\end{array}$ & $\begin{array}{c}\mathrm{N} . \text { de } \\
\text { mulheres } \\
\text { agricultoras }\end{array}$ & $\begin{array}{l}\text { Área } \\
\text { (ha) }\end{array}$ & $\begin{array}{l}\text { Produção de algodão } \\
\text { em caroço } \\
\text { (Mil toneladas) }\end{array}$ & $\begin{array}{l}\text { Produção de algodão } \\
\text { em pluma } \\
\text { (Mil toneladas) }\end{array}$ \\
\hline $1^{\circ}$ & $\begin{array}{l}\text { Sul da } \\
\text { Ásia }\end{array}$ & $\begin{array}{l}\text { Índia*(Não foi } \\
\text { incluído o } \\
\text { Paquistão no } \\
\text { período } \\
\text { analisado) }\end{array}$ & Média, longa & 100 & 184.029 & & $\begin{array}{r}253 . \\
161\end{array}$ & 312.131 & 103.004 \\
\hline 2 & $\begin{array}{l}\text { Europa, } \\
\text { Oriente } \\
\text { Médio, } \\
\text { Norte } \\
\text { da } \\
\text { África e } \\
\text { Ásia } \\
\text { Central }\end{array}$ & $\begin{array}{l}\text { Egito, Israel, } \\
\text { Quirguistão, } \\
\text { Síria, } \\
\text { Tajiquistão, } \\
\text { Turquia }\end{array}$ & $\begin{array}{l}\text { Curta, média, } \\
\text { longa, extralonga }\end{array}$ & 13 & 1.273 & 261 & 12.733 & 44.441 & 16.464 \\
\hline 3은 & África & $\begin{array}{l}\text { Benin, } \\
\text { Burkina } \\
\text { Faso, Mali, } \\
\text { Senegal, } \\
\text { Tanzania, } \\
\text { Uganda }\end{array}$ & Curta, média, longa & 9 & 25.584 & 6.625 & 38.821 & 21.721 & 8.922 \\
\hline $4^{\circ}$ & China & Xinjiang & Média & 8 & 1.993 & 952 & 4.218 & 18.804 & 8.106 \\
\hline $5^{\circ}$ & $\begin{array}{l}\text { Estados } \\
\text { Unidos }\end{array}$ & $\begin{array}{l}\text { Califórnia, } \\
\text { Carolina do } \\
\text { Norte, Texas } \\
\end{array}$ & Média, extralonga & 6 & 40 & 6.495 & & 4.772 & 1.980 \\
\hline $6^{\circ}$ & $\begin{array}{l}\text { América } \\
\text { Latina }\end{array}$ & $\begin{array}{l}\text { Brasil, } \\
\text { Nicarágua, } \\
\text { Paraguai } \\
\text { Peru }\end{array}$ & $\begin{array}{l}\text { Curta, média, } \\
\text { longa, extralonga, } \\
\text { colorida }\end{array}$ & 15 & 1.252 & 233 & 1.644 & 2.442 & Dado não disponível \\
\hline
\end{tabular}

Quadro 17 - Produção de algodão orgânico no mundo (2016).

Fonte: TEXTILE EXCHANGE, 2016. ORG. LIRBORIO, L. F, 2016. 
Ainda sobre essa investida do Instituto C\&A certamente será o Estado que irá oferecer as condições necessárias para o crescimento da atividade, como a oferta de pesquisa agronômica (EMATER-PB e Embrapa Algodão), extensão rural (EMATER PB). Essa ação da C\&A aponta para um cenário futuro na produção de algodão orgânico que provavelmente terá maior demanda. $\mathrm{Na}$ ocasião em que os representantes do Instituto $C \& A$ estiveram na Paraíba, os mesmos visitaram a sede da Embrapa Algodão e conheceram alguns campos de algodão orgânico branco e colorido no estado.

A tendência observada na pesquisa é que o cultivo de algodão branco orgânico se amplie no estado da Paraíba e no Nordeste, de modo geral. Do mesmo modo, é uma tendência para outras regiões do Brasil que antes produziam algodão branco e que tiveram suas produções inviabilizadas pelos custos de produção e não têm condições de fazer frente ao poder dos cotonicultores dos Cerrados. A produção de algodão de forma orgânica se constitui uma alternativa econômica para a agricultura familiar. Além da Paraíba, outros estados como Alagoas, Ceará, Pernambuco e Rio Grande do Norte estão estimulando a produção de algodão orgânico.

Fora do Nordeste, Lima e Souza (2006) indicam que há produção de algodão orgânico por agricultores do Paraná. As principais diferenças apontadas pelos autores citados entre a produção de algodão orgânico no Nordeste e a do Paraná é que, no Nordeste é comum a produção de algodão em consórcio, enquanto no Paraná, a produção é feita em sistema de monocultura.

No caso da Paraíba, há alguns fatores que podem contribuir para o deslanchar da especialização produtiva de algodão orgânico. Destaca-se a presença da Embrapa Algodão que vem ao longo de mais de 40 anos pesquisando sobre a cultura de algodão, tanto no desenvolvimento de novas cultivares, quanto em toda a cadeia de produção dessa cultura (sistemas de manejo, técnicas de campo, mercado, entre outras). Existe nessa instituição um grande acúmulo de know-how. É preciso não esquecer que a Embrapa Algodão foi uma das principais instituições responsáveis pela presença do Brasil entre os 5 maiores produtores de algodão do mundo. A modernização da cotonicultura brasileira possui forte base nos esforços dessa instituição.

Em relação ao reconhecimento do potencial da Paraíba e das instituições presentes nesse estado na produção de algodão destaca-se a participação do Brasil 
na transferência de tecnologia, referente a cultura do algodão, para alguns países da América Latina (Argentina, Bolívia, Colômbia, Equador, Paraguai e o Peru) através do Programa de Cooperação Sul-Sul para o fortalecimento do setor algodoeiro. A Organização das Nações Unidas para Alimentação e Agricultura (FAO), é parceira nesse projeto, junto com a Agência Brasileira de Cooperação, que é vinculada ao Ministério das Relações Exteriores e Instituto Brasileiro do Algodão (IBA).

No assentamento Margarida Maria Alves atualmente se encontra a maior produção de algodão colorido orgânico, com uma área de 22 ha cultivada por 16 famílias. Este foi inclusive umas das áreas escolhidas para ser registrada as boas práticas da cultura do algodão orgânico e posteriormente ser compartilhado com os agricultores familiares dos países que fazem parte do Programa de Cooperação SulSul, que também têm na produção do algodão o importante complemento de suas rendas. $\mathrm{O}$ incentivo da $\mathrm{FAO}$, em relação a cultura do algodão pela agricultura familiar, tem a ver com o fato de que o cultivo do algodão contribui para a segurança alimentar - devido ao fato de que pode ser desenvolvido em consórcio com produtos alimentares.

Durante os trabalhos de campo tive a oportunidade participar e de encontrar com duas missões da FAO, uma do Uruguai (2015) e outra do Peru (2016), que vieram conhecer experiências brasileiras na produção de algodão pela agricultura familiar. Nas visitas dessas missões técnicas, a Embrapa Algodão e sua infraestrutura de pesquisa foram sempre um dos primeiros lugares a serem conhecidos pelos grupos (Figuras 34, 35, 36 e 37). 


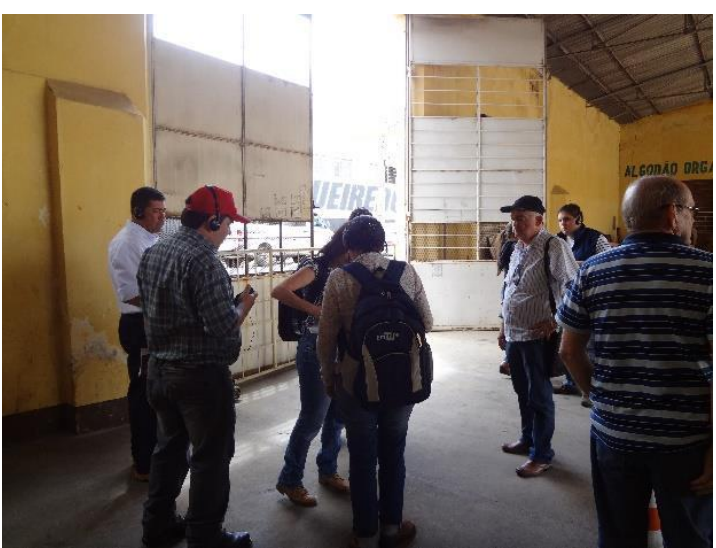

Figura 34 - Missão Técnica do Paraguai conhecendo as instalações da CAMPAL, Patos-PB.

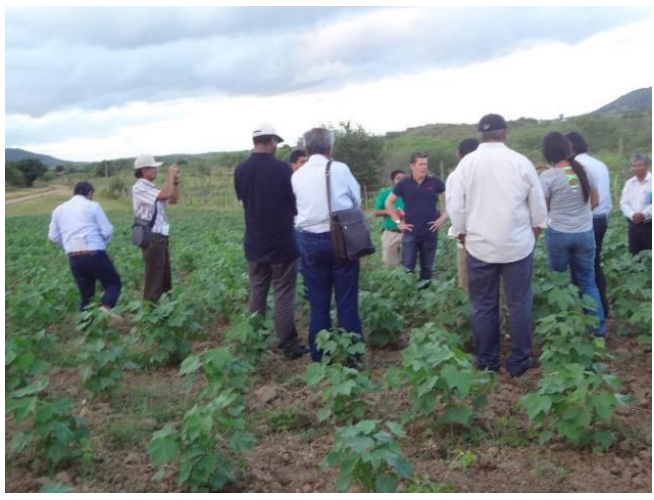

Figura 36 - Missão Técnica do Peru Visita ao campo de multiplicação de sementes do Assentamento Margarida Maria Alves - Juarez Távora-PB

Foto: LIRBORIO, L.F. 2016.

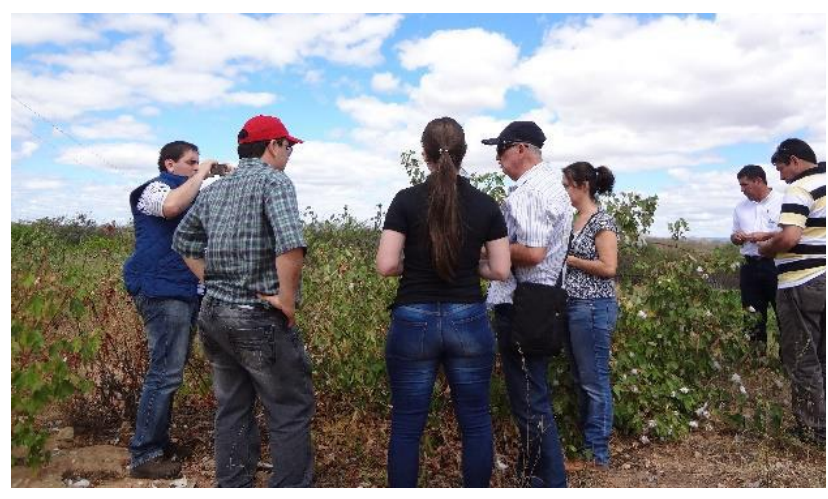

Figura 35 - Missão Técnica do Paraguai conhecendo o Campo Experimental da Embrapa Algodão Patos - PB.

Foto: LIRBORIO, L.F. 2015.

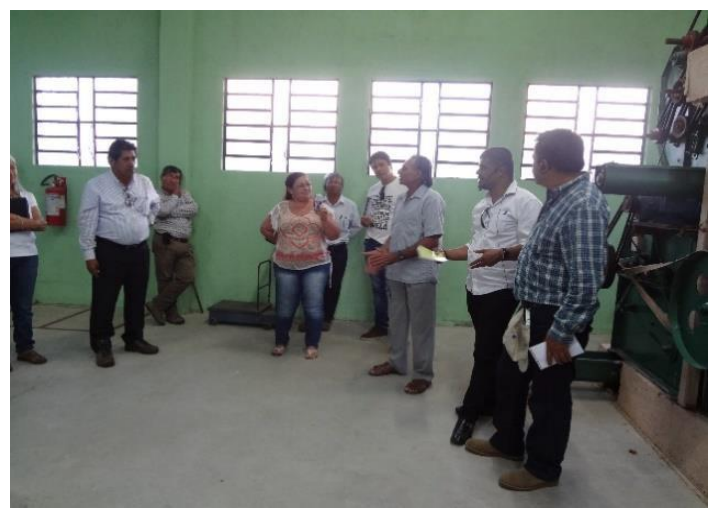

Figura 37 - Missão Técnica do Peru - Visita Mini usina de beneficiamento de algodão do Assentamento Margarida Maria Alves - Juarez Távora-PB.

Foto: LIRBORIO, L.F. 2016.

O grupo que formavam essas missões era composto por engenheiros agrônomos dos Departamentos de Agricultura desses países, técnicos da FAO, presidentes de cooperativas de agricultores, além de alguns agricultores desses países. Ficou evidente nessas visitas que o Brasil atingiu um diferencial na sua cadeia de produção de algodão que foi fortemente influenciada pelas ações da Embrapa Algodão.

Retomando a questão da forma como tem sido feito o comércio do algodão colorido, desde 2010 os agricultores só plantam mediante o contrato de compra antecipada. Os agricultores recebem $80 \%$ do valor de sua produção quando termina 
a safra e os outros $20 \%$ recebem depois que o algodão é certificado. A certificação que comumente é feita pelo IBD, devido a credibilidade desse instituto diante do mercado internacional, é realizada de forma subsidiada. Como se trata de uma tecnologia agrícola, o SEBRAE paga $60 \%$ do valor, os empresários pagam $30 \%$ e os agricultores pagam $10 \%$.

Como cada campo é certificado isoladamente, ou seja, o assentamento Margarida Alves tem uma certificação, o assentamento Queimadas outra certificação, se houver ano em que a produção for muito pequena é possível que não seja certificado, como relatado em trabalhos de campo pelos empresários. Atualmente, os agricultores em parceria com o Estado (Embrapa Algodão, EMATER - PB) estão em processo para ter a certificação participativa, o SisOrg, junto ao Ministério da Apicultura Pecuária e Abastecimento (MAPA).

A certificação SisOrg é feita por auditoria, através de uma certificadora pública ou privada cadastrada no MAPA. O acesso a esse tipo de certificação deverá aumentar os rendimentos dos agricultores e lhes dará maior liberdade na comercialização de seu produto; isso porque, atualmente, como o maior percentual da certificação é pago pelas empresas, isso implica ainda uma dependência dos agricultores.

Essa dependência também está relacionada com o fato de os agricultores, em sua maioria, possuírem baixa escolaridade e, dessa forma, seu acesso a alguns serviços se torna mais difícil. Além de buscar esse tipo de certificação social é imprescindível a formação educacional e de liderança dos mais jovens nesses assentamentos, pois é mais comum, atualmente, o acesso deles à escola.

A produção do algodão colorido no campo, até pouco tempo, atendia especialmente a demanda dos compradores da Paraíba, como o grupo COOPNATURAL, Redes Santa Luzia e Natural Cotton Collor. Entretanto, nos últimos anos, alguns agricultores, inclusive de estados vizinhos - Rio Grande do Norte, Ceará e Pernambuco estão plantando algodão para empresas de outros países, como a Fox Fibre Colorganic, da Espanha. A Fox Fibre é uma empresa Catalã que trabalha com produtos derivados do algodão colorido.

Em relação a entrada de novos compradores do algodão colorido, devemos fazer algumas reflexões. A Fox Fibre atua há 25 anos no mercado de algodão colorido 
orgânico. Essa empresa possui influência direta da pesquisadora e empresaria Sally Fox, pioneira no uso do algodão colorido orgânico e de quem compravam a matériaprima para confecção de seus produtos.

Existem alguns motivos que podem explicar o interesse dessa empresa no algodão produzido por agricultores familiares no Semiárido nordestino, tais como: o algodão colorido brasileiro possuir fibras com qualidades superiores às produzidas nos EUA; vender um produto que foi cultivado pela agricultura familiar brasileira passou a ser importante forma de marketing social, já que o consumidor final não está comprando só um produto orgânico, mas todo um modo de vida, portanto, há aí um apelo ecológico e social muito forte.

Não temos informação sobre o valor que esses empresários estão pagando aos agricultores, mas acreditamos que o valor não seja muito superior ao que é pago pelos compradores nacionais, $\mathrm{R} \$ 11,00$. A mediação para que o empresário da Fox Fibre chegasse aos agricultores brasileiros foi feita a partir COOPNATURAL, que intermediou a participação dessa empresa na Rede de Algodão Agroecológico do Semiárido.

Segundo a presidente da COOPNATURAL, essa empresa tomou conhecimento do algodão colorido brasileiro em um evento internacional de produtos ecológicos promovido pela Textile Exchange, do qual o Brasil participou. É evidente que a produção de algodão orgânico brasileiro se insere em uma lógica de mercado mundial. A rede geográfica em escala mundial é formada por ONGs que, inclusive, extrapolam os limites do território nacional. As ações dessas ONGs, por sua vez, demonstram que a produção propriamente dita possui uma base territorial, ao mesmo tempo que evidência a clara divisão territorial do trabalho.

Na Figura 38, que traz três selos de produção orgânica da Fox Fibre, a produção da matéria-prima, fiação e tecelagem, é possível identificar algumas das informações utilizadas por essa empresa para reforçar o fato de sua produção ser sustentável. Entre elas podemos destacar: o algodão ser produzido no Brasil, sem o uso de irrigação, as sementes não transgênicas, no campo não é utilizado máquinas de grande porte, é utilizado bioinseticidas, produzido de forma orgânica, pela agricultura familiar, o algodão é naturalmente colorido e é biodegradável. 


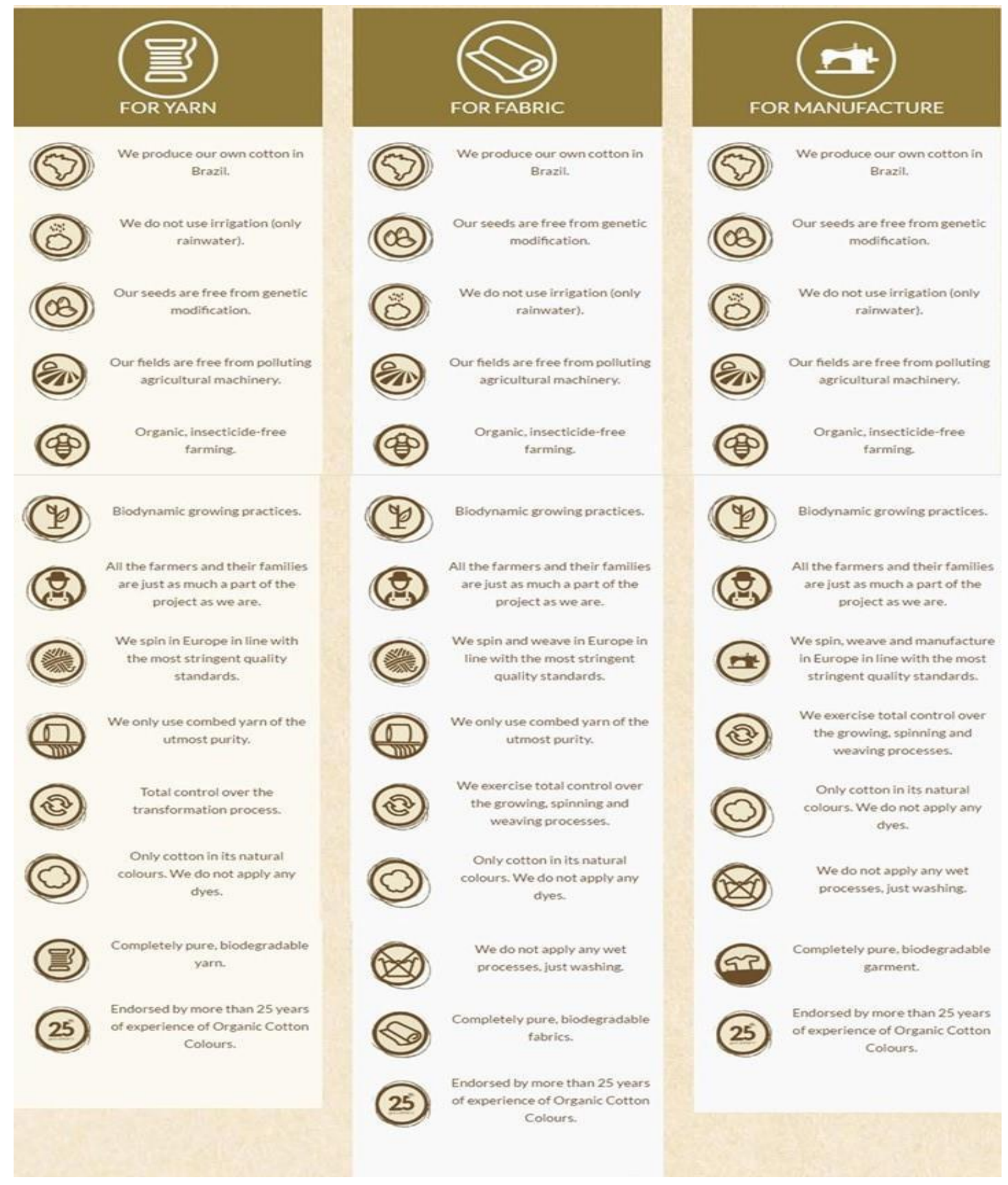

Figura 38 -Selos de produção orgânica Fox Fibre.

Fonte: Disponível em: http://www.organiccottoncolours.com/occguarantee/ Acessado em: setembro de 2016.

A exportação do algodão colorido em pluma marca novo período na sua produção, uma vez que antes só era exportado na forma de produtos acabados. A seguir vamos analisar o processo de beneficiamento. 
5.2 - O beneficiamento do algodão e as novas possibilidades para a agricultura familiar

Quando começou a produção de algodão colorido na Paraíba, por ser uma atividade nova, foi montado todo o circuito espacial de produção. Para a fase de beneficiamento do algodão colorido foi utilizada a usina de beneficiamento da CAMPAL, localizada em Patos- PB. A utilização do parque industrial da CAMPAL, no início da década de 2000, foi vivida com certa euforia, pois acreditava-se que o algodão colorido poderia alavancar a retomada da produção de algodão no estado. $O$ indício dessa expectativa pode ser constatado na frase escrita na parede da cooperativa "CAMPAL DE VOLTA AO PROGRESSO" (Figura 39). Concordamos com Santos (2008 [1985]), quando este nos diz que as rugosidades do espaço, nesse caso representado por uma forma geográfica, são reveladoras da dinâmica espacial.

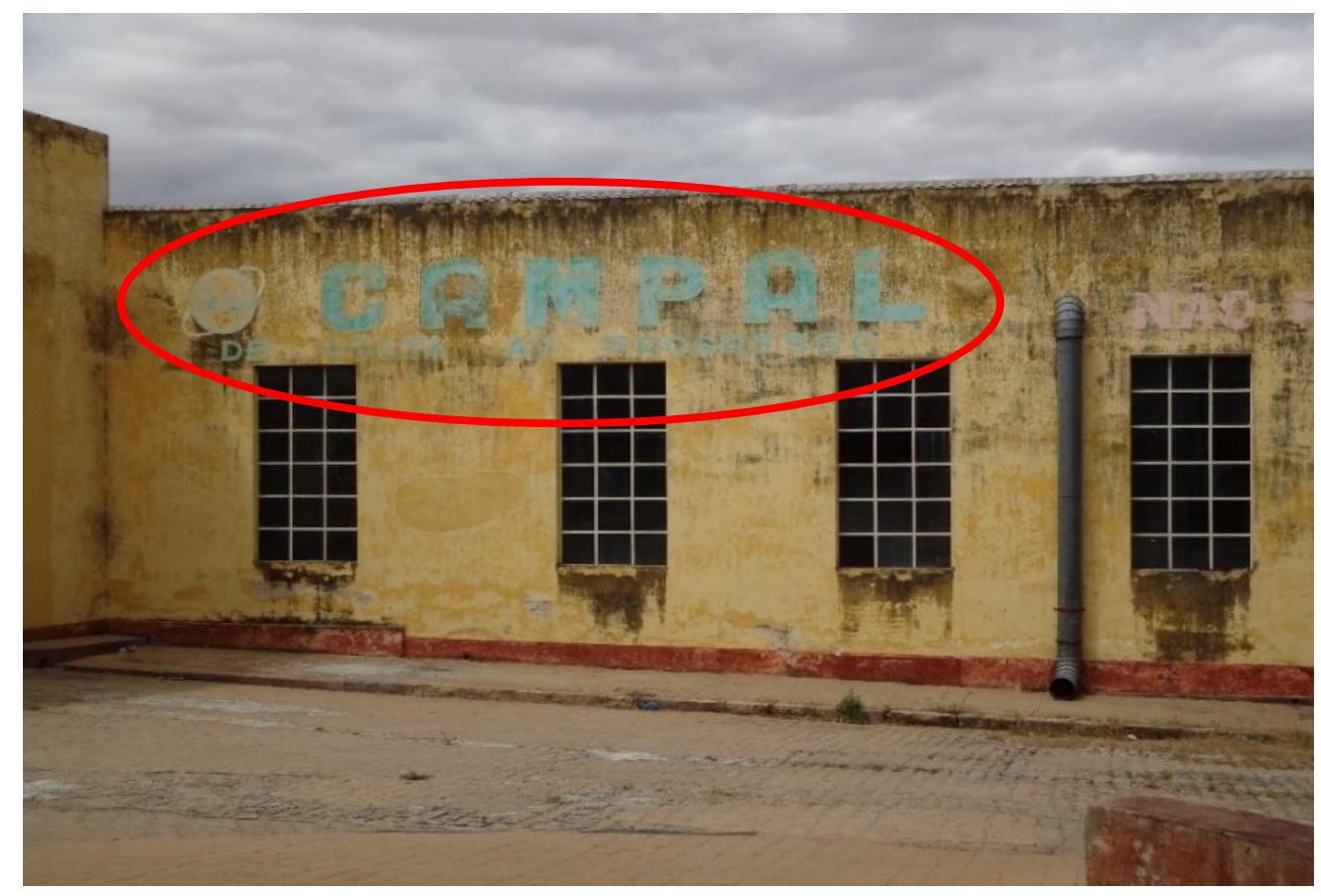

Figura 39 - Parede Interna da CAMPAL com frase alusiva ao novo " ciclo" de produção de algodão da Paraíba.

Fonte: LIRBÓRIO, L. F. 2015.

O uso da infraestrutura da CAMPAL, naquele momento, se justificava devido à grande quantidade de algodão que estava sendo plantado e que seria processado em suas instalações. Todo o algodão colorido produzido no estado da Paraíba era direcionado para essa cooperativa. Alguns motivos contribuíram para isso: os municípios que passaram a produzir algodão estavam na proximidade geográfica do 
município de Patos, onde funcionava a cooperativa; o cultivo era feito por pequenos produtores cooperados a CAMPAL; a infraestrutura da CAMPAL estava ociosa em função da crise do algodão branco; por ser algodão de fibra colorida, beneficiadoras, que também trabalham com algodão branco não têm interesse em beneficiar o algodão colorido, pois precisariam antes e depois do processo de descaroçamento limpar todos os equipamentos, evitando assim a mistura de cores.

O impacto gerado pela produção do algodão colorido foi de tamanha proporção que, conforme apresentado por Farias (2010), a cooperativa precisou mudar seu status de cooperativa regional, para cooperativa Estadual:

No ano 2000, quando agentes públicos, privados e do terceiro setor, atuando em cooperação, começaram a estruturar o circuito espacial de produção do algodão colorido, [...] necessitavam de bases espaciais e de agentes sociais para realizar o beneficiamento, foi a CAMPAL a eleita para realizar essa função. [...] a função de beneficiar o algodão colorido, obrigou-lhe, segundo o seu presidente, a mudar de categoria, ou seja, deixou de ser regional (dos produtores de Patos) para ser estadual, aberta para a associação de produtores de qualquer município do Estado (FARIAS, 2010, p. 249).

Essa cooperativa desempenhou importante função no início da formação do circuito espacial de produção de algodão colorido, atualmente não exerce mais função alguma em relação a esse produto. Em trabalho de campo realizado para conhecer as instalações da CAMPAL, em julho de 2014, deparei-me com a inatividade da usina algodoeira. Nas Figuras 40, 41 e 42 é possível ver elementos do auge e da decadência do beneficiamento do algodão por essa cooperativa.
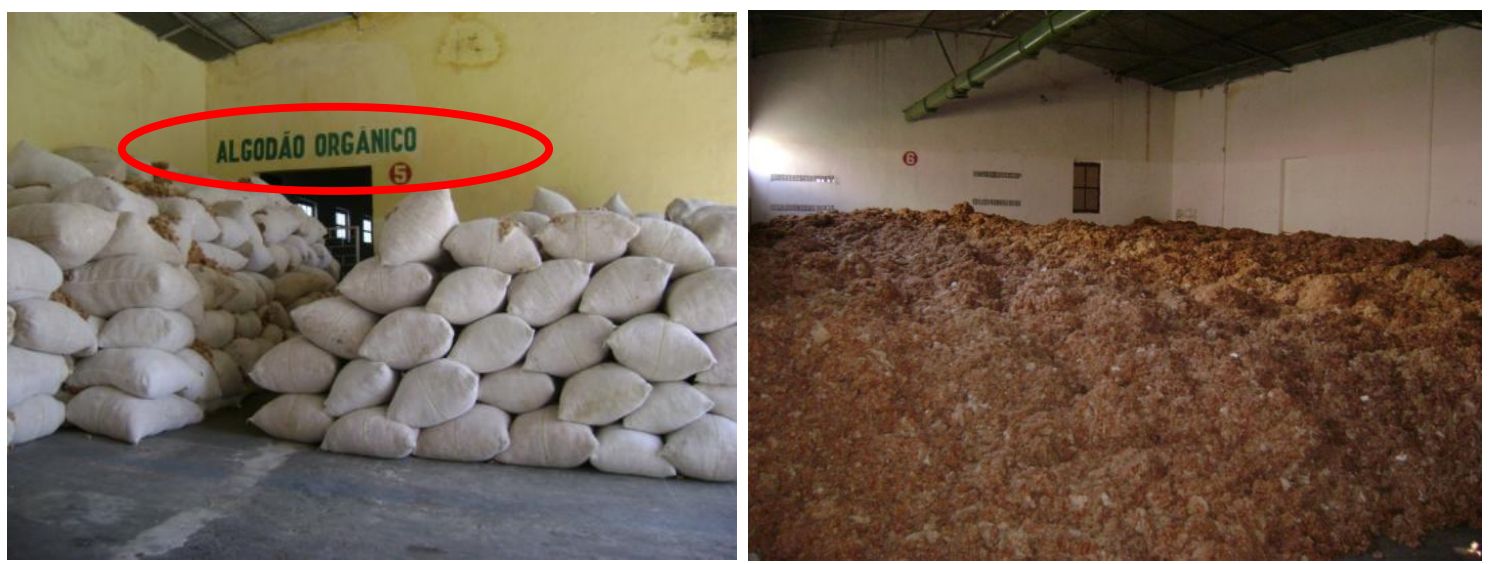

Figuras 40 e 41 - Algodão colorido no interior da CAMPAL a espera de beneficiamento Fonte: FARIAS, 2010, p. 250. 


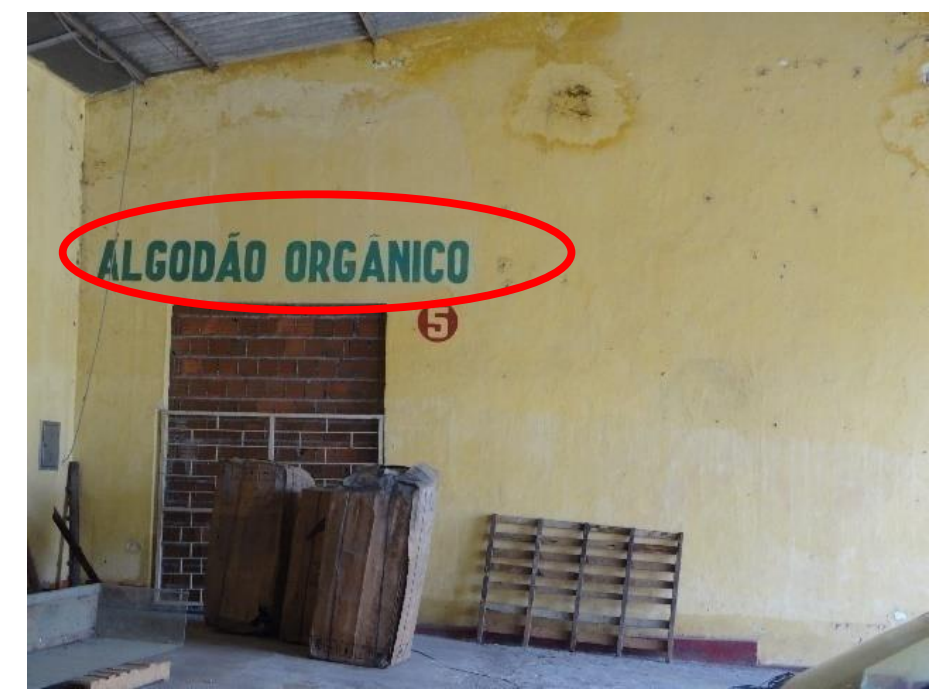

Figura 42 - Local onde antes era armazenado algodão colorido orgânico na CAMPAL, hoje inativo.

Foto: LIRBÓRIO, L.F. 2015.

Segundo o Presidente da CAMPAL na época em exercício (2015), o declínio da cooperativa e a utilização de sua infraestrutura para beneficiar o algodão colorido ocorreu devido à redução drástica das áreas de cultivo no estado. Entre os motivos apontados para o declínio na produção de algodão colorido no estado e consequente inviabilidade do uso da usina com o porte da existente na CAMPAL, de algum modo, isso foi a tentativa por parte de compradores dessa matéria prima em manter o mesmo modelo de comércio do algodão, que era praticado com o algodão branco na região, por atravessadores.

Somam-se à esta situação, embora houvesse demanda para o algodão colorido, uma grande quantidade produzida que ultrapassou as necessidades dos pequenos empresários do setor de confecção e derivados do algodão colorido. Como naquela época, a circulação da matéria prima estava limitada ao território paraibano, haja vista que os produtores locais exerciam uma espécie de monopólio sobre o produto, e geralmente, o algodão colorido em pluma não circulava fora do estado, mas somente após ser beneficiado em forma de confecção, isso agravava ainda mais os problemas. Com o algodão estocado em suas casas, os agricultores que já não contavam mais com o papel ativo da CAMPAL, viram suas produções se desvalorizarem. Assim, o algodão colorido, que tinha um valor agregado em muitos casos, chegou a ser vendido por valor muito inferior ao algodão de fibra branca. 
Por sua vez, não se pode afirmar que todo o algodão fosse comprado por intermediários, pois além da própria CAMPAL, algumas empresas que faziam uso do algodão colorido, compravam diretamente do agricultor. Mas, como não havia um contrato oficial que garantia a compra, por vezes, esse algodão também ficava estocado. Ainda sobre o papel nefasto que a figura do atravessador teve na produção do algodão colorido perante os agricultores, é verificado na fala da presidente da empresa de confecção Natural Cotton Color ao relatar as dificuldades na obtenção dessa matéria prima em $2010^{90}$ :

\begin{tabular}{l} 
Presidente da Natural Cotton Color'1 : (...) comprávamos do repassador. \\
Para nós, ainda era economicamente viável passamos a ter o controle da \\
cadeia produtiva completa na hora que se percebeu que o repassador não \\
tinha nenhum compromisso com relação a contrato de compra e venda com os \\
\hline agricultores, pagamento de preço justo a estes agricultores, estoque \\
permanente/regulador mínimo, ou seja, se tivesse um ano de seca, eles não \\
tinham estoque para o ano seguinte e chegamos a ficar quase zerados. (...) é \\
ele quem leva o lucro. Porque quando as empresas chegaram nesse ponto de \\
escassez de matéria prima surgiu a necessidade de passar a limpo a cadeia \\
produtiva, por causa de rumores do próprio repassador chegar a dizer: 'Ah, tem \\
agricultor que tá revoltado lá em Patos e quer queimar o algodão'. E eu dizia: \\
'Como assim quer queimar o algodão? Quem mandou esses agricultores \\
\hline plantar esse algodão? Por que quem mandou comprar não pagou ainda? '. \\
Então, eles sem saber, estavam se auto denunciando. E foi daí que dissemos: \\
'agora vamos trabalhar com esse plantador'.
\end{tabular}

Além dos problemas relacionados a venda do algodão, o longo período de seca pela qual vem passando a região, também foi apontado como causa para redução do plantio do algodão colorido a falta de mão de obra para trabalhar na lavoura. Ainda, em relação a mão de obra, é preciso dizer que a maioria das pessoas que plantam o algodão são os próprios agricultores familiares em suas propriedades, mais também se constata eventualmente a produção com mão de obra assalariada.

Em alguns casos, os agricultores também preferem investir em culturas mais lucrativas, como o ihame, a batata doce e até mesmo o coentro, que a depender da época, apresenta bom preço e propicia um retorno financeiro mais rápido. Diante dessa situação, o fluxo migratório de pessoas das áreas rurais para os centros urbanos e a valorização do salário mínimo desde o ano 2002 tem aumentado o custo da remuneração da mão de obra rural.

90 Entrevista realizada durante trabalho de campo em João Pessoa em 15 de julho de 2016. 
5.2.1 - O Assentamento Margarida Maria Alves: polo de produção e beneficiamento do algodão colorido da Paraíba

Como mencionado no item anterior, a redução da área plantada de algodão colorido na Paraíba retirou do circuito espacial de produção a usina de beneficiamento da CAMPAL. Destaca-se que em uma eventual expansão da cultura essa infraestrutura pode voltar a ser utilizada ${ }^{92}$.

Em substituição ao papel exercido pela CAMPAL, entra em cena o acesso a miniusina de beneficiamento de algodão, desenvolvida pela Embrapa Algodão, em parceria com a Metalúrgica Airus, de Campina Grande, o SEBRAE e o Banco do Nordeste do Brasil (BNB). A miniusina é composta por um descaroçador de 50 serras e uma prensa hidráulica para o enfardamento da fibra. Esta tem capacidade para beneficiar a produção de até 350 hectares de algodão e descaroçar até $360 \mathrm{Kg} / \mathrm{h}$. Quando foi desenvolvida e colocada no mercado em 2000 essa máquina tinha um custo de $\mathrm{R} \$ 30.000,00$ (ver Figuras 43 e 44) (SILVA, 2000).

\footnotetext{
92 Não podemos deixar de mencionar a grave crise financeira que essa cooperativa vem enfrentando. No período em que foi realizado o trabalho de campo, vários prédios que compõem o patrimônio da cooperativa estavam em processo de venda. Sem manutenção haverá também desgaste do maquinário da usina algodoeira da CAMPAL.
} 


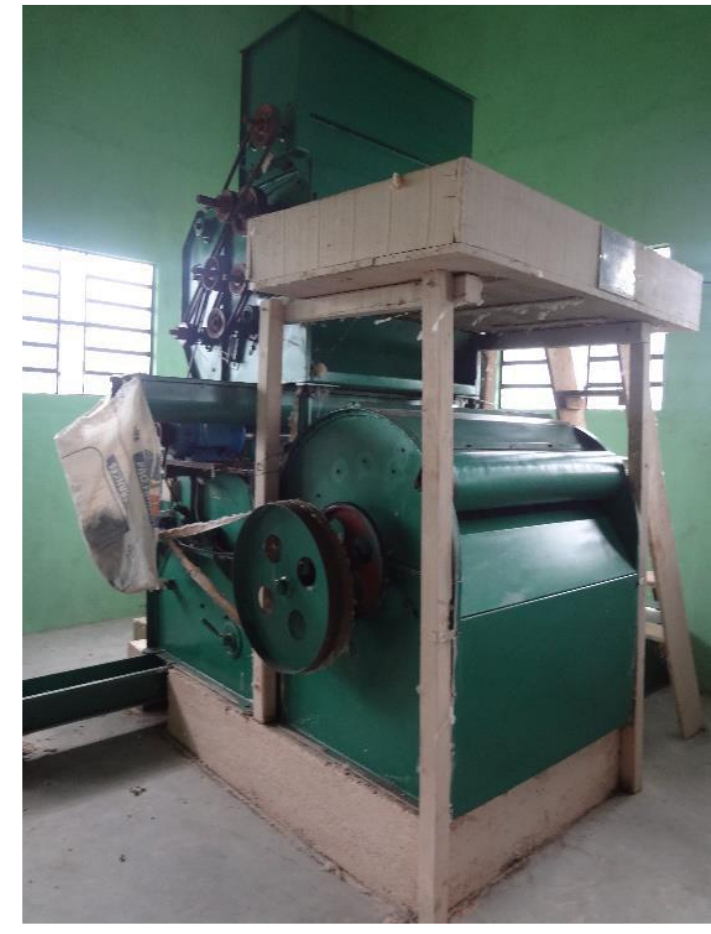

Figura 43 - Descaroçador de algodão de 50 serras.

Foto: LIRBÓRIO, F. L. 2015

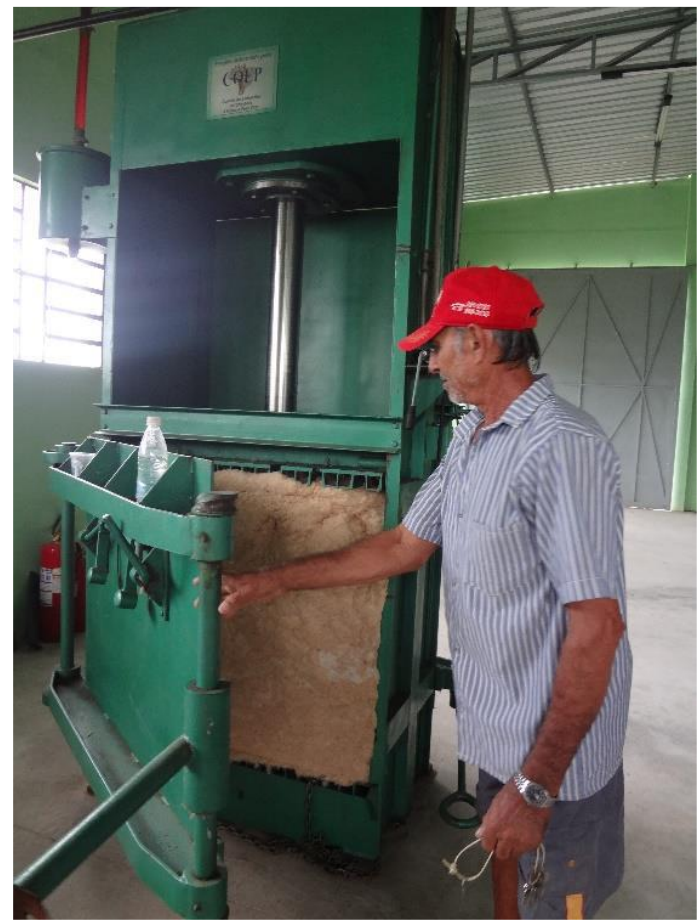

Figura 44 - Prensa hidráulica para enfardar o algodão sendo manuseada por um agricultor Foto: LIRBÓRIO, F. L. 2015

$\mathrm{Na}$ época em que a miniusina foi desenvolvida (2000), estava em curso no Nordeste do país um movimento pela retomada da produção do algodão como alternativa de renda para a agricultura familiar. A Embrapa Algodão, em parceria com outras organizações como o Comitê de Entidades no Combate à Fome e Pela Vida $(\mathrm{COEP})^{93}$, deram início ao Projeto Algodão e Cidadania. Entre as ações do COEP, que atuava na perspectiva do desenvolvimento local de 24 comunidades do Semiárido brasileiro, merece atenção a oferta de alguns equipamentos que ajudariam no desenvolvimento dessas comunidades. Para sua atuação era feito um diagnóstico da comunidade e quais as potencialidades de cada comunidade, principalmente com base nas atividades que elas já desenvolviam.

Por meio do COEP algumas comunidades foram beneficiadas com a construção de barragens subterrâneas, cisternas coletivas, instalação de telecentros de informática, sistema de criação de caprinos e ovinos, plantios de palma forrageira,

${ }_{93}$ O COEP foi criado em 1993 e teve como um de seus idealizadores o sociólogo Herbert de Souza, Betinho. O Objetivo que levou à criação dessa rede foi reunir e somar esforços na articulação e implementação de ações voltadas para combater a fome e à miséria. As ações do mesmo são desenvolvidas em parceria com diversas organizações públicas e empresas privadas, atuando nas 27 unidades da federação e em 29 municípios. 
aprisco para animais reprodutores, instalação de cisternas, através do Programa Um Milhão de Cisterna $(\mathrm{P} 1 \mathrm{MC})^{94}$, viveiro de mudas, incentivo à adoção de sementes selecionadas nas comunidades que desenvolviam a cotonicultura ou a ricinocultura (cultivo de mamona), distribuição de miniusinas para beneficiamento do algodão ou da mamona, teares elétricos de pequeno porte além de capacitações e diagnóstico dessas comunidade (COEP, 2006).

Os trabalhos do COEP no Nordeste beneficiaram seis estados: Alagoas, Ceará, Paraíba, Pernambuco, Piauí e Rio Grande do Norte. No desenvolvimento dos diagnósticos das comunidades, desenvolveu parceria com algumas universidades desses estados. Foi criado em parceria com o CNPq o Projeto Universidade Cidadã, que tinha como objetivo fazer a aproximação entre o conhecimento científico e a realidade vivida nessas comunidades.

As universidades que participaram do Projeto Universidade Cidadã no Nordeste foram: Universidade Federal do Piauí (UFPI), Universidade Federal de Sergipe (UFS), Universidade Federal do Rio Grande do Norte (UFRN), Universidade Federal de Campina Grande (UFCG), Universidade Federal Rural de Pernambuco (UFRPE) e Universidade Regional do Cariri (URCA).

Nesse contexto o assentamento de reforma agrária Margarida Maria Alves, criado em 1998, foi contemplado com uma miniusina de beneficiamento do algodão pelo COEP em parceria com a Embrapa Algodão. Percebe-se que um conjunto de ações contribuíram para a transformação do assentamento Margarida Maria Alves em um polo de produção e beneficiamento de algodão colorido, configurando uma situação geográfica.

Segundo Santos (2014[1988]), a situação geográfica pode ser entendida como o movimento das variáveis que atuam no espaço geográfico de forma que um determinado lugar está em constante processo de mudança, ou seja um lugar é resultado de um processo histórico, acumulação desigual de tempos e pode ser organizado a partir de ações locais ou externas a ele.

A configuração territorial desse assentamento começou a ser modificada a partir do ano 2000, quando por meio de dos projetos conduzidos pela COEP, o mesmo

${ }^{4}$ O P1MC é um projeto desenvolvido pela Articulação do Semiárido (ASA) iniciado em 2000 que visa assegurar água potável para um milhão de famílias do Semiárido brasileiro com vista a promover a convivência com o Semiárido. 
passou a ser beneficiado com algumas infraestruturas. No lugar onde hoje é o assentamento Margarida Maria Alves, antigamente era uma fazenda tradicional com pecuária extensiva e plantação de algodão.

A maioria das famílias hoje assentada nas terras dessa antiga fazenda é formada por ex-moradores de condição ${ }^{95} \mathrm{ou}$ meeiros ${ }^{96}$. Alguns dos assentados relataram que seus pais já moravam e trabalhavam na fazenda, como é o caso do Sr. Aluísio, que desde os sete anos de idade trabalhava com sua família na lavoura do algodão. Esses agricultores possuem longa trajetória na lavoura algodoeira, mas sempre subjugados pela estrutura fundiária do Nordeste e das relações de trabalho, Ainda sobre as relações de trabalho na agropecuária brasileira, nem mesmo a instituição de leis trabalhistas conseguiu pôr fim a exploração do trabalhador rural ${ }^{97}$.

A pessoa que dá nome a esse assentamento foi a agricultora Margarida Maria Alves, grande líder sindicalista rural na luta pelo direito à terra. Por ser uma liderança política na reinvindicação dos direitos trabalhistas e melhores condições de vida para o trabalhador do campo, a sindicalista fez grandes inimigos, principalmente os grandes proprietários de terras e usineiros, tendo sido assassinada em 1983.

Além da miniusina foi construído, no referido assentamento, um galpão com toda a estrutura necessária para armazenar e beneficiar o algodão nas condições adequadas, de forma a assegurar a boa qualidade do mesmo, conforme pode ser ilustrado no mosaico da Figura 45.

\footnotetext{
95 Como morador de condição, o morador deveria trabalhar alguns dias da semana para o dono da propriedade, conforme destacado por Andrade (2011[1963], p. 196) "morando em uma propriedade, tinha o trabalhador que dividir o seu trabalho entre o roçado próprio e o do patrão. $O$ trabalho para o patrão era, às vezes, remunerado em dinheiro, caso em que o morador necessitava pagar rendas da terra que cultivava para si em dinheiro ou com parte da produção; outras vezes ele tinha a terra para cultivar sem pagar rendas, mas obrigava-se a dar três dias de serviços gratuitos para o proprietário, estando, assim, sujeito ao 'cambão' ".

${ }^{96} \mathrm{Na}$ condição de meeiro era comum o agricultor vender a parte que the cabia na produção ao próprio dono das terras e por preços muitas vezes a baixo do mercado e total condição de subordinação.

97 A criação do Instituto do Trabalhador Rural em 1963 (Lei N. 4.914 de 2 de março de 1963) é considerado um marco na luta pelos direitos trabalhistas do trabalhador rural, embora conforme destacado por Prado Junior (2007 [1979]) o mesmo possua muitos problemas, como por exemplo não ter tratado com mais atenção as especificidades e complexas relações de trabalho existente na agropecuária brasileira, e com poucas mudanças apenas ter estendido os direitos dos trabalhadores urbanos para o trabalhador do campo.
} 


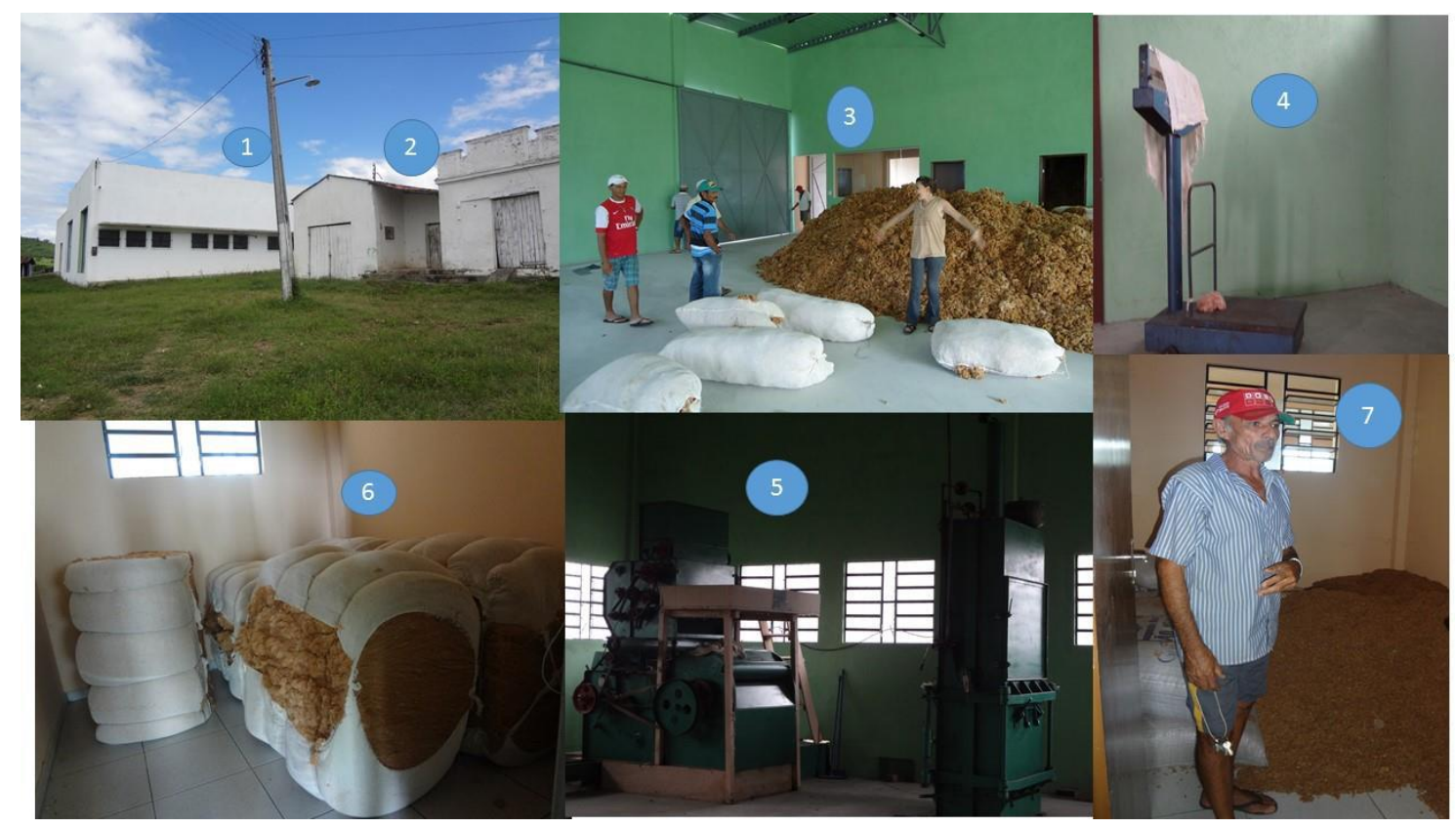

Figura 45 - Miniusina de beneficiamento de algodão do assentamento Margarida Maria Alves 1 - Forma geográfica que abriga a mini usina de beneficiamento de algodão; 2 - Forma geográfica do antigo local onde era armazenado o algodão branco; 3 - algodão em caroço para ser beneficiado; 4 - balança; 5 - Mini usina; 6 - Fardos de Algodão Rubi; 7 - Agricultor mostrando o local onde ficam armazenado as sementes.

Fotos 1, 4,6,5: LIRBÓRIO, L. F. 2015. Foto 7: LIRBÓRIO, L. F.2014. Foto 3 - Natural Cotton Color.

A instalação da miniusina de beneficiamento de algodão, pode ser considerado um evento portador de mudança para os agricultores desse assentamento rural e uma inovação para a produção algodoeira pela agricultura familiar no nordeste Semiárido, onde os recursos e políticas públicas eficientes disponíveis para essa parcela da população são muito escassos.

Silva,. et al (2000, p. 4) destacam que como se trata de uma tecnologia que beneficia o pequeno produtor, sendo também uma possível concorrente com as grandes usinas algodoeiras que antes obtinham grande lucro com a compra do algodão em caroço, é possível que na hora da comercialização da pluma, os agricultores tenham problemas para comercializar com as indústrias e por isso, recomendam que sejam tomadas as medias para assegurar a venda da produção, como pode ser constatado a seguir:

Como é um sistema novo que beneficia diretamente os produtores, as usinas de beneficiamento de não têm interesse no desenvolvimento nem na consolidação desse processo, uma vez que se trata de um concorrente direto podendo, portanto, as usinas criarem barreiras para o comércio da pluma; por isto, recomenda-se fazer um estudo prévio sobre a comercialização dos fardos junto à indústria têxtil, inclusive, se possível, um pré-contrato de compra e venda (SILVA, et al., 2000). 
Os autores citados estão considerando o uso dessa tecnologia para toda a produção de algodão produzido pelos pequenos produtores, seja o branco convencional ou o orgânico, ou ainda, o algodão colorido. Por sua vez, como a produção de algodão orgânico ainda é limitada, as grandes usinas algodoeiras não têm interesse em beneficiá-lo, sobretudo, o algodão de fibra colorida.

Mesmo sendo uma iniciativa inovadora, o número de miniusinas na região ainda é muito pequeno. Na Paraíba, além do assentamento Margarida Maria Alves, tem na outra comunidade de Lagoa de Dentro, localizada no município de São José de Piranhas. Além da Paraíba, os outros municípios dos estados nordestinos contemplados pelo COEP com a miniusina são: Água Branca - AL (comunidade Quixabeira), Surubim - PE (comunidade Furnas) e Nova Cruz - RN (comunidade José Rodrigues Sobrinho) (COEP, 2006).

Além da miniusina de 50 serras, foi desenvolvida outra miniusina móvel de 20 serras, com capacidade para beneficiar até 3 toneladas de algodão por dia. A miniusina de 20 serras é recomendada para grupos de até 10 produtores e artesãos que trabalham com o algodão colorido. A miniusina de 20 serras foi desenvolvida pela Empresa Metalúrgica Barros (antiga Aírus) em parceria com a Embrapa Algodão (ver Figura 46) (QUEIROGA; CARVALHO; CARDOSO, 2008). 

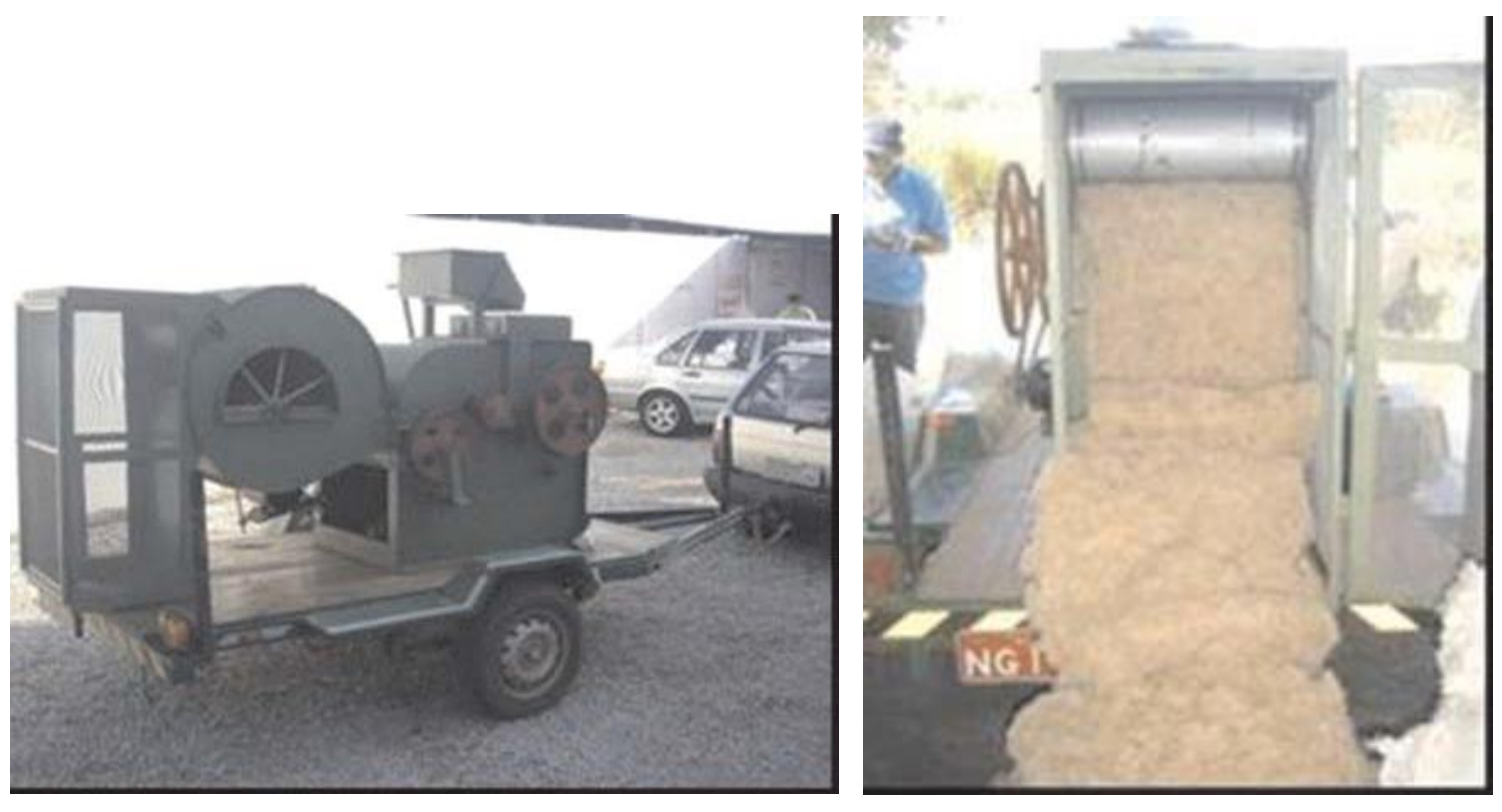

Foto 46 - Miniusina de beneficiamento de algodão móvel de 20 serras.

Fonte: QUEIROGA, CARVALHO, CARDOSO, 2008, p. 38.

Queiroga, Jeronimo e Meleán (2010), já alertavam para as vantagens que o uso da miniusina proporcionaria na geração de renda para a agricultura familiar, pois ao invés de os agricultores venderem o algodão em rama para a CAMPAL, que ficava com parte significativa dos lucros, esses agricultores agora poderiam vender a pluma diretamente para indústria. Como veremos no próximo item desse capítulo, a pluma é vendida a associações representantes das empresas do setor de confecção que as repassam para as indústrias têxteis.

No nordeste do Brasil, é característico o perfil de pequenas propriedades gerenciadas por agricultores familiares realizarem a tradicional venda direta do algodão em rama para as usinas beneficiadoras, como a CAMPAL. Após o beneficiamento, geralmente a fibra é comercializada para a cooperativa COOPNATURAL de Campina Grande e a semente para o mercado especifico, ficando a CAMPAL intermediando o beneficiamento e participando com uma fatia significativa do lucro da operação. A comunidade de pequenos produtores familiares dispondo de mini-usina com capacidade de beneficiar à própria produção é possível agregar maior rentabilidade em favor dessas famílias, por vender as fibras e os subprodutos sem intermediário. (QUEIROGA; JERONIMO; MELEÁN, 2010, p. 303).

A miniusina do Assentamento Margarida Alves passou a ser a principal unidade de beneficiamento do algodão colorido a partir de 2009, mas desde o ano 2002, quando a infraestrutura do galpão foi concluída, que o beneficiamento da produção desse assentamento é realizado nessa estrutura. Em 2000, quando o COEP começou 
seu projeto no referido assentamento, a produção de algodão da comunidade já era de 30 toneladas/ano. O sistema de cultivo era o convencional e o algodão produzido era o arbóreo de ciclo produtivo semi precoce de fibra branca (COEP, 2006).

Com o início do plantio de algodão colorido da região e a partir do Projeto Algodão e Cidadania conduzido pela Embrapa Algodão em parceria com o COEP, teve início nesse assentamento a produção de algodão colorido. Os agricultores relatam que nunca antes tinham ouvido falar em algodão colorido, embora também afirmem terem lembrança de arrancar do meio das plantações de algodão branco, plantas com algodão colorido que eles chamavam de algodão mocó, em referência à cor do animal mocó que também é o nome da principal variedade de algodão arbóreo já cultivado no Nordeste.

Um grupo de 15 famílias aderiu a produção do algodão colorido, a média de hectares cultivadas por esses agricultores era de 2 ha, na produção eram utilizado insumos industrializados (inseticidas), para combater o bicudo, o regime de cultivo é o de sequeiro. Toda a produção do assentamento era vendida em pluma para a COOPNATURAL e não havia contrato de compra entre essa empresa e os agricultores.

O grande diferencial para a produção do assentamento, veio com a introdução do cultivo de algodão orgânico a partir de $2009^{98}$. Com acompanhamento sistemático dos técnicos da Embrapa Algodão e da EMATER-PB os agricultores aprenderam formas de combater o bicudo sem o uso de venenos. Além do conhecimento técnico científico oferecido pela assistência técnica, que afirmo ser condição fundamental para o atual quadro de desenvolvimento dessa cultura no caso em questão, os próprios agricultores também contribuíram muito com sua experiência para melhorar a produção.

Foi por meio de observação dos agricultores assentados, por exemplo, que se verificou que quanto maior for o espaço entre uma fileira e outra, menor é a incidência da praga do bicudo. Observou-se que, em um clima muito seco, quando uma maçã

\footnotetext{
${ }^{98}$ A transição para a produção orgânica nesse assentamento tem início em 2006. O período mínimo para que uma área que plantava no sistema convencional ser orgânica é de três anos, até completar esses três anos é chamada agricultura de transição. Vale destacar que como a produção desse assentamento era destinada a COOPNATURAL que teve seu primeiro campo de cultivo orgânico em 2007 as áreas que plantavam algodão para essa empresa começaram sistematicamente a produzir de forma orgânica.
} 
ou botão floral cai no chão, uma elevada temperatura do solo e o distanciamento maior das fileiras, há a criação de um microclima que não é favorável a proliferação desse inseto. A partir de então, os agricultores passaram a plantar em espaçamento maior do que o recomendado pela Embrapa Algodão que é de 1,10 X 0,40 m (ver Figura 47).

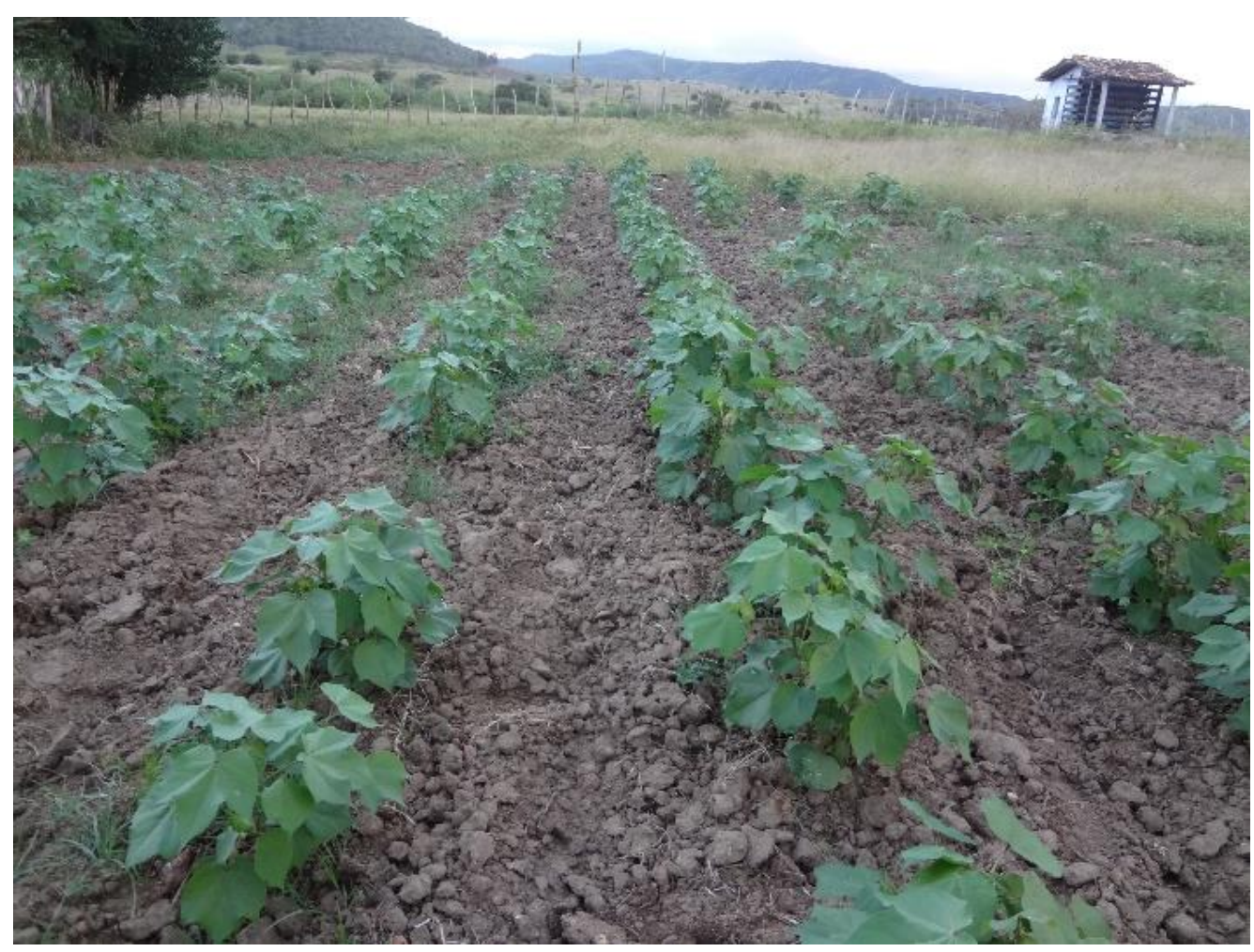

Figura 47 - Espaçamento entre as fileiras de algodão colorido - Assentamento Margarida Maria Alves - Juarez Távora-PB.

Foto: LIRBÓRIO, L.F. 2016.

Além do aumento do espaçamento, os agricultores perceberam que quanto mais tarde plantassem o algodão, menor será as possibilidades de infestação do bicudo. Assim, ao invés de plantarem nas primeiras chuvas em março ou abril, passaram a plantar no final de maio início de junho, alterando seu calendário agrícola. Desta forma as cultivares possuem ciclo de 120-140 dias e a floração começa por volta dos 90 dias, se eles plantassem nas primeiras chuvas, a floração começaria em junho, que é um mês mais chuvoso na região e, como o bicudo gosta de ambiente mais úmido, teria mais chances de sobreviver. 
Os agricultores também passaram a plantar todos em uma mesma época. No assentamento há um trator que foi doado pela prefeitura de Juarez Távora-PB, que eventualmente eles utilizam para gradear a terra. Os instrumentos de trabalho mais utilizados pelos agricultores são a enxada e o arado movido à tração animal, geralmente o boi. Há agricultores que plantam o algodão consorciado com outras culturas e outros que preferem plantá-lo "solteiro".

É muito comum no assentamento práticas de trabalho solidário, como trocas de dias de trabalho que pode ser chamada de "ajutório", e o mutirão. O mutirão é mais comum no período da colheita do algodão que é feita manualmente (Figura 48).

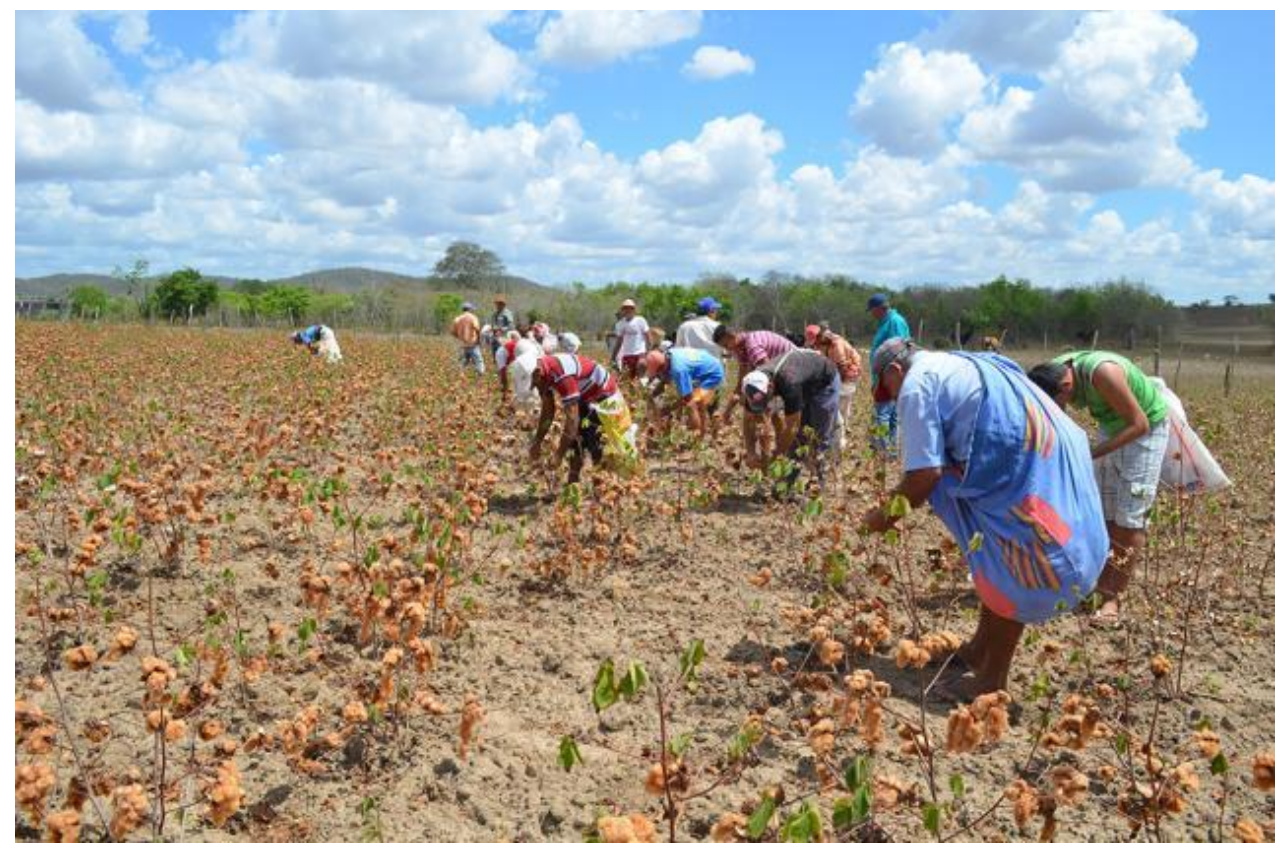

Figura 48 - Mutirão para colheita do algodão colorido no assentamento Margarida Maria Alves - Juarez Távora-PB.

Fonte: Embrapa Algodão - Disponível em:

< https://www.embrapa.br/image/journal/article?img_id=10524536\&t=1457529989897> Acessado em: março de 2016.

No beneficiamento do algodão também os agricultores se ajudam. Para operacionalização da miniusina, um grupo de agricultores foram capacitados, assim também os próprios agricultores operam os equipamentos. Em média são necessários 5 agricultores para o processo de beneficiamento. Pelo uso da miniusina, os agricultores pagam uma taxa à associação dos agricultores desse assentamento. $O$ valor adquirido com o pagamento das taxas de uso da miniusina é utilizado para pagar os custos com energia e manutenção das máquinas ou ainda alguma necessidade 
comum aos associados. Os fardos de algodão têm em média $120 \mathrm{~kg}$ e a produção de cada agricultor é identificada pelo nome do agricultor e peso do fardo (ver Figura 49).

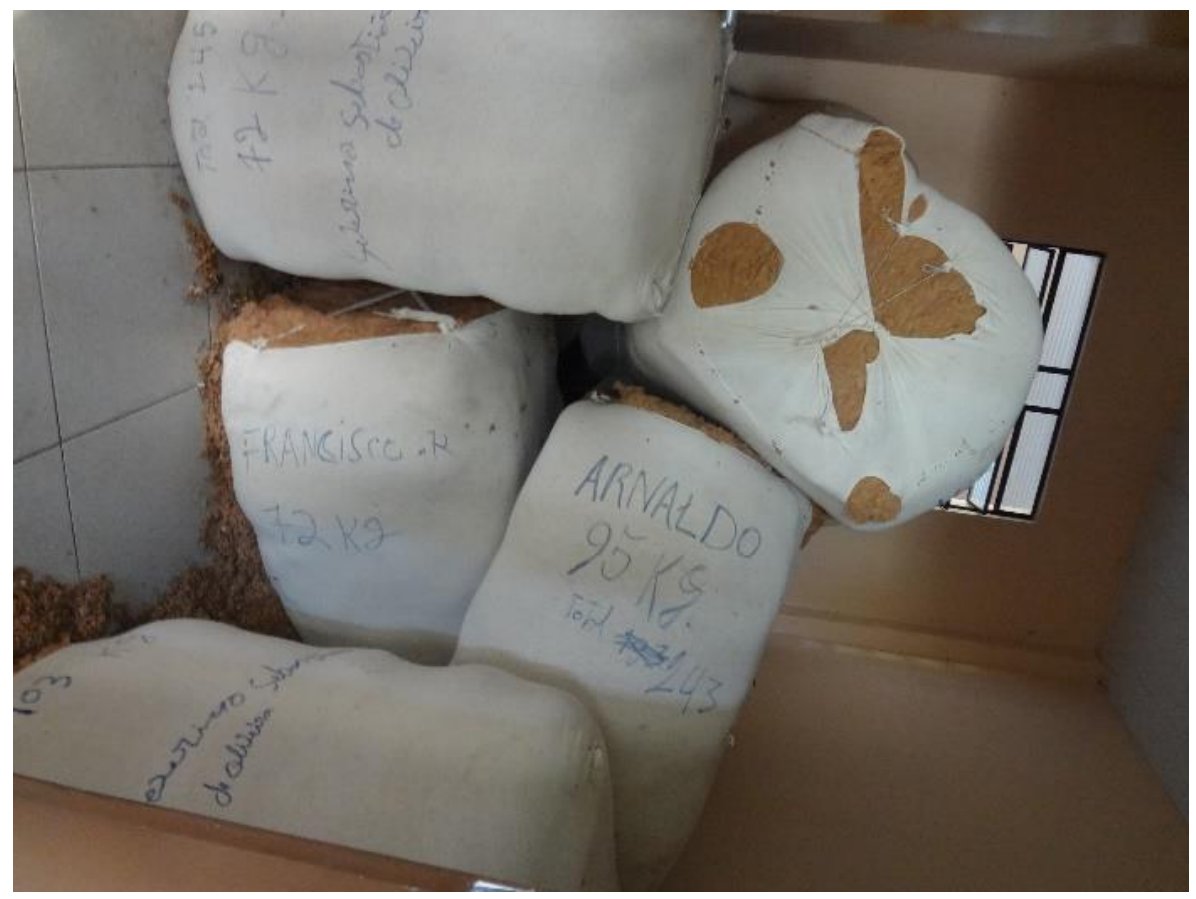

Figura 49 -Fardos de Algodão colorido Foto: LIRBÓRIO, L.F. 2016.

Atualmente, a miniusina do assentamento beneficia algodão de outras comunidades produtoras no estado da Paraíba, bem como de outros estados. O algodão colorido ou branco orgânico é levado para esse assentamento pelas empresas que compram o algodão. Estas empresas, ou agricultores, também pagam para beneficiar o algodão. A semente ou o caroço são devolvidos para os agricultores que podem utilizar na próxima safra, vender para extração de óleo e as cascas podem ser utilizadas da ração dos animais.

Há em torno da miniusina desse assentamento certa polarização devido à falta de outras unidades e pelo fato de que a mesma se enquadra nos padrões exigidos pelas normas de certificação de orgânico. A relativa proximidade do mesmo em relação aos principais polos de confecção de roupas e derivados desse algodão, Campina Grande e João Pessoa também contribui. O sucesso do assentamento também está no fato de que os agricultores possuem um espirito de associativismo muito forte e, em parte, potencializado pela própria cultura do algodão colorido. 
Além das produções individuais nesse assentamento, há um campo de multiplicação de sementes de algodão colorido, as quais são produzidas de acordo com as normas de produção de sementes exigidas pelo MAPA e supervisionado por técnicos da Embrapa SNT. O referido campo de multiplicação está instalado na área coletiva do assentamento e todos os assentados, mesmo os que não produzem algodão, trabalham nesse campo. O dinheiro obtido com a venda das sementes e da pluma do campo de sementes é direcionado para a associação e utilizado de acordo com as necessidades dos assentados, deliberado em assembleias.

Nos quatro últimos anos, a média de área plantada com o algodão colorido nesse assentamento tem sido de 22 ha, com um rendimento de aproximadamente 22 toneladas de algodão em caroço. Após ser beneficiado $1.000 \mathrm{~kg}$ de algodão em caroço, se obtém cerca de $600 \mathrm{~kg}$ de sementes, $40 \mathrm{~kg}$ de impurezas (folhas, galhos, ramas, pedras, areia e perda de umidade) e $360 \mathrm{~kg}$ de pluma. Assim dessas 22 toneladas em algodão em rama se obtém aproximadamente 8 toneladas de pluma ${ }^{99}$.

Atualmente (2016) o quilo da pluma de algodão colorido orgânico certificado é vendido por $R \$ 12,00$, o que gera uma renda total de $R \$ 95.040,00$. A distribuição desse valor entre os agricultores é feita de acordo com suas respectivas produções. Considerando que pelo menos 16 famílias plantam algodão e que cada uma produz meia tonelada de pluma, as mesmas recebem aproximadamente $R \$ 5.000 .00$ ao final do ciclo de produção. Isso é uma projeção caso todos plantassem e obtivessem os mesmos resultados, no entanto, na prática esses valores variam de família para família considerando que nem sempre o resultado da colheita é padrão.

Como é o caso de um agricultor, o Sr. Aloísio, que já chegou a plantar com sua família 7 ha. Além de possuir a maior área plantada com essa cultura do assentamento, tem por prática acumular o esterco do gado que ele utiliza para adubar o solo. Como resultado, a produtividade de sua plantação é maior.

Tomamos por referência os custos de produção ${ }^{100}$ do algodão colorido, de acordo com o levantamento realizado pela CONAB em parceira com a Embrapa Algodão (SEBRAE, 2015), que considerou que para cada 1 ha são necessários 2

\footnotetext{
${ }^{99} \mathrm{Para}$ indicação das quantidades citadas tomamos por base o estudo de Queiroga, Jerônimo, Meléan, 2010, p.302.

${ }^{100}$ As variáveis que definem o custo de produção são muito mais complexas, por exemplo incluir o custo da renda da terra, custo dos equipamentos agrícolas etc., fatores que não foram aqui considerados para fins desse estudo.
} 
trabalhadores, o valor do custo de produção foi calculado com base no total de meses dedicados a cultura (5 meses) para se chegar ao valor de quanto o agricultor receberia por dia. Para isso, foi calculado o valor do quilo da pluma de algodão colorido orgânico certificado e o valor do quilo da semente. Embora nem todas as sementes sejam vendidas, já que uma parte serve para plantio nas próximas safas e outra parte é destinada à ração animal, para concluir o raciocínio vamos incluí-las em nossa estimativa.

Nossos cálculos têm por base a estimativa da produção de algodão colorido do assentamento apresentado anteriormente ( 22 ha plantada, uma produção total de aproximadamente 22 toneladas de algodão em rama, que gera $7.920 \mathrm{~kg}$ de pluma e $13.200 \mathrm{~kg}$ de sementes), a pluma é vendida a $R \$ 12,00$ e a semente a $R \$ 1,04 \mathrm{Kg}^{101}$, como resultado, o agricultor recebe aproximadamente $\mathrm{R} \$ 17,00$ por dia de trabalho. Contudo, o valor da diária do atual salário mínimo $(R \$ 860,00)^{102}$ é de $R \$ 29,00$, ou seja, esse agricultor ainda continua ganhando menos que o mínimo estabelecido por lei. Ainda assim para esses agricultores essa renda é muito importante, já que a maioria dos outros produtos de suas propriedades familiares são para autoconsumo e com o algodão eles conseguem obter dinheiro.

Percebe-se que, embora o agricultor tenha a certeza de que seu produto tem garantia de compra e para eles essa renda tenha um grande significado, os mesmos recebem valor inferior ao seu trabalho. Por sua vez, não se pode ignorar o conjunto de ações empreendidas por um grupo de pesquisadores da Embrapa Algodão, sobretudo, em sua atuação no Comitê Gestor do Algodão, para que o preço pago pelo quilo da pluma do algodão ao final do processo corresponda, no mínimo, ao valor do salário mínimo.

Analisamos que, mesmo que essa tecnologia social seja portadora de inovação, percebe-se que ainda há um longo caminho a ser percorrido. Ainda em relação ao êxito na forma de produção alcançada pelos agricultores do assentamento Margarida Maria Alves, há em torno dele um efeito de demonstração para outras comunidades, já que o mesmo é frequentemente visitado por diversos grupos de agricultores, pesquisadores, empresários interessados no resultado desse trabalho.

101 Esse era o valor da semente na época do levantamento feito pela Embrapa Algodão e CONAB, mantivemos para fins desse cálculo os mesmos valores.

102 Valor do salário mínimo no ano de 2016. 
5.3 - O fio e as tramas do algodão naturalmente colorido

Como já explicitado, o algodão colorido, no atual período histórico, é uma inovação, transformado a partir do conhecimento científico e tecnológico em produto que atende as exigências técnicas de produção. As características naturais do algodão silvestre era um obstáculo a seu uso em escala industrial, bem como a limitação de cores e o interesse do mercado pelo algodão branco. Mesmo que se tenha chegado a outro padrão tecnológico e os derivados desse tipo de fibra apresentem demanda crescente no mercado, o mesmo ainda enfrenta algumas limitações.

No caso especifico da industrialização do algodão colorido no Nordeste, que consiste na fiação e tecelagem, fase em que são produzidos o fio e os tecidos, ainda há muitas dificuldades. Como se trata de pequenas quantidades de algodão produzido, as indústrias têxteis têm restrições para beneficiar as pequenas produções, pois por se tratar de fibra colorida é necessário a limpeza das peças antes e depois do processamento como forma de evitar contaminação do algodão colorido com o branco e vice-versa.

De acordo com as duas principais organizações que atuam na produção e comercialização de roupas feitas com o algodão colorido, a COOPNATURAL e o grupo Natural Cotton Color ${ }^{103}$, para que o algodão seja industrializado, elas precisam pagar de duas a três vezes o valor do que seria cobrado para produzir o fio ou tecido com algodão branco, conforme pode ser constatado nos relatos a seguir:

\footnotetext{
Presidente da Natural Cotton Color ${ }^{104}$ : Enquanto a gente paga o dobro do preço ao agricultor, o maquinista, o dono da fiação ele nos cobra três vezes o valor que ele usa porque é um produto específico, então, é como se fosse um favor que ele está fazendo à gente. A tecelagem é a mesma coisa: duas, três vezes a mais o valor do preço do serviço (Presidente da COOPNATURAL).

Hoje a gente comprando direto do agricultor, pagando o preço da fiação quase triplicado (em relação ao preço do algodão comum) - porque as fiações são muito grandes e a produção nossa é muita pequena, então para eles pararem o filatório, tenho que pagar mais caro a tecelagem, pelo menos o dobro
}

\footnotetext{
${ }^{103}$ Nossa menção a esses dois grupos de deve ao fato de que os mesmos controlam a cadeia de produção do campo à indústria. Os artesões que também fazem uso do algodão colorido, apenas compram o tecido pronto.

${ }^{104}$ Entrevista realizada em 15 de julho de 2016, em João Pessoa.
} 
Como já salientamos a produção de algodão colorido é pequena, e não compromete a produção dos produtos finais no que diz respeito a quantidade necessária para as suas produções. Para que o algodão seja fiado é preciso que haja um acúmulo de algodão, do contrário, os custos de produção não compensam. Além do acúmulo da pluma, às vezes, para produzir o tecido, os empresários precisam estocar os fios para ter quantidade suficiente de produção dos tecidos.

Afora essas ações, os empresários precisaram inovar no desenvolvimento de tecidos, empregando outras matérias primas orgânicas, como a seda, e o algodão branco orgânico. Essa atitude por um lado, diminui o problema da reduzida quantidade de matéria prima, e acaba dando maiores possibilidades dos empresários criarem suas coleções, pois por possuir poucas cores, a mistura entre as cores existentes proporciona novas tonalidades. Por outro lado, o aumento do uso do algodão banco orgânico, também acaba sendo uma forma de baratear os custos de produção, já que mesmo o algodão branco orgânico tem preço mais alto que o algodão convencional, além disso e mais barato que o algodão colorido.

Atualmente, a pluma do algodão colorido chega até as indústrias de fiação e tecelagem via representações dos empresários. Em Campina Grande, onde está localizada a COOPNATURAL, desde o início a compra do algodão é feita por essa cooperativa que distribui para as indústrias têxteis de acordo com o tipo de tecido que queiram produzir.

Segundo a presidente da COOPNATURAL, atualmente, a cooperativa está trabalhando com estoques de tecidos produzidos com algodão de outras safras. Além da COOPNATURAL, na primeira fase de produção do algodão colorido que se deu com certa euforia, por ser produto novo no mercado e com grande apelo ecológico e social por ser desenvolvido pela agricultura familiar, como já analisado os agricultores não se beneficiaram como esperado. Outro ator que teve importância significativa na compra da pluma e transformação em fios foi o presidente da CAMPAL (2004 - 2008), proprietário da Evetest Têxtil, que faz fios de algodão. O mesmo foi ainda o primeiro presidente da ONG Credação, que fazia parte da estrutura da AMDE, responsável pela concessão de empréstimos para as empresas de confecção. Foi via essa ONG que as primeiras sementes de algodão chegaram aos agricultores na forma de 
empréstimo. O referido empresário, em 2009 quando foi criada a Associação Paraibana de Produtores de Algodão da Paraíba ${ }^{105}$ (APPAB), foi eleito seu presidente.

Em João Pessoa onde está localizado a outra principal organização do setor, o grupo Natural Cotton Color que passou a fazer parte do circuito espacial de produção de produção de confecção e afins do algodão colorido, a partir de 2003, compravam a matéria prima de atravessadores ${ }^{106}$. Só a partir de 2010 , quando houve redução drástica de oferta de algodão colorido, foi que a Natural Cotton Color estabeleceu contato diretamente com os agricultores e assim passou a ter controle do circuito da fase de produção no campo até a comercialização final do produto. A compra do algodão por esse grupo atualmente tem sido feita através da AIVEST.

Por conta das especificidades apontadas em relação ao algodão colorido, verificou-se que o seu processamento industrial possui algumas dinâmicas particulares. Por não ser um produto comum demanda infraestruturas de produção diferenciada. Em 2000, quando a COOPNATURAL levou para a FENIT as primeiras peças feitas com algodão colorido, a fiação foi feita na EMBRATEX, unidade industrial da COTEMINAS em Campina Grande ${ }^{107}$.

Na Figura 50 a seguir há uma das peças expostas na FENIT, o primeiro vestido de noiva do país feito em algodão colorido. O momento registrado na figura abaixo ocorreu em 2010, quando o SEBRAE Paraíba, participou da Bienal Brasileira de Design, que teve como tema "Design, inovação e sustentabilidade".

${ }^{105}$ A APAPB foi criada através de incentivo da Embrapa Algodão, como forma de os atores que participavam do circuito de produção do algodão na Paraíba (agricultores, indústria, Centros de Pesquisa, Extensão Rural e empresários) se integrassem de forma a fortalecer o setor, contudo ao que parece essa Associação não despontou. Essa Associação foi criada nos moldes de outras associações estaduais de produtores de algodão no Brasil, tais como: Associação Baiana de Produtores de Algodão (ABAPA), Associação Maranhense de Produtores de Algodão (AMAPA), Associação Sul-Mato Grossense de Produtores de Algodão ( AMPASUL), Associação Piauiense de Produtores de Algodão ( APIPA), Associação dos Cotonicultores Paraense ( ACOPAR), Associação Mineira dos Produtores de Algodão (AMIPA), Associação Goiana dos Produtores de Algodão (AGOPA), Associação Matrogrossense dos Produtores de Algodão (AMPA), Associação Paulista dos Produtores de Algodão (APPA).

${ }^{106}$ Como compravam de atravessadores esse algodão não podia ser certificado, pois nas certificações da agricultura orgânica, a produção é certificada no campo. Assim o grupo apenas utilizava o algodão colorido como diferencial, mas não podia vende-lo como orgânico, talvez esteja aí, também uma explicação para que esse grupo procurasse ter o controle da cadeia desde a mateira prima.

${ }^{107} \mathrm{~A}$ COTEMINAS é uma das maiores indústrias têxteis do país, pertencente à família do ex-presidente da república Jose de Alencar. 


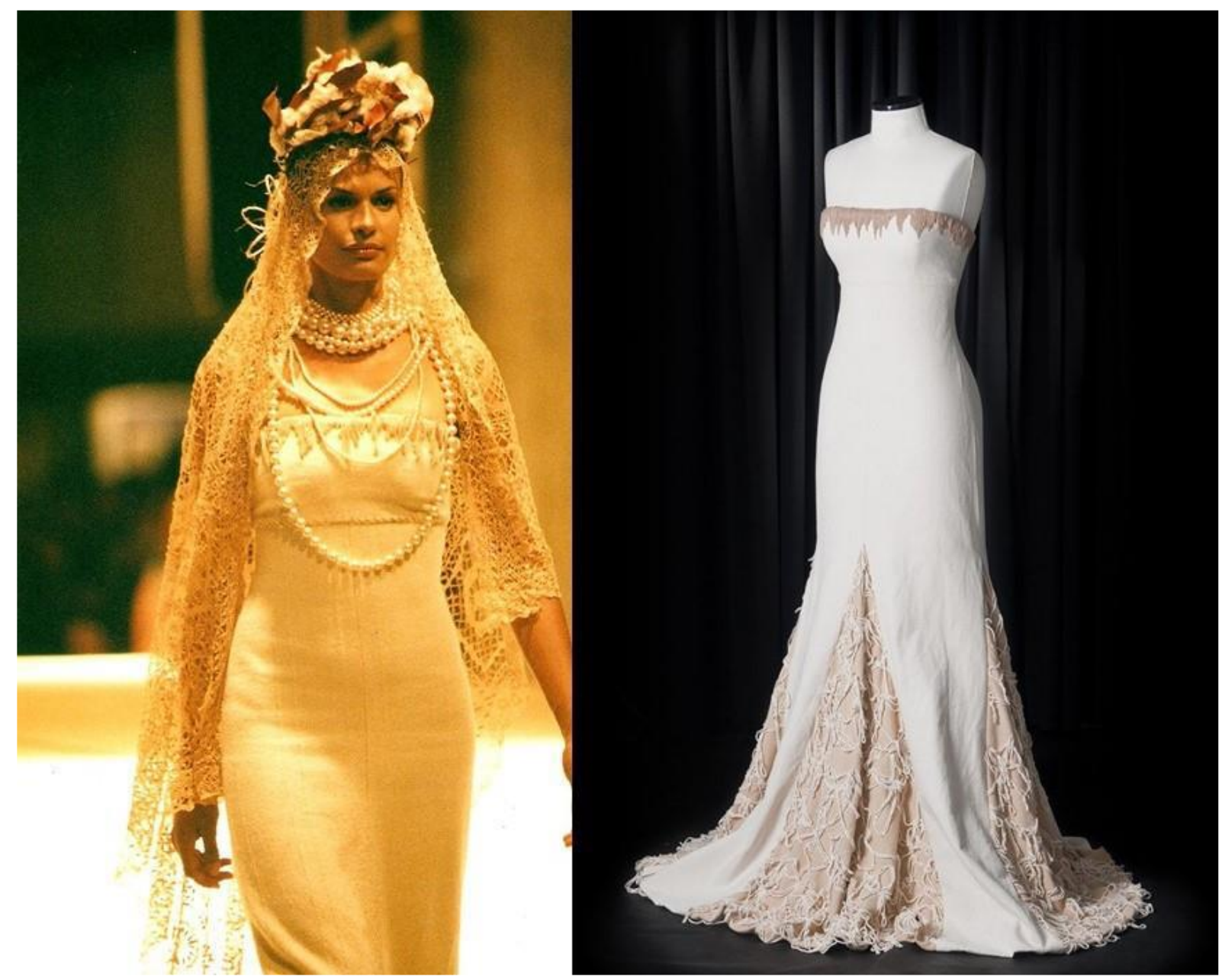

Figura 50 - Primeiro vestido de algodão colorido natural feito no Brasil na Bienal Brasileira de Desing

Fonte: Disponível em http://lounge.obviousmag.org/meus sete instrumentos/2015/03/oalgodao-que-ja-nasce-colorido---design-e-artesanato.html

Acessado em: setembro de 2016.

A EMBRATEX só participou da industrialização do algodão colorido naquele momento. $O$ beneficiamento nessa unidade provavelmente aconteceu a partir de mediação da Embrapa Algodão, que também encontrou na FENIT, a possibilidade de divulgação da tecnologia do algodão colorido. Como a FENIT é a maior feira do setor têxtil e de confecções, esta foi a oportunidade para que essa novidade, em termos de matéria prima têxtil, alcançasse outros patamares. A própria Embrapa Algodão havia realizado os testes de desempenho industrial do algodão colorido nessa indústria conforme destacado por Freire (1999, p. 38-39):

Neste ano de 1999, estão sendo efetuados testes de desempenho industrial do algodão colorido na indústria EMBRATEX; do Grupo Coteminas, sediada em Campina Grande, na Paraíba. Para isso, foram fornecidos dois fardos de pluma, os quais estão sendo processados em equipamentos industriais de 
série para produção de fio de título Nec 25,25; confecção de malha e de camisetas. A produção industrial do fio colorido na fiação da EMBRATEX apresentou resultados considerados satisfatórios pelos engenheiros têxteis da empresa (Freire, 1999, p. 38-39).

Em decorrência do grande porte da referida indústria, a COOPNATURAL precisou encontrar outras indústrias onde pudesse fabricar o fio. Conforme destacado por Piccioto e Shewchenko (2006), coube à indústria Malharia Limoeiro toda a produção dos fios de algodão colorido e também a produção de alguns tecidos grossos utilizados para confecção de almofadas, colchas e redes.

Em relação à tecelagem do algodão colorido em 2000, quando foram processados os $300 \mathrm{~kg}$ de pluma doadas pela Embrapa Algodão, à COOPNATURAL foi feita na unidade do Serviço Nacional de Aprendizagem Industrial (SENAI) de Pernambuco, no Centro Regional de Tecnologia Têxtil (CERTEX/SENAI), onde também foram realizados os testes para produção de malha pela Embrapa Algodão. Além do CERTEX/SENAI, é possível que outras indústrias da região tenham sido mobilizadas. Pelo fato do CERTEX/SENAI ser uma unidade escolar, a mesma apenas deu esse suporte inicial.

Em 2001, quando efetivamente a COOPNATURAL começa produzir peças para exportação, a fiação, como já apontamos, era feita na Malharia Limoeiro e a tecelagem era feita tanto pela Malharia Limoeiro, quanto pela Indústria Matesa Têxtil, localizada em João Pessoa. Segundo Farias (2010), além das indústrias têxteis citadas, havia outras que participavam dessa fase de produção, pois haviam determinados tipos de tecidos que não eram possíveis serem produzidos na Paraíba pela ausência de industrias que trabalhassem com aqueles tipos específicos.

Segundo o autor citado, os três tipos de tecidos utilizados nas confecções eram: a tecelagem manual, realizado em teares semi industriais, tecelagem plana e malharia. O primeiro tipo de tecelagem era feito por uma empresa associada a COOPNATURAL, a Entrefios. Percebe-se a coexistência de sistemas técnicos utilizados, desde um tear manual a estruturas industriais, com elevado grau de modernidade e com sua produção controlada por sistemas técnicos de informação.

Há também produção de tecidos no município de Galante - PB. Os tecidos produzidos em Galante são feitos nos teares manuais. Os tecidos são mais rústicos, utilizados na produção de artefatos de decoração como tapetes, redes, jogos americanos, entre outros. 
De acordo com Farias (2010), a tecelagem plana era feita no estado de Sergipe pela empresa Ribeiro Chaves. Na mesma empresa, eram produzidos os seguintes tipos de tecidos: brim, para fabricação de calças; o linhão, utilizado para confecção de bermudas; e o tricoline para a produção de camisas. A Matesa Têxtil, produzia a malharia. Ainda segundo o autor (op cit., p.253), "para isso, utilizavam teares elétricos e semi-eletrônicos na produção de malhas de diferentes tipos como o Piquet, o canelado, o moleton, a meia malha e a ribana. Conforme destacado por Farias (2010), a empresa Limoeiro Malhas encerou suas atividades deixando de realizar a etapa de fiação do algodão colorido. A mudança constante de indústrias tem a ver com o fato de muitas das estruturas utilizadas serem remanescentes do período anterior à crise iniciada na década de 1990 .

Atualmente a produção de fios de algodão é feita na Evetest Têxtil que se mantem no circuito de produção do algodão colorido desde sua criação. A UNITÊXTIL e UNITEX, ambas localizadas em João Pessoa, também produzem fios. As ações dessa última indústria não se limitam a produção e venda de fios e tecidos, a mesma tem participado da divulgação desse produto em eventos internacionais de produtos orgânicos. Nas Figuras 51 e 52 podem ser vistos stand da Unitex na Biofach de 2015. A Biofach acontece anualmente e é considerada um dos maiores eventos de produtos orgânicos do mundo. 

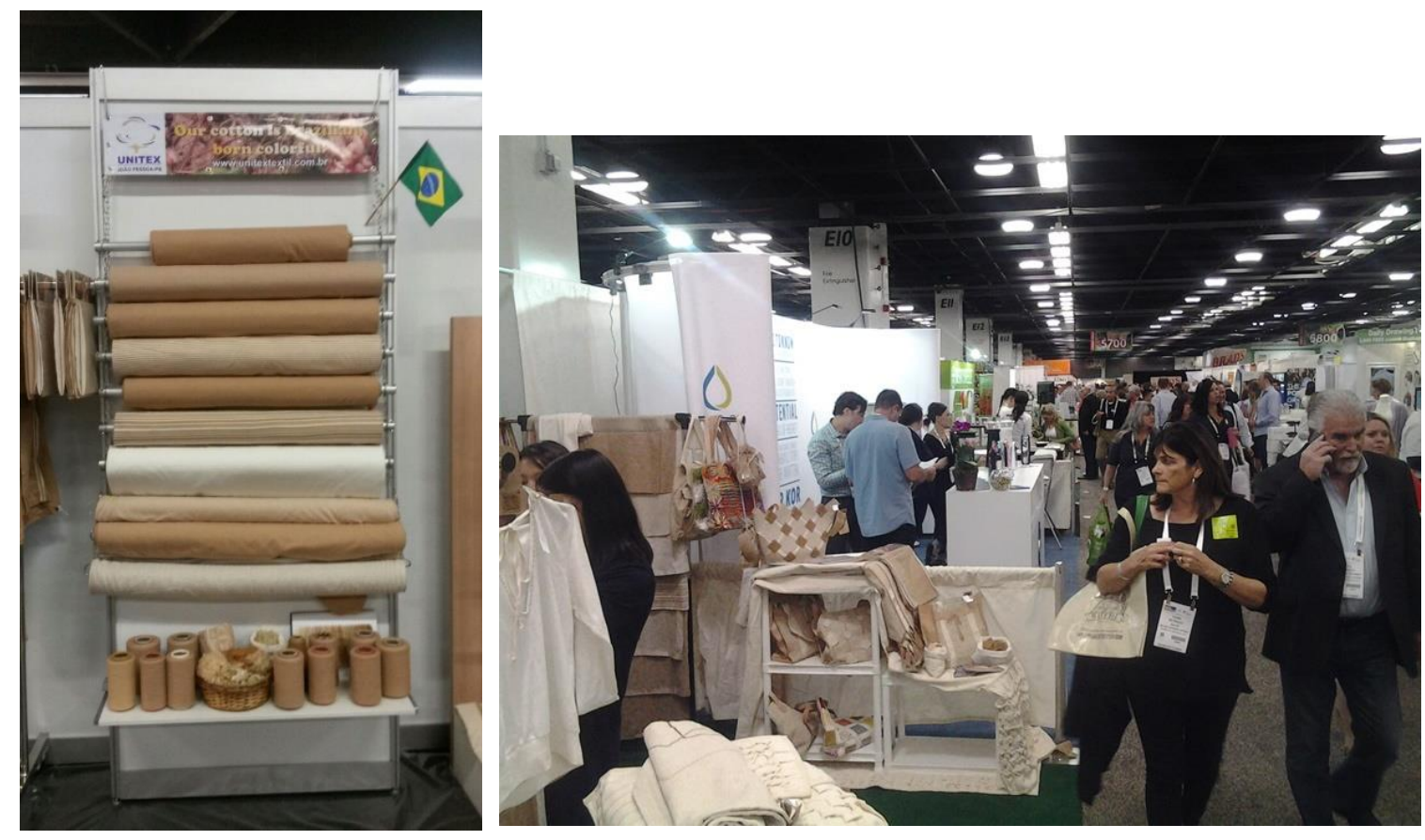

Figura 51 e 52 - Exposição de tecidos e artigos feitos com algodão colorido na BIOFACH - 2015. Fonte: Disponível em:< http://unitextextil.com.br/?p=510>. Acessado em setembro de 2016.

Essa empresa recebe a pluma a ser beneficiada da COOPNATURAL ou da AIVEST. Assim, os tecidos produzidos por essa indústria retornam para as referidas organizações que redistribui com as empresas que fazem parte de seus respectivos grupos. Após esses grupos adquirirem os tecidos necessários e as suas produções, a UNITEX, pode vender o que sobrar para pequenos empresários e artesões.

O controle da matéria prima pelos grandes grupos envolvidos na produção de confecções fez com que os artesãos tivessem dificuldade no acesso ao produto e, consequentemente, tivessem que encontrar outros meios para se estabelecerem nos seus negócios.

De acordo com algumas artesãs e a presidente da Natural Cotton Color, até o ano de 2006, embora o algodão naturalmente colorido cultivado na Paraíba fosse resultado de uma pesquisa pública a qual os resultados deveriam beneficiar à todos, apenas as empresas cooperadas a COOPNATURAL tinham acesso ao produto. Deste modo, mesmo 0 artesanato sendo algo que fomenta as peças produzidas com esse tipo de algodão, na medida que agregam valor ao produto, os artesões, a princípio, só podiam participar com a venda de seu trabalho para essa cooperativa. 
$\mathrm{Na}$ época de 2000 a 2009, mais ou menos, aqui em Campina Grande, tinha uma espécie de monopólio. A pessoa que única e exclusivamente tinha o direito de trabalhar com o algodão colorido era o pessoal da Natural Fashion, que dizem que lá é uma associação, é uma cooperativa eu não sei, só sei que eles é que tinha o monopólio, aos poucos os artesões foram comprando algodão colorido de fora. (...) Como o acesso era difícil, desisti, investi em outra área, trabalhando com cores. Aí passei esse tempo todo somente trabalhando com cores. Há dois anos para cá que o algodão colorido se expandiu muito e outras pessoas passaram a ter acesso comecei a comprar e voltei para o algodão colorido (Artesã de Campina Grande) ${ }^{108}$.

Como já mencionado, atualmente a Unitex vende tecidos e fios de algodão aos artesãos. Por sua vez, para esses artesãos terem acesso aos tecidos e fios do algodão colorido, eles precisam comprar no mínimo 50 quilos, pois não é vendido em metro e precisam ter CNPJ. Nesse caso, há o CNPJ da associação dos artesãos com o qual as mesmas podem comprar, pois também é necessário fazer um cadastro na UNITEX que os credenciam como compradoras.

Algumas artesãs que já possuem mercados mais consolidados e que trabalham com confecção de roupas que são peças maiores, conseguem com menor dificuldade comprar os rolos de algodão colorido. As artesãs que trabalham com peças menores e, por isso, usam menor quantidades de algodão, se juntam para comprar a peça de tecido de algodão colorido. Depois a associação redistribui o tecido com as artesãs, a partir da necessidade de cada uma delas, que compram em quilo.

A necessidade da cooperação entre as artesãs é também a forma das mesmas se manterem na atividade, percebe-se aí uma solidariedade orgânica que ocorre no ambiente da proximidade do cotidiano. Mesmo que todas as artesãs trabalhem com o algodão colorido, suas especializações de produção são diferentes, então, poucas concorrem entre si com os produtos. A seguir, nas Figuras 53, 54 e 55, podem ser vistos os rolos de tecidos de algodão colorido fracionados para serem repassados as artesãs, bem como, algumas das especialidades do artesanato encontrado na Vila do Artesão.

108 Informação obtida durante pesquisa de campo na Vila do Artesão em Campina Grande-PB em 13 de julho de 2016. 

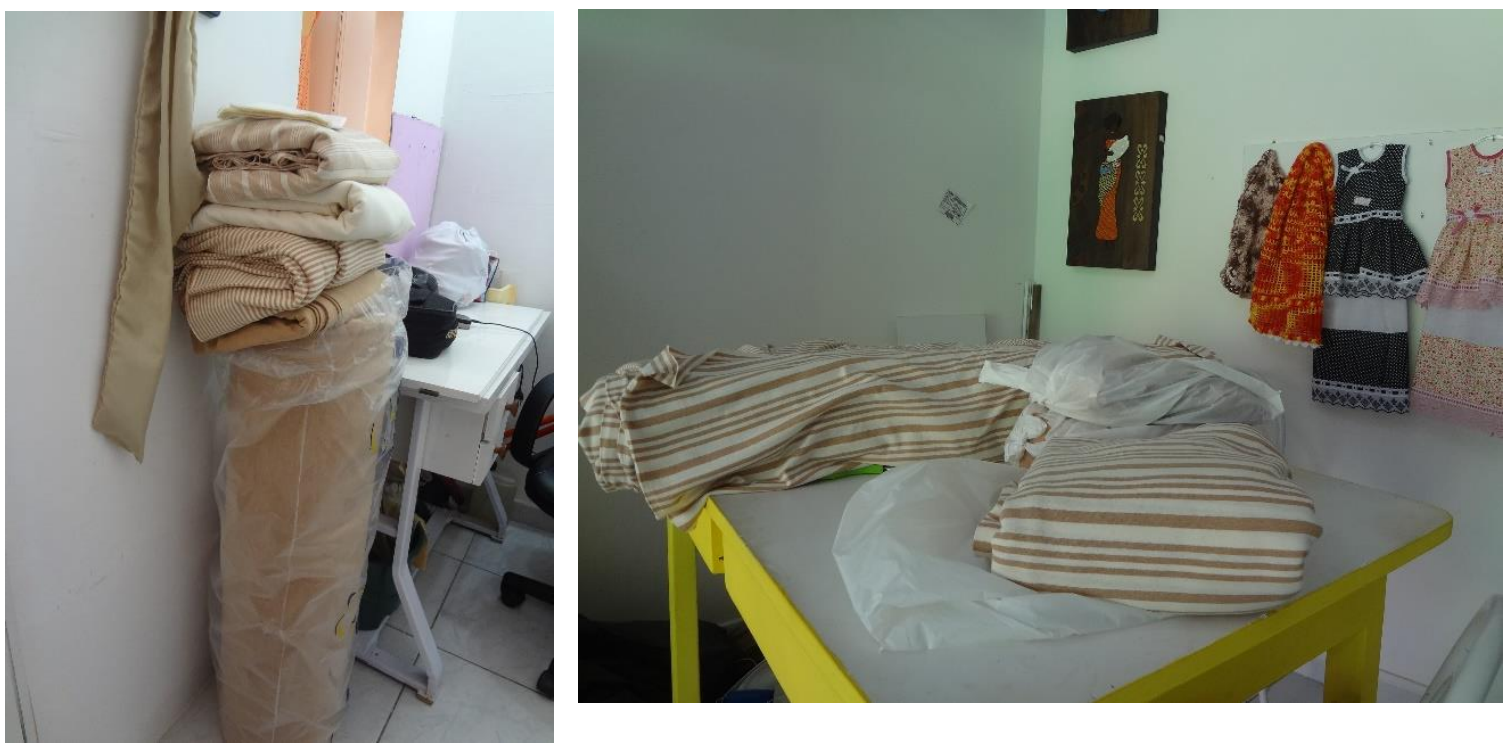

Figuras 53 e 54 - Peças de algodão fracionadas para as artesãs Vila do Artesão - Campina Grande-PB

Foto: LIRBÓRIO, L.F. 2016.
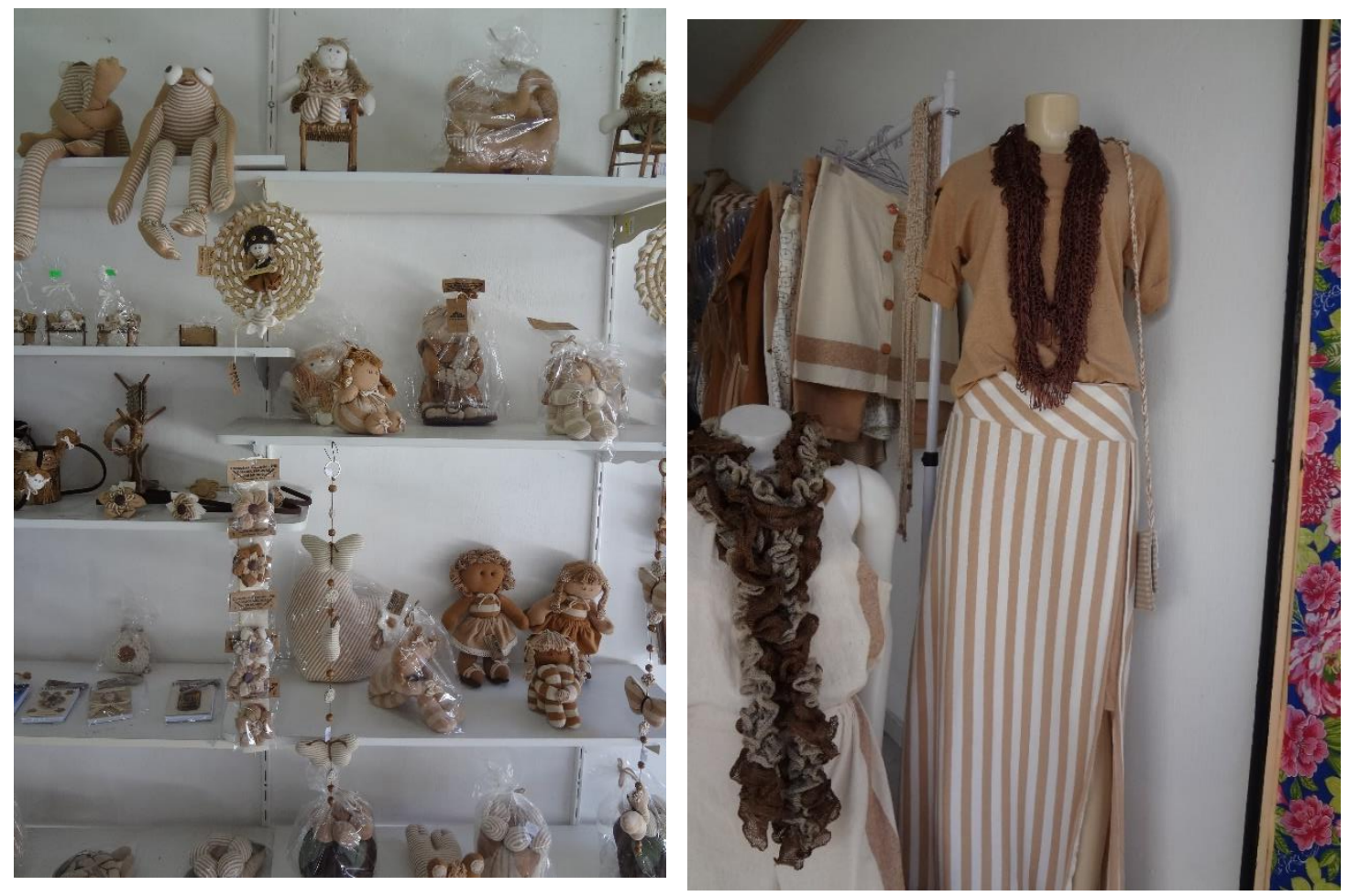

Figuras 55 - Artesanato feito com algodão colorido Vila do Artesão - Campina Grande-PB Foto: LIRBÓRIO, L.F. 2016. 
5.4 - Os lugares de produção de confecções e afins do algodão colorido da Paraíba e sua circulação no mercado

Há uma diversidade de produtos derivados do algodão colorido, desde os artesanatos que são vendidos como pequenas lembranças, a peças de vestuário mais elaboradas. A produção das mesmas é realizada em diversos municípios do território paraibano. A divisão territorial do trabalho está distribuída entre os locais onde são desenvolvidas as coleções (criação, modelagem, corte das peças, distribuição para os cooperados ou terceirizado), recebimento dos produtos prontos, comercialização e distribuição dos produtos finais; lugares de confecção das peças, lugares de desenvolvimento do artesanato.

Nessa divisão territorial do trabalho, os trabalhos administrativos, financeiro, de divulgação e gerenciamento da produção estão concentrados nas sedes das empresas. Apesar da escala de comércio não ser elevada, o setor demanda que os produtores constantemente se renovem e busquem novos mercados.

A atividade de confecção das peças e o artesanato, comumente utilizado para agregar valor nas peças, estão mais distribuídas no território. Mesmo que as atividades artesanais estejam mais capilarizadas no território, é comum que os produtos sejam confeccionados por cooperativas, o que centraliza também a produção e dá segurança para os que terceirizam esse tipo de serviço.

A princípio, distinguimos quatro tipologias de produtos produzidos com 0 algodão naturalmente colorido na Paraíba: (1) o típico artesanato, (2) objetos de decoração, (3) roupas básicas e (4) roupas com design mais sofisticado. Na categoria artesanato, destacamos dois tipos de trabalho: artesanato desenvolvido e comercializado por típicos artesões, que criam suas peças e eles mesmos comercializam em feiras, ou ainda, revendem para lojistas, e o artesanato desenvolvido sob encomenda pelas empresas de confecção e que os utilizam para agregar valor ao produto.

Os diferentes tipos de artesanato regional, como o bordado manual, a renda renascença, o macramê e outros, desde o início da montagem do circuito espacial de produção do algodão colorido, foram incorporados no desenvolvimento dos produtos à base do algodão colorido. A introdução do artesanato regional, especialmente a 
renda renascença, tem por objetivo agregar valor as peças e, por isso, as confecções feitas com algodão colorido são considerados produtos com alto valor agregado.

A produção propriamente dita, assim como a produção do algodão no campo, é intensiva em mão de obra. O artesanato é uma das fases em que há maior utilização de mão de obra, justamente por ser trabalho manual. Observa-se certo predomínio da mão de obra feminina nessa fase. Além do trabalho feminino, alguns artesões envolvem toda a sua família.

A atividade artesanal é desenvolvida na casa dos artesãos, no espaço das cooperativas de artesanatos e, no caso, ainda das artesãs da Vila do Artesão de Campina Grande, estas utilizam o espaço onde tanto são comercializados seus produtos como também para os produzirem. No caso da COOPNATURAL e da Natural Cotton Color, os artesanatos são feitos de forma terceirizada. Geralmente a terceirização é feita por artesão associados a cooperativas ou ainda por artesões independentes.

Entre os principais artesanatos utilizados, merecem destaque a renda renascença, considerada um dos artesanatos mais caros do Brasil, e, por isso, agrega maior valor aos produtos. Vale destacar que no caso dos produtos feitos com o algodão colorido, esse tipo de renda tem sido utilizado mais como detalhe das peças, do que a elaboração de peças inteiras. Como consequência, há economia da quantidade de algodão colorido utilizado e o trabalho é desenvolvido em menor tempo. Por desenvolver peças em tamanhos menores, as artesãs também recebem mais rápido pelo seu trabalho.

A COOPNATURAL, tanto tem utilizado em suas peças detalhe a partir da renda renascença, elaborados tanto com algodão colorido, quanto com algodão convencional tingido. A seguir nas Figuras 56 e 57 podem ser vistos alguns dos tipos de artesanato utilizado na elaboração das peças. Na Figura 56 são artesanatos produzidos para COOPNATURAL e na Figura 57 para a Natural Cotton Color. 

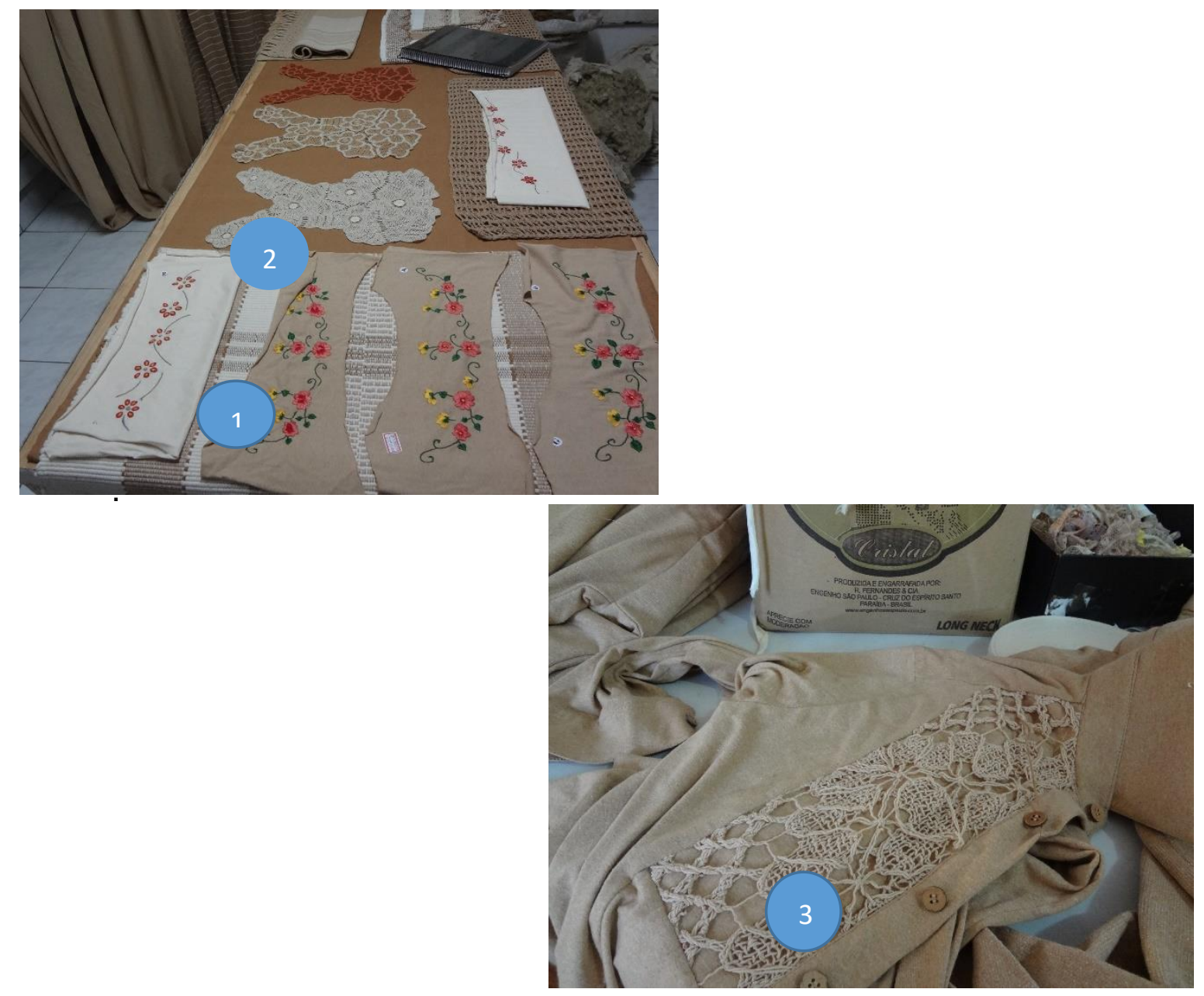

Figuras 56 e 57 - Algumas técnicas de artesanato manual utilizadas nas confecções de algodão colorido (1 - bordado manual, 2 - renda renascença e 3- renda filé). (Foto 56 - Campina Grande, Foto 57 - João Pessoa).

Fotos: LIRBÓRIO, L. F., 2016.

A seguir destacamos os lugares de produção do artesanato para a COOPNATURAL: Areal (crochê), Alagoa Nova (bordado manual), Serra Rajada (renda labirinto), Monteiro (renda renascença). Além desses artesanatos, há também a confecção de bonecos, animais, chaveiros, esses são confeccionados por artesãos de Campina Grande e João Pessoa. Os animais são criados tendo como inspiração aqueles que existem no cotidiano da região.

Na Figura 58, por exemplo, está disposto o jumento, feito com o algodão BRS Rubi e detalhes em BRS 200 Marrom $^{109}$. O dinossauro que embora não exista nos dias atuais é uma alusão ao sitio arqueológico de Souza no Sertão Paraibano, deu

${ }^{109}$ Esse jumento é um mascote da COOPNATURAL, se chama Frederico e como reflexo da importância do algodão colorido há uma peça desse animal no Museu da Casa Brasileira em São Paulo. 
origem a coleção "pangeia". Existe uma diversidade de produtos menores que são produzidos com os restos de retalhos das confecções de roupas. Todos os subprodutos do algodão colorido são minimamente aproveitados.

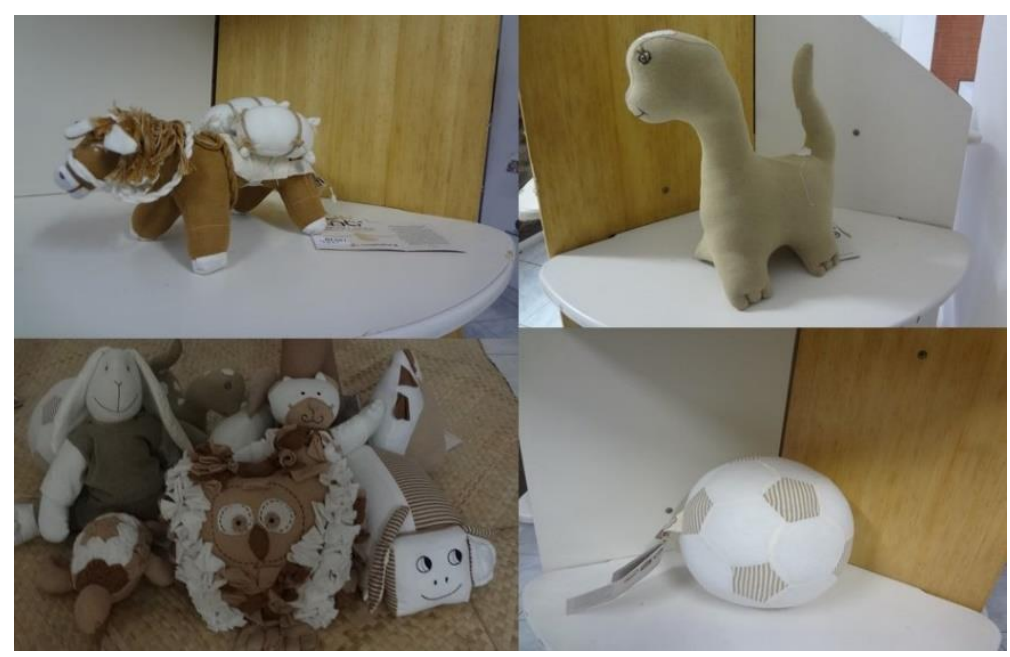

Figura 58- Artesanato com algodão colorido - COOPNATURAL Fotos: LIRBÓRIO, L.F. 2016.

O design é parte essencial no desenvolvimento das coleções e consequentemente das futuras vendas dos produtos. No caso da COOPNATURAL, a própria presidente da cooperativa, que é formada em desenho industrial, elabora os modelos e, eventualmente, contrata profissionais especializados em design. Além disso, são frequentes as parcerias com o Serviço Nacional de Aprendizagem Industrial (SENAI) de Campina Grande. A cooperativa conta ainda com o apoio da unidade do Serviço de Apoio às Micro e Pequenas Empresas (SEBRAE), presente nessa cidade.

O SENAI oferece diversos cursos de formação técnica na área de confecção e moda, o que assegura a oferta de mão de obra qualificada. Os cursos oferecidos pelo SENAI são: curso de modelista, costureiros de máquinas industriais, modeslista de vestuário, desenhista de moda, vestuário, produção de moda, modelagem do vestuário, técnicos em produção de moda e técnicos em calçados.

Acrescenta-se ainda que a cidade de Campina Grande possui considerável infraestrutura de ciência e tecnologias que favorecem maior dinâmica nas atividades econômicas da região, inclusive do algodão colorido, pois por ser um centro regional, 
atrai para si grande fluxo de comércio e de negócios. Atualmente, há claro reconhecimento de que o algodão colorido é um produto da Paraíba, e sobretudo, de Campina Grande.

Essa identidade regional do produto foi ainda mais reforçada com a obtenção do selo de Indicação Geográfica (IG), em 2013, concedido pelo Instituto Nacional de Propriedade Industrial (INPI). O Pedido de IG, foi feito pela COOPNATUAL em 2010, e se constituía mais uma forma de agregar valor à produção dos produtos derivados do algodão naturalmente colorido desse estado. Assim, hoje muitos artesãos e empresários se referem ao algodão naturalmente colorido como "algodão colorido da Paraíba" (ver Figura 59 e 60).

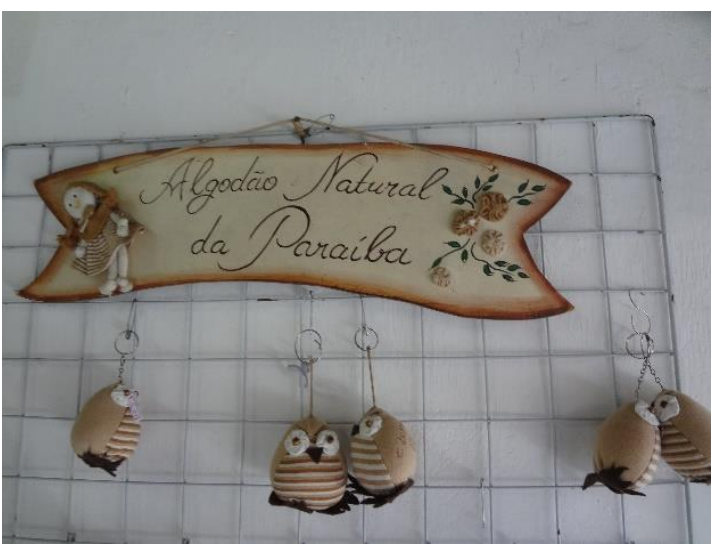

Figura 59 - Referência dos artesões a identidade geográfica do algodão colorido

Foto: LIRBÓRIO, L.F., 2016

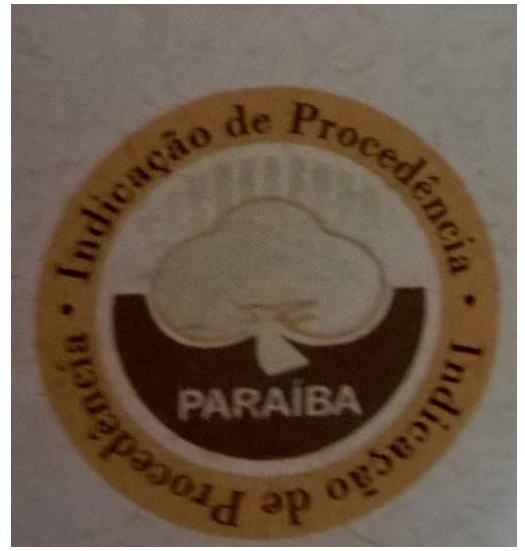

Figura 60 - Selo de Indicação Geográfica do Algodão naturalmente colorido da Paraíba

Foto: LIRBÓRIO, L.F., 2016

O selo de indicação geográfica é concedido especialmente para produtos alimentares, naturais ou industrializados, que apresentam particularidade por ser exclusiva de um território delimitado geograficamente, o exemplo mais conhecido é o do champanhe da região de Champanhe na França. $O$ apelo pela questão territorial de origem geográfica é chamado por Benko (2001, p. 38) de "d'appelation controlée". O controle de apelação geográfica evidencia que mesmo no período de globalização, as particularidades do lugar são valorizadas, sobretudo, com finalidades econômicas.

A concessão do selo de IG do algodão naturalmente colorido é considerado caso inédito no setor têxtil brasileiro. Há esclarecimentos, pois o mesmo pode ser produzido em quase todos os lugares do Nordeste. O INPI nesse caso especifico 
concedeu o IG do algodão naturalmente colorido, pelo seu diferencial tecnológico. O recebimento de selo de IG teve um efeito positivo em alguns aspectos, para além da agregação do valor propriamente dito, o artesão e outros empresários que, de alguma forma, tinham dificuldades de acessar essa matéria prima, agora tem a liberdade de cobrar acesso ao produto: se ele é da Paraíba, não é de uso exclusivo de um dado grupo, mas de todos paraibanos.

Retomando algumas das vantagens que a cidade de Campina Grande oferece para o desenvolvimento do circuito espacial de produção do algodão colorido, a infraestrutura de ciência e tecnologia é certamente um diferencial significativo. A rede de ensino e pesquisa dessa cidade pode ser equiparada a da capital do estado, João Pessoa. A rede de ensino e pesquisa é composta por instituições federais, estaduais, municipais e privadas. As instituições federais são: Universidade Federal de Campina Grande (UFCG), Embrapa Algodão, Instituto Federal de Educação, Ciência e Tecnologia; no âmbito estatual, conta com um campus da Universidade Estadual da Paraíba (UEPB); as particulares na modalidade Educação a Distância: Universidade do Norte do Paraná (UNOPAR), Centro Universitário Internacional (UNINTER), Universidade Paulista (UNIP), Universidade de Salvador (UNIFASC), Universidade de Uberaba ( UNIUBE); universidades particulares modalidade presencial: Faculdade de Ciências Sociais Aplicada (FACISA). Campina Grande conta também com boa infraestrutura de serviços bancários conforme pode ser verificado na Quadro 18. 
Quadro 18 - Bancos Públicos e Privados em Campina Grande - PB

\begin{tabular}{|l|r|}
\hline Banco & Número de Agências \\
\hline \multicolumn{2}{|c|}{ Bancos Públicos } \\
\hline Banco do Brasil & 5 \\
\hline Caixa Econômica Federal & 1 \\
\hline \multicolumn{2}{|c|}{ Bancos Privados } \\
\hline Banco Bradesco & 2 \\
\hline Banco Santander & 2 \\
\hline Banco Itaú & 2 \\
\hline Banco BMG & 1 \\
\hline BANCO UNICRED & 1 \\
\hline
\end{tabular}

Fonte: Disponível em: <http://www.telelistas.net/pb/campina+grande/bancos> Organização: LIRBÓRIO,L.F, 2016.

Na sede da COOPNATURAL são produzidas as peças piloto, o corte das peças que é feito por máquinas industriais. Posteriormente, as peças cortadas são encaminhadas para os cooperados de acordo com suas especificidades (roupas de criança, moda feminina ou masculina). Depois essas peças voltam para a sede que também é responsável pela comercialização e distribuição do produto final para o consumidor (ver Figura 61). O comércio dos produtos da COOPNATURAL é feito principalmente em atacado.

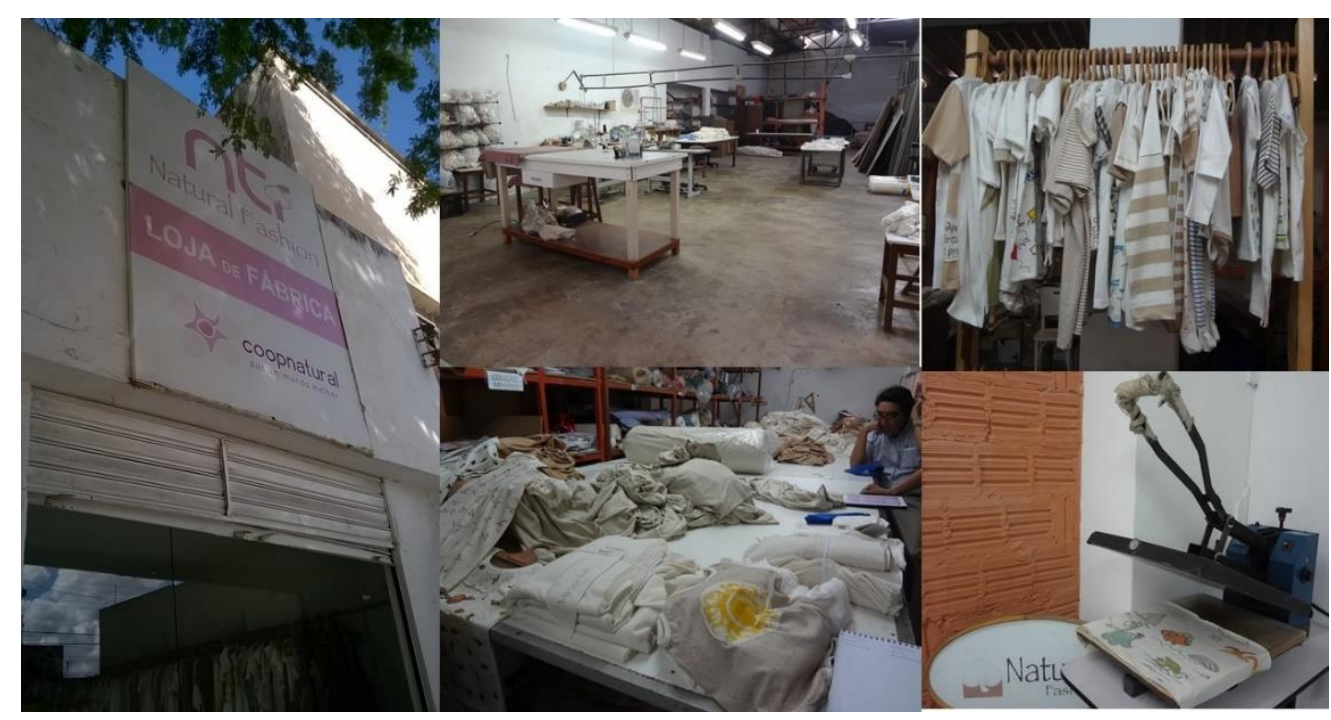

Figura 61 - COOPNATURAL

Fotos: LIRBÓRIO, L. F. 2016. 
O mercado consumidor da COOPNATURAL já nasceu internacional. Conforme mencionado no capítulo 4, o que antes era a associação de pequenos empresários (Natural Fashion - 2000) do setor de confecção de Campina Grande, composta por 10 empresas, transformou-se em consórcio de exportação (2002), e, em 2003, foi transformada em cooperativa para poder agregar mais empresas vinculadas ao setor que, diante do contexto de grande demanda de produtos feitos com o algodão colorido, também queriam participar desse bom momento do produto. Atualmente conta com 23 empresas cooperadas. O volume de produção dos anos iniciais dessa cooperativa pode ver verificada na Tabela 6 a seguir:

Tabela 6 - Produção Mensal de Pecas COOPNATURAL 2004/2005

\begin{tabular}{|l|l|l|l|}
\hline \multicolumn{4}{|l|}{ PRODUÇÃO MENSAL COOPNATURAL (No DE PEÇAS) - 2004/2005 } \\
\hline Mês & $\mathbf{2 0 0 4}$ & $\mathbf{2 0 0 5}$ & TOTAL \\
\hline Janeiro & 4.355 & 4.695 & 9.050 \\
\hline Fevereiro & 2.283 & 3.882 & 6.165 \\
\hline Março & 2.930 & 3.444 & 6.374 \\
\hline Abril & 2.088 & 4.027 & 6.115 \\
\hline Maio & 3.445 & 3.040 & 6.485 \\
\hline Junho & 3.290 & 4.929 & 8.219 \\
\hline Julho & 2.839 & 4.767 & 7.606 \\
\hline Agosto & 2.797 & 7.067 & 9.864 \\
\hline Setembro & 1.814 & 6.085 & 7.899 \\
\hline Outubro & 2.858 & 8.318 & 11.176 \\
\hline Novembro & 4.139 & 5.116 & 9.255 \\
\hline Dezembro & 4.949 & 4.468 & 9.417 \\
\hline Total & 37.787 & 59.838 & 97.625 \\
\hline
\end{tabular}

Fonte: DUARTE, 2006, p. 11 Apud. (FARIAS, 2010, p. 264).

Pelo fato de os produtos derivados do algodão colorido terem preços mais elevados do que produtos similares, mas com outro material, o público a que se destina é formado principalmente de pessoas de classe média alta do Brasil e do exterior.

As empresas, primeiramente voltadas para o mercado externo, depois começam a credenciar pontos de venda em algumas cidades brasileiras, principalmente pontos turísticos, já que o produto feito para o público brasileiro tinha uma característica mais de artesanato, camisas com paisagens regionais, uso de cordel, xilogravura, etc. Há alguns anos, devido ao reconhecimento do potencial do mercado nacional, também esse mercado também tem sido buscado. 
Segundo Farias (2010), os países para os quais a COOPNATURAL exportava suas produções e onde tinha representantes comerciais eram: Estados Unidos, Chile, Portugal, Espanha, França, Inglaterra, Itália Suécia, Correia do Sul e Japão. No caso de Portugal, a loja era física. Além da COOPNATURAL, a Natural Cotton Color no período estudado por Farias (2010), exportava suas produções para: Portugal, Espanha, Inglaterra, Suécia, Austrália e Japão. A empresa Redes Santa Luzia do município de São Bento -PB comercializava seus produtos (redes, colchas, mantas, tapetes, xales e capas de almofada) para os Estados Unidos, a Espanha, a Suíça e a Finlândia (ver Figura 62).

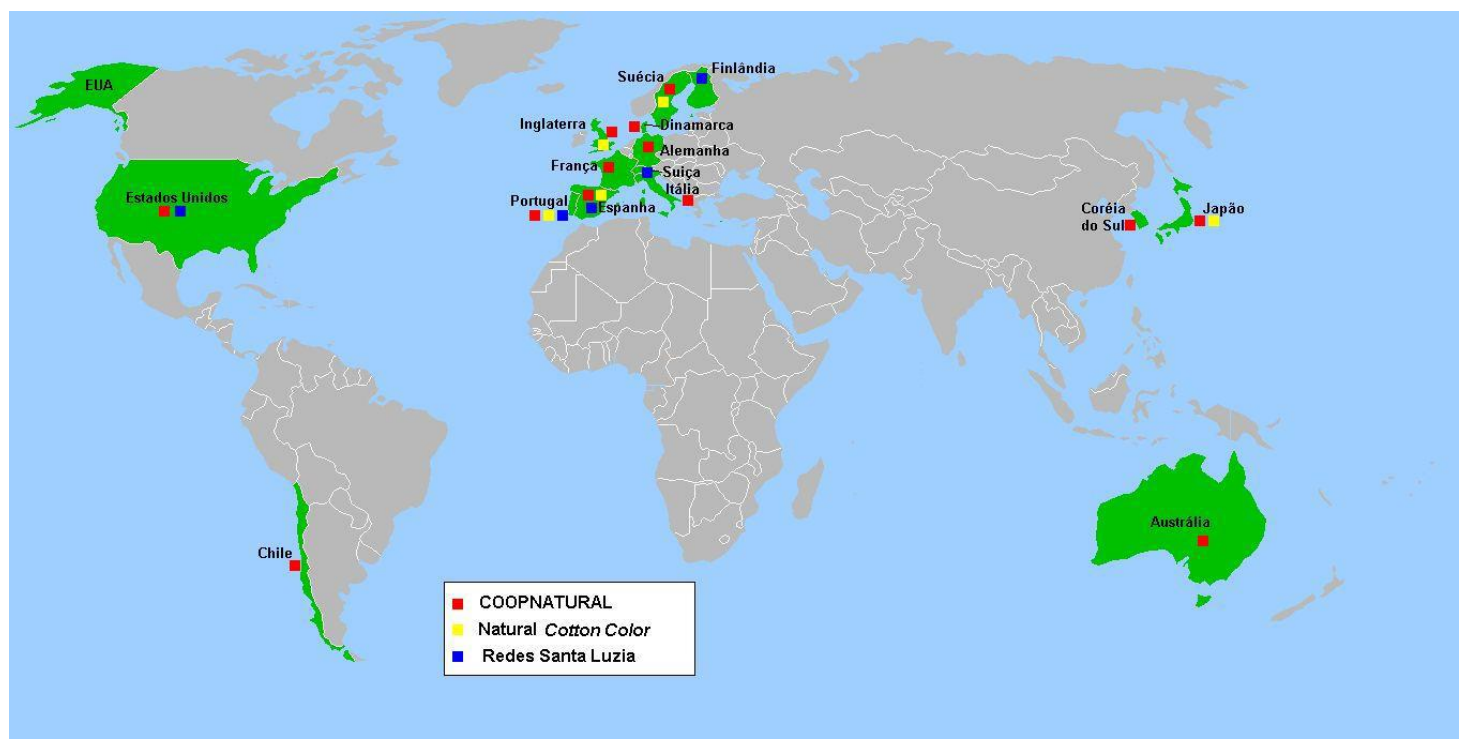

Figura 62 - Países onde eram comercializados os produtos derivados do Algodão Colorido da Paraíba (2010)

Fonte: FARIAS, 2010, p. 282).

O mercado é dinâmico e muda com o tempo. Atualmente, a COOPNATURAL já não atua em alguns desses países. Segundo a presidente da COOPNATUAL, a crise econômica mundial de 2008 desencadeada pelos problemas financeiros da maior economia do mundo, os EUA, contribuiu para redução desses pontos de comércio. A loja de Portugal foi fechada, já não há mais representação dessa empresa nos EUA, Chile, França, Inglaterra, Suécia, Correia do Sul e Austrália. Hoje em dia, a mesma tem representantes comerciais nos seguintes países: Espanha, Itália, Noruega, Alemanha, Suíça e Holanda ${ }^{110}$..

${ }^{110}$ Mesmo tendo informado sobre a redução no mercado internacional dos produtos comercializados pela COOPNATURAL, no cadastro das empresas brasileiras que exportam para fora do Brasil, a referida cooperativa informou elevado número de países para os quais exporta. Esses dados foram 
A Natural Cotton Color manteve seus representantes comerciais e ampliou alguns. Atualmente, essa empresa está presente nos seguintes países: Alemanha, Canadá, Estados Unidos, Espanha, França, Portugal, Inglaterra, Arábia Saudita e Japão. Os países para os quais a COOPNATURAL e o grupo Natural Cotton Color exportam os produtos derivados do algodão naturalmente colorido pode ser visualizados no Mapa 10. exportados pela COOPNATURAL e pelo grupo Natural Cotton Color em 2016. 


\section{Mapa 10 - Mundo: Destino da exportação de produtos derivados de algodão naturalmente colorido da Paraíba, 2016}

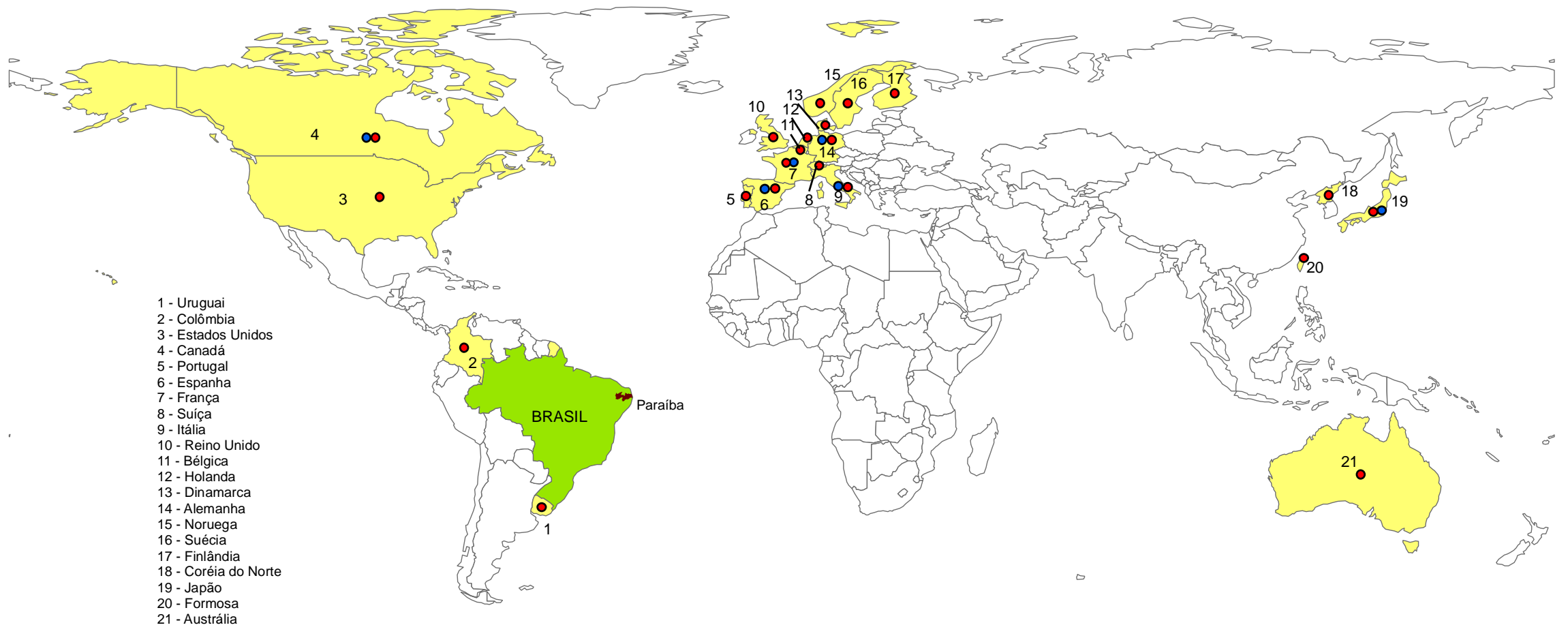

\section{LEGENDA}

\section{Paraíba}

Brasil

Países de destino da exportação

- COOPNATURAL

Grupo Natural Cotton Color
Base Cartográfica: ESRI

Organização: LIRBÓRIO, L. F.

Elaboração: VENCESLAU, I. 
Outra forma de comercialização dos produtos que vem sendo realizada por esses grupos é a comercialização via internet (e-comerce). O uso dos sistemas de informação para divulgação e comercialização dos produtos dessas empresas possibilitou a venda tanto em grandes quantidades, quanto por unidade. No caso da COOPNATUAL, a mesma possui uma loja virtual. A Natural Cotton Color em 2015 criou sua e-comerce: NCC Ecobrands. A Santa Luzia Rede e Decorações, também tem comercializado suas produções pelo NCC Ecobrands, assim como, os demais participantes do grupo Natural Cotton Color.

A participação do Brasil em feiras nacionais e internacionais de moda e de produtos orgânicos se constitui em meios de divulgação dos produtos feitos com o algodão colorido. A participação nos eventos internacionais tem contado com o apoio financeiro da Apex-Brasil, que financia parte dos custos para que os empresários participem das feiras e os produtos brasileiros sejam expostos.

As feiras internacionais são verdadeiros eventos. Por se tratarem de feiras especializadas em produtos orgânicos, os contatos com futuros compradores, e representantes comerciais são, sobremaneira, facilitados. Além dessas feiras especializadas tem crescido nos eventos de moda novos espaços criados para produtos sustentáveis. São nessas feiras também potenciais consumidores da matéria prima brasileira surgem, pois ao tomarem conhecimento da produção brasileira de algodão orgânico, seja o naturalmente colorido, ou o branco, estes, por meio dos contatos que fazem com as empresas brasileiras presentes nessas feiras, também podem obter a matéria prima da agricultura familiar brasileira. Já foi mencionado nesse capítulo, por exemplo, a empresa espanhola Fox Fibre Colorganic que hoje tem agricultores do nordeste brasileiro produzindo algodão para a referida empresa.

A entrada desses novos atores pode proporcionar o crescimento da produção de algodão orgânico no país. Para participar dessas feiras, os empresários precisam que os seus produtos estejam de acordo com os padrões exigidos pelos organizadores dos eventos. Internamente no país também há seleção criteriosa por parte da Apex-Brasil na escolha das empresas que podem representar o Brasil.

A Natural Cotton Color vem se destacando entre as empresas do setor de produção do algodão naturalmente colorido orgânico nesses grandes eventos. A referida empresa tem investido em designer e moda, valorizando o artesanato 
regional, principalmente a renda renascença que é o seu carro chefe, conforme destacado pela presidente da Natural Cotton Color, "Nosso "carro chefe" aqui é a renda renascença, até porque é um dos artesanatos mais valiosos hoje no Brasil. Porém, a gente não usa a peça inteira nunca até para dar o espaço para o algodão." ${ }^{111}$

A Natural Cotton Color tem participado de renomados eventos internacionais, alguns nos quais os participantes são rigorosamente selecionados, como: Salão So Ethc da Prêt à Porte Paris (França), Pure London (Inglaterra), Salão Internacional de Moda de Madri - SIMM (atual Momad Metropólis), Project Las Vegas (EUA), Ethical Fashion de Berlin (Alemanha) e Biofach Japão. A participação na Biofach Japão, possuiu um significado simbólico, no qual os pesquisadores da Embrapa Algodão consideram ter pago sua dívida com os japoneses que haviam demonstrado interesse em adquirir o algodão naturalmente colorido no final da década de 1980 (CARVALHO, 2016. (ver Figura 63).

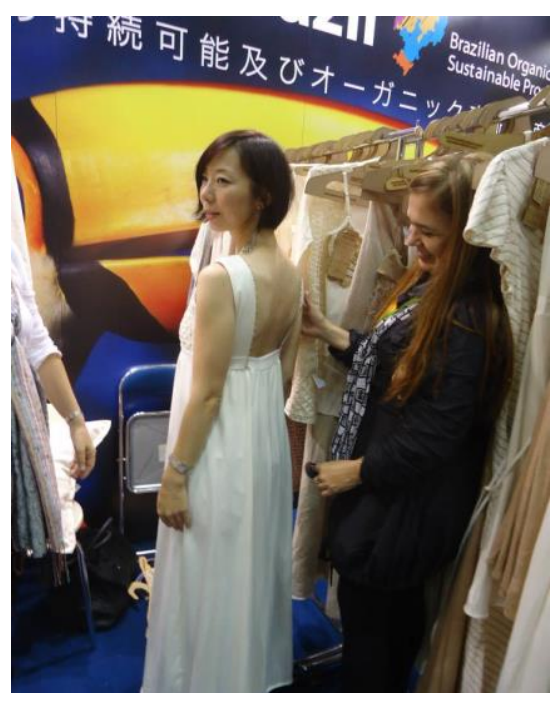

Figura 63 - Cliente experimenta um vestido de algodão colorido na BIOFACH - Japão (2013)

Foto: VIEIRA, Francisca, 2013.

Do mesmo modo que a COOPNATURAL, o processo de criação das coleções, corte das peças, pilotagem e distribuição das peças da Natural Cotton Color são feitas na sede da empresa. As montagens das peças são feitas por costureiras terceirizadas de João Pessoa. Além dessas costureiras na sede da referida empresa têm três costureiras que trabalham fazendo os acabamentos finais necessários. Essas

111 Entrevista realizada durante trabalho de campo em 14 de julho de 2016. 
funcionárias também são responsáveis por fazerem o controle de qualidade das peças. O artesanato empregado nas peças é produzido por artesãos da Paraíba e de outros estados. Isso acontece especialmente no caso renda renascença, por ser um trabalho artesanal mais complexo os artesãos precisam de mais tempo para fazê-la. Além das artesãs do município de Monteiro na Paraíba, há artesãos da cidade de Pesqueira no Sertão Pernambucano que também produzem peças em renascença para essa empresa (Ver Figura 64).
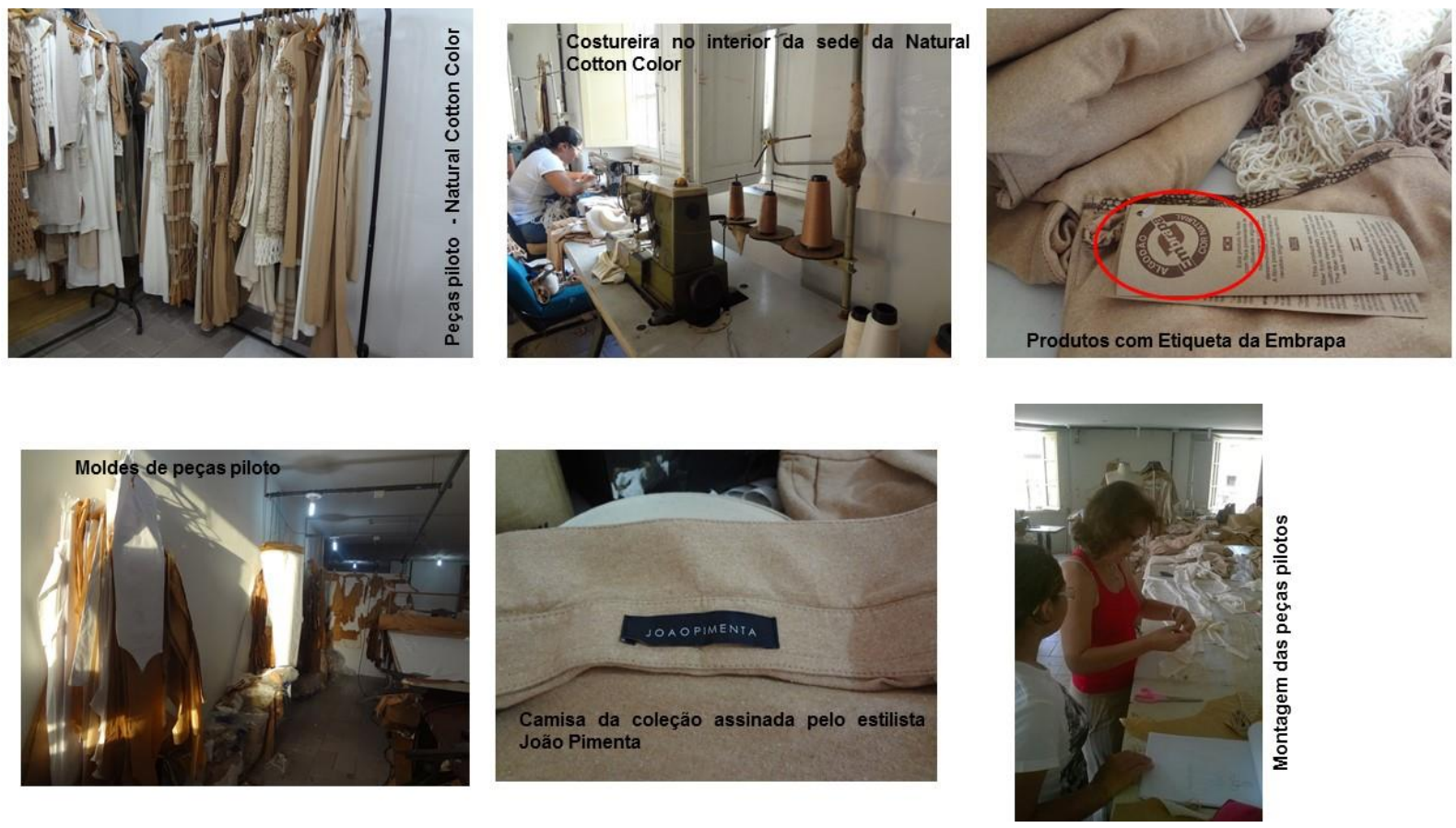

Figura 64 - Lugar de produção da Natural Cotton Color Fotos: LIRBÓRIO, L.F., 2016.

A divulgação dos produtos feitos com o algodão colorido, cada vez mais tem ganhado espaço. Em 2015, o algodão colorido inspirou uma coleção desenvolvida pelo estilista João Pimenta, que expôs suas criações com o algodão colorido na São Paulo Fashion Week (SPFW). O trabalho foi feito em parceria com a Natural Cotton Color, que cedeu o tecido de algodão naturalmente colorido e a Santa Luzia Rede e Decorações, que fez o trabalho de tecelagem, tipo rede de pesca, feito em tear manual (ver Figura 65). Essa não foi a primeira vez que roupas feitas com o algodão colorido desfilam nas passarelas da SPFW, em 2002 com um trabalho feito pelo estilista Angelo Rafael. 

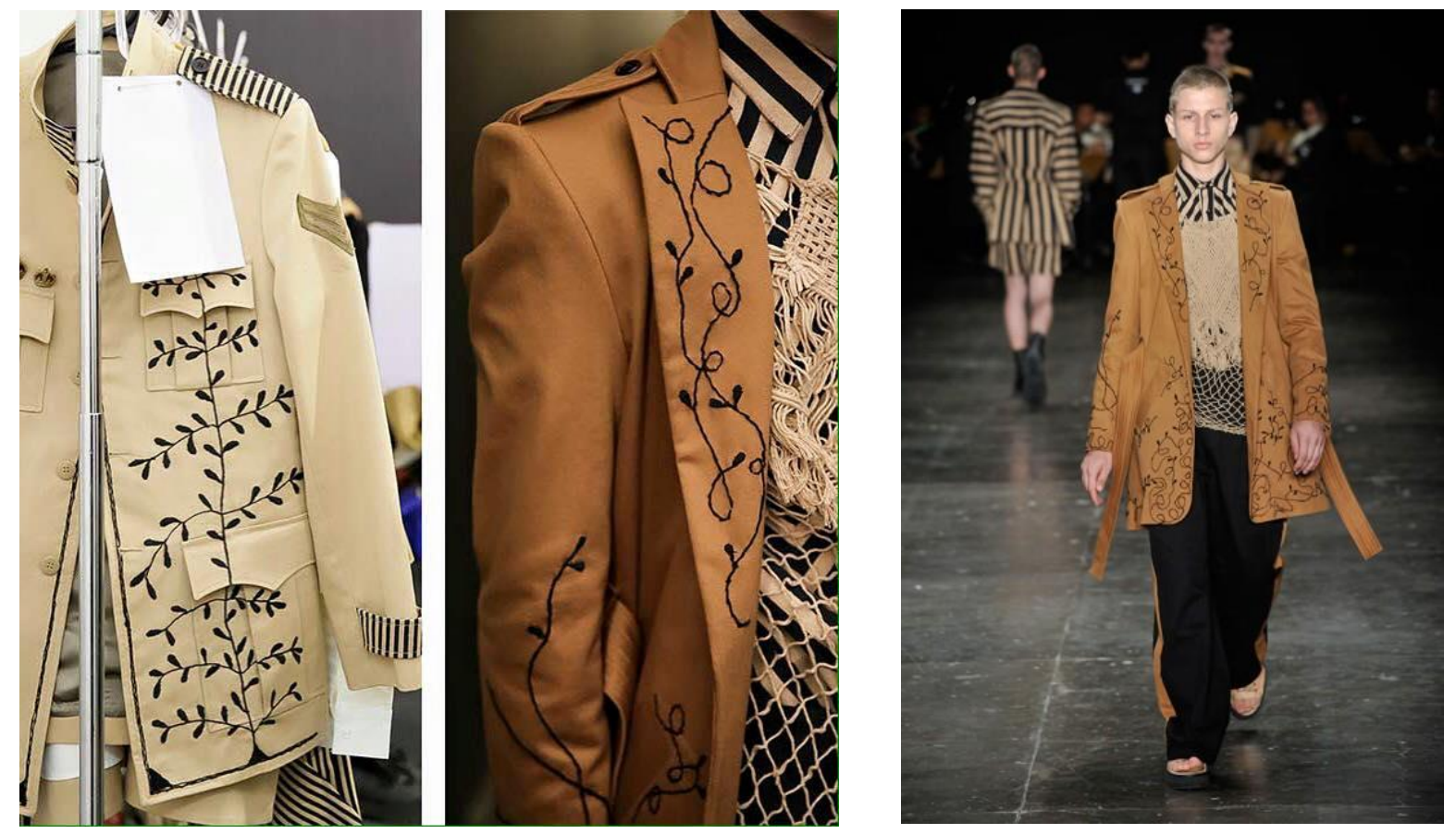

Figura 65 - Roupas feitas com algodão naturalmente colorido na São Paulo Fashion Week (2016) Fonte: http://www.lilianpacce.com.br/desfile/joao-pimenta-abril-2016/\#

Os produtos das empresas que formam o grupo Natural Cotton Color são vendidos em atacado para lojistas e no mercado externo, os produtos são comercializados através de representantes e do NCC Ecobrans. Os produtos desenvolvidos por essa empresa não são peças com valores populares, sendo consumidos por pessoas com poder aquisitivo mais elevado, reforçando a ideia de que se trata realmente de um produto para um público seleto.

Se os produtos feitos com o algodão naturalmente colorido orgânico já possuem valor superior, por suas especificidades, a Natural Cotton Color bem como as empresas que fazem parte desse grupo, buscam inserir cada vez mais seus produtos em um mercado principalmente de elite econômica. Em junho de 2016 foi inaugurada em duas lojas representações da Natural Cotton Color na Lado Basic nos shoppings JK Iguatemi e Cidade Jardim - São Paulo.

Como demonstrado, a circulação de produtos feitos com 0 algodão naturalmente no Brasil, em especial da Paraíba, tem chamado a atenção, seja pelas características da fibra adequada para o uso industrial, ou pela forma como algumas empresas vem se dedicando para o ocupar espaço no mercado da "moda 
sustentável". Não se pode deixar de citar alguns dos problemas enfrentados pelos empresários e artesões que trabalham com esse produto, especialmente algumas denúncias de comerciantes que estavam falsificando o algodão colorido, tingindo tecidos e fazendo passar por naturalmente colorido. Por ser naturalmente colorido os produtos feitos com esse algodão não desbotam nem mesmo com o uso de alvejantes já os produtos falsificados mancham nas primeiras lavagens.

Na Figura 60 pode se visualizar uma matéria publicada em 5 de janeiro de 2014 no jornal Correio da Paraíba, em que a presidente do grupo Natural Cotton Color denuncia a comercialização de derivados do algodão colorido por lojistas. Esse tipo de prática compromete a confiança na qualidade do produto. Segundo as diretoras da COOPNATURAL e da Natural Cotton Color, uma forma de os compradores se assegurarem se o produto é verdadeiro ou não é o próprio preço cobrado, pois geralmente um produto falsificado apresentará significativa diferença de preço. 


\section{Algodão colorido é alvo de falsificação

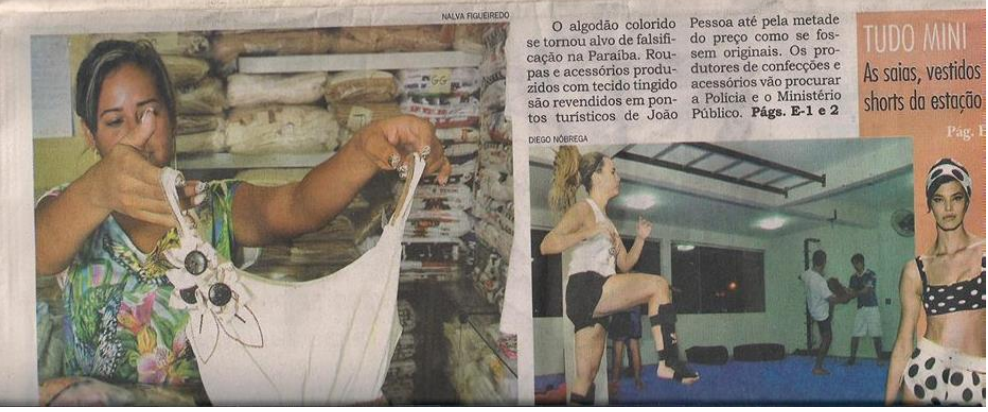

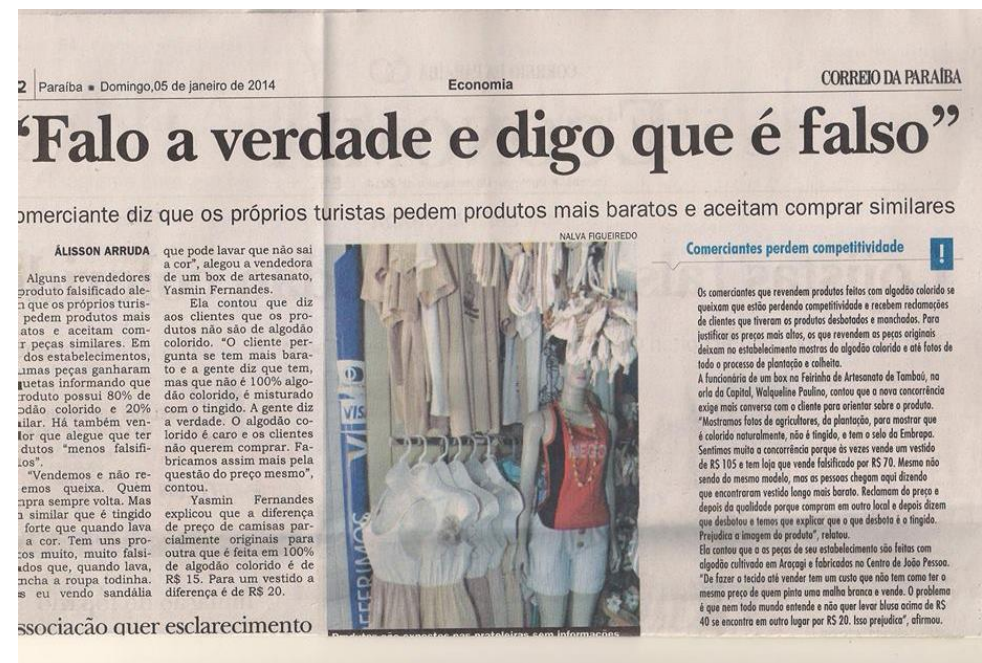

Figura 66 - Denuncia de falsificação de algodão colorido na Paraíba.

Fonte: Material coletado na página do facecook da empresa Natural Cotton Color

Disponível:

em:

<https://www.facebook.com/NaturalCottonColor/photos/a.685947501430605.1073741831.536951 196330237/712789095413112/?type=3\&theater>

Acessado:em: 25 de agosto de 2015.

O consumidor, que eventualmente adquirir um produto feito com algodão falsificado sem saber, porque também há relatos de compradores que tem conhecimento de que o produto é falsificado e mesmo assim o adquire, só se dará conta na hora da lavagem. Como forma de se proteger dos possíveis prejuízos, a credibilidade na garantia de que o produto fosse verdadeiro, os empresários do setor passaram a utilizar além do selo de Indicação Geográfica (COOPNATURAL), o selo de certificação de produto orgânico, o selo de que o algodão foi produzido com tecnologia da Embrapa. 
A adoção da tag da Embrapa é feita tanto pela COOPNATURAL, quanto pelo grupo Natural Cooton Color. No caso dos artesões em geral, eles não dispõem dessas certificações, no entanto, quando vão vender seus produtos, estes fazem menção à Embrapa, inclusive, existe alguns que possuem folhetos que contam a história das cultivares de algodão colorido desenvolvidas por este centro de pesquisa e amostras da pluma colorida. 


\section{CONSIDERAÇÕES FINAIS}

Ao longo dessa pesquisa foi possível identificar e analisar as metamorfoses da produção algodoeira no Brasil desde o período pré-técnico ao período técnicocientífico -informacional e como foram surgindo as iniciativas de pesquisa para o setor. A criação da Embrapa e de suas unidades de pesquisa pode ser considerada, em certa medida, a integração da pesquisa agrícola à nível nacional. Até a década de 1970 o número de instituições de pesquisa com foco na agricultura era bastante reduzido e aquelas que existiam preocupavam-se em solucionar os problemas ligados ao seu território próximo. Tal fato é justamente o reflexo da criação tardia, neste âmbito, das instituições de ensino e pesquisa no país e da integração territorial do conhecimento desenvolvido a partir das mesmas.

A Embrapa Algodão surge como um novo marco no padrão tecnológico da cultura algodoeira no país. Pela primeira vez, o algodão passa a contar com um quadro técnico de pesquisa que se preocupa com essa lavoura em qualquer parte do território nacional. A presença de instituições de pesquisa é uma fonte para transformação das condições locais. Como demonstramos, o sistema de ações dessa empresa permitiu a concretização de possibilidades para a agricultura familiar do Semiárido através da introdução do algodão colorido.

Embora a escala de produção do algodão naturalmente colorido seja pequena, alguns agricultores familiares puderam sentir mais profundamente a valorização e 0 reconhecimento do seu trabalho. Ainda que o valor pago ao agricultor por seu trabalho esteja aquém do que consideramos ser justo, há outros valores intrínsecos à produção do algodão naturalmente colorido orgânico que têm contribuído para autoestima desses agricultores, como comprovamos no assentamento Margarida Maria Alves.

A centralização das pesquisas relacionadas a produção do algodão na Embrapa Algodão não tira a importância das instituições que existiam em outras regiões e que já possuem longa experiência sobre a cultura. Em outras palavras, a infraestrutura de pesquisa da Embrapa Algodão promoveu a reorganização espacial da produção algodoeira nacional através de sua criação e das ações relacionadas ao desenvolvimento de novas cultivares adaptadas paras as condições geográficas que as recebia. Conforme destacado, com a crise do algodão a empresa passou a 
pesquisar outros sistemas de produção como o amendoim, mamona, sisal e gergelim. Fato que ampliou a possibilidade de novas oportunidades para os agricultores do Semiárido e de outros lugares do território nacional.

Mesmo cada centro de pesquisa da Embrapa possuindo uma especificidade, há uma integração das pesquisas desenvolvidas entre elas, o que amplia as possibilidades de desenvolvimento do setor agropecuário do país. $\mathrm{O}$ acesso às tecnologias desenvolvidas pela Embrapa ainda encontra muitas barreiras, pois para acessar as tecnologias e o conhecimento sobre as mesmas é necessário maior conhecimento por parte dos usuários. No caso dos empresários, estes têm mais condições de pressionar as agências de pesquisa para atender suas demandas, enquanto os pequenos agricultores ainda vão ficar limitados ao que as infraestruturas locais possam mobilizar.

Conforme demonstrado na pesquisa realizada pelo Instituto Internacional de Políticas Alimentares (International Food Policy Research Institute) (2016), o Brasil é apontado como o país da América Latina que mais investe em Pesquisa e Desenvolvimento em agropecuária proporcionalmente ao PIB agropecuário do país. Ao mesmo tempo que a Embrapa e suas unidades de pesquisa descentralizadas no território, possuem competência técnico-científica-informacional em vasta gama de produtos e atividades, há por outro lado uma centralização. Isso se deve ao fato dessa instituição, mesmo buscando desenvolver parcerias com as organizações estaduais de pesquisa e com o setor produtivo, concentrar a maior parte dos ativos de pesquisa agrícola do país. Em relação as fontes de investimento em pesquisa agrícola no país, o Estado é o principal financiador por concentrar o maior percentual de pesquisadores com dedicação em tempo integral em pesquisa agropecuária em instituições públicas, sejam elas federais, como a própria Embrapa que concentra $42 \%$ ou as universidades que respondem por $26 \%$ dos pesquisadores desse setor. Ainda na esfera do Estado, provavelmente são as OEPAS e outros laboratórios de pesquisa que empregam $29 \%$ desses pesquisadores, enquanto as organizações sem fins lucrativos respondem por apenas $3 \%$ desse total.

Podemos ainda dizer que, com a criação da Embrapa as unidades de pesquisa de produto foram direcionadas para os lugares onde aqueles produtos tinham 
expressão. Por exemplo, a Embrapa Algodão foi instalada no Nordeste, o qual possuía a maior área plantada com essa cultura na época.

O fato da Embrapa Algodão ter ido para Campina Grande se deve a centralidade que essa cidade tinha em relação ao comércio do algodão. Ainda que quando foi instalada a referida cidade já não mais respondesse como principal centro de comercialização do algodão, posição que ocupou até a década de 1920, quando São Paulo a superou. Contudo, existia em Campina Grande toda uma relação histórica e geográfica com essa cultura, e o próprio desenvolvimento econômico e urbano da cidade possui estreita relação com a cultura algodoeira. Além disso, não se pode ignorar o fato da mesma já possuir universidade, o que de algum modo asseguraria a oferta de mão de obra qualificada.

Os Campos Experimentais das unidades de pesquisa dessa empresa demonstram como a pesquisa agrícola é territorializada, na medida em que são nesses espaços que novas tecnologias são desenvolvidas e adaptadas. Tal situação demonstra a importância da existência de uma empresa nacional de pesquisa agrícola. Analisamos o caso do algodão, mas certamente se tivéssemos nos dedicado a estudar as inúmeras tecnologias agrícolas desenvolvidas pela Embrapa, ao longo dos seus quase 50 anos de existência, teríamos condições de avaliar com mais nitidez os impactos de suas pesquisas e os benefícios gerado pela mesma.

Nos dias atuais. tão importante quanto dispor de terras com boa fertilidade e recursos naturais, como acesso à água, e vias de circulação que facilitem o deslocamento das produções, é ter capacidade técnico-científica que possa competir com países que estão na fronteira do conhecimento. Uma vez que são estes que determinam os rumos da produção e criam tendências. Dentro desta visão, pode-se dizer que o Brasil atualmente possui uma expertise agrícola comparavelmente expressiva.

Ficou evidente na pesquisa a conformação de duas regiões geográficas de produção de algodão no país: a região do Cerrado e a região Semiárida do Nordeste Brasileiro. Na região do Cerrado é cultivado o algodão de fibra branca, produzido em sistema agrícola, onde predomina a mecanização e o uso intensivo de conhecimento técnico científico informacional nas diversas fases de cultivo, do plantio a colheita. $\mathrm{A}$ lavoura é desenvolvida em grandes propriedades de modo empresarial, intensiva em 
capital, com uso excessivo de agroquímicos e pouca utilização de mão-de-obra. A lavoura de algodão na região Semiárida do Nordeste brasileiro, onde historicamente a cultura algodoeira foi atividade de importância econômica e social, apresenta área ocupada por essa cultura bem reduzida. O cultivo de algodão que vem se desenvolvendo nessa região é feita principalmente por agricultores familiares e predominando a pequena produção. Os fatores técnicos de produção ainda são semelhantes aos utilizados até a década de 1980, tais como o uso da enxada, do arado movido à tração animal, pouca utilização de insumos agrícola e quase todas as fases de produção continuam sendo desenvolvidas manualmente.

Dois sistemas de produção estão desenvolvidos nessa região, ambos baseados em sistemas técnicos rudimentares. Exceto pelas sementes melhoradas, os novos valores sociais que envolvem a produção são: o cultivo de algodão naturalmente colorido orgânico e algodão branco orgânico, e o cultivo de algodão branco em sistema convencional, podendo ser a produção de algodão orgânico uma tendência dessa cultura na região.

As ações de políticas públicas nas esferas Federal e Estadual se destacam nesse processo, haja vista que instituições vinculadas a essas administrações políticas vem atuando junto aos agricultores (EMBRAPA, EMATER-PB). A exemplo do incentivo aos agricultores da Paraíba via assistência técnica para que estes se sintam motivados a voltarem a produzir o algodão, de forma a atender esse mercado especializado que é a de produção orgânica.

Do ponto de vista territorial, pode-se afirmar que a proximidade geográfica entre a Embrapa Algodão e o território circundante contribuiu para que a instituição buscasse meios de tentar revitalizar a cotonicultura na região e não apenas atender aos interesses dos grandes produtores dos Cerrados. Por sua vez, como o volume do comércio do algodão colorido é pequeno, comparado com o sistema de produção do algodão branco convencional, constatou-se que apenas um pequeno número de pesquisadores estão envolvidos com as pesquisas relacionadas ao algodão colorido.

Por possuir um know how acumulado, em relação ao sistema de produção de algodão e outras culturas, a Embrapa Algodão atrai para Campina Grande pesquisadores de outras instituições e países que querem conhecer essas 
tecnologias. Nesse intercâmbio, além de difundir tecnologias sobre o algodão branco convencional, também é divulgado o algodão naturalmente colorido.

A proximidade geográfica entre a Embrapa Algodão e o assentamento de reforma agrária Margarida Maria Alves, fez com que esse assentamento por ter se adequado aos padrões exigidos em termos de boas práticas agrícolas seja utilizado como efeito de demonstração e difusão e conhecimento para outros agricultores, tanto à nível local quanto internacional. Contudo, os fatores históricos, a exemplo da falta de acesso a crédito, baixo nível de escolaridade limita as possibilidades de ascensão desses agricultores. Por sua vez, não se pode ignorar efeitos futuros que a interação entre técnicos da Embrapa Algodão possam ter na aquisição de direitos e melhores oportunidades para os agricultores familiares.

A organização dos agricultores em associações e cooperativas é uma forma de fortalecimento no sentido de acessar novos conhecimentos e melhorar suas condições de vida, foi o que constatamos, por exemplo, no assentamento Margarida Maria Alves. Mesmo que nesse sentido ainda seja visível a necessidade de maior aproximação entre as Organizações Estaduais de Pesquisa e as Unidades da Embrapa. A ação articulada entre a pesquisa pública federal e a pesquisa pública estadual, no caso específico Embrapa Algodão e EMATER-PB, denota como é fundamental a articulação entre diferentes atores na demonstração e difusão de conhecimento e inovação e criação de novas oportunidades.

A globalização do produto mesmo destinado a um público seleto, também, pode transformar as condições de produção no campo. A rastreabilidade dos produtos via empresas de certificação e das próprias empresas que se utilizam do marketing ecológico e social, não apenas regulam a forma como deve ser realizada a produção, como permitem que o consumidor final possa identificar, desde a cadeia primaria de produção até o produto final e dessa forma cobrem por melhores condições de vida desses agricultores, já que os produtos são vendidos como fair trade.

O atual modelo de sociedade em que há valorização do conhecimento e informação, também abre novas perspectivas para valorização do conhecimento empírico dos agricultores, mesmo que isso ainda seja incipiente. 


\section{REFERÊNCIAS}

ALBUQUERQUE, Ana Christina Sagebin; SILVA, Aliomar Gabriel da (Ed.). Agricultura Tropical: quatro décadas de inovações tecnológicas, institucionais e políticas. Brasília: Embrapa Informação Tecnológica,, 2008. Cap. 1. p. 634-649. (Vol. 1).

ALBUQUERQUE, Eduardo da Motta. Sistema Nacional de Inovação no Brasil: uma análise introdutória a partir de dados disponíveis sobre ciência e tecnologia. Revista de Economia Política, v.16, n.3 (63). p. 56-72, jul./set.1996.

ALBUQUERQUE, Eduardo da Motta; CASSIOLATO, José Eduardo. As especificidades do sistema de inovação do setor saúde: uma resenha da literatura como introdução a uma discussão sobre o caso brasileiro. Belo Horizonte: FESBE, 2000. (Estudos FESBE, 1).

ALMEIDA, José Nilson. A Produção do Algodão Orgânico no Projeto de Assentamento Queimadas, Remígio - PB. 2011. 46 f. TCC (Graduação) Curso de História, História, Universidade Estadual da Paraíba, Campina Grande, 2011.

AMARAL, Luís. Pequena História do Algodão no Brasil: de 1 de maio de 1500 a 1938. Economia - Ano I, N. 7. São Paulo, dezembro de 1949. In: Boletim Geográfico.

AMARAL, Luís. História Geral da Agricultura Brasileira: no tríplice aspecto político-social e econômico.1958

AMARAL, Jose Américo Bordini do; BELTRÃO, Napoleão Esberard de Macêdo; SILVA. Madson Tavares. Zoneamento Agrícola do Algodão no Nordeste Brasileiro Safra 2004/2005. Estado da Paraíba Algodão Colorido BRS 200 Marrom. Dezembro/2004. Campina Grande - PB (Comunicado Técnico - 235)

ANDRADE, Manuel Correia de. A Terra e o Homem no Nordeste: contribuição ao estudo da questão agrária no Nordeste. 8. ed. São Paulo: Cortez, 2011[1963].

ANDRADE, Manuel Correia de. Poder Político e Produção do Espaço. Recife: Massangana, 1984.

ARBILDO, Dora Cortijo de; IPARRAGUIRRE, Rómulo Saúl Cancio. Innovación tecnológica para recuperar el algodón nativo de color. Ingeniería Industrial n. ${ }^{\circ} 30$, pp. 225-245. enero-diciembre, 2012.

ARAÚJO, Tânia Bacelar de. Ensaios sobre o Desenvolvimento brasileiro: Heranças e Urgências. Rio de Janeiro, RJ: Revan, 2010.

ASHEIN, B Jørn; GERTLER, Meric S. The Geography of Inovation: Regional Systems. In: FAGERBERG, Jan; B MOWER, Dadid C.; NELSON, Richard R. The Oxford Handbook of Innovation. New York:University Press,. v.1,p. 291317, 2005. 
BASTOS, Humberto. Assucar \& Algodão: ensaio histórico e econômico. Maceió:

Casa Ramalho, 1938.

BEINTEMA, N.M; AVILA, A.F.D., PARDEY P.G. P\&D Agropecuário: Política, Investimentos e Desenvolvimento Institucional. Washington, D.C.: IFPRI, Embrapa, and Fontagro, agosto. 2001.

BECKER, Bertha K.; EGLER, Claudio A. G.. Brasil: uma nova potência regional na economia-mundo. 2. ed. Rio de Janeiro: Bertrand Brasil, 1994.

BELTRÃO, Napoleão Esberard de Macêdo; AZEVEDO, Demóstenes Marcos Pedrosa de. O Agronegócio do Algodão no Brasil. 2. ed. Brasília: Embrapa Informação Tecnológica, 2008. (Vol. 1).

BELTRÃO, Esberard Napoleão de Macêdo, ARAÚJO Alderi Emídio de. Editores Algodão: o produtor pergunta, a Embrapa responde .Embrapa Algodão. Brasília, DF : Embrapa Informação Tecnológica, 2004. (Coleção 500 perguntas, 500 respostas).

BELTRÃO, Napoleão Esberard de Macêdo Cultivo de Algodão Herbáceo na Agricultura Familiar. 2 $2^{\mathrm{a}}$ Ed. Campina Grande: CNPA - Embrapa, 2006. (Embrapa - CNPA - Sistema Produtivo,Versão Eletrônica

BELTRÃO, Napoleão Esberard de Macêdo; CARVALHO, Luiz Paulo de. Algodão Colorido no Brasil, e em Particular no Nordeste e no Estado da Paraíba. Embrapa Algodão - Campina Grande, PB. 2004 (Documentos - 128).

BERNARDES, Júlia Adão; ARRUZZO, Roberta Carvalho (Org.). Novas fronteiras da técnica no Vale do Araguaia. Rio de Janeiro: Arquimedes Edições, 2009.

BRANDÃO; Carlos Antônio. 0 processo de subdesenvolvimento, as desigualdades espaciais e o "jogo das escalas." In: Superintendência de Estudos Econômicos e Sociais da Bahia. Desigualdades Regionais. Salvador: SEI, 2004. (Série estudos e pesquisas, 67). p.09-37.

BRAUDEL, Fernand. Civilização material, economia e capitalismo: séculos XV XVIII As estruturas do cotidiano. 2. ed. São Paulo: Martins Fontes, 2005.

BRASIL. Lei no 12383, de março de 2011. Regula o direito da Embrapa poder desenvolver qualquer atividade em outro país. In: Legislação Repúblicana Brasileira. Brasília, 2011. Disponível em: $<$ http://www.planalto.gov.br/ccivil 03/ Ato20112014/2011/Lei/L12383.htm>Acesso em: 18 de jan. 2012.

BRASIL, Decreto oㅜ 11.475, de 5 de Fevereiro de 1915 Crêa o Serviço do Algodão. Serviço do Algodão. Acessado em: fevereiro de 2016. Disponível em: < http://www2.camara.leg.br/legin/fed/decret/1910-1919/decreto-11475-5fevereiro-1915-518361-públicacaooriginal-1-pe.html> . 
BRASIL. Ministério da Agricultura, Pecuária e Abastecimento.Cadeia produtiva do algodão / Ministério da Agricultura, Pecuária e Abastecimento, Secretaria de Política Agrícola, Instituto Interamericano de Cooperação para a Agricultura; Antônio Márcio Buainain e Mário Otávio Batalha (Coord.), Pedro Vieira Junior, Sheila Ferreira Leite. - Brasília : IICA : MAPA/SPA, 2007.

BROWN, A.M. COTTON History, Species, Varieties, Morphology, Breeding, Culture, Diseases, Marketing, and Uses. Ney York: McGRAW-HILL BOOK COMPANNY, 1927.

BUANAIN, Antônio Márcio et al. O mundo rural no Brasil do século 21: A formação de um novo padrão agrário e agrícola. Brasília: Embrapa, 2014.

CABRAL, José Irineu. Sol da manhã: memória da Embrapa. Brasília: UNESCO, 2005.

CANABRAVA, Alice P.. O desenvolvimento da Cultura do Algodão na Província de São Paulo ( 1861-1875). 2. ed. São Paulo: Edusp, 2011[1951].

CAMARA, Manuel Arruda. Memória sobre a cultura dos algodoeiros, e sobre o methodo de o escolher e ensacar,e etc. Lisboa: Oficina Literária da Casa do Arco do Cego, 1797.

CARVALHO, Luiz Paulo de. O gênero Gossypium e suas espécies cultivadas e Silvestres. In: BELTRÃO, Napoleão Esberard de Macedo; AZEVEDO, Demóstenes Marcos Pedrosa de (Ed.). O Agronegócio do Algodão no Brasil. 2. ed. Brasília: Embrapa Informação Tecnológica, 2008. Cap. 8. p. 251270. (Vol. 1).

CARVALHO, Luís Paulo de; ANDRADE, Francisco Pereira de; SILVA FILHO, João Luiz da. CULTIVARES DE ALGODÃO COLORIDO PARA A REGIÃO

SEMIÁRIDA DO BRASIL. In: FURTADO, Dermeval Araújo; BARACUHY, José Geraldo; FRANCISCO, Paulo Roberto Megna (Org.) Difusão de tecnologias apropriadas para o desenvolvimento sustentável do

Semiárido brasileiro. Campina Grande: EPGRAF, 2013.

CASTRO, Iná Elias de; GOMES, Paulo Cesar da Costa; Corrêa, Roberto Lobato (Org.). Geografia: Conceitos e Temas. 10. ed. Rio de Janeiro: Bertrand Brasil, 2007.

CENTRO DE GESTÃO E ESTUDOS ESTRATÉGICOS. Estudo sobre o papel das Organizações Estaduais de Pesquisa

Agropecuária : OEPAs, Brasília: CGEE. 2009.

CRESTANA, Silvio; SOUSA, Ivan Sergio Freire de. Agricultura tropical no Brasil. In: ALBUQUERQUE, Ana Christina Sagebin; SILVA, Aliomar Gabriel da. Agricultura Tropical: quatro décadas de inovações tecnológicas, institucionais e políticas. Brasília: Embrapa Informação Tecnológica,, 2008. Cap. 1. p. 42-66. (Vol. 1). 
COHEN, Wesley M.; NELSON, Richard R.; Walsh John P. Links and Impacts: the Influence of Public Research on Industrial R\&D. Management Science, vol. 48, n.1. p.1-23. January. 2002.

COSTA, Sérgio Rodrigues; BUENO, Miguel Garcia. A saga do algodão: das primeiras lavouras à ação na OMC. Rio de Janeiro: Insight Engenharia, 2004.

DINIZ, Clélio Campolina; GONÇALVES, Eduardo. Economia do conhecimento e desenvolvimento regional no Brasil. In: DINIZ, Clélio Campolina; LEMO, Mauro Borges (Org.). Economia e Território. Belo Horizonte: Ufmg, 2005. p. 131-170.

DOSSA, Alvaro Augusto. COOPERAÇÃO TECNOLÓGICA ENTRE UNIVERSIDADES E INSTITUTOS PÚBLICOS DE PESQUISA NO SETOR AGROPECUÁRIO BRASILEIRO: UM ESTUDO NA EMBRAPA. 2010. 209f.Dissertação (Mestrado em Administração) - Universidade Federal do Paraná, Paraná, 2010.

EDQUIST, Charles. Systems of Innonation:perspectives and challengs. In: FAGERBERG, Jan.;B MOWER, Dadid C.; NELSON, Richard R. The Oxford Handbook of Inovation, New York:University Press, 2005, p.181-208.

EDQUIST, Charles. The Systems of Innovation Approach and Innovation Policy: An account of the state of the art. Lead paper presented at the DRUID Conference, Aalborg, June 12-15, 2001. Disponível em $<$ http://folk.uio.no/ivai/ESST/Outline\%20V05/edquist02.pdf> Acessado em: $20 / 06 / 2011$

EMBRAPA, Embrapa Informação Tecnológica. Sugestões para formulação de um Sistema Nacional de Pesquisa Agropecuária. Brasília, 2006.

EMBRAPA, Recursos Genéticos e Biotecnológicos. Intercambio Germoplasma. Disponível em: <http://www.cenargen.embrapa.br/intercambio/index.html> Acesso em: 17 de jan. 2012.

EMBRAPA, EMPRESA BRASILEIRA DE PESQUISA AGROPECUÁRIA. Labex. 2012. Disponível em: <http://www.embrapa.br/a embrapa/labex>. Acesso em: 17 de jan. 2012.

ELIAS, Denise. Globalização e Agricultura. São Paulo: Edusp, 2003.

ELIAS, Denise. Agronegócio e desigualdades socioespaciais. In: ELIAS, Denise; PEQUENO, Renato (Org.). Difusão do Agronegócio e Novas Dinâmicas Socioespaciais. Fortaleza: Banco do Nordeste do Brasil, 2006. p. 25-82.

ELIAS, Denise. Agronegócio e novas regionalizações no Brasil. R.B. Estudos Urbanos e Regionais. Vol. 13, N. 2, novembro, 2011.

FARIAS, Paulo Sergio Cunha. Os Circuitos Espaciais de Produção e os Círculos de Cooperação do Algodão Colorido e Derivados da Paraíba: uma dimensão 
da flexibilização do produto, da produção e do consumo de moda, fibras, têxteis e confecções. 2010. 303 f. Tese (Doutorado) - Curso de Geografia, Geografia, Universidade Federal de Pernambuco, Recife, 2010.

FARIAS, Paulo Sergio da Cunha. O uso das identidades ecológica e territorial como diferenciação marginal das confecções produzidas com o algodão colorido da Paraíba. In: SÁ, Alcindo José de; FARIAS, Paulo Sergio da Cunha (Org.). Ética, Identidade e Território. Recife: Ccs Gráfica e Editora, 2012. p. 203-240.

FERNANDES, A. C. A; SILVA, A. S.; SOUZA, B. C. Demanda e oferta de tecnologia e conhecimento em região periférica: a interação universidade-empresa no Nordeste brasileiro. Recife UFPE, mimeo.2009.

FERNANDES, A. C. A. A dimensão espacial da inovação: contribuições a partir de dois sistemas locais de inovação periféricos. Recife UFPE, mimeo. 2010.

FREYRE, Gilberto. Nordeste: aspectos da influência da cana sobre a vida e a paisagem do Nordeste do Brasil. 7. ed. rev. São Paulo: Global, 2004.

FREEMAN, Chris. The "National System of Innovation" in historical perspective. Cambridge Journal of Economics. 1995, v.19, 5-24.

FREIRE, Eleusio Curvelo. Distribuição, coleta, uso e preservação das espécies silvestres de algodão no Brasil. Campina Grande, 2000. (Embrapa Algodão. Documentos, 78).

Algodão colorido. Biotecnologia Ciência \& Desenvolvimento, v.1,n.9, p.36-39, 1999.

FREIRE, Eleusio Curvelo; BELTRÃO, Napoleão Esberard de Macedo. Impulsionando a produção e a produtividade agrícola: o caso do algodão. In: ALBUQUERQUE, Ana Christina Sagebin; SILVA, Aliomar Gabriel da (Ed.). Agricultura Tropical: quatro décadas de inovações tecnológicas, institucionais e políticas. Brasília: Embrapa Informação Tecnológica,, 2008. Cap. 1. p. 634-649. (Vol. 1).

FREIRE, Eleusio Curvelo; BARREIRO NETO, Miguel. A Pesquisa Algodoeira no Nordeste do Brasil. EMBRAPA - Centro Nacional de Pesquisa do Algodão. Campina Grande - PB. 1983. (Documentos - № 18).

FREITAS, Elisa Pinheiro de. TERRITÓRIO, PODER E BIOCOMBUSTíVEIS: As ações do Estado brasileiro no processo de regulamentação territorial para a produção de recursos genéticos alternativos. 2013. $501 \mathrm{f}$. Tese (Doutorado) Curso de Geografia Humana, Geografia, Universidade de São Paulo, São Paulo, 2015.

FURTADO, Celso. Formação Econômica do Brasil. 32. ed. São Paulo: Companhia Editora Nacional, 2005. 
GERTLER, Meric S.Tacit Knowledge in production systems: how important is geography? In: POLENSKE, karem R. The Economic Geography of Innovation. Cambridge University Press, 2007.

GOODMAN, David; SORJ, Bernardo; WILKSON, Jonh. Da lavouras às Biotecnologias. Rio de Janeiro: Campus, 2008. Edição on line. Disponível em: <http://fibe.edu.br/arq/201508131509211027916102.pdf>. Acesso em: 02 abr. 2016.

GTDN - Grupo de Trabalho para o Desenvolvimento do Nordeste. SUDENE. Uma política de desenvolvimento econômico para o Nordeste. 2.ed. -. Recife: Sudene, 1967

JERÔNIMO, Jeane Ferreira; SILVA et al. DESCAROÇADOR E PRENSA ENFARDADEIRA ITINERANTE PARA O BENEFICIAMENTO DO ALGODÃO. In: FURTADO, Dermeval Araújo; BARACUHY, José Geraldo; FRANCISCO, Paulo Roberto Megna (Org.) Difusão de tecnologias apropriadas para o desenvolvimento sustentável do Semiárido brasileiro. Campina Grande: EPGRAF, 2013.

HARVEY, David. A Produção Capitalista do Espaço. 2. ed. São Paulo: Annablume, 2006.

HOLANDA, Sérgio Buarque de. Caminhos e Fronteiras. 2. ed. São Paulo: Companhia das Letras, 1994.

IBANEZ, Pablo. Geopolítica e Inovação Tecnológica: uma análise da Subvenção Econômica e das Políticas de Inovação para Saúde. 2011. 231 f. Tese (Doutorado) - Curso de Geografia Humana, Geografia, Universidade de São Paulo, São Paulo, 2011.

IANNI, Octavio. Estado e planejamento econômico no Brasil. Rio de Janeiro: Civilização Brasileira, 1991.

KOSTER, Henry. Viagens ao Nordeste do Brasil. Tradução: Luiz da Camara Cascudo. Companhia Editora Nacional. São Paulo, 1942 [1817].

LIRBÓRIO, Lúcia Ferreira. Modernização da agricultura brasileira: conhecimento e inovação na produção de algodão. In: Anais do VI Congresso Iberoamericano de Estudios Territoriales y Ambientales, 2014 out 8-12; São Paulo: Universidade de São Paulo, 2014. p. 3585-3599. 
LIRBÓRIO, Lúcia Ferreira. Pesquisa científica na agricultura: sistema de produção de algodão naturalmente colorido na Paraíba (PB). Produção Acadêmica, [S.I.], v. 1, n. 2, mar. 2016. Disponível em: <https://sistemas2.uft.edu.br:8004/index.php/producaoacademica/article/v iew/1994>. Acesso em: 06 maio. 2016.

LIRBÓRIO, Lúcia Ferreira. Interação instituto de pesquisa - empresas: contribuições da Embrapa Semiárido para o desenvolvimento da fruticultura irrigada no Vale do Submédio São Francisco. 2012. 186 f. Dissertação (Mestrado) - Curso de Geografia, Geografia, Universidade Federal de Pernambuco, Recife, 2012.

LUNDVALL, Bengt-Åke. The Social Dimension of The Learning Economy.1996.

MALERBA, Franco. Sectoral Systems of Innovation and Production. In: DRUID Conference on: National Innovation Systems, Industrial Dynamics and Innovation Policy Rebild, June 9-12, 1999.

MARIZ, Celso. Evolução Econômica da Paraíba. João Pessoa: A União Editora, 1939.

MAZZOLENI, R; NELSON,R. The Roles of Research at Universities and Public Labs in Economic Catch-up. August. 2005

Disponivel em: <http://policydialogue.org/files/events/Mazzoleni Nelson Roles of Universities and Public Labs in Catch Up.pdf>

Acessado em: Vários acessos.

MELO, Mário L. de. Os Agrestes: estudo dos espaços nordestino do sistema gadopolicultura de uso de recursos. Recife, SUDENE: Estudos Regionais 4, Coord. Planej. Regional, 1980.

MORGAN, K. The Exaggerated death of geography: learning, proximity, and territorial innovation system. Journal of Economic Geography, p.3-21. 2004.

MAZOYER, Marcel; ROUDART, Laurence. História das agriculturas no mundo: do neolítico à crise contemporânea. São Paulo: Unesp, 2010.

MÉNDEZ, Ricardo. Geografia Económica: La lógica espacial del capitalismo global. Barcelona: Editoração Ariel, S.a., 1997.

MONTEIRO, Manoel. O Milagre do Algodão Colorido.( Literatura de Cordel). Campina Grande: 2003.

MOREIRA, Isabel Martins. O Algodão Sem Veneno do Assentamento Queimadas, na Paraíba: Agentes sociais, alinhamento em "rede", produção e comercialização. 2012. 182 f. Dissertação (Mestrado) - Curso de Antropologia Social, Antropologia, Universidade Federal de Campina Grande, Campina Grande, 2012. 
MOREIRA, José de Alencar Numes et al. Algodoeiro mocó: uma lavoura ameaçada de extinção. Campina Grande. EMBRAPA - CNPA, 1989.(EMBRAPA-CNPA. Documentos, 36).

MOREIRA, José de Alencar Nunes; SANTOS, Robério Faria dos. Origem, Crescimento e Progresso da Cotoniculturaa no Brasil. Campina Grande: Embrapa - Centro Nacional de Pesquisa de Algodão, 1994.

MOUTINHO, Lúcia M.G. A Co - Evolução de Empresas e Instituições em

Arranjos Produtivos Locais. In: Revista Econômica do Nordeste, Fortaleza, v. 38, no 2, abr-jun. 2007.

NEVES, Marcos Fava; PINTO, Mirun Junqueira. (Coord.) A Cadeia do Algodão Brasileiro: desafios e estratégias. ABRAPA, 2012.

OECD. Manual de Oslo: diretrizes para coleta e interpretação de dados sobre inovação. Tradução: Flávia Gouveia. Ed.3롤

OLIVEIRA, Luiz Bezerra de; SILVA JUNIOR, Josué Francisco da; SILVA, Maria Sonia Lopes da. IPEANE: uma história da pesquisa agropecuária no Nordeste do Brasil. Rio de Janeiro, Aracaju: Embrapa Solos, Embrapa Tabuleiros, 2011.

PAN RURAL: A revista do Agronegócio. ANO IV - n. 57 - NOV. 2003. ALGODÃO: a tecnologia que reveste o campo.

PICCIOTTO, Gabriela; SHEWCHENKO, Marília Carvalho. Projeto de

Fortalecimento da Cadeia Produtiva do Algodão Colorido. Relatório de

Pesquisa. Escola de Administração de Empresas de São Paulo. Fundação Getúlio Vargas. São Paulo, 2006.

PRADO JUNIOR, Caio. A Questão Agrária no Brasil. 2. ed. São Paulo: Brasiliense, 1979.

PRADO JUNIOR, Caio. Formação do Brasil Contemporâneo. 23. ed. São Paulo: Brasiliense, 2004[1942].

PUTNAM, Robert D. Comunidade e democracia a experiência da Itália moderna. Rio de Janeiro: Fundação Getúlio Vargas, 1996.

QUEIROGA, Vicente de Paula; CARVALHO, Luiz Paulo de; CARDOSO, Gleibson Dionízio. Cultivo do Algodão Colorido Orgânico na Região Semi-Árida do Nordeste Brasileiro. Embrapa Algodão - Campina Grande, PB. 2008. (Documentos - 204).

QUEIROGA, Vicente de Paula; JERONIMO, Jeane Ferreira; MELEÁN, Jesus Ávila. Experiência sobre a produção de algodão de fibra colorida por duas cooperativas do Estado da Paraíba. Rev. Agronomia Topical. Vol. 60, ํo 3, 2010, pág. 295-304. 
SÁ, lêdo Bezerra; SILVA, Pedro Carlos Gama da (Ed.). Semiárido Brasileiro: Pesquisa, Desenvolvimento e Inovação. Petrolina: Embrapa Semiárido, 2010.

SANTANA, João Célio Farias de.et al. POTENCIAL DE NOVAS LINHAGENS DO ALGODOEIRO ARBÓREO (Gossypium hirsitun L. r. marie galante) DE FIBRAS SELECIONADAS NO NORDESTE DO BRASIL. Embrapa Algodão - C

SANTANA, João Célio Farias de.et al. potencial de novas linhagens do algodoeiro arbóreo ( Gossypium hirsitun L. r. marie galante) de fibras selecionadas no Nordeste do Brasil. Embrapa Algodão - Campina Grande, 1997. (Comunicado Técnico - 62).

SANTANA João Cecílio Farias de. et. al. . Desempenho Industrial da Fibra, do Algodão BRS 200 Marrom. Campina Grande, 2001. (Embrapa Algodão. Comunicado Técnico, 138).

Serviço Brasileiro de Apoio às Micro e Pequenas Empresas (SEBRAE). Projeto SEBRAE de atendimento à cadeia produtiva do algodão colorido da Paraíba 2015 (mimeo).

SINGH, P.; SINGH, V. V. ; WAGHMARE, V. N.. NATURALLY COLOURED COTTON. In: Technical Bulletin from CICR (www.cicr.org.in) s/d.

SHAND, Hope. La História de lós Algodones de Pigmentacíon Natural em lãs Américas. Rafi Comunique. Rural Advancement Foundation International, Noviembre, 1993.

SANTOS, Milton. A Natureza do Espaço: Técnica e Tempo, Razão e Emoção. 4. ed. São Paulo: Edusp, 2008 [1996].

SANTOS, Milton. Economia Espacial. 2. ed. São Paulo: Edusp, 2011 [1979]

SANTOS, Milton. Espaço e Método. 5. ed. São Paulo: Edusp, 2008 [1985].

SANTOS, Milton. Metamorfoses do Espaço Habitado. 6. ed. São Paulo: Edusp, 2014 [1988].

SANTOS, Milton. O espaço Dividido. 2. ed. São Paulo: Edusp, 2004 [1979].

SANTOS, Milton. O Trabalho do Geografo no Terceiro Mundo. São Paulo: Hucitec, 1978 [1978].

SANTOS, Milton. Por uma Geografia Nova. 6. ed. São Paulo: Edusp, 2008.

SANTOS, Milton. TÉCNICA, ESPAÇO, TEMPO: Globalização e meio técnico científico- informacional. 5. ed. São Paulo: Edusp, 2008.

SANTOS, Milton; SILVEIRA, María Laura. O Brasil: Território e Sociedade no início do século XXI. 15. ed. Rio de Janeiro,são Paulo: Record, 2011. 
SANTOS, Robério Ferreira dos; KOURI, Joffre; SANTOS, José Wellingthon dos. O agronegócio do algodão: crise e recuperação no mercado brasileiro da matériaprima agrícola. In: BELTRÃO, Napoleão Esberard de Macedo; AZEVEDO, Demóstenes Marcos Pedrosa de (Ed.). O Agronegócio do Algodão no Brasil. 2. ed. Brasília: Embrapa Informação Tecnológica,, 2008. Cap. 2. p. 31 60. (Vol. 1).

SILVA, Odilon Reny Ribeiro Fereira da. et. al.. Mini-Usina de Beneficiamento de Algodão de $\mathbf{5 0}$ Serras e Prensa Hidráulica, uma Alternativa para Associação de Pequenos Produtores. Embrapa Algodão (Campina Grande - PB), 2000 (Comunicado Técnico 128).

SILVA, João Carlos Camilo da. et. al.. Organização da produção para a comercialização do algodão agroecológico no território da cidadania da Borborema. In: Cadernos de Agroecologia - ISSN 2236-7934 - Vol 6, No. 2, Dez 2011.

SILVA, José Graziano da. Progresso Técnico e Relações de Trabalho na Agricultura. São Paulo: Hucitec, 1981.

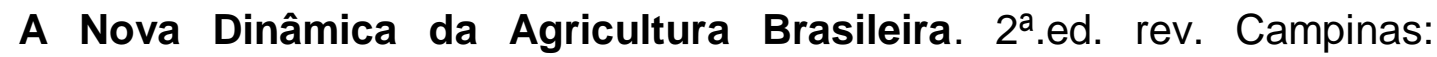
UNICAMP, 1996

SILVA, Carlos Gama da; GUIMAREAES FILHO, Clóvis. Eixo Tecnológico da Ecorregião Nordeste. In: SOUSA, Ivan Sergio Freire de. (Editor Técnico). Agricultura familiar na dinâmica da pesquisa agropecuária. Brasília, Embrapa Difusão de Tecnologia, 2006.

SILVA, Marlene Maria da; LIMA, Diva Maria de Andrade. Sertão norte: área do sistema gado-algodão. Recife: Sudene, Divisao de Politica Espacial, 1982. (Estudos Regionais).

SILVA, Rafaela Fernandes e. A relação campo-cidade em Campina Grande a partir da produção do algodão colorido. 2011. 119 f. Dissertação (Mestrado) - Curso de Geografia Humana, Geografia, Universidade Federal da Paraíba, Campina Grande, 2011.

SILVEIRA, José Maria Ferreira Jardim da; BORGES, Izaias de Carvalho; BUAINAIN, Antonio Márcio. BIOTECNOLOGIA E AGRICULTURA da ciência e tecnologia aos impactos da inovação. São Paulo em Perspectiva, v. 19, n. 2, p.101-114, abr./jun. 2005.

SOUSA, Gabriel Soares de. Tratado descritivo do Brasil em 1587. São Paulo: Editora Nacional, 1987.

SOUZA, Júlio Seabra Inglês. et al.,(Org). Enciclopédia Agrícola Brasileira: A-B. Vol. 1São Paulo: USP, 1995. 
SOUSA, Julio Seabra Inglez de; PEIXOTO, Aristeu Mendes; TOLEDO, Francisco Ferraz de. Enciclopédia Agrícola Brasileira a-B. São Paulo: Edusp, 1995. (Vol. 1).

SOUZA, Maria Célia Martins de. Algodão Orgânico: o papel das organizações na coordenação do sistema agroindustrial do algodão. 1998. 2001 f. Dissertação (Mestrado) - Curso de Economia, Administração e Contabilidade, Administração, Universidade de São Paulo, São Paulo, 1998.

SUZIGAN, Wilson; ALBUQUERQUE, Eduardo da Mota e. A interação entre universidades e empresas em perspectiva histórica. In: SUZIGAN, Wilson; ALBUQUERQUE, Eduardo da Mota e; CARIO, Silvio Antonio Ferraz (Org.). Em busca da inovação: interação universidade - empresa no Brasil. São Paulo: Autêntica, 2011. Cap. 1. p. 17-43.

REBELO, Tânia. C\&A Brasil quer usar algodão 100\% orgânico e sustentável até 2020. Acessado em: < http://vida-estilo.estadao.com.br/blogs/alimentosorganicos/ca-brasil-quer-usar-algodao-100-organico-e-sustentavel-ate-2020/>

Acessado em: 22 de maio de 2016.

VALE, Mário. Conhecimento, Inovação e Território. Lisboa: Edições Colibri, 2012.

VALE, Dalfran Gonçalves. et al. Algodão Colorido: "Tecnologia Embrapa para a geração de emprego e renda na agricultura familiar no Brasil”. Campina Grande: Embrapa Algodão, 2011. (Folder de Divulgação).

VINCENZI, Nelson de. Algodão: na economia brasileira. Rio de Janeiro: Coord da Mobilização Econômica, 1944.

VREELAND JR, James. The Revival of Colored Cotton. In: Scientific American, New York, v. 280, n. 4, p. 112-118, Abr. 1999.

WANDERLEY, Maria Nazareth Baudel. O Mundo Rural como um Espaço de Vida. Porto Alegre: Ufrgs, 2009.

ZISCHKA, Antoine. Guerra secreta pelo algodao. Porto Alegre: Globo, 1936.

\section{SITES CONSULTADOS}

ASTI (Agricultural Science and Technology Indicators). ASTI database. International Food Policy Research Institute (IFPRI)http://www.asti.cgiar.org/es/brasil

Apex -Brasil - http://www.apexbrasil.com.br/home/index

COOPNATURAL - http://www.naturalfashion.com.br/site/

Embrapa - https://www.embrapa.br/

Embrapa Algodão - https://www.embrapa.br/algodao

Mecanismo Online para Referências - http://novo.more.ufsc.br/inicio 
Natural Cotton Color - http://www.naturalcottoncolor.com.br/

TextilExchange - http://farmhub.textileexchange.org/organic-cotton-round-table

EMATER-PB - http://gestaounificada.pb.gov.br/emater-pb

COEPE - http://www.coepbrasil.org.br/coep20anos/HTML/comunidades-semiarido/espinheiros4.htm

Comitê Consultivo do Algodão (ICAC) - https://www.icac.org/ 